\title{
INTENSITY AT THE EDGE
}

An investigation into experiential and protective architecture at the sea edge

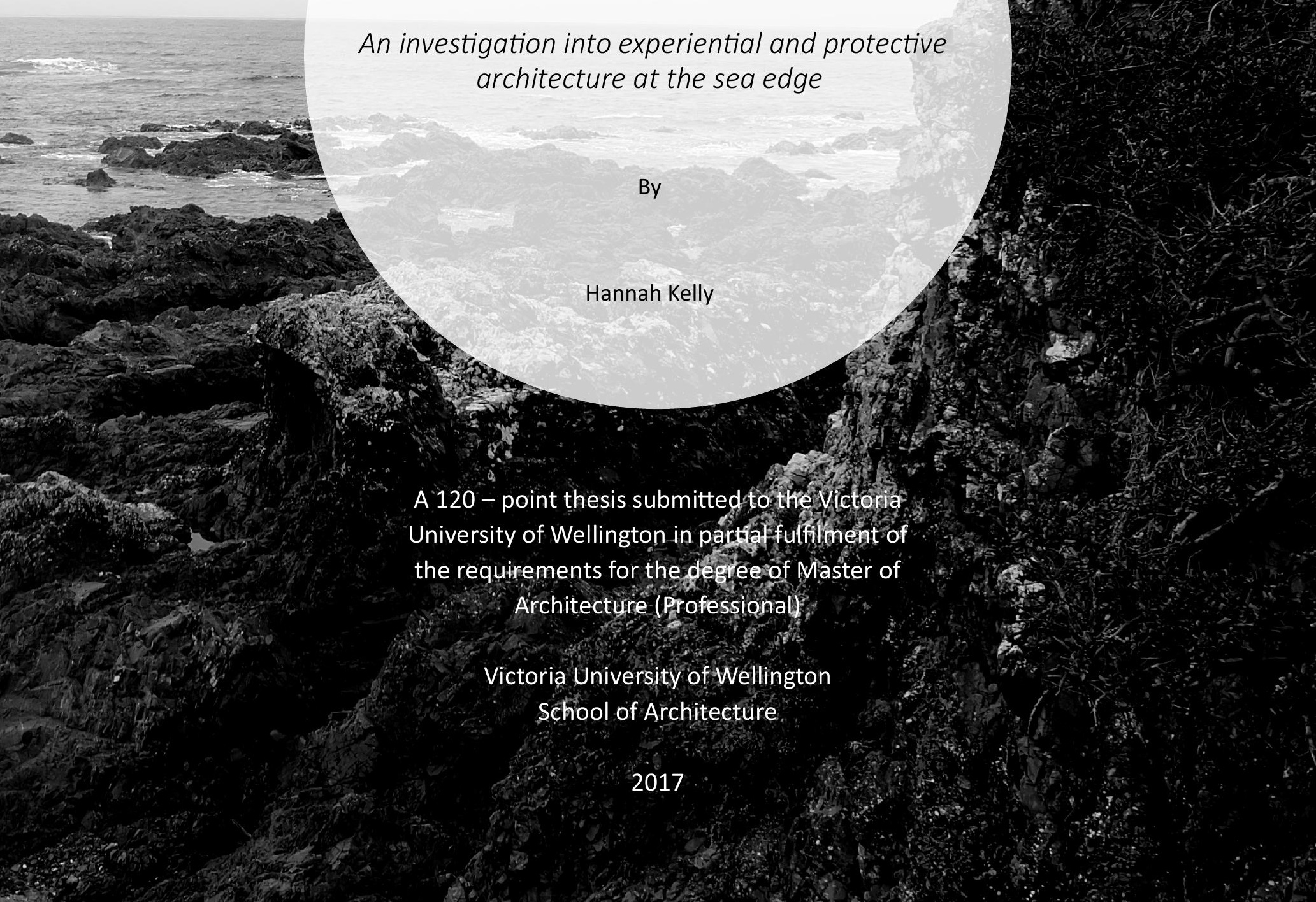




\section{Acknowledgements}

Firstly I would like to thank my supervisor, Christina MaKay, for all of your guidance, dedication and expertise through the year.

Secondly to my family, Debbie, Howard and Emily, thank you for everything you have done and continue to do. The past five years would not have been possible is it wasn't for your support, patience and advice.

To my grandparents I will always be extremely thankful for all of the encouragement and support that you have given me with my endeavours.

Finally I would like to thank my friends for their help and friendship over the years. You have made this a great educational experience. 


\section{Abstract}

There is an inherent relationship between New Zealanders and the coast and has become part of our culture and identity. The coastal threshold is a place of emersion in time, surface and weathering process of materials and the marks and traces of time, this thesis explores architectural expression on Wellingtons coastline.

This project proposes the design of a series of six interventions along Wellington's south coast. This research explores how architecture can respond to the temporality and extreme contextual conditions of the diverse landscapes. By developing an inherent architectural language of shelter that identifies and embodies the contextual and programmatic narrative, this thesis proposes for the occupation of site through a protective and experiential architecture. 


\section{Contents}

Acknowledgements $v$

Abstract $\quad$ vii

Contents viii

$\begin{array}{lr}\text { Chapter } 1 \text { - Identifying the opportunities } & 1\end{array}$

The Opportunities $\quad 2$

Research Question $\quad 3$

Scope and Limitations of the Design 4

Aims and Objectives $\quad 4$

$\begin{array}{ll}\text { Methodology } & 5\end{array}$

$\begin{array}{lr}\text { Chapter } 2 \text { - Context/Site } & 9\end{array}$

Wider Site Selection $\quad 10$

Land, Sea and Sky Analysis - Site and Climate Conditions 12

Sun 12

Wind $\quad 13$

Rain $\quad 14$

Topography $\quad 15$

Waves and Currents $\quad 16$

$\begin{array}{ll}\text { The Stars } & 17\end{array}$

$\begin{array}{ll}\text { Detailed Site Selection } & 18\end{array}$

$\begin{array}{lr}\text { Conclusion } & 19\end{array}$

$\begin{array}{ll}\text { Chapter } 3 \text { - Literature Review } & 21\end{array}$

Experience $\quad 22$

Material weathering and imperfection $\quad 23$

Responding to place $\quad 25$

Conclusion 26

$\begin{array}{lr}\text { Chapter } 4 \text { - Design Filters } & 29\end{array}$ 
Leca Swimming Pools

Brion-Vega Cemetery

The Therme Vals

40

Te Kopahou Reserve Gateway

Cairn

Conclusion

Owhiro Bay

Island Bay

Princess Bay

Te Raekaihau Point - 'Sharks Tooth'

Chapter 8 - Conclusion 


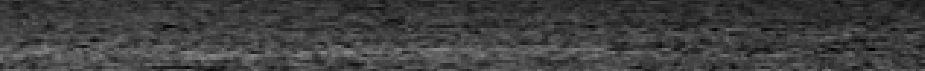

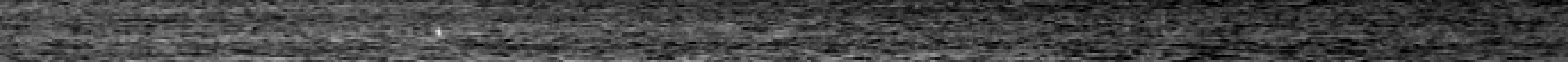
Lith

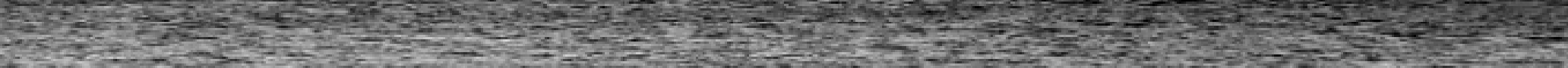

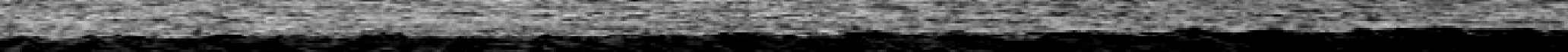

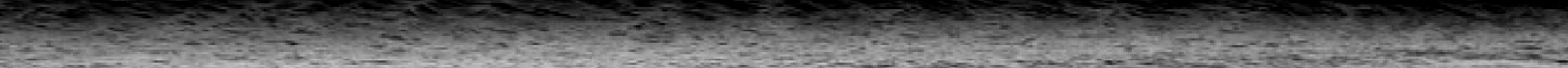

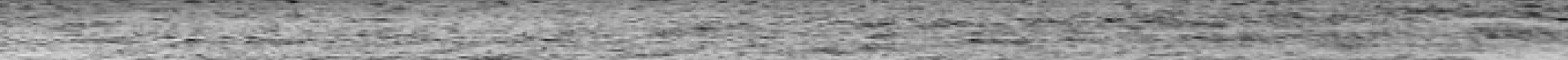

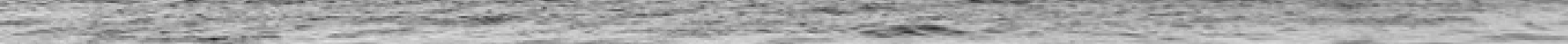

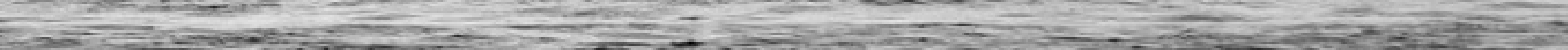

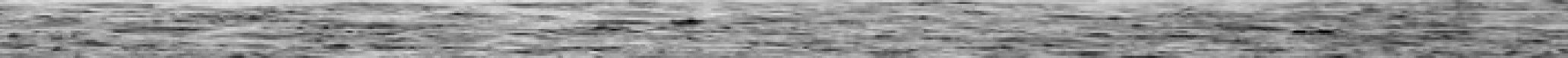

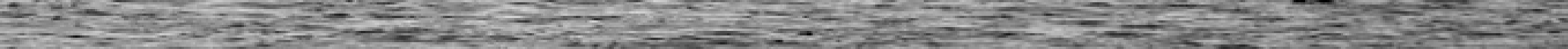
Fon

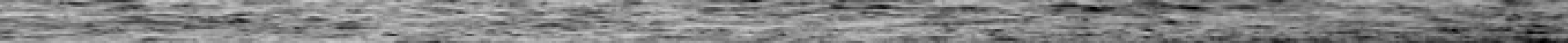
ave

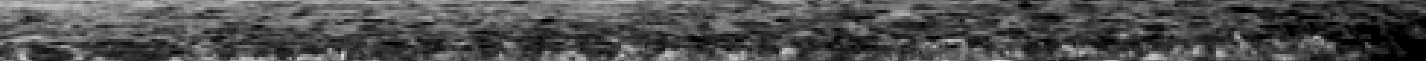

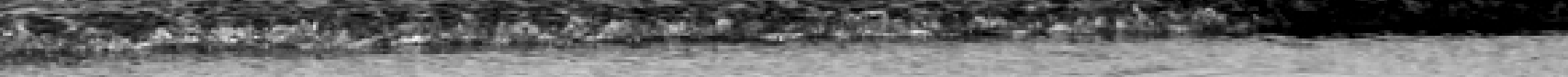

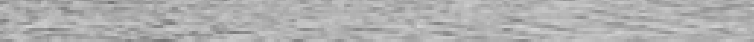

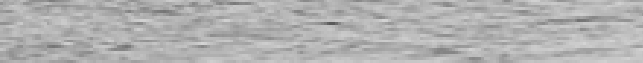


Chapter 1

Identifying the opportunities 


\section{The Opportunities}

As New Zealanders, the seashore is a fundamental part of our culture and identity. The meeting of the land and sea is a place where one can immerse oneself, where the limits of time, surface and depth are in constant flux and motion. This immersive notion of the edge is one reason why the seashore is a popular place for summer relaxation in the sun.

"With around 15,000 kilometres of coastline and more than 25 marine reserves, ocean-scented scenery is entwined with New Zealand's outdoorsy way of life."

100\% Pure New Zealand http://www.newzealand.com/int/scenic-highlights+beaches-and-coast/

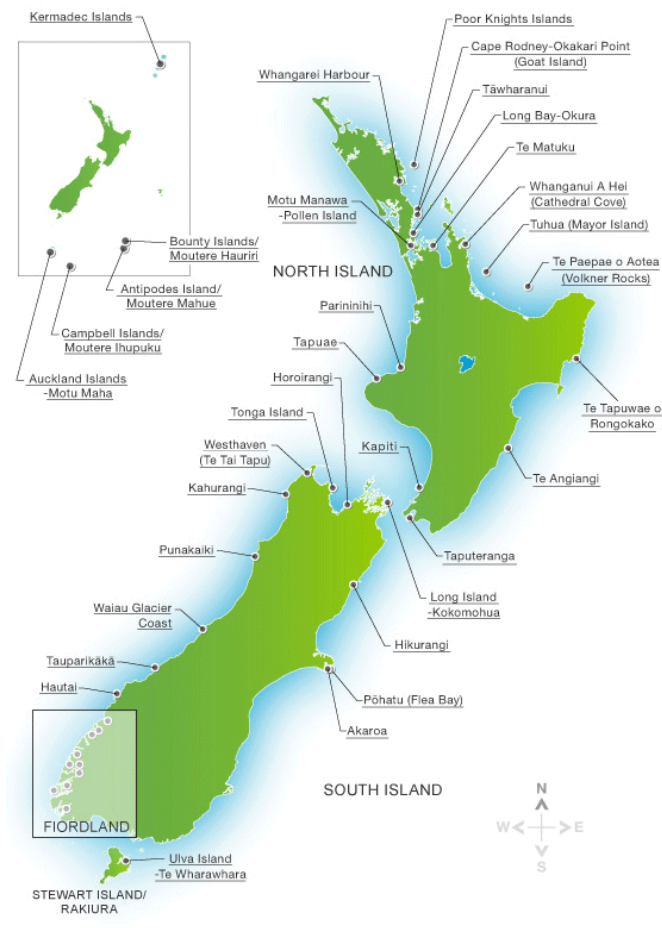

Fig 1.02. Location of New Zealand marine reserves

Wellington's south coast features a range of rugged and diverse natural landscape. Throughout the year, many extremes of weather can be experienced. In summer, swimmers, walkers and tourists etc, enjoy the landscape for its natural beauty however in winter it turns in to a churning, windswept, unforgivable place that's relentless in its force. There is an absence of any built form to provide shelter from the strong summer sun and harsh winter extremes.

Shelter, as defined by the Oxford Dictionary is "A place giving temporary protection from bad weather or danger, a shielded or sake condition; protection." Shelter not only provides a place for protection from weather and danger but it also provides a place of meeting and sense of ownership. It is the mediator between the landscape and human occupation where notions of experience and connection to the site can be explored. Therefore there is an opportunity to develop a series of built forms, which explore the notion of coastal shelter. 


\section{Research Question}

How can architecture intensify the experience of the sea edge and provide shelter for users?

In answer to this question, a series of architectural interventions have been designed as vehicles allowing people to engage and experience the raw diversities of the coast within responsive architecture. 


\section{Aims and Objectives}

- $\quad$ Educate users of the effects of the environment through architecture and its materiality highlighting the correlation between the environmental effects, architecture and human experience.

- Create awareness of nature's effects on the architecture through highlighting and celebrating the weathering.

- $\quad$ Create a series of architectural interventions along Wellington's south coast that highlight and respond to the diverse contextual conditions of each site.

- Intensify and enrich the experience of site and architecture through developing an under standing of activating elements that evoke our senses to respond to the space.

- $\quad$ This project will examine and explore temporal conditions at the sea/coastal edge allowing the development of a responsive architecture.

\section{Scope and Limitations of the Design}

The scope of this thesis is the design of six speculative individual architectural interventions on different sites on Wellington's south coast between Owhiro Bay and Lyall Bay. These architectural interventions aim to highlight extreme weather conditions and unique narratives of the coast. Each intervention will embody historical, narrative and programmatic factors relating to its site through the use of a series of developed design filters. The idea of building on the sea edge is contentious. No consideration has been given to cost considerations and resource consent requirements and processes. Although the sites have extensive meaning for Maori, the author chooses not to investigate this in depth. The focus is on a person response by the author. 


\section{Methodology}

This thesis used both 'research for design' and 'research by design' methodologies. In the initial stages of the thesis, emphasis was placed on exploring relevant literature and data to develop a knowledge basis, which could then be drawn upon throughout the design phases of the thesis.

Wellington's south coast from Owhiro Bay to Lyall Bay was selected due to it's varying and intense site conditions and its naturally rugged beauty. Its close proximity to Wellington allowed the author to make frequent visits to the site. Specific sites were identified through a series of walks and analysis of findings. Through experiencing the sites, a greater embodied understanding of the context could be gained.

A series of design 'filters' were developed. The filters are used to investigate the unique conditions on the sites. These filters of, narrative, emotional encounter, contextual narrative, level of contact with threshold and materials, collected and married together both tangible and un-tangible experiential qualities. These filters then provided a poetical framework to develop an architecture, which responded to these qualities. Throughout the briefing process informal discussions took place with users of the coast to collect ideas that informed the design filters. This collection process was a key method in facilitating the exploration of how a series of collections and artefacts from each site could distil the essence of place. A dialogue was created with the existing evocative richness of the context.

Initial design ideas were developed with little rational reasoning. The design process used intuitive and creative responses to both the site and the individual programs of each of the shelters, without having the restraints of rational thinking potentially stifling the creative thinking. Through the use of intuitive drawing and collaging, design ideas gradually unfolded these were then informed by rational considerations such as program, accessibility, and construction. This highlighted the intuitive creative process of creation through both art and architecture and the act that takes place of translating the collected ideas into a built form.

An iterative process was applied to all six sites to develop a coherency in the approach. Multiple designs were worked on at once meaning that they were not being forced, when one design would become stuck the next design was worked on and then later coming back to the previous. While consciously working on one design the sub-conscious is unfolding the thoughts, not forcing the design but letting it naturally develop.

Rigorous and iterative modes of experimentation such as drawing, collaging and modelling extract design principles, which can then manifest in an architectural response that is expressive of the context's intensity of experience. 


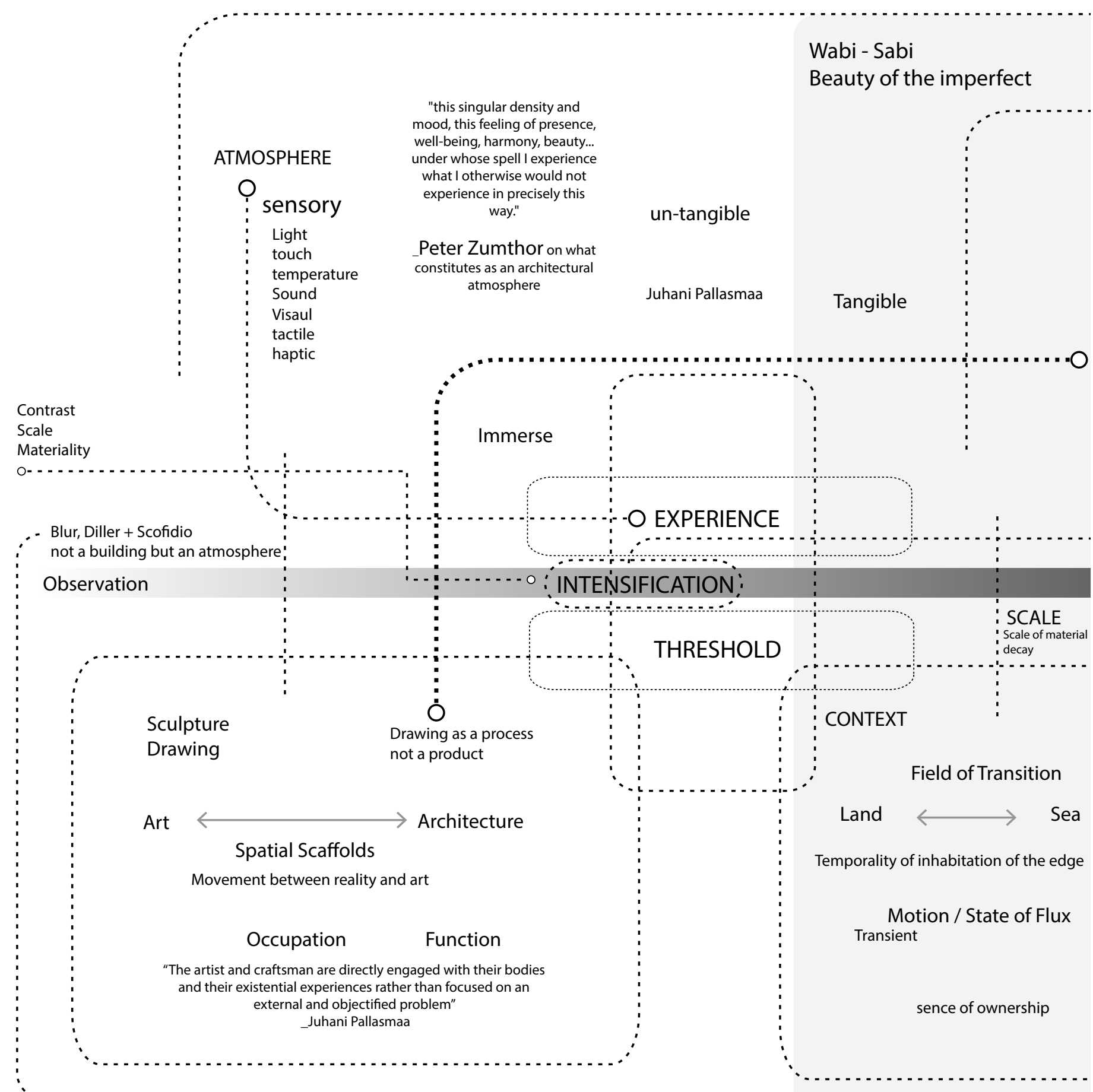

Exploration of the materials instabilities of the sea edge

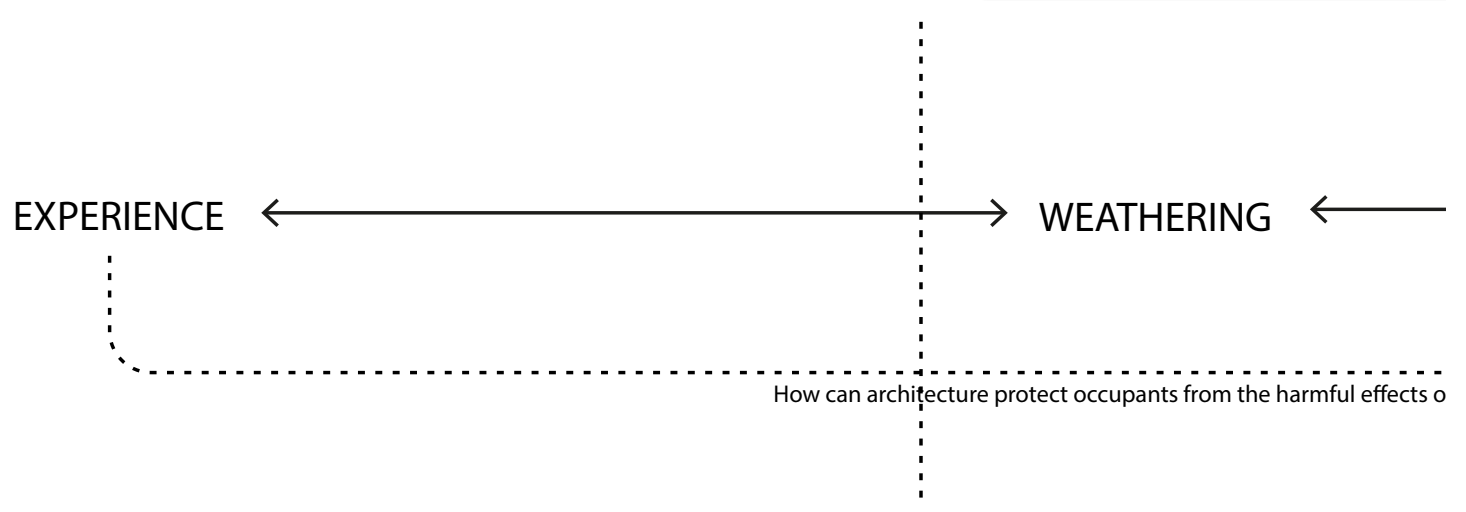




\section{MATERIALITY}

\section{Surface \\ Texture \\ Deterioration \\ Layering}

The ending of an architectural project in not the finishing of construction, this is merely a moment within the buildings continuous metamorphosis. A building has an unending weathering process where the final product is only a moment in an ever-changing finish.

Carlo Scarpa

Brion-Vega Cemetery

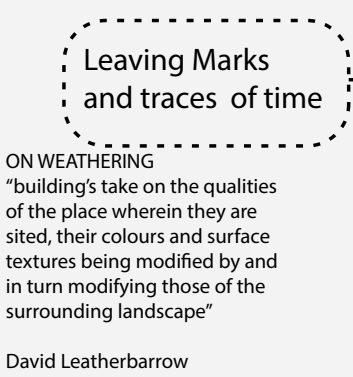

Allowing the traces of time to

reveal the relationship between

the architecture and its

Light/ natural sun Light How to control

TIME inhabited context

Sun Intensity:

\section{Interaction}

\section{SHELTER}

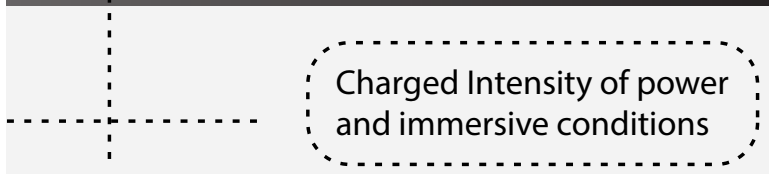

History of the sea edge

Precedence

What has been built on these sites:

Local

Wharf Structures

_Red Rocks, Wellington

Boulder Bank, Nelson

Boat Sheds

The Bait House aquarium, Island Bay

Rhythem

Pattern

International

_Kastrup Sea Bath, White Architects

_Leça Swimming Pools, Alcaro Siza
Political Issues

Queens Chain -

not allowed to

build on this

edge
Sun leaving its trace in the skin through exposure

\section{PROBLEM}

Sun

Wind

Rain

Sea

Sand

\section{Coastal Shelter}

\section{Temporary vs Permanent}

Sculpture vs Architecture

Richard Serra

reveal and conceal
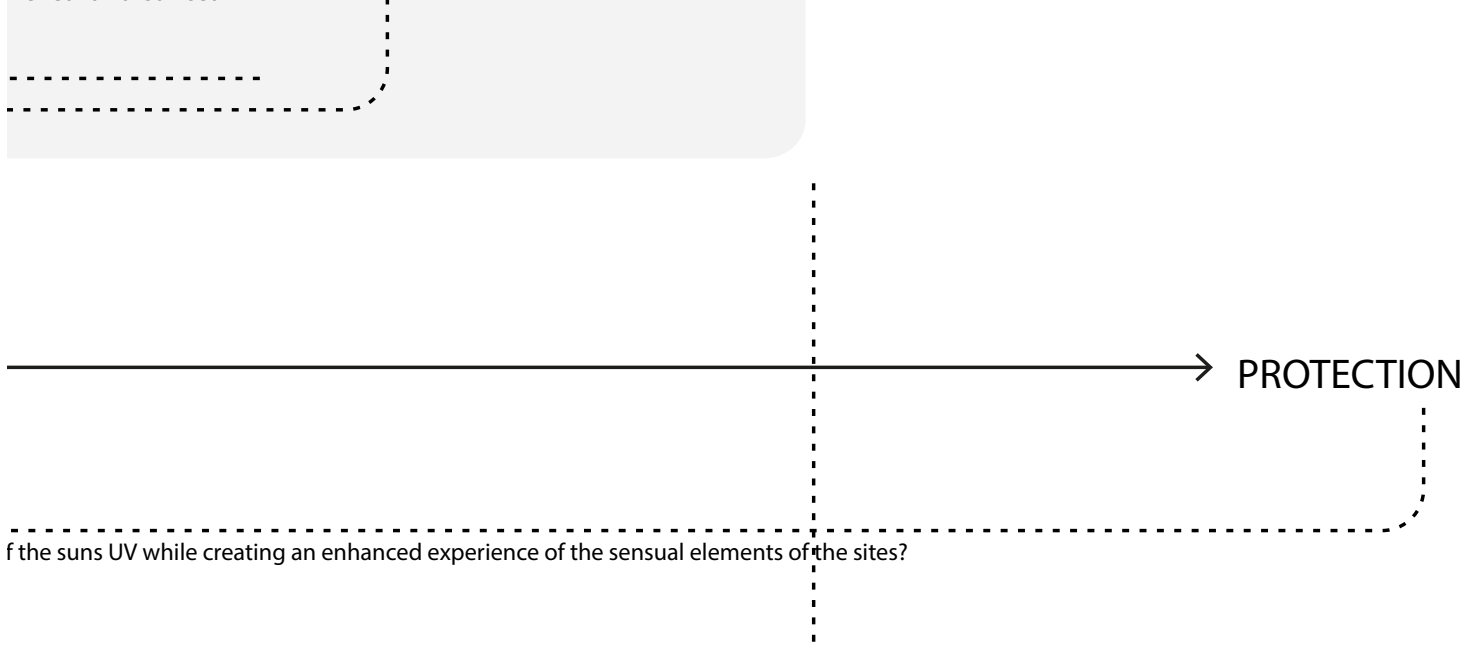


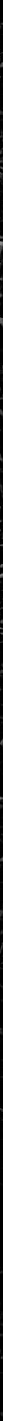




\section{Chapter 2 Context/Site}

This chapter focuses on the overall site and context. As this project is heavily driven by site it is important to understand the strong contextual conditions that are at play, affecting both the physical attributes of the architecture as well as the experiential qualities of the site. Therefore facilitating and developing a greater understanding of how the architecture and site can affect each other. 


\section{Wider Site Selection}

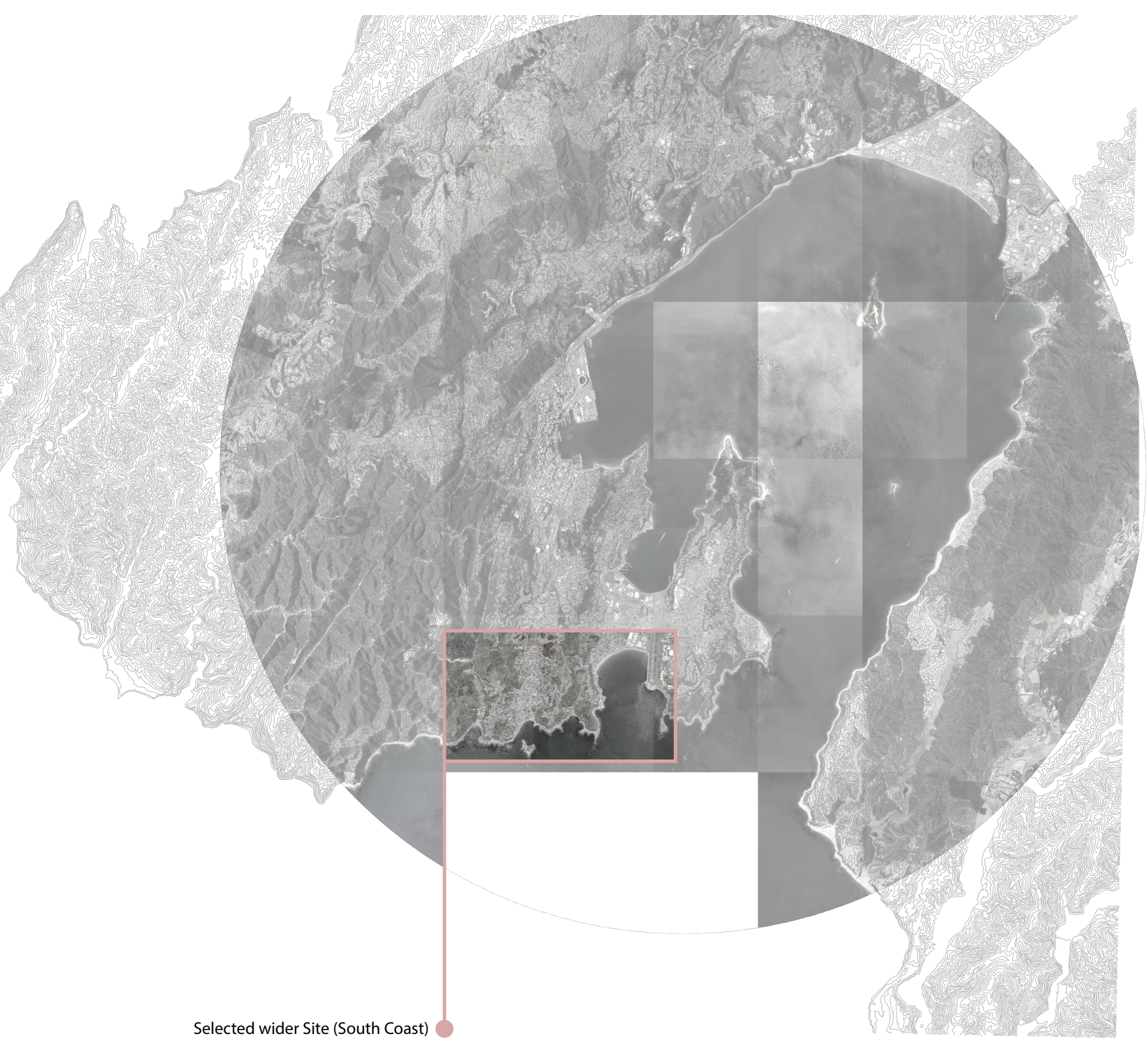

Fig 2.02. Wider site selection 
Situated in the lower North Island, the site for the design proposals is Wellington's south coast, between Owhiro Bay and Lyall Bay. This coast has been selected due to its diverse range of costal landscapes and close proximity to Wellington City. It is used by Wellingtonians for a variety of recreational activities.

Taking a walk along this $6.3 \mathrm{~km}$ section of coast line one is confronted with its rugged and natural beauty. Each turn around the next point reveals a new coastal vista to be explored. From windy, rocky points to sheltered calm beaches, this coastline highlights many types of coastal diversities. However the experience is heavily influenced by the weather. Just like the physical properties of the site the climate conditions are contrasting and diverse.

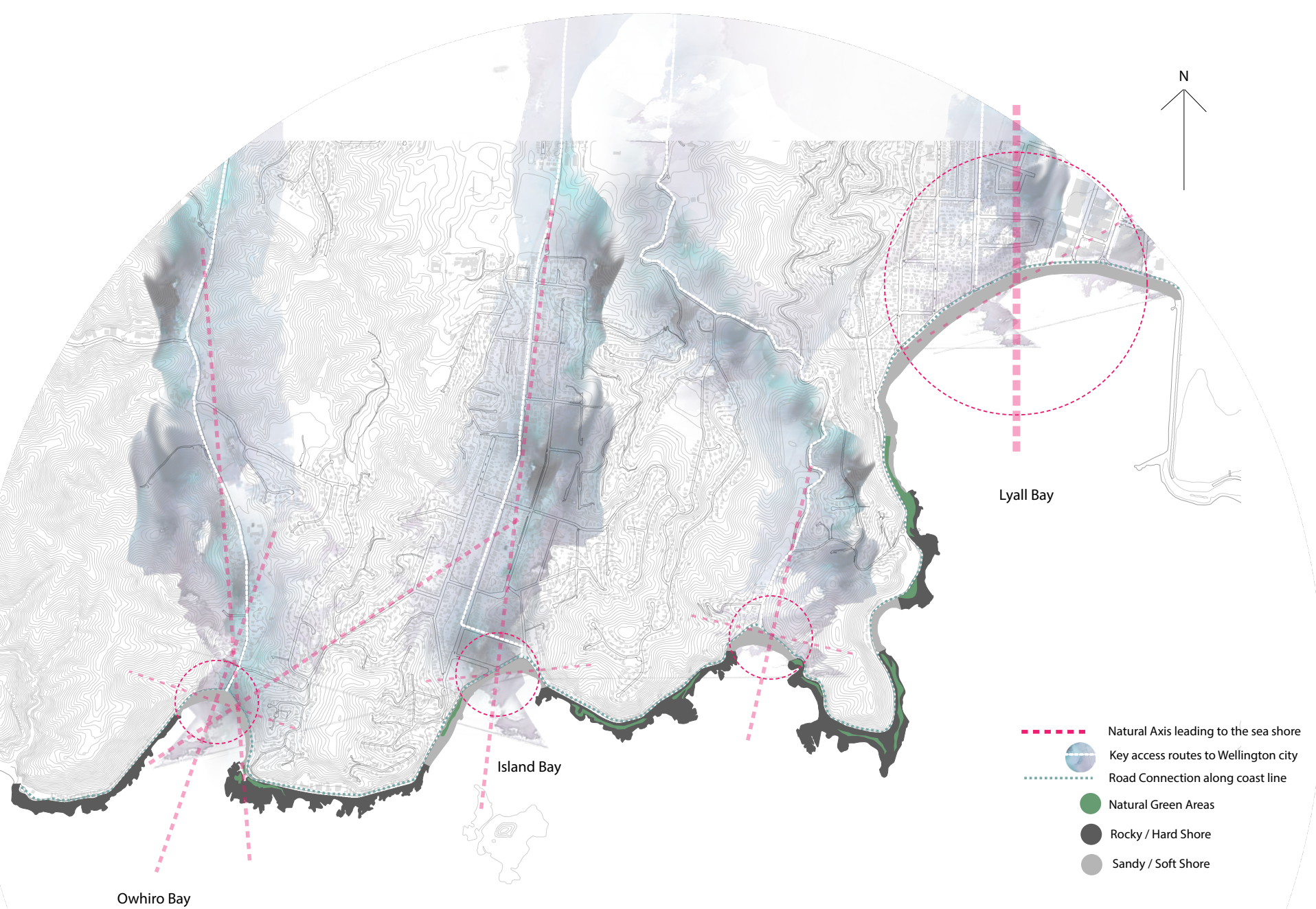

Fig 2.03. Selected wider site analysis 


\section{Land, Sea and Sky Analysis - Site and Climate Conditions}

\section{Sun}

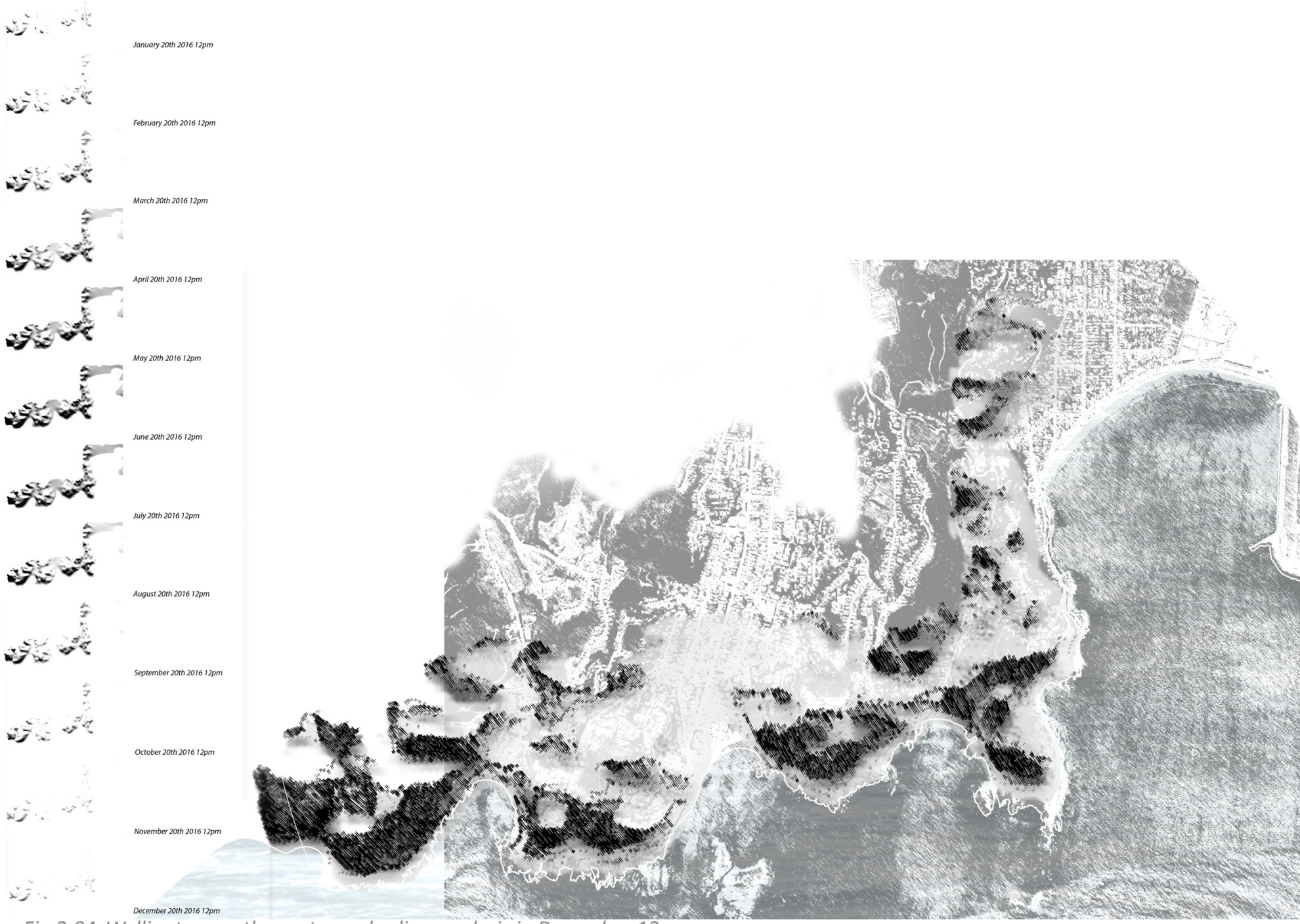

Fig 2.04. Wellington south coast sun shading analysis in December $12 \mathrm{pm}$

The power of the sun is a key element in the deterioration and weathering of materials. During summer, New Zealand experiences high levels of UV radiation which is harmful to human skin and aids in the deterioration of building materials. Along Wellington's south coastline there are varying degrees of shading levels that can be seen due to the topography of the coast. The topography provides a natural sun barrier resulting in low levels of sun in some areas. However where it is most popular for people to spend long periods of time on the coast, for example on the sandy beaches, these are the locations where there is little to no protection from the sun. On average Wellington experiences between 2,001 - 2,250 sunshine hours per year (NIWA). Where there is no shade source the direct sun can lead to thermal discomfort from the heat as well as visual discomfort from the glare. 


\section{Wind}

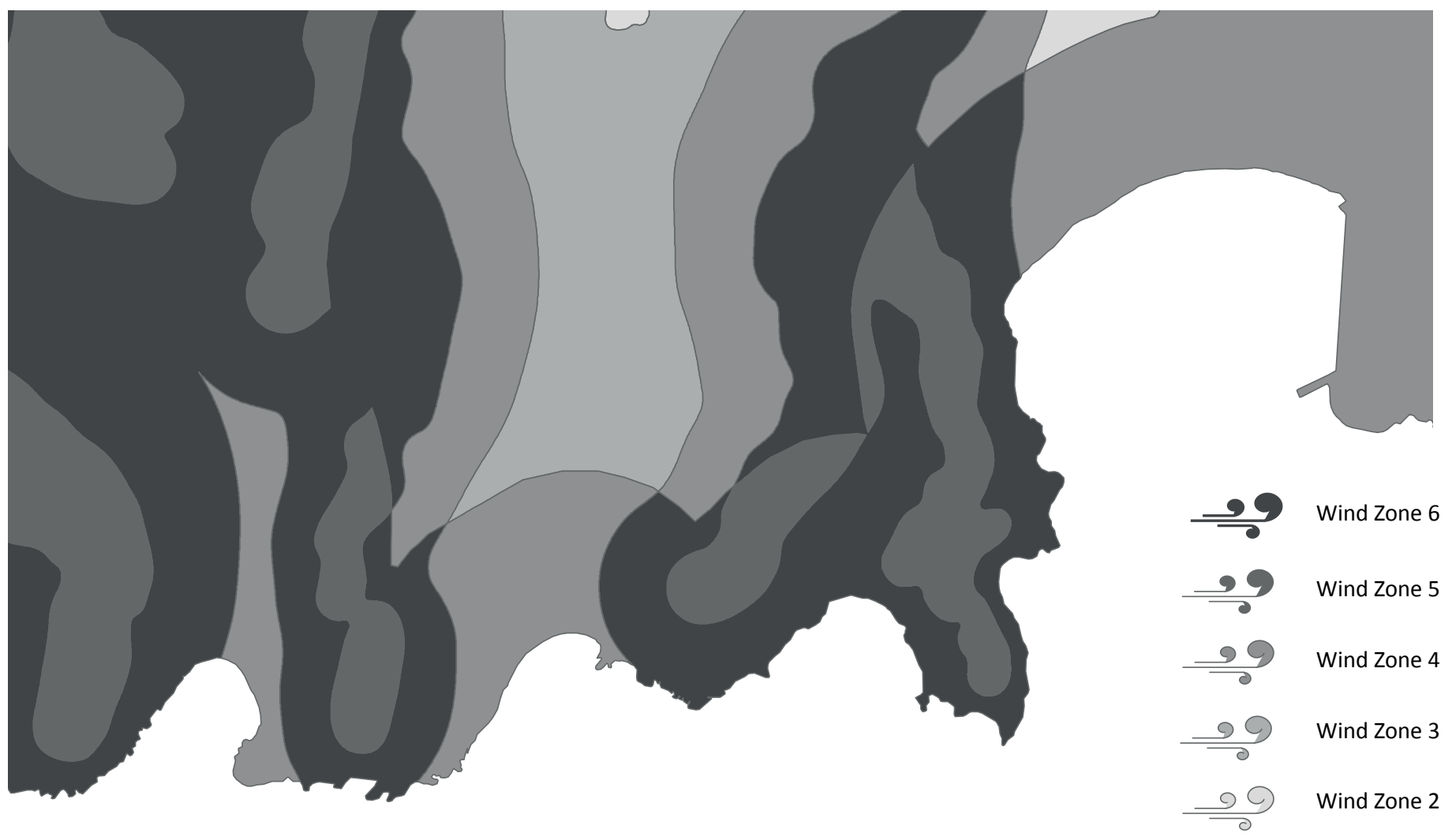

The wind is a large aspect of Wellington's character, which is often referred to as "Windy Wellington". Due to Wellingtons close proximity to Cook Strait there is a high frequency of high winds. The Cook Strait has a funnelling and strengthening effect. Together with this, Wellington cities steep topography strongly influences the wind. These geographical and topographical influences result in the south coast and surrounding area having on average the highest average wind speed in the lower North Island area. The prevailing wind is northwest, with southerly winds most frequently experiences in the winter of May through to August. 


\section{Rain}

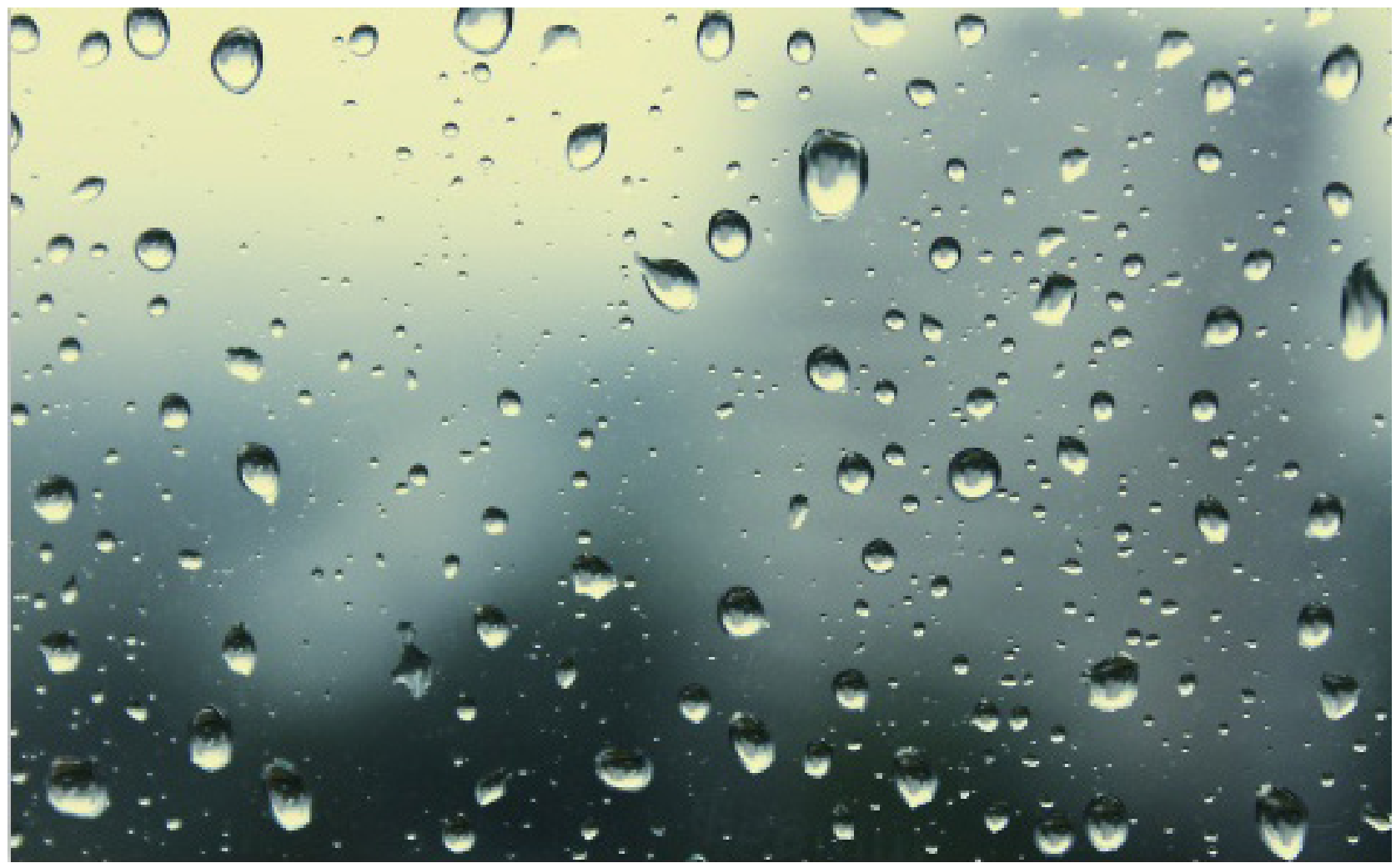

Fig 2.06. Image distortion from rain

Rain transforms the coast to a cool blurred environment where your vision is obscured. The scent of the sea becomes stronger and the sound of the rain hitting the rocks and seawater adds to the rhythm of the waves. Water is a key climatic factor that contributes to the deterioration of materials over time. It stains, distresses and eats away at the materials revealing their honesty and fragility. The average rain fall for Wellington is $1270 \mathrm{~mm}$ annually (Guide). The season variations in rainfall can be seen in figure 2.06 with on average June and July being the wettest months. 


\section{Topography}

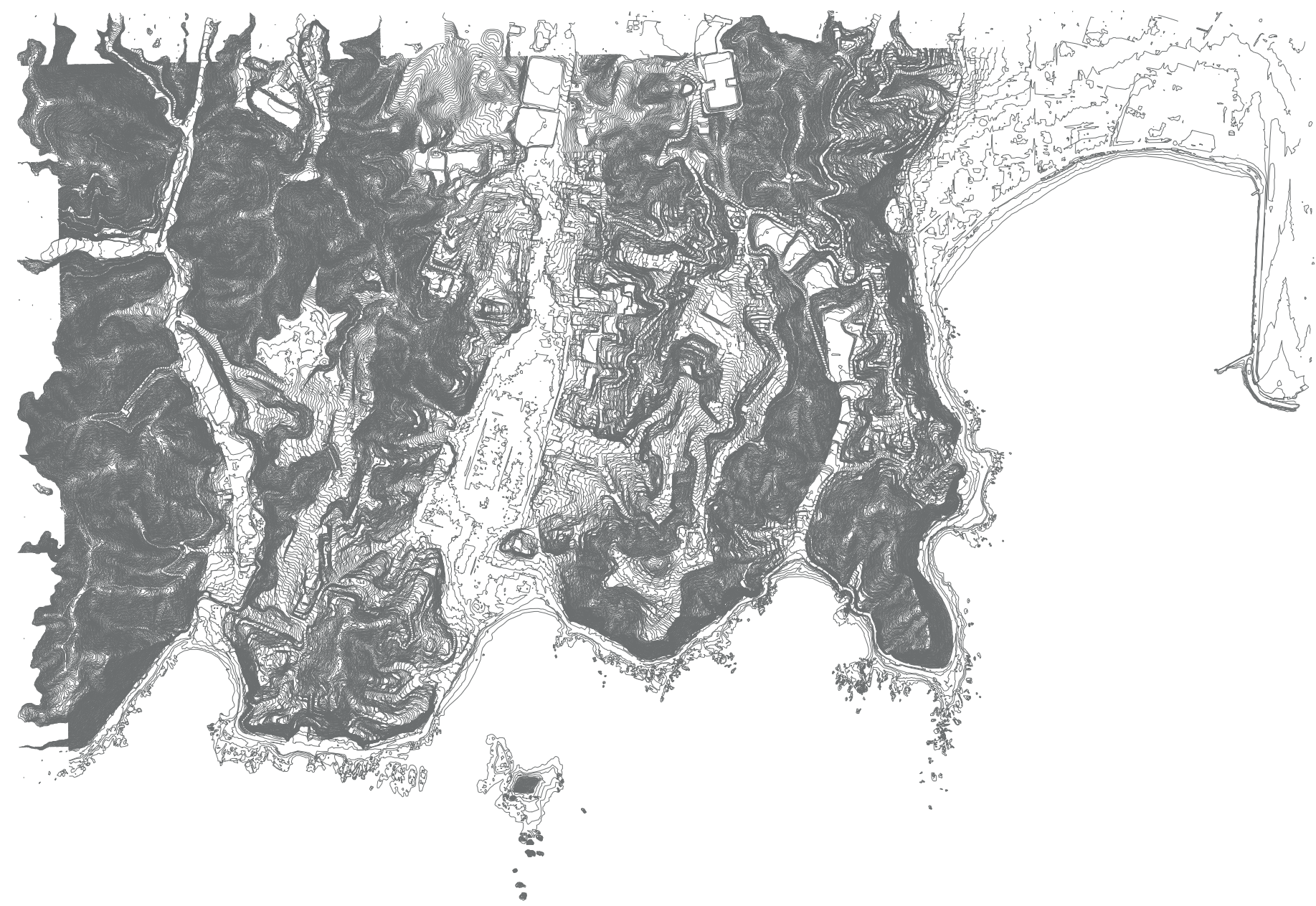

Fig 2.07. Topography of Wellington's south coast 1 m contours

Topography is the fundamental element of how we experience a site. It modifies weather and reveals the traces of nature and human interactions. Topography has a powerful and sometimes subtle language that shapes our environments, from steep hills to flat beaches, all of which enhance the diversity that can be experienced along this coastline. 


\section{Waves and Currents}

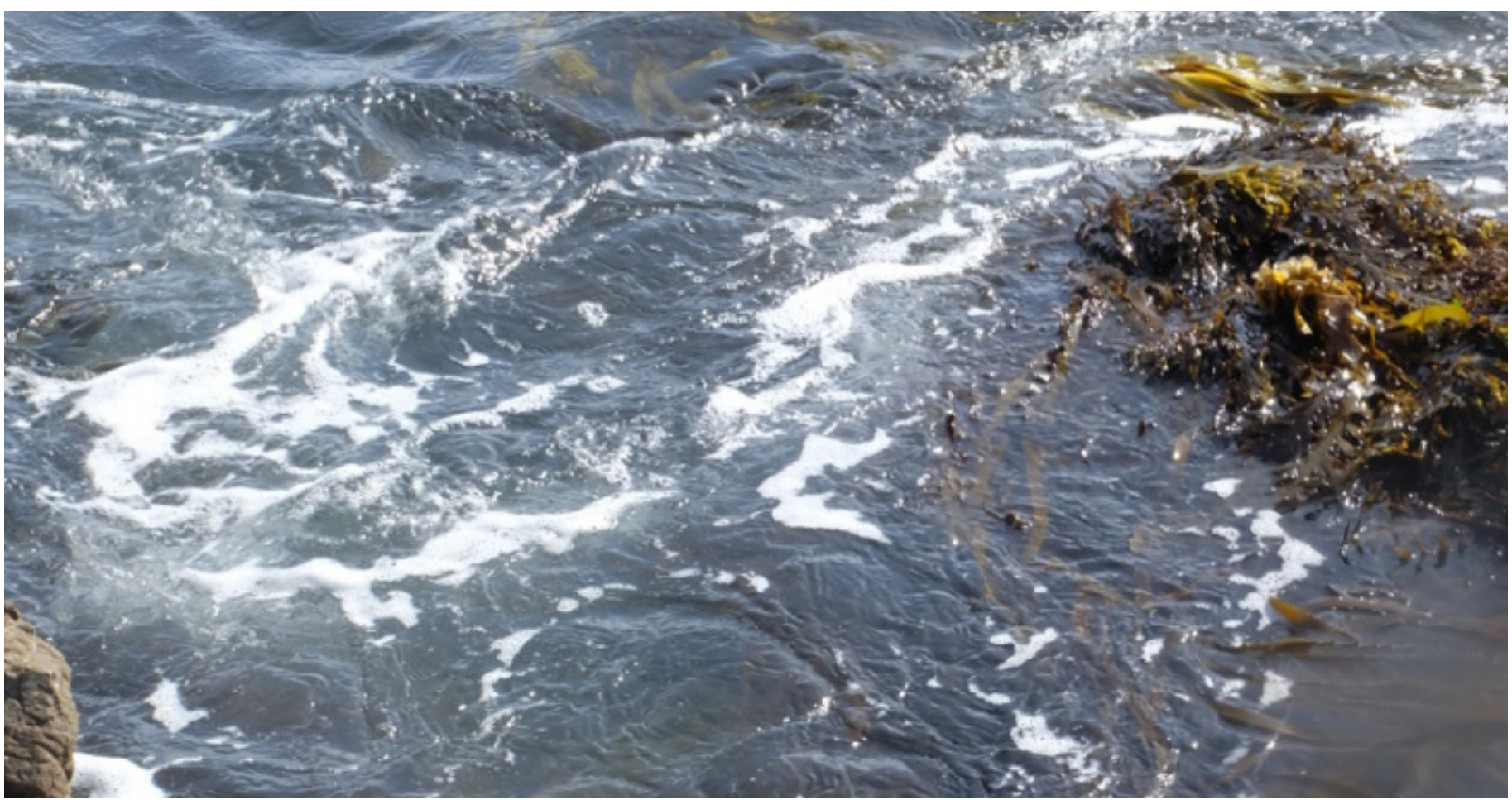

Fig 2.08. Currents of the sea

Wellington's south coast offers a diverse range of shorelines, from sandy beaches to sharp rock platforms. One of the main influences in the sea conditions is the narrowing of the Cook Straight, which intensifies the currents, and ocean swells. In Southerly conditions this shoreline becomes wild and untamed with large swells and strong winds. Average swells are around $1.2 \mathrm{~m}$ to $2.2 \mathrm{~m}$ however large swells are around $5 \mathrm{~m}$ (with a highest recording of $12 \mathrm{~m}-14 \mathrm{~m}$ in 2002). In mean spring tides there is a tidal range of $1 \mathrm{~m}$. ("Shore Geology and South Coast Habitats")

Like many coastal areas wave erosion is a significant force in shaping the shoreline. The forceful shocks that are produced by the pounding waves slowly shape the sea edge revealing material qualities of the different rocks, for example the hardness/softness of the sandstone/argillite. ("Shore Geology and South Coast Habitats") These strong storms and swells also lift sand and other abrasive elements, which weather and break down both natural and manmade forms in its path. 


\section{The Stars}

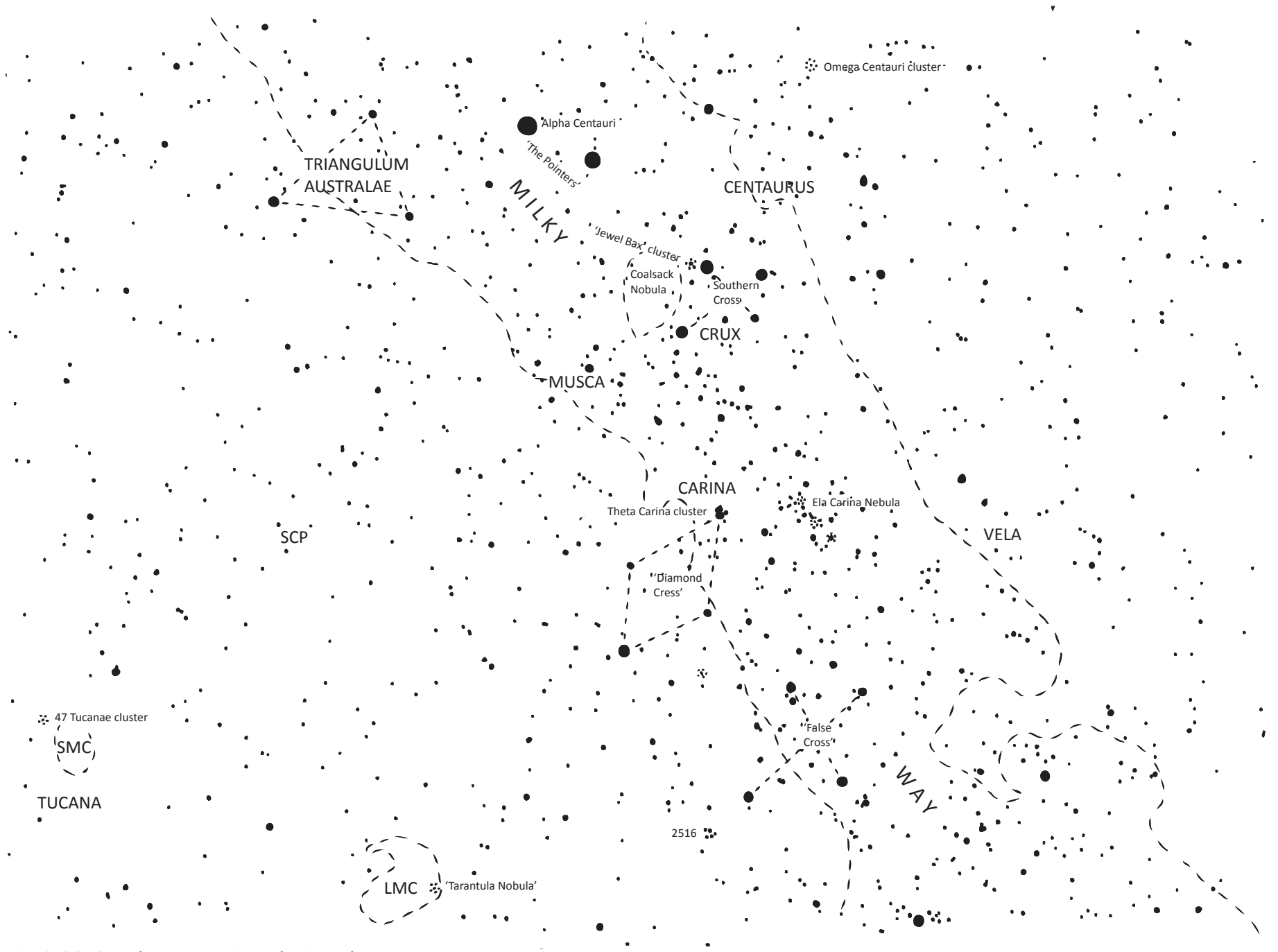

Fig 2.09. Southern evening sky in July

This section of coastline is considered to be one of the best places to star gaze in Wellington due to the low level of light pollution and easy access from Wellington City. Long clear winter nights are one of the best times to stargaze, as the Milky Way Galaxy is high above New Zealand. 


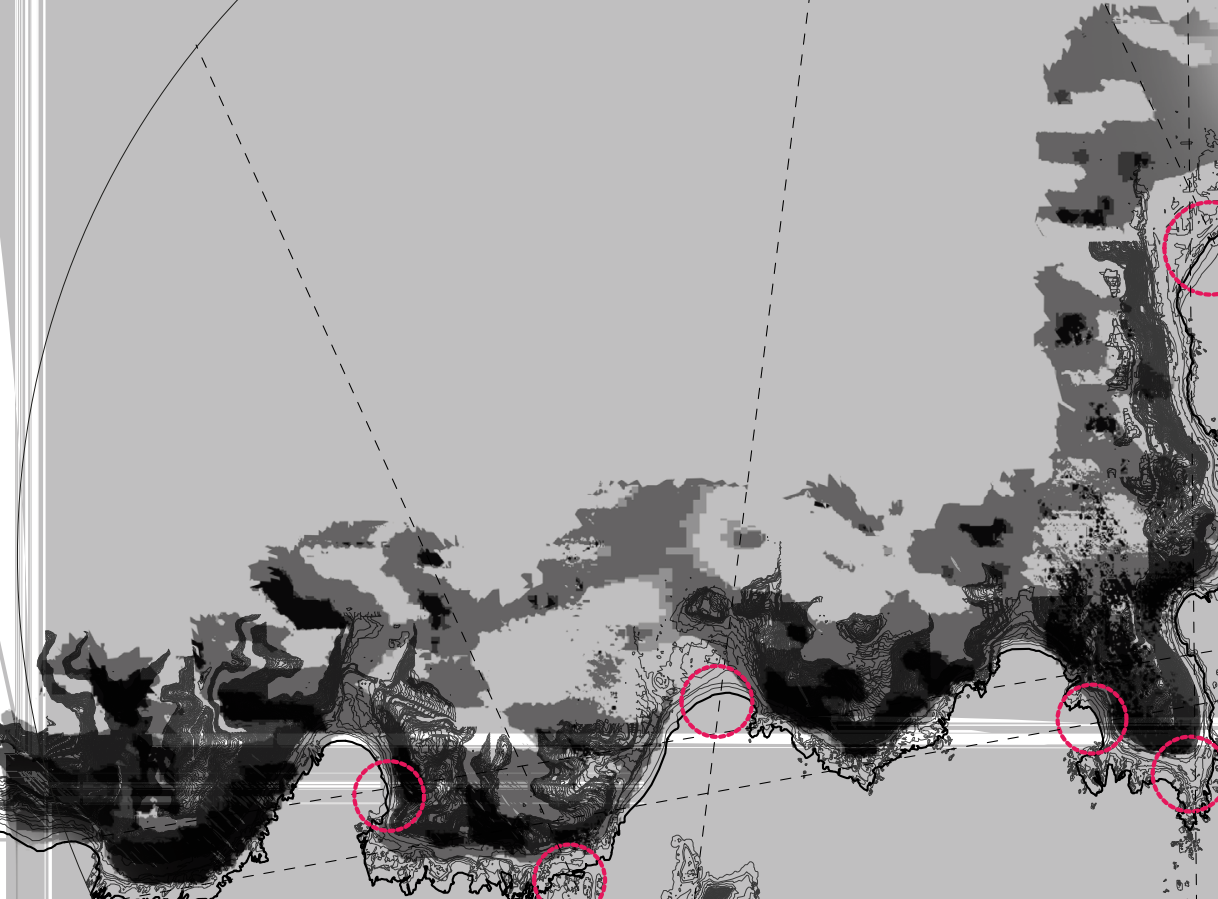




\section{Conclusion}

The physical conditions of the site are the fundamental element for understanding how we experience a place. Each condition contribute and facilitate a particular response or experience that is unique to that particular condition for example the intense heat of the sun or the cooling wet rain. From this tangible understanding of the conditions of the sites, the un-tangible aspects of the experiences can be explored. Through highlighting these conditions specific sites were selected that encapsulated the diversities of this place. From this, detailed site analysis can develop an in-depth understanding of the key drivers behind each site and how they can facilitate a responsive architecture that focuses on the context and experience. 


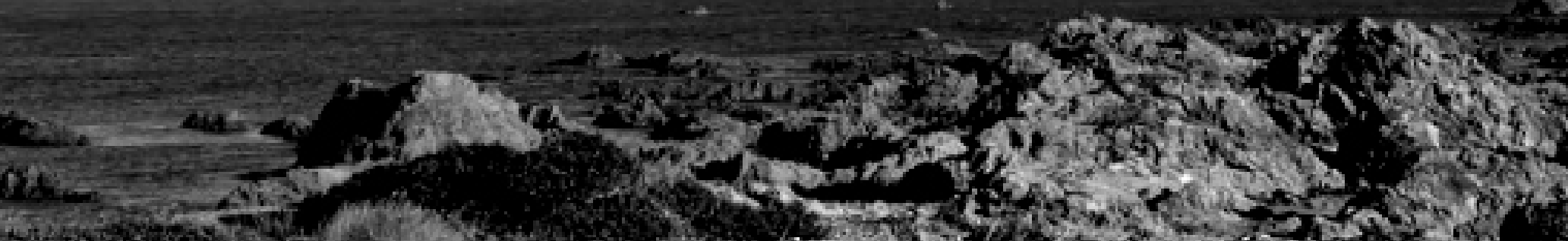

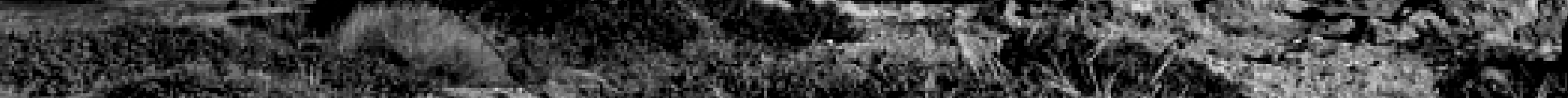

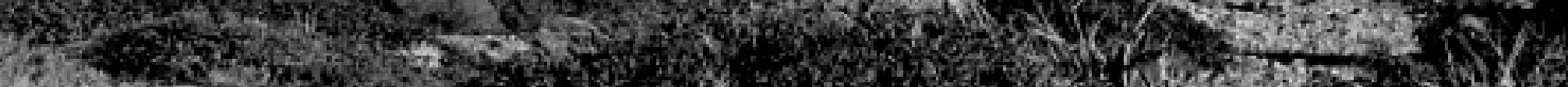

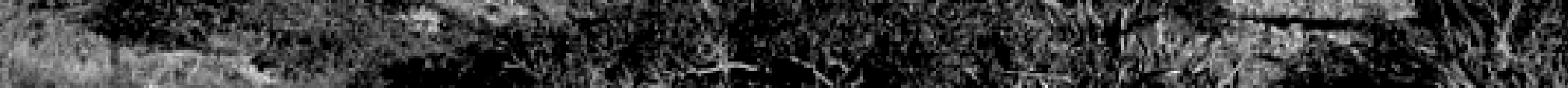
H. L. and

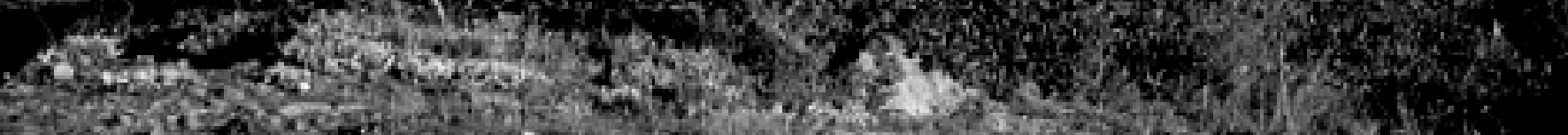

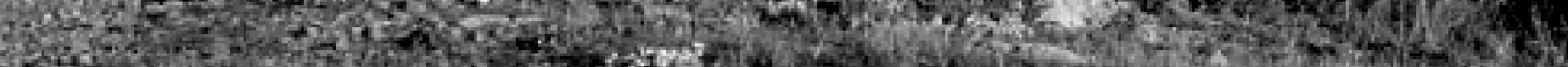

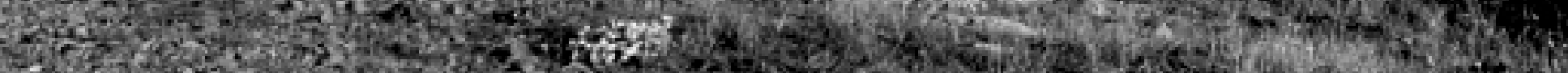

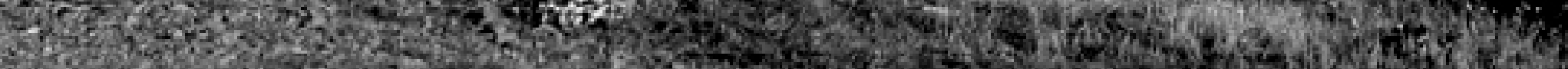

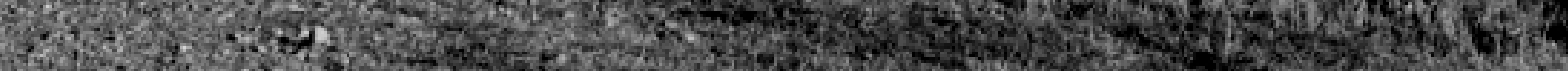

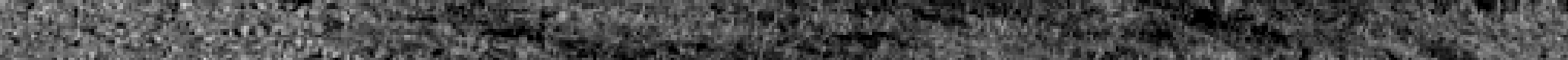

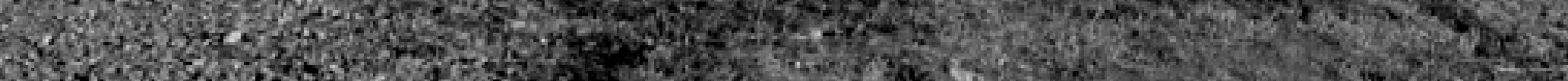

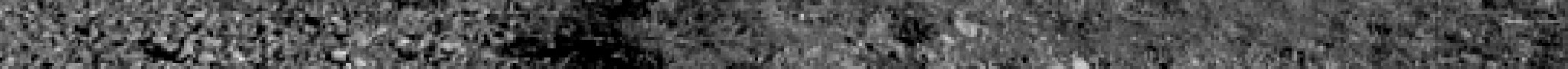
5.

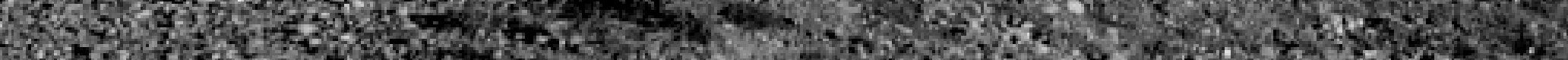

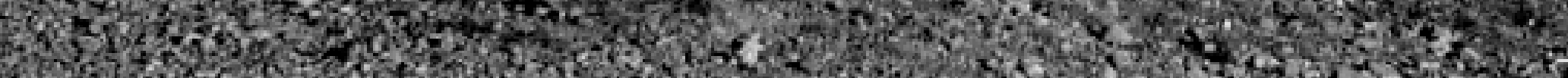

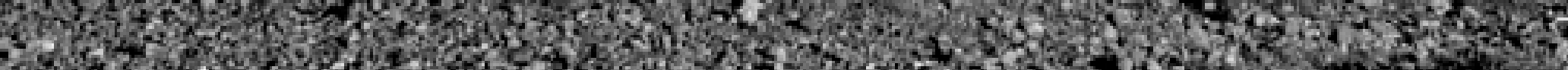

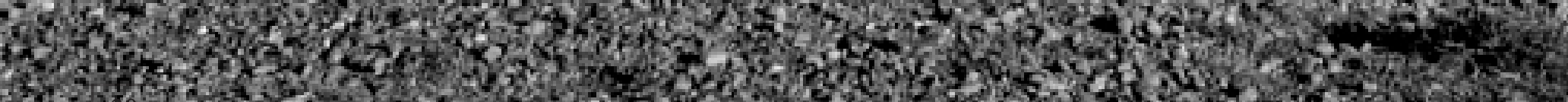

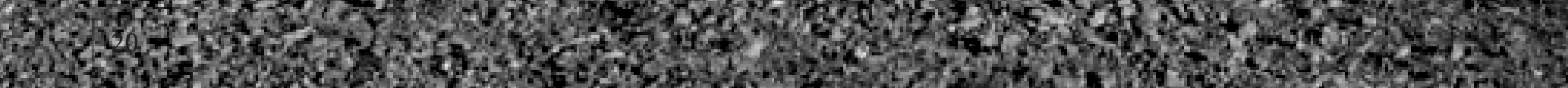
20, 


\section{Chapter 3 Literature Review}

This chapter explores the key ideas around experience, surface, time, and place. Firstly it explores the notions of experience and how we can develop an intensified experience of both architecture and place. The notions of weathering and imperfections are also explored. Over time built forms continually change, developing traces of time affecting the way in which the building is experienced in the environment. The effect of weathering from the environment and human interaction, are inevitable. By exploring the theoretical basis of these concepts the aim is to develop a framework that can then test these ideas through design. 


\section{Experience}

The notions of experience, place and dwelling have long been considered by theorists and architects. One of the most famous philosophers dealing with these ideas in relation to architecture is Martin Heidegger. Heidegger was writing in the post war era when actions were commonly justified by economic and technical development, however he "pleaded that the immediacies of human experience shouldn't be forgotten" (Sharr 2). He argued "People make sense first through their inhabitation of their surroundings, and their emotional responses to them." (Sharr 2) He saw the need to firstly consider the emotional and experience before the quantifiable aspects of architecture when designing spaces. This central idea of qualities of human experience within architecture has been explored by many architects including Peter Zumthor, Steven Holl and Juhani Pallasmaa.

Juhani Pallasmaa argues, that experiencing space through the human senses allows us to become integrated with the environment through our body. "Our bodies and movements are in constant interaction with the environment" (Pallasmaa The Eyes of the Skin 40), we are never without some kind of sensory experience. Pallasmaa argues that there are seven sensory qualities that are at one point enhancing our experience of the space around us "Every touching experience of architecture is multi-sensory; qualities of matter, space and scale are measured equally by the eye, ear, nose, skin, tongue, skeleton and muscle"(Pallasmaa "An Architecture of the Seven Senses" 42). When these qualities are combined, a strengthened experience is formed of one's self within the world.

Both Zumthor and Heidegger have comparable ideas about experience in architecture. Throughout his work Zumthor places a strong emphasis on the experiential and sensory aspects of the architecture over other focuses such as technological or cultural. In his text, Thinking Architecture, he writes on his aunt's house and the memories and sensual qualities that "contain the deepest architectural experiences"(Zumthor 8). Memories are one of the greatest tools when dealing with experiences. Powerful experiences become ingrained within you. Hiding away and then reappearing with a particular sensual awakening such as smell, texture, sound. Through qualities that both play on the senses and people's inhabitation of space, rich powerful architecture can be created that is centred around the human experience. 


\section{Material weathering and imperfection}

Throughout the lifetime of a building the materials are in continual change. Each material weathers in specific ways that reflect the local context and conditions. Over time a greater connection is created between the architecture and the environment. A layer of physical memory is created on every surface highlighting the unique marks and traces of its exposure over time. Whether this weathering is desired or not, it is inevitable in some form, therefore it should be embraced and even celebrated. Throughout the research into weathering and time ideas surrounding these topics have been positively influenced by Joseph Sheperd's thesis "The Weathered Trace".

Each element within this coastal edge, whether built or natural, is a series of layers, which are either added to or subtracted from over time. Weathering is an ever-changing process of addition and subtracting (Sheperd 16). All materials have hidden dimensions that are revealed through the weathering process highlighting the temporality of a surface or element, "Marking reveals, through weathering, nature's temporality; the beginning and end of things (Mostafavi and Leatherbarrow 103)." From Leatherbarrow it can be considered that both the human body and materials have the same natural process of growth and decay. All materials are temporary, with the only question being how long they can resist the effects of weathering and if they become richer and positively changed over time.

"While it may be possible to see all weathering as deterioration, the production of distracting marks that dirty original surfaces, this recognition of the play of shadows and the inevitability of marking suggests an alternative interpretation, one of weathering as a process that can productively modify a building over time (Mostafavi and Leatherbarrow 42)".

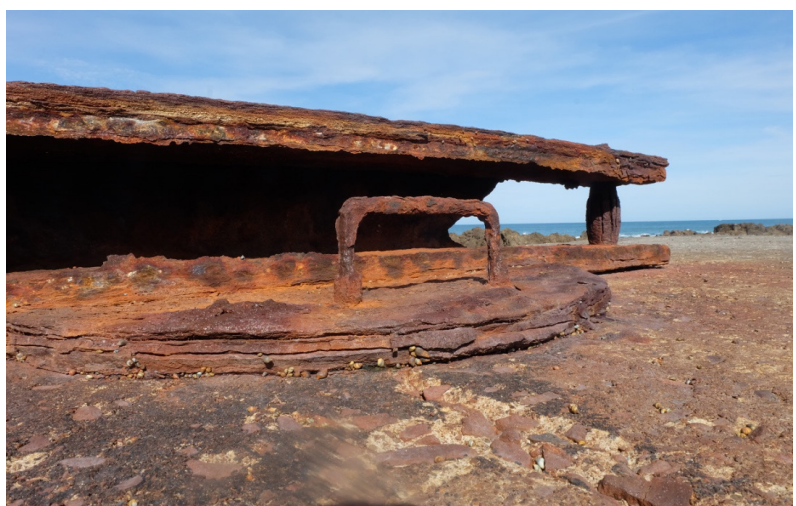

Fig 3.02. Material weathering at Houghton Bay,

Wellington's south coast

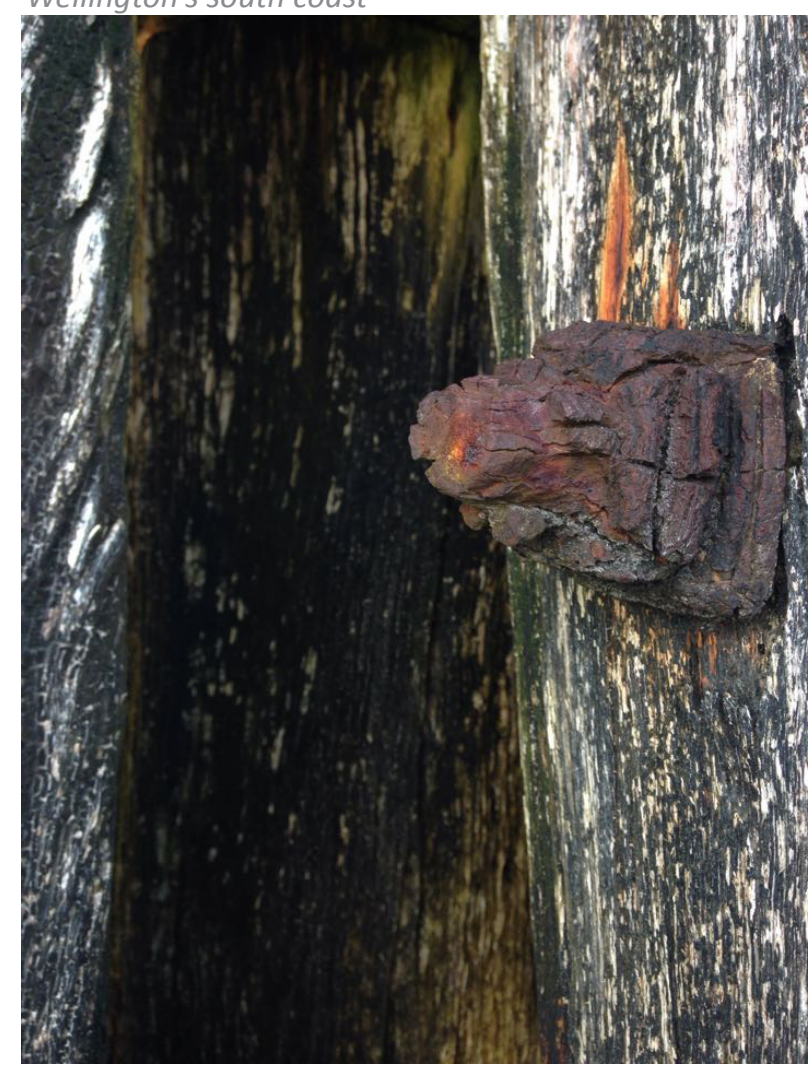

Fig 3.03. Material weathering on Eastbourne wharf 
The notion of celebrating the imperfect and the effects of weathering has long been seen within Japanese culture. Wabi-sabi is a key Japanese aesthetic concept, and is best explained by Leonard Koren "Wabi-sabi is a beauty of things imperfect, impermanent, and incomplete. It is a beauty of things modest and humble. It is a beauty of things unconventional." (Koren 7) This concept not only refers to the imperfection of materials but also to the imperfection of form. As can be seen in figure 3.04 where the material qualities of the clay was explored. The simplicity of the finish celebrates the imperfection in the form and the qualities for the material. When referring to material qualities of Wabi-sabi it can be considered that things Wabisabi highlight the vulnerability of a material to the effects of weathering and their ability to trace rain, sun wind etc. This concept can be seen as having the desire to accept things as they are and the natural qualities that is found within each material.

Marks and traces left over time are an inevitable product from the integration with nature, architecture and material interaction over time. Modern materials such as some finishes on metals and plastics are shiny and evenly finished. Any imperfections are seen as damage and negative. However as described by Koren "All things are imperfect. Nothing that exists is without imperfections, when we look really closely at things we see flaws ... Every craftsman knows the limits of perfection: the imperfection glare back. And as things begin to break down and approach the primordial state, they become even less perfect, more irregular."(Koren 49) As stated by Sheperd, when we have the ability to understand the process and influence of nature on materials we have the facility to develop and design to a new idea of perfection that is found with imperfection (8-9).

When materials are used that celebrate their imperfections there is an element of truth and vulnerability shown within the architecture. Through weathering the site develops a form of ownership of the architecture. The built form shows and highlights nature's effect on the building. "In the time after construction, building's take on the qualities of the place where in they are sited, their colours and surface textures being modified by and in turn modifying those of the surrounding landscape (Mostafavi and Leatherbarrow 72)". Just as the materials settle into their environment and take on the qualities of the place, the human body too becomes more relaxed in places that are imperfect. When we are put into spaces that are unfamiliar and perfect there is a certain amount of anxiety that comes from not wanting to affect or create disorder within the 'perfect' space (Sheperd 26). This highlights the notion of place and how the human body interacts and responds to space. We must fundamentally focus on the process of the architecture rather than a defined final product.
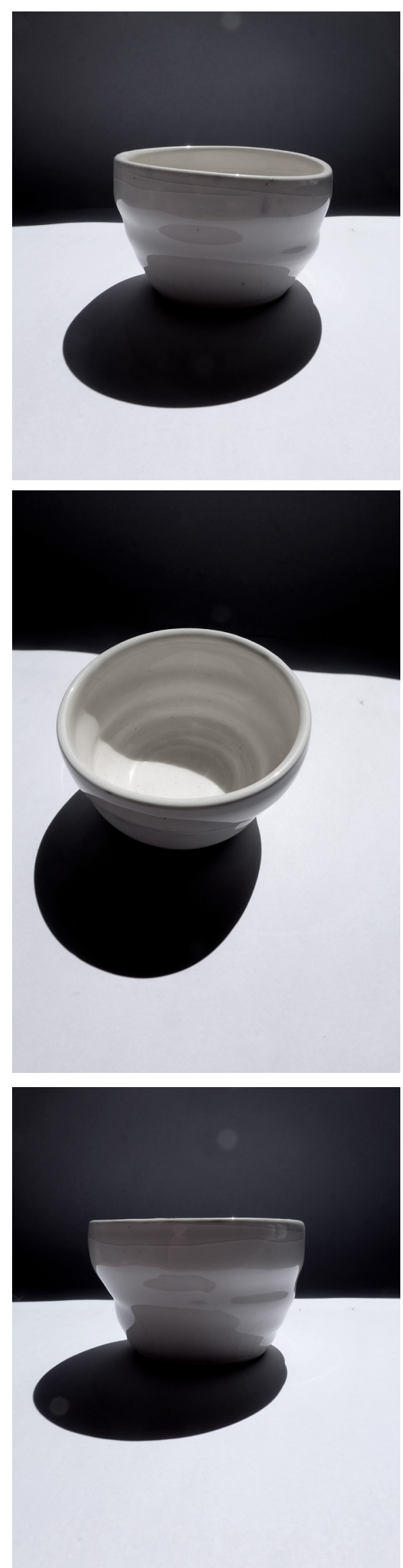

Fig 3.04. Ceramics made by author celebrating the imperfections of form 
In aiming to understand how architecture can respond to the unique attributes of a particular site we first need to understand the importance of place in understanding the world around us. "Place is where the mind touches the world, a place is a configuration of architectural elements that seems (to the mind informed by its senses) to accommodate, or offer the possibility of accommodation to, an object, a person, an activity, a mood ..."(Unwin 25) The physical and emotional experience of a place connects space in time. Every place has layers of dialogue from history to materials each of which has the ability to enrich our connection to a particular place in time.

Time within nature takes on a unique meaning. Time is experienced at many scales and through many different forms, from hours in a day to seasons in a year, time provides a frame of engagement. "Time is a dimension of experience " (Pallasmaa "The Space of Time" 54) however it is an element of experience that is often disregarded. As described by Pallasmaa, architecture "mediates human's relation with the fleeting element of time"(Pallasmaa "The Space of Time" 54). Time is constant, it cannot be changed or altered. The places in which we engage with this form of experience need to highlight the connection between place and architecture. Site and architecture become related and even come from each other.

Places in nature take on different meanings to different people. They are places of freedom and possibilities. Heidegger explored the creation of place through the site of a bridge...
"The (place) is not already there before the bridge is. Before the bridge stands, there are of course many spots along the stream that can be occupied by something. One of them proves to be a (place), and does so because of the bridge. Thus the bridge does not come first to a (place) to stand in it; rather a (place) comes into existence only by virtue of the bridge."

When designing in nature it is important to create a strong connection between architecture and the natural environment (Sheperd 7). When "Structure and landscape fuse, grow together and establish an inimitable place." (Zumthor 101) Both architecture and landscape become integrated, responding to and enhancing each other. "An architectural work is not experienced as a series of isolated retinal pictures, but in its fully integrated material, embodied and spiritual essence"(Pallasmaa The Eyes of the Skin 12). When architecture becomes one with place it is no longer about the physical object in space but the embodied exchange between place and architecture, where place becomes intrinsically connected to the architecture.

The skin is the primary human layer for tactile experience. The skin is a membrane that both protects and exposes us. This can be developed into the correlation of the skin being the main experiential membrane and also the first layer that begins to deteriorate from the exposure to sun. As stated by Pllasmaa "The eye is the organ of distance and separation, whereas touch is the sense of nearness, intimacy and affection"(Pallasmaa The Eyes of the Skin 46). Through touch, the body becomes integrated with the world. Whether it is the touch of a rough stone or the presence of the hot sun on your skin, the body becomes integrated with the world around it. 


\section{Conclusion}

This chapter has explored key ideas around experience, weathering and inhabiting place. It has been highlighted that built form and materials are continually evolving. They are going through an everchanging process of weathering which creates a layer of marks and traces on the architecture. Place and time takes a hold in architecture. Through embracing this process and celebrating its resulting imperfections we will become more engaged with both the architecture and the environment around us. It also allows us to become more aware of our own fragility in relation to the environment. We need to focus on both the experience of a space and the process of the architecture rather than a final product. 


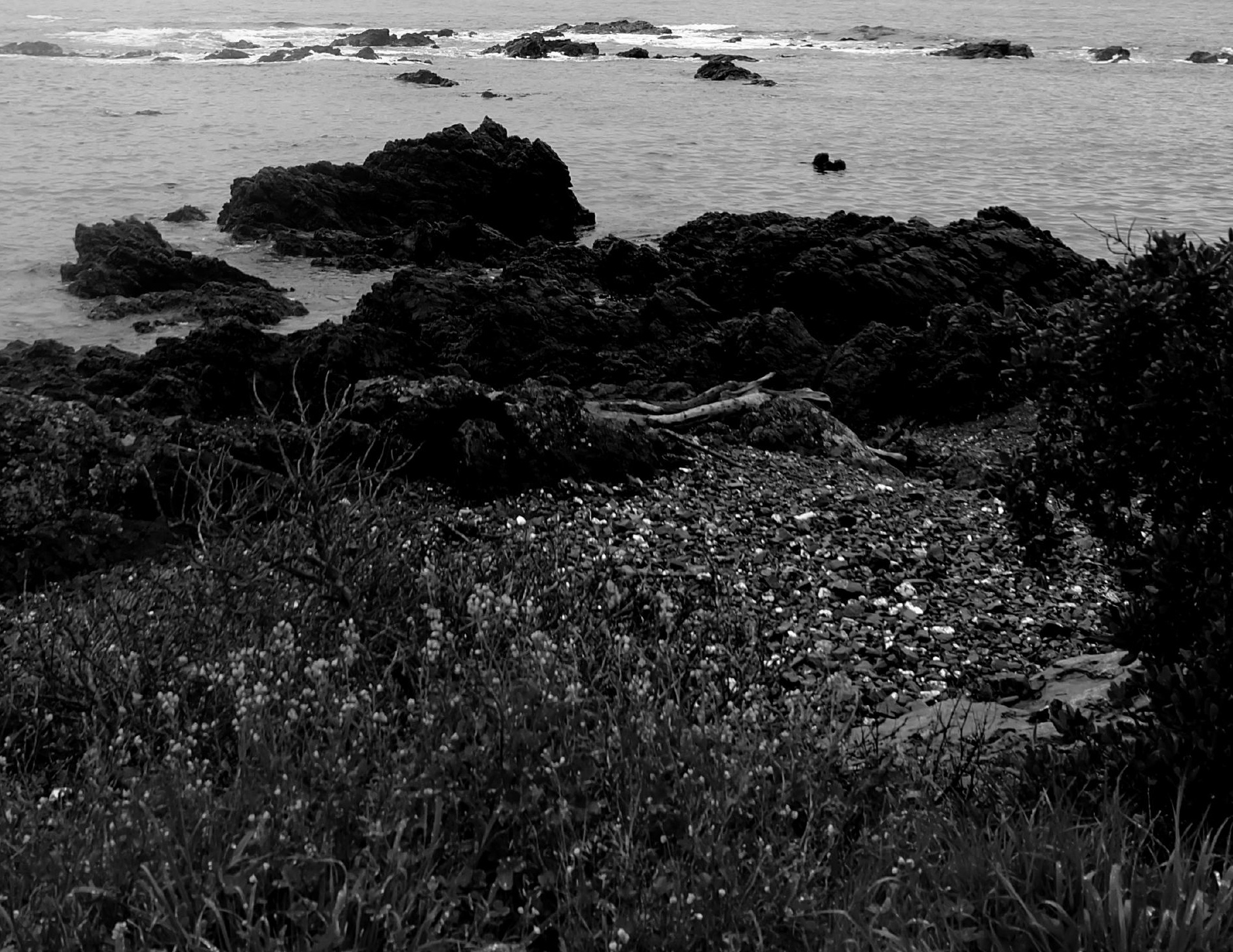




\section{Chapter 4 Design Filters}

From the ideas explored in the previous chapters, a series of design filters have been generated to support the design process. These filters develop a framework for the design process for ideas to be tested and explored. 


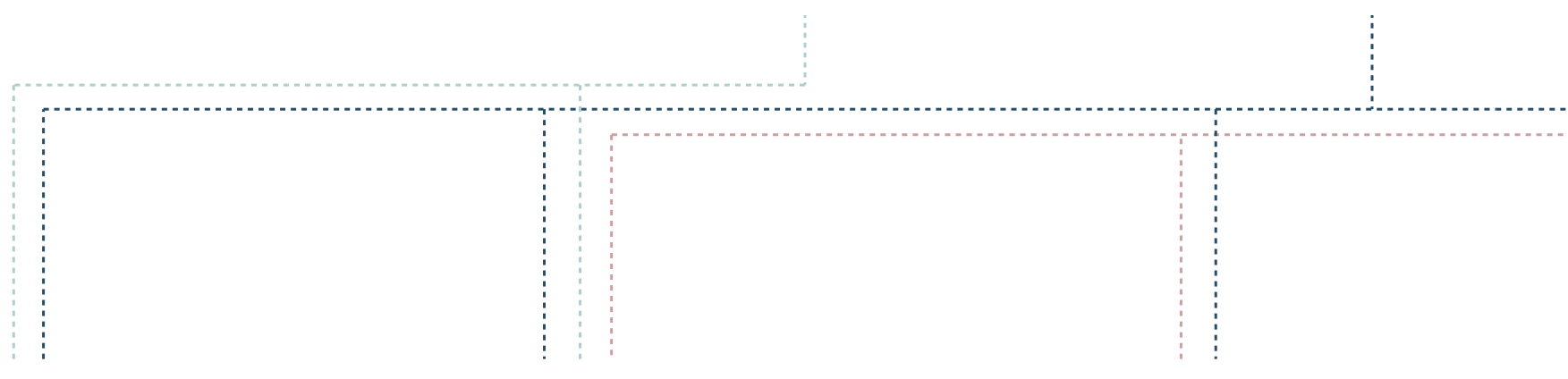

\section{PROGRAM NARRATIVE}

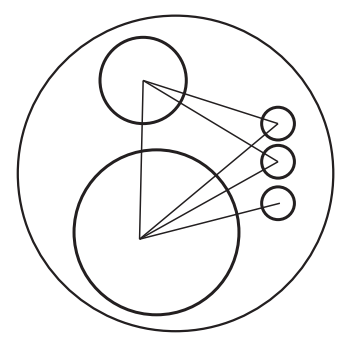

Who are the main occupants of the architecture and how will it be used?
EMOTIONAL ENCOUNTER

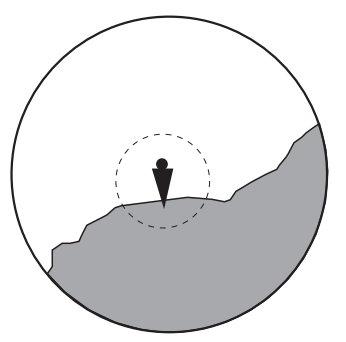

What are the unique contextual drivers that facilitate an emotional experience of the site? How are the connection between site, architecture and occupant being designed to fully respond to the context?
LEVEL OF CONTACT WITH THE THRESHOLD

THE 'THRESHOLD' IS THE POINT AT WHICH LAND TRANSFORMS INTO SEA

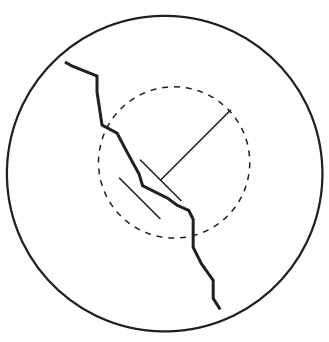

How does the proximity and contact between architecture and sea edge intensify the experience of the context?

Fig 4.02. Design filters framework and parameters derived from the outlines opportunities, site analysis and literature review 
Chapter 5

Design Precedents 


\section{Case Studies}

In this chapter, a range of case studies are explored in relation to the design filters, program narrative, emotional encounter, level of contact with threshold, contextual narrative, material and processes and view. Each of the case studies that have been selected are examples of existing architecture that have similar design intentions. The design filters will be used as parameters and points of investigation within the design process to discuss and evaluate the design propositions. 
Leca Swimming Pools

Alcaro Siza

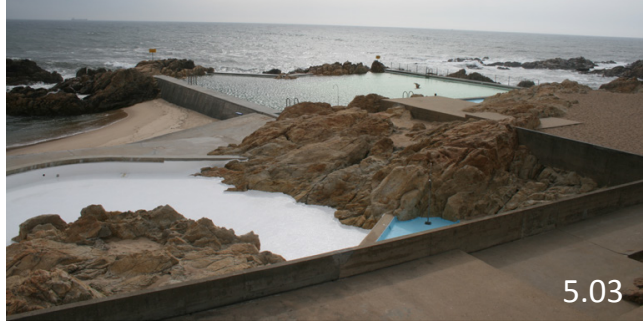

Brion - Vega Cemetery Carlo Scarpa

Therme Vals Peter Zumthor
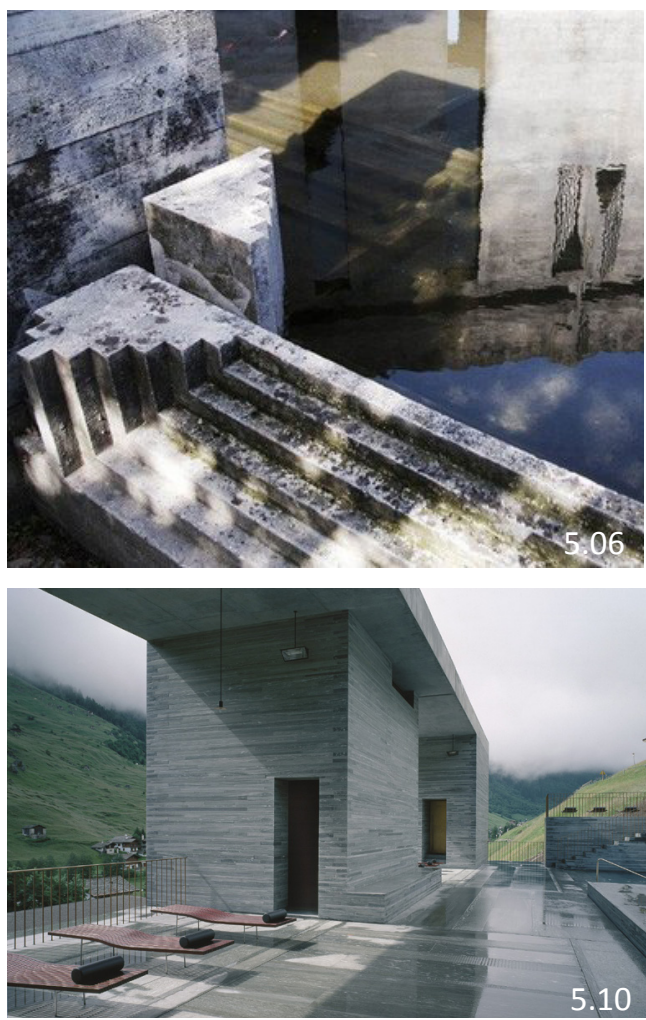

Te Kopahou Reserve Gateway Wellington City Council

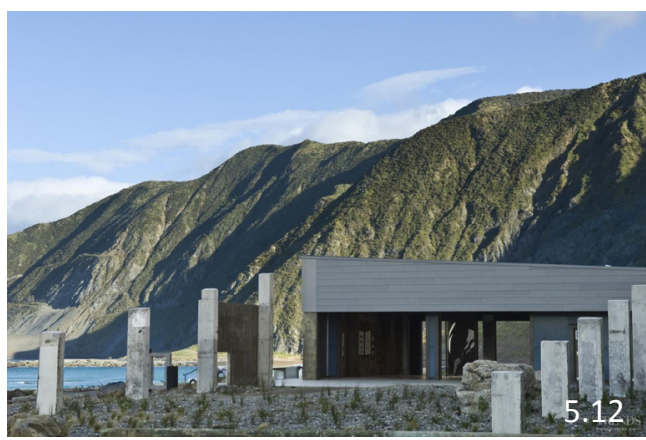

Cairn Andy Goldsworthy

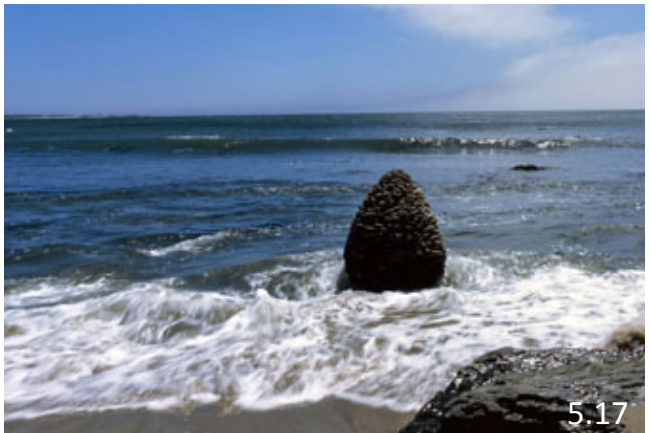




\section{Leca Swimming Pools}

Architect: Alcaro Siza

Location: Leça de Palmeira, Portugal

Year: 1966

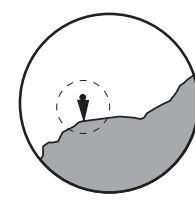

The Leça Swimming Pools, located along Portugal's rocky shoreline are an example of architecture on the edge of the shoreline. They respectfully integrate with the existing landscape through both form and material.

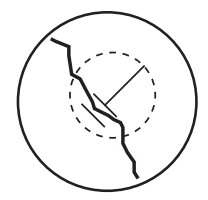

There are two main aspects to the design the pools and the café/ changing rooms. Each of these two elements work together to create a heightened experience of both architecture and context.

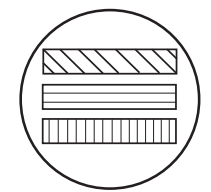
The journey through the architecture has been carefully planned to enhance the sensory experience. As experienced within the entrance to the building, "With no views, the ocean beyond becomes audible and the transition between roadway and ocean is captured in a sensory experience within the building "(Balters). This intensifies the experience of the sea edge through subtracting and then revealing particular elements that play on different senses. The occupant's experience of the space becomes heightened, their senses revealing aspects that would otherwise not been experienced.

The materials that have been used within the design are such that they are able to withstand the corrosive marine environment. A limited palate of materials "achieve an unusual level of homogeneity: the rough concrete, of a slightly cooler hue than the rock formations, smooth and washable concrete panels for the pavement, Riga wood carpentry, and green copper roofs, which seen from the coastal avenue attain a colour similar to the pools." (Berger) The threshold between architecture and context has become distorted; new and natural materials have a continuity of texture, solidity and colour revealing a common language between architecture and context. 


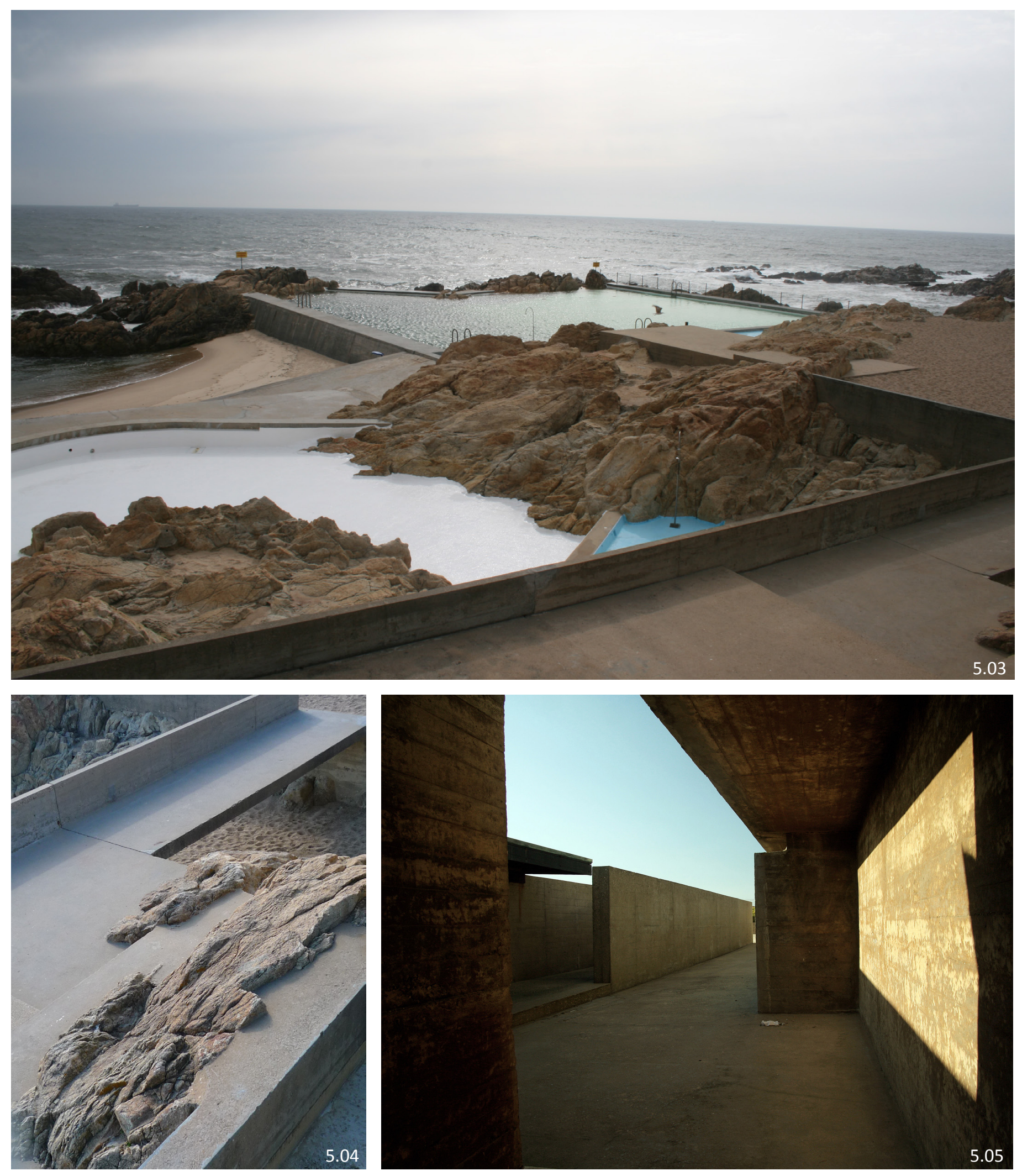



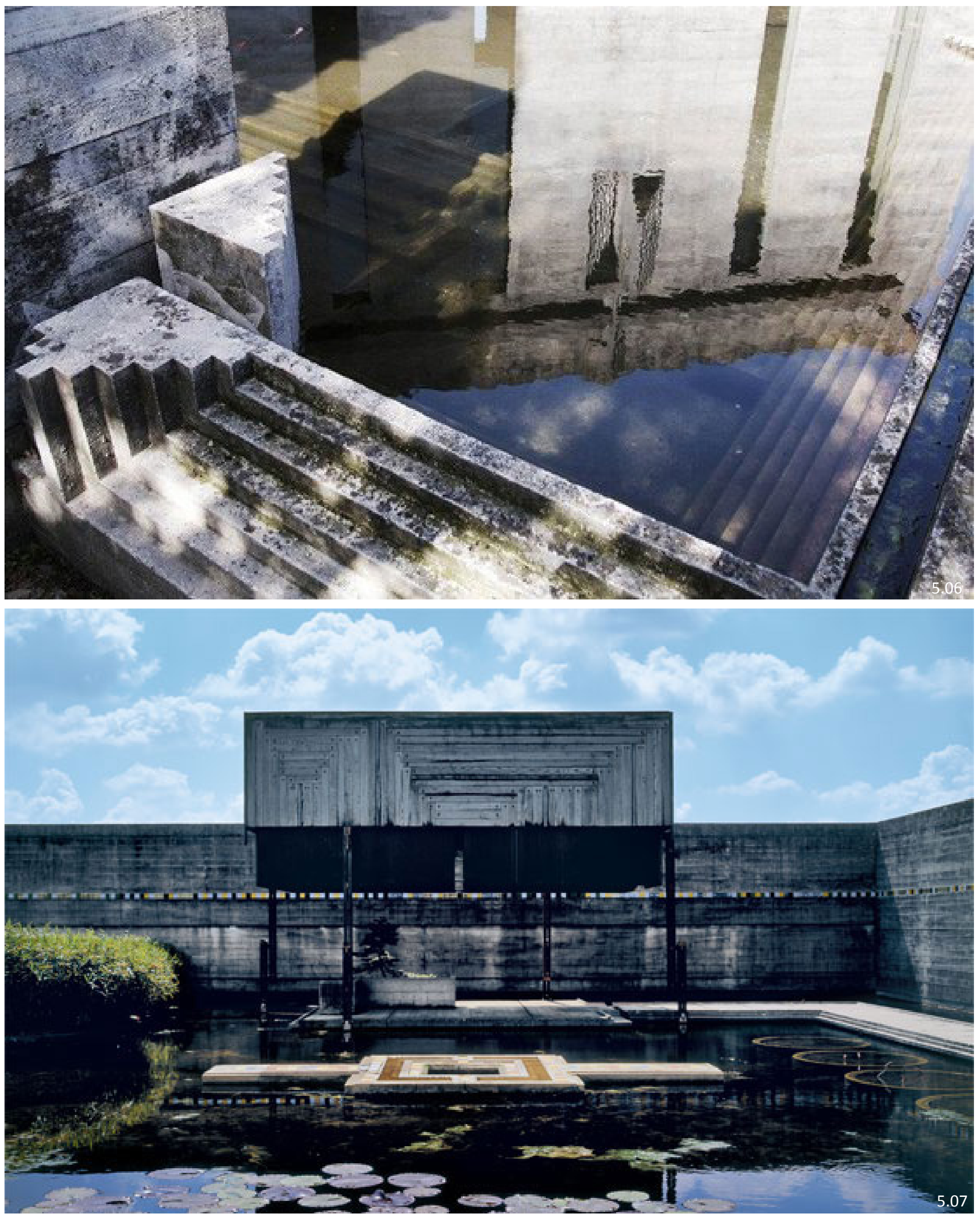


\section{Brion-Vega Cemetery}

Architect: Carlo Scarpa

Location: San Vito di Altivole, Italy

Year: 1970 - 1981

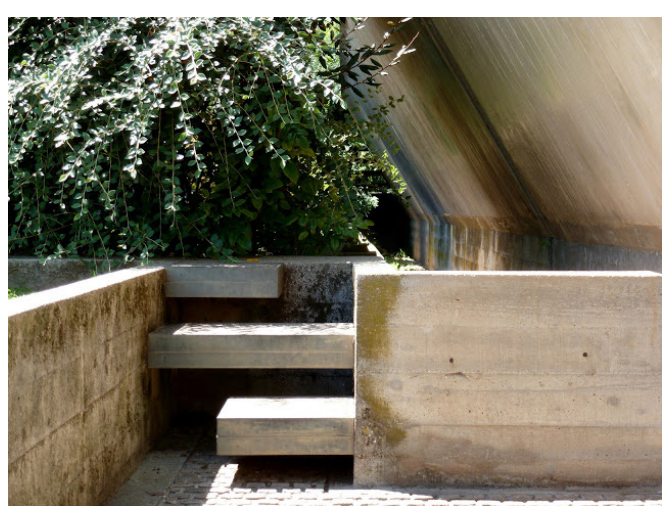

Fig 5.08. Brion-Vega Cemetery
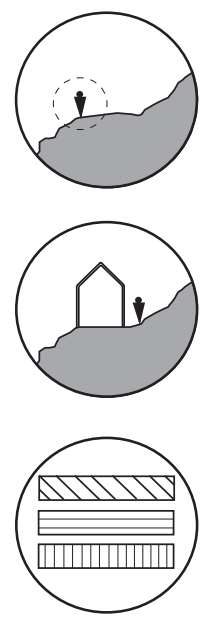

The Brion-Vega Cemetery is one of the best examples of the reinterpretation of weathering as a positive effect on a building. Details and material treatment have been designed to articulate the process of a buildings life over time. "A simple cornice and a black wall: is the mark a stain? Should it be cleaned? It seems possible to argue that Scarpa designed the black (white) wall as the possibility for showing the life of the building in time, which was a creative reinterpretation of the fact of weathering" (Mostafavi and Leatherbarrow 103). Time constructs a basis of engagement with the building. The imperfections that are created over time allow us to experience the architecture through an active relationship between nature and architecture.

With the design being primarily constructed from concrete the building can be seen as a study of how one material weathers and ages through a number of scenarios. There is a variety of surface textures, from dark mottled staining on the exterior where it has a greater exposure to the rain, to lighter, flatter textures in the interior surfaces. The staining creates a depth to the surface where "Everyday building deterioration has been used deliberately as a device for marking and infecting the purity of the new building surface" (Mostafavi and Leatherbarrow 103). This creates an affective awareness of the relationship between architecture and place. 


\section{The Therme Vals}

Architect: Peter Zumthor Location: Graubunden, Switzerland Year: 1996
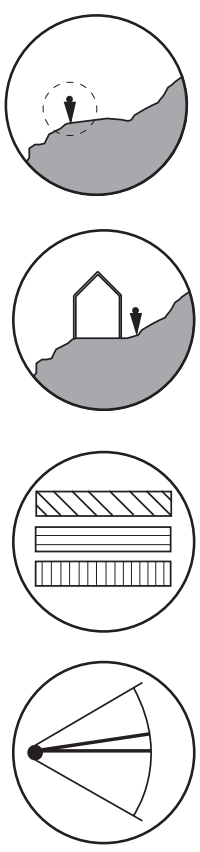

The materials have also been carefully considered to reinforce this idea. Built primarily of stone from the mountains each material has been carefully choreographed according to their evocative qualities. Texture, temperature, light, smell and sound have all been used to trigger sensory experiences. These sensory experiences and atmosphere are considered as another material.

A sense of mystery and discovery is seen throughout the building highlighted mainly through perspective and light. The view is controlled allowing for glimpses of both internal and external space. Light is also a key material quality that is used. The reflection of light is used to create a serene space that is mysterious and calming. 


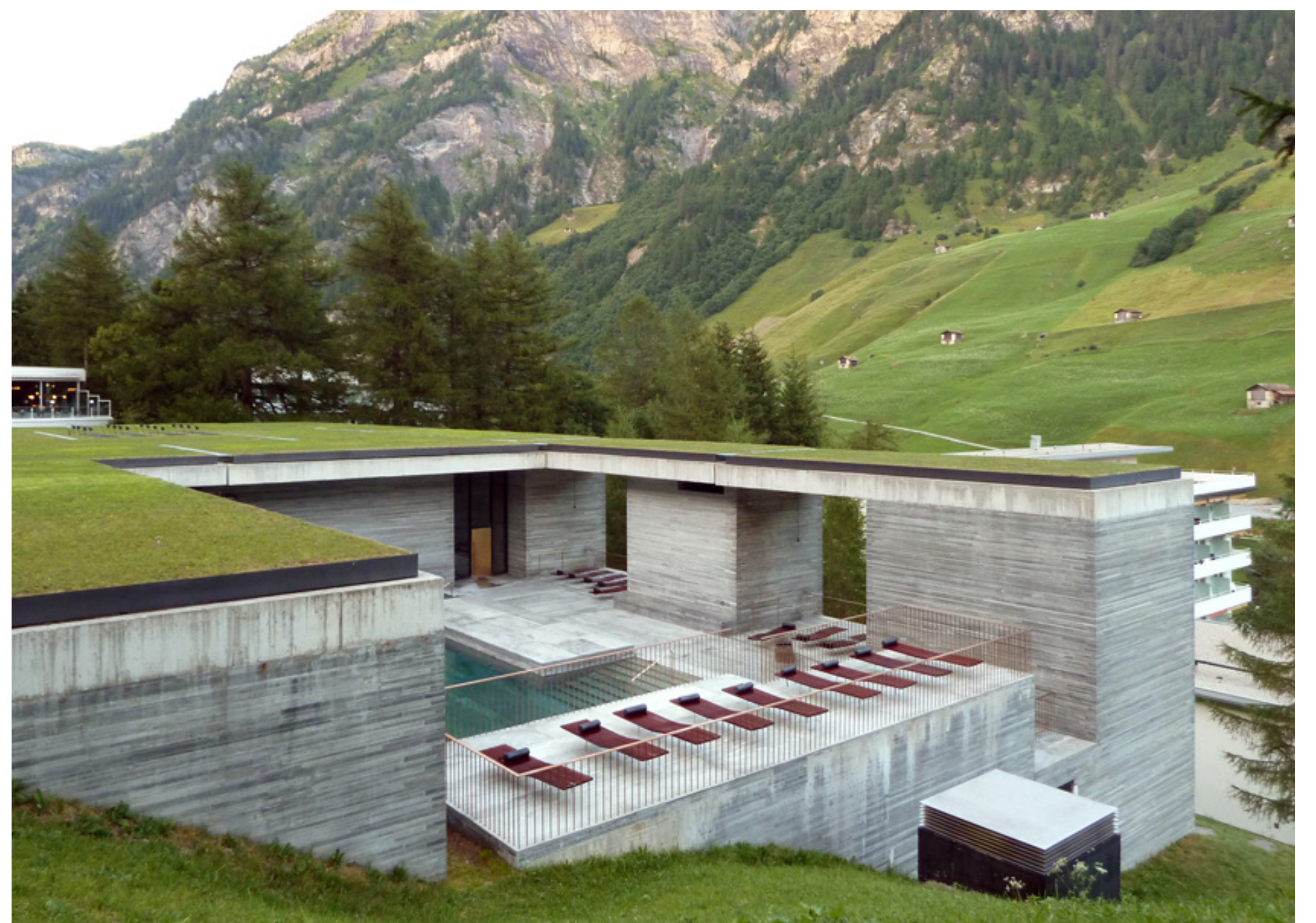

5.09
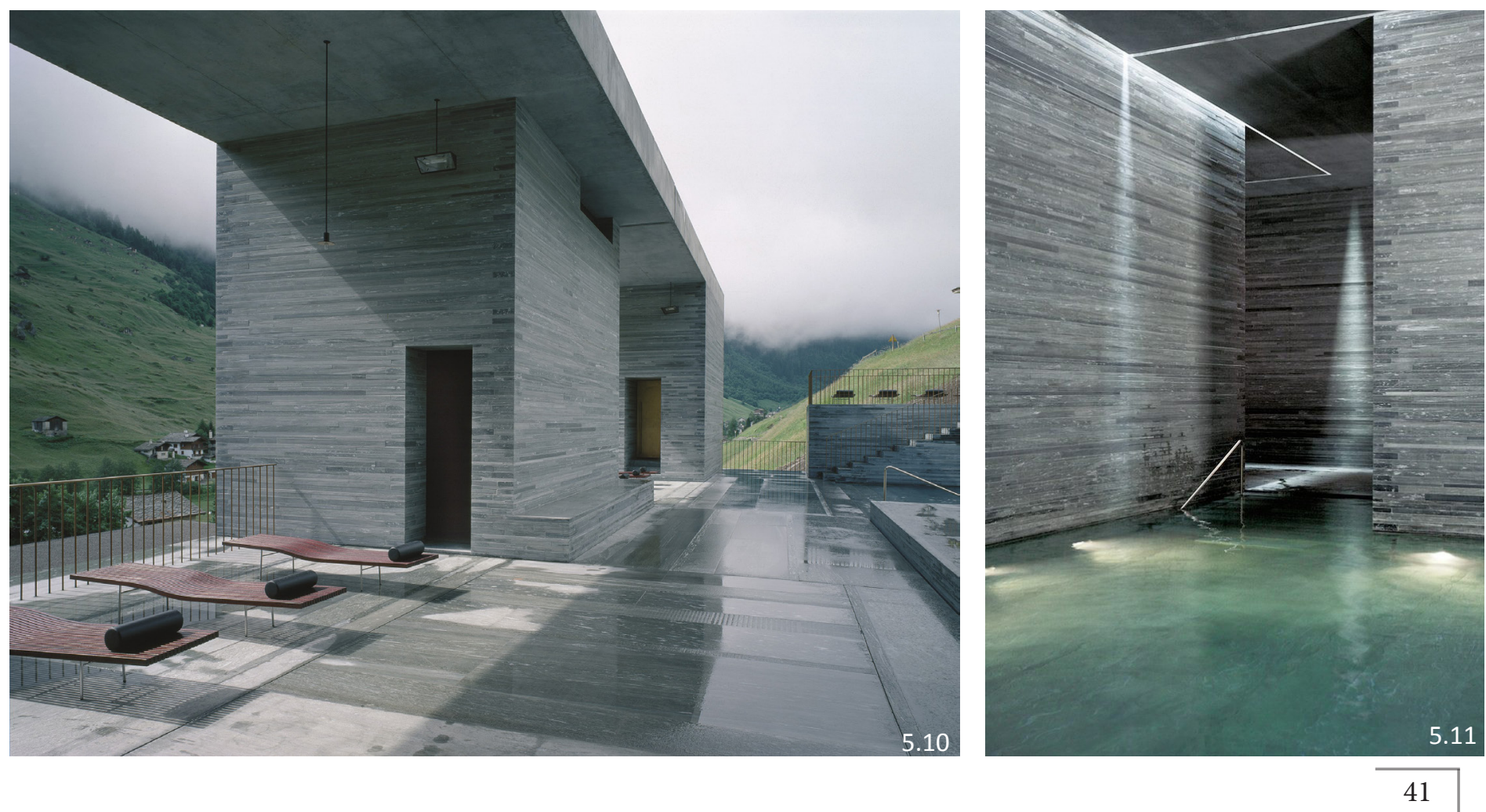


\section{Te Kopahou Reserve Gateway}

Architect: Charles Gordon and Wellington City Council Location: Wellington

Year: 2008
The entrance to the To Kopahou Reserve on Wellingtons' south coast features a visitor's shelter and is a sympathetic use of an old industrial site. Previously this site was home to a quarry workshop with little surrounding natural vegetation.

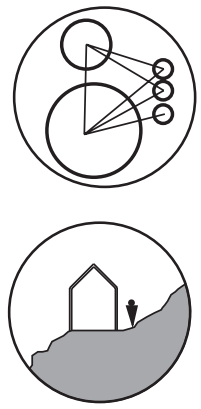

There are two typologies within the site, one if of the historical quarry and the other is of the coastal context. The heritage of the site was used as a key design driver in establishing a sensitive response to the site's past. The footprint of the original building was used to create an information shelter for visitors to the area. The original trusses and concrete columns have also been reused to reinforce the sense of heritage and place.

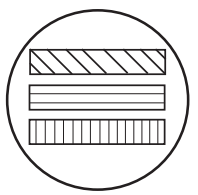

Throughout the development of the site, materials such as wharf timbers, large rocks and corten steel have been featured. Not only have they been used due to their durability in this harsh coastal environment they also develop a visual language between architecture and context enhancing the local character. The subtly and honesty of the materials and regeneration of the natural condition enriches the occupants experience while celebrating its history. 

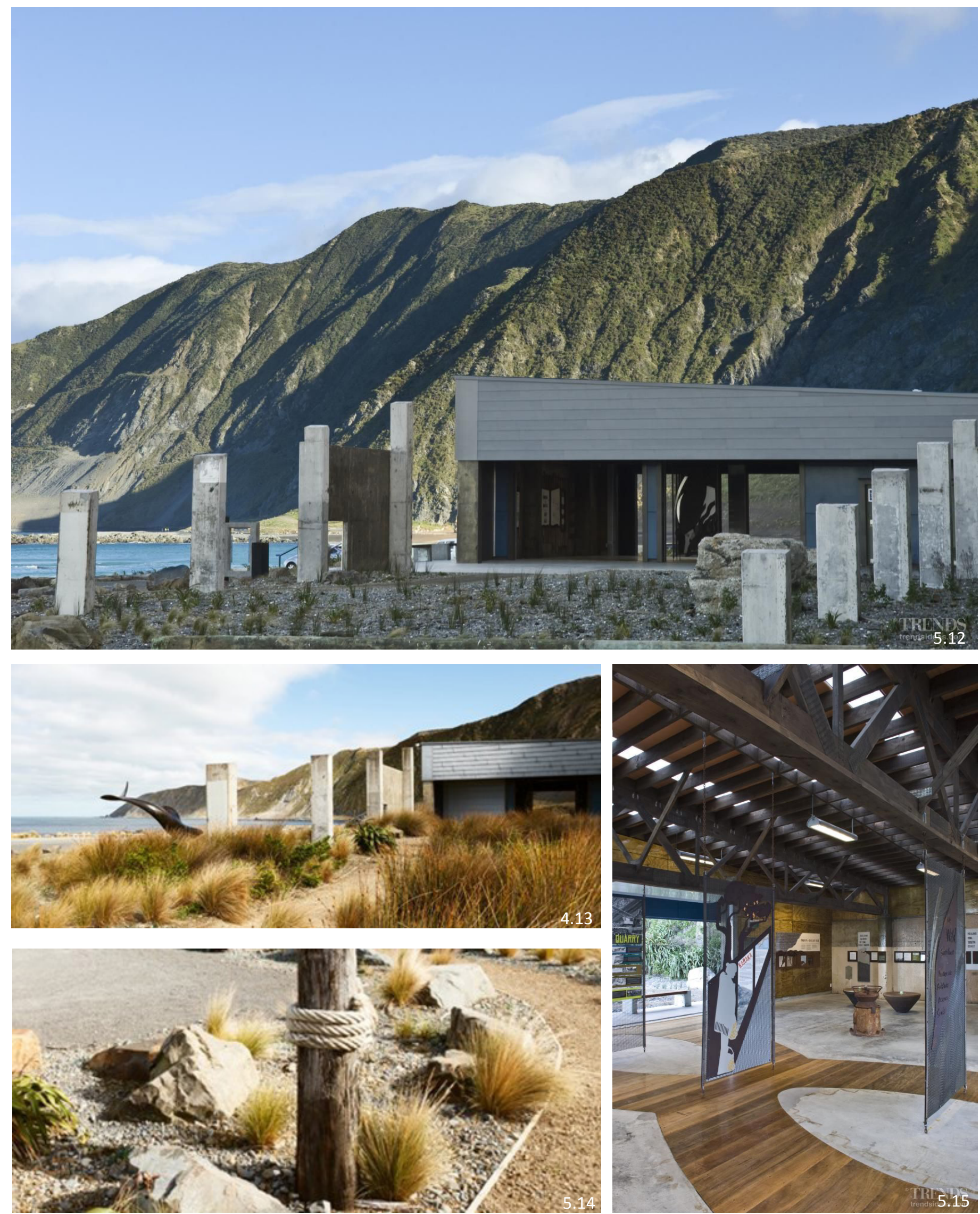


\section{Cairn}

Sculptor: Andy Goldsworthy Location: Canada

Year: 1999

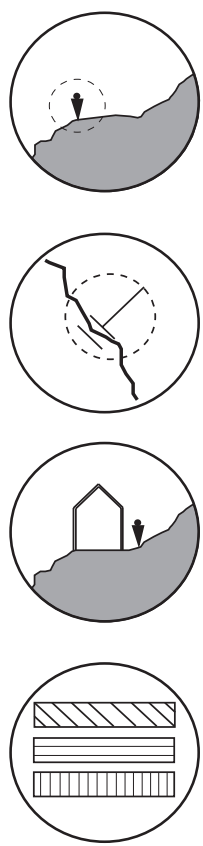

Andy Goldsworthy is a well-known Canadian sculptor, photographer and environmentalist. His work focuses on land art in both natural and urban contexts. His work highlights three key elements - time, change and place. He finds delight in the transience of nature, both creating works with a short life span but also constructing within the limits of nature's time for example between tides. The installations are then photographed before nature takes over and they start to decay. He makes this decay an integral aspect of his work so that it becomes stronger and more complete as it falls apart and disappears" (Goldsworthy 7). Due to this shortened time frame, compared to that of a building, the experience of time and decay is intensified. The viewer is confronted with nature's control and the honesty of time. One of his installations, the Cairn, was constructed between tides after several attempts, from local stones, on a sandy beach. A powerful sense of time is embedded within the work were the evolution and beauty of the installation comes from the force of nature on the work.

Within his work he most commonly only uses one material. The material comes from the place in which he is working. Both place and material are intertwined, appearing to grow from the site. 'The form emerges slowly as each stone is added in a process generated by and rooted in its internal structure. Each stone is tied into the work' (Goldsworthy 23). The material highlights the relationship between place and installation, the work come from, is part of, and will return to the same place. 

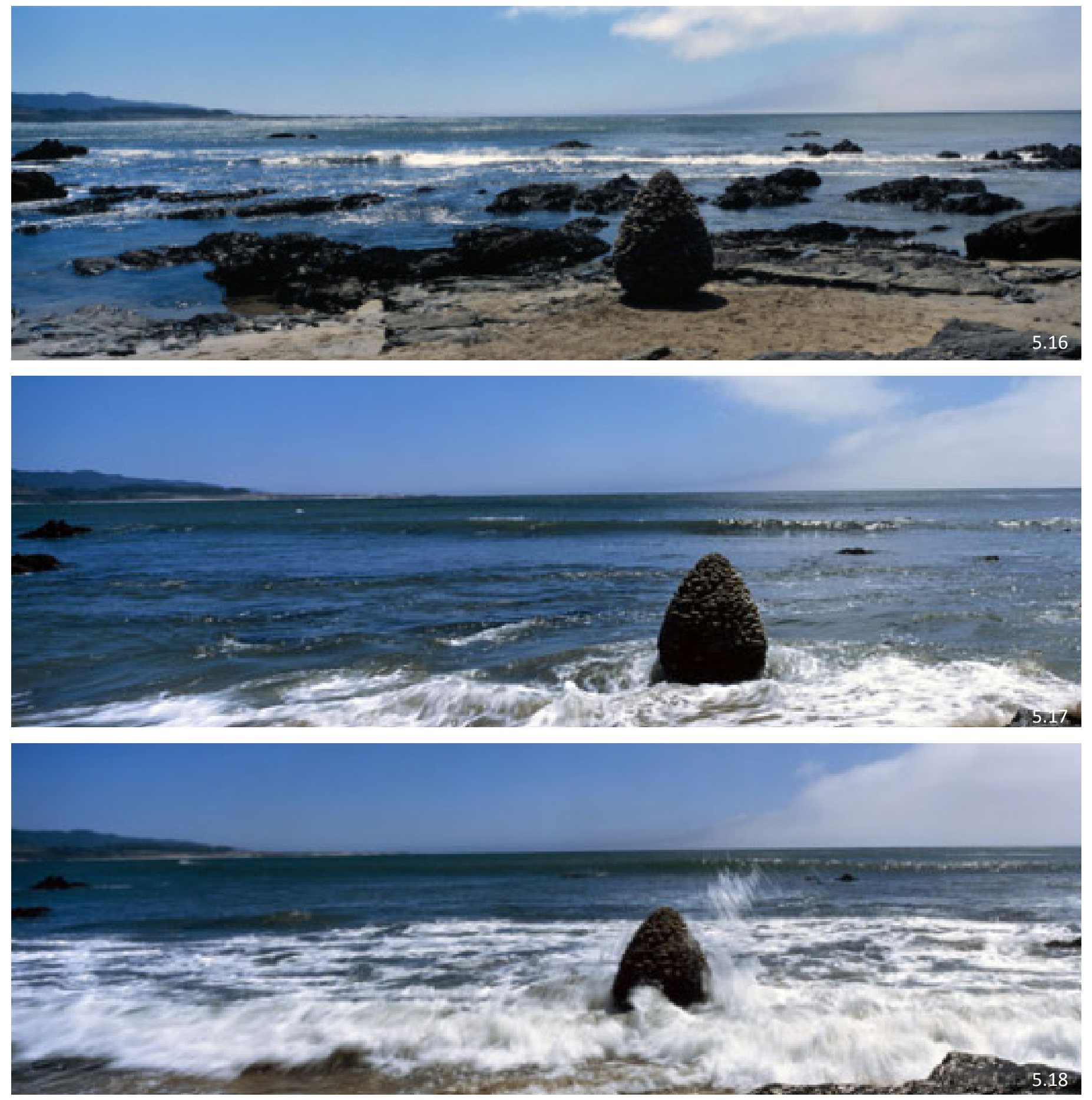
The case studies all explored elements of the design framework/ filters that have been set out. Each case study highlights how existing and built works have approached similar design criteria's. The investigation of these case studies highlighted the absence of built form on the coast that dealt with a similar program of costal shelter. There is also an opportunity that is provided by these case studies in revealing new ways and methods at exploring the ideas set out in the design framework. 


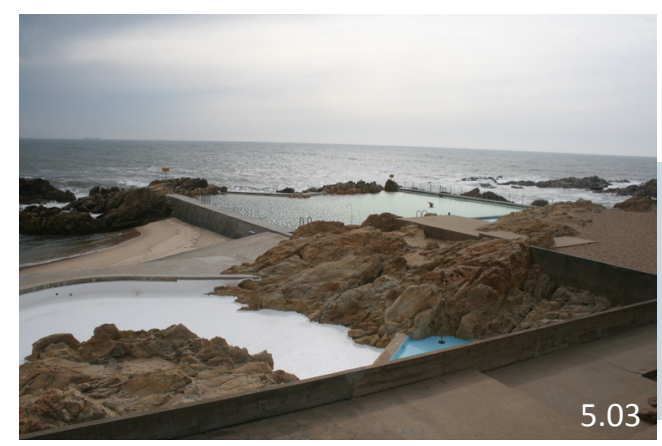

Leca Swimming Pools

Alcaro Siza
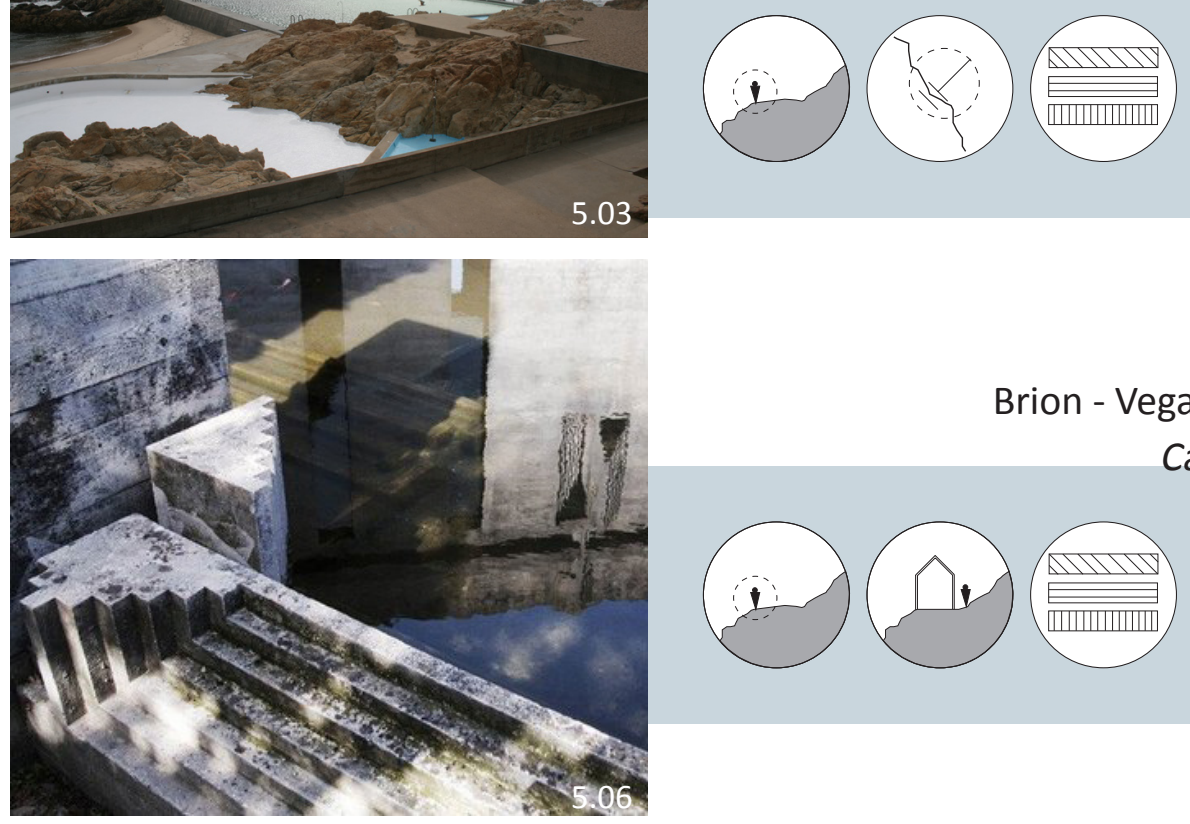

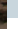
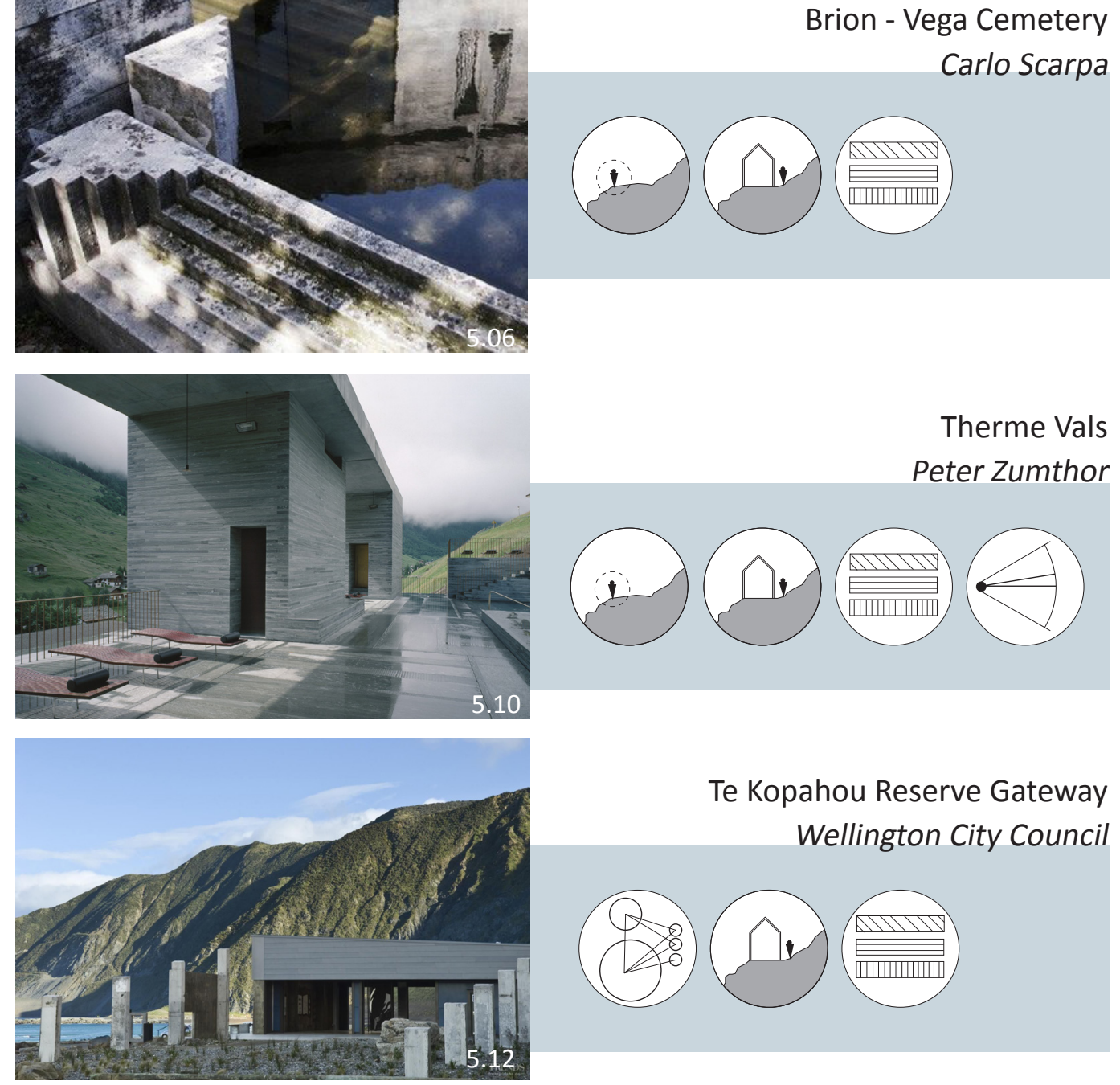

Te Kopahou Reserve Gateway Wellington City Council

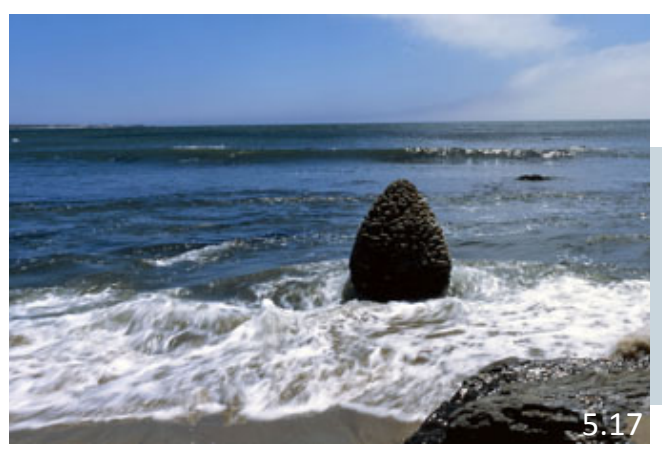

Cairn

Andy Goldsworthy
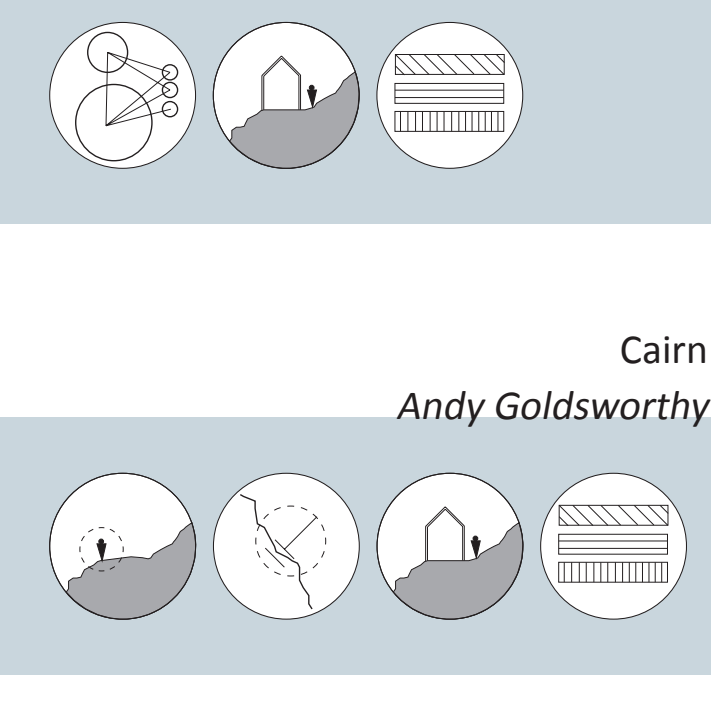

Fig 5.19. Corresponding case studies to design framework and filters 


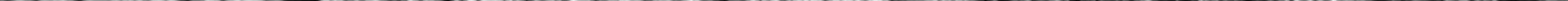




\section{Chapter 6}

\section{Pre - Design + Design Exploration}

Each site was selected to highlight the range of weather, topographical and experiential conditions found along this coastline. The range of sites recognise distinctly different landscapes. Each design proposals can be uniquely informed by each place.

Firstly, the overall south coast is explored through a series of three drawings and a physical model of the topography. For clarity, the pre-design phase of each shelter are combined with the design exploration phase. Secondly, each site is investigated in sequence, from Owhiro Bay to Lyall Bay. The aim of these interventions is to capture the characteristics of the coast and then re-interoperate and create an extension of the coastal character. To encapsulate the qualities of the sites, individual briefs were developed to respond to specific characteristics and narratives. This section develops a conceptual design for each of the six sites. Through a range of $2 \mathrm{D}$ and $3 \mathrm{D}$ techniques the designs will be developed in response to the initial design filters set out in the previous chapter. The aim for the design exploration is to develop a responsive design to the specific contextual narratives and conditions of each of the different sites. However in doing this there also needs to be a coherency that connects the interventions so that they can be read as a part of greater whole. 


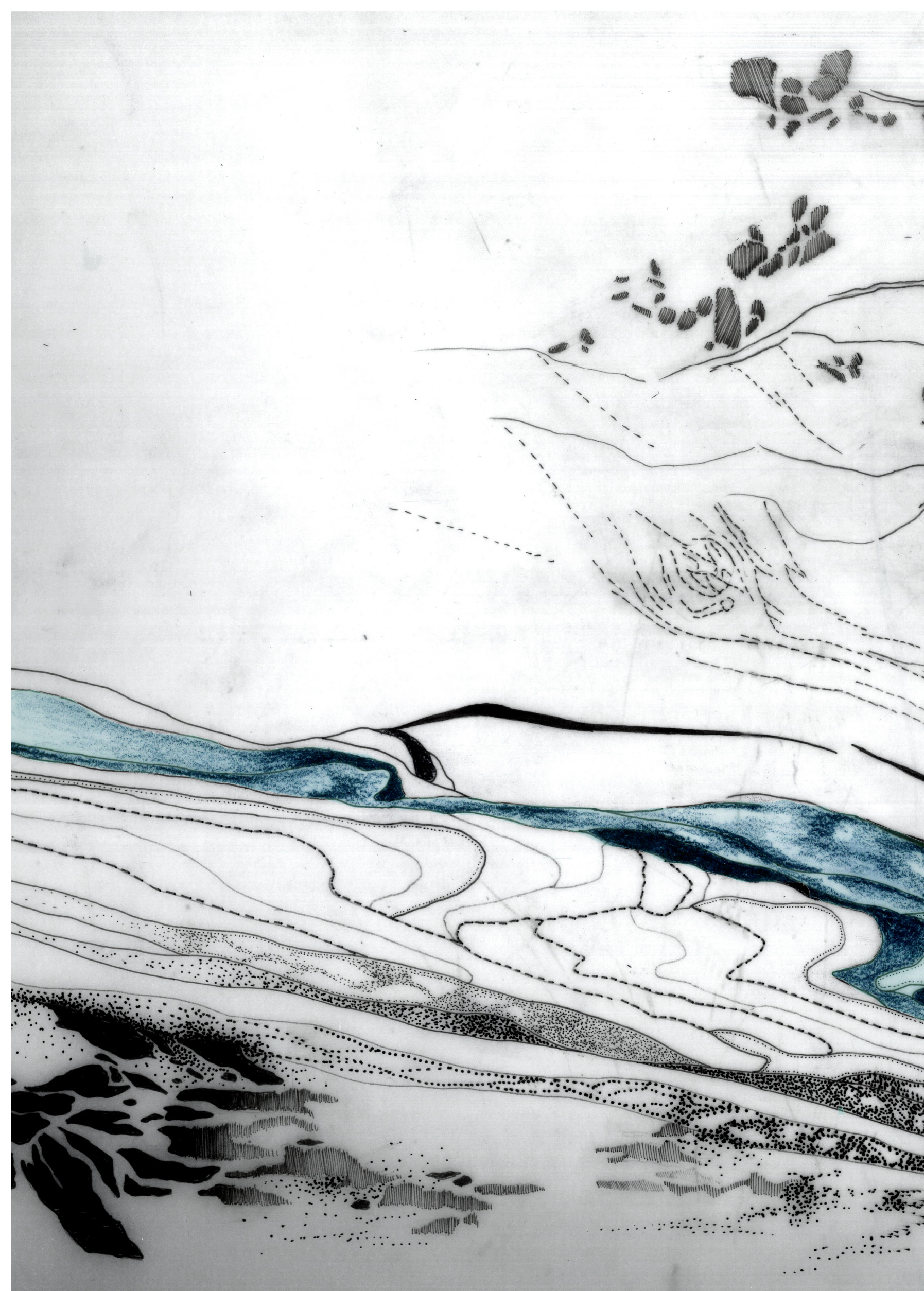




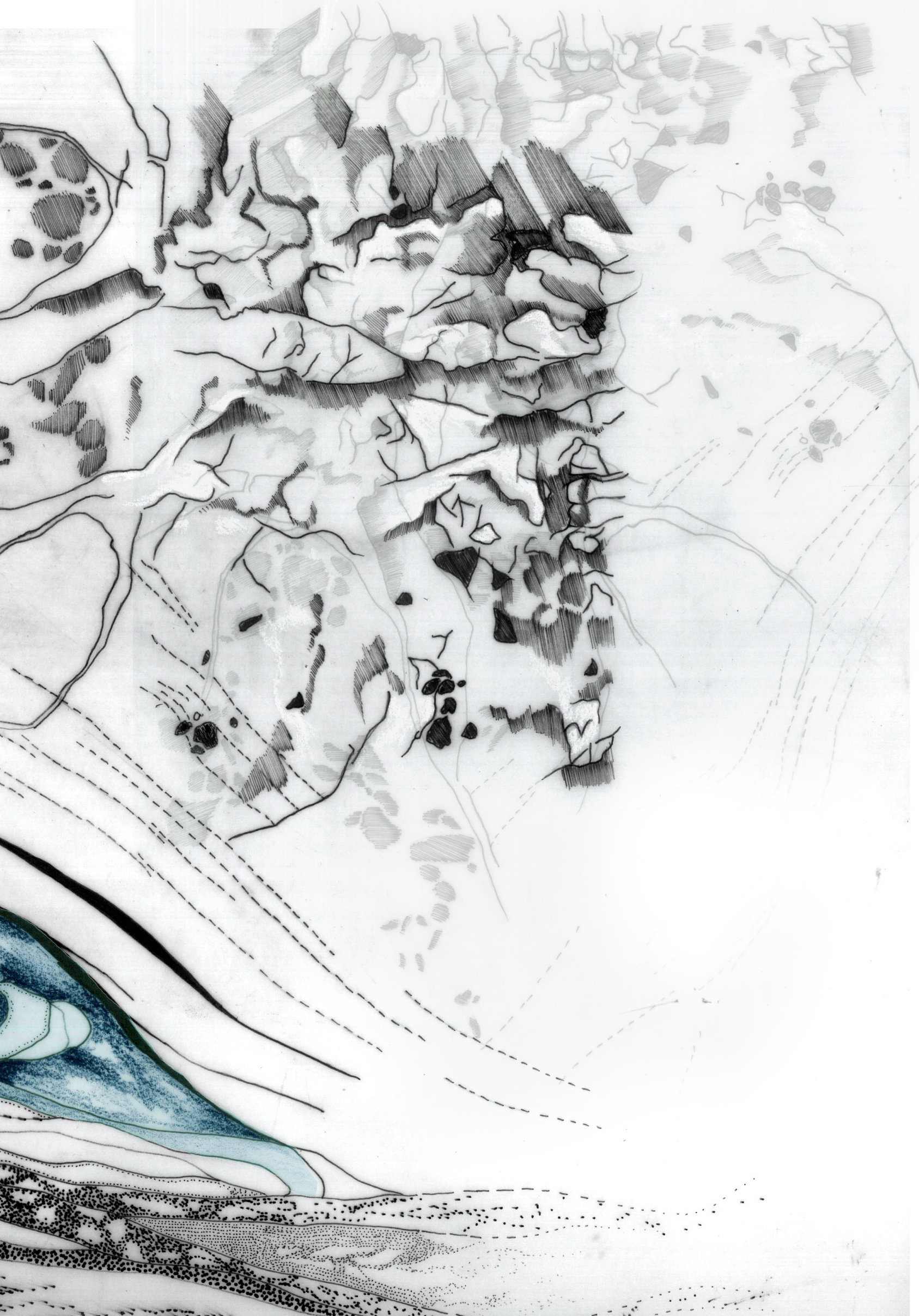

.......

non.s...

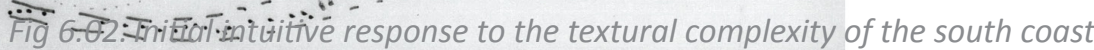




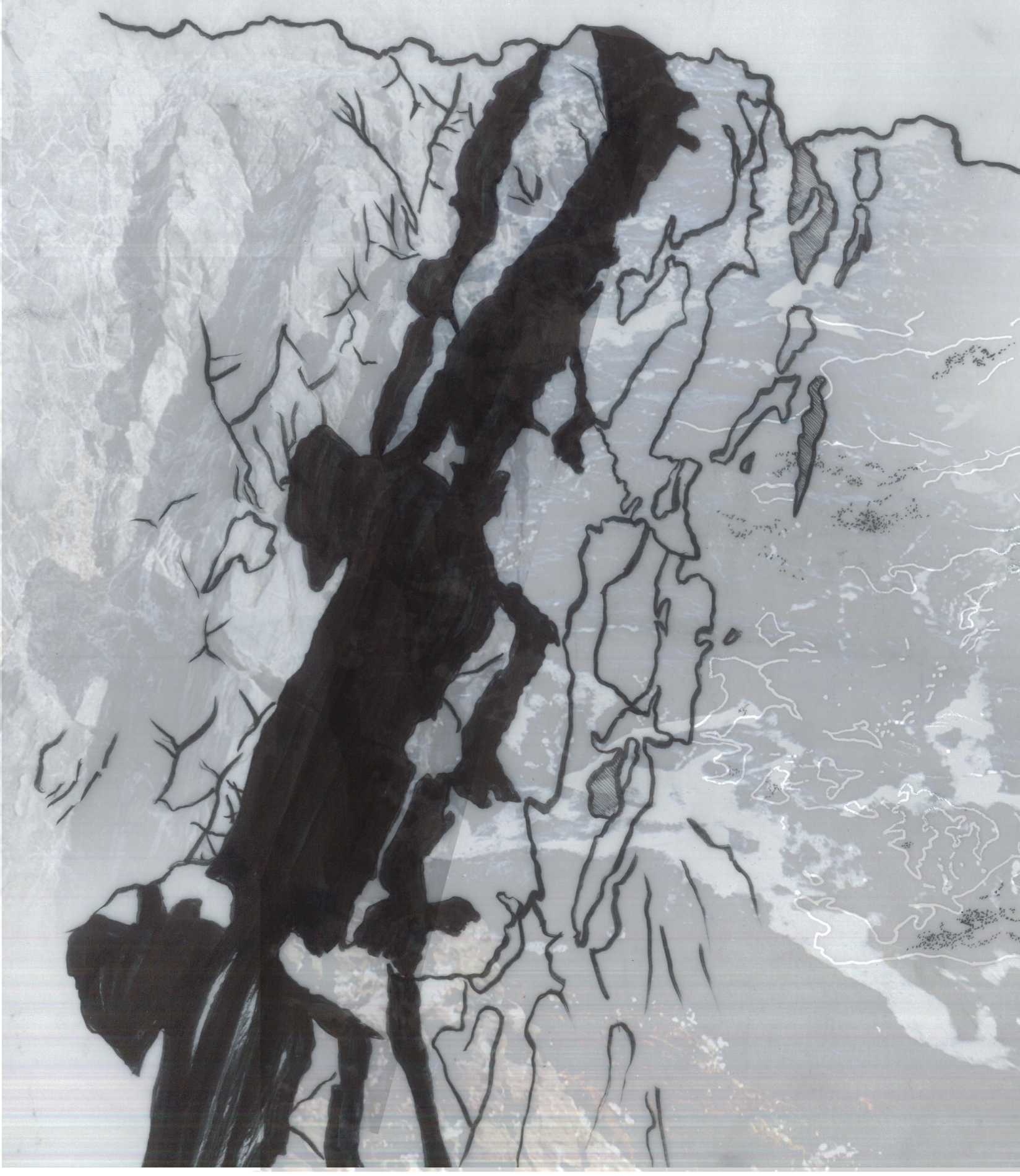


$4+2 y^{2}$
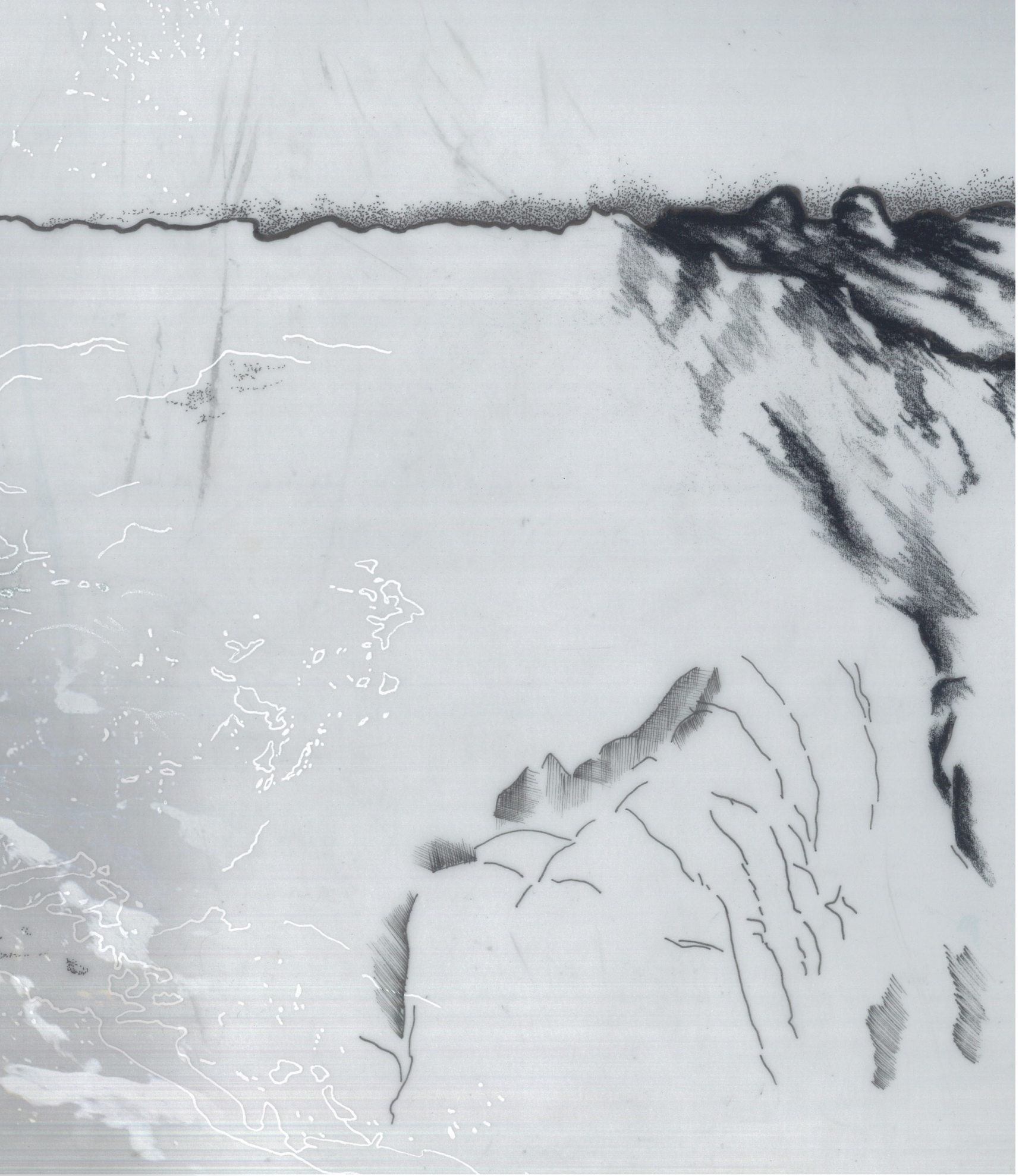


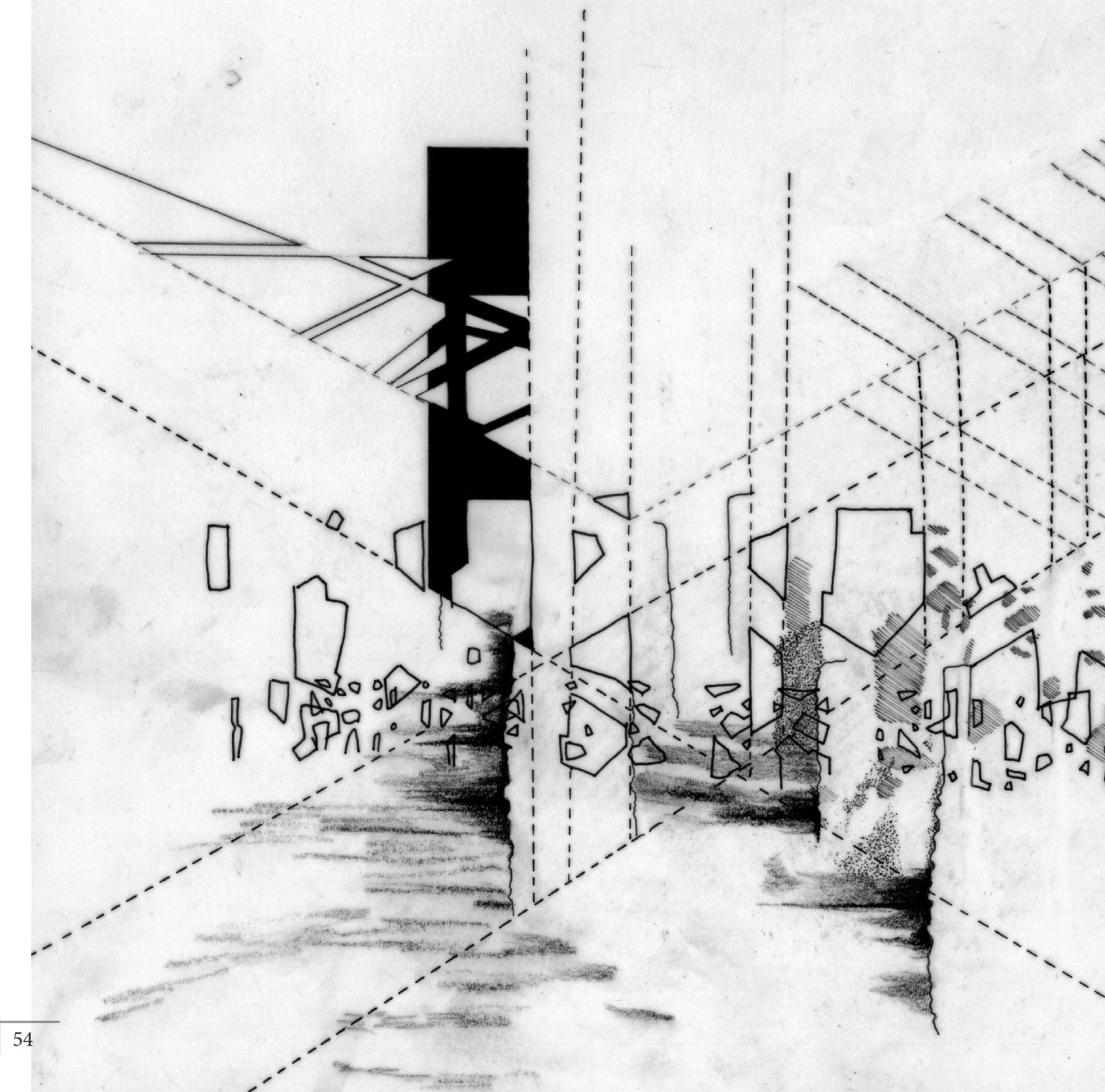




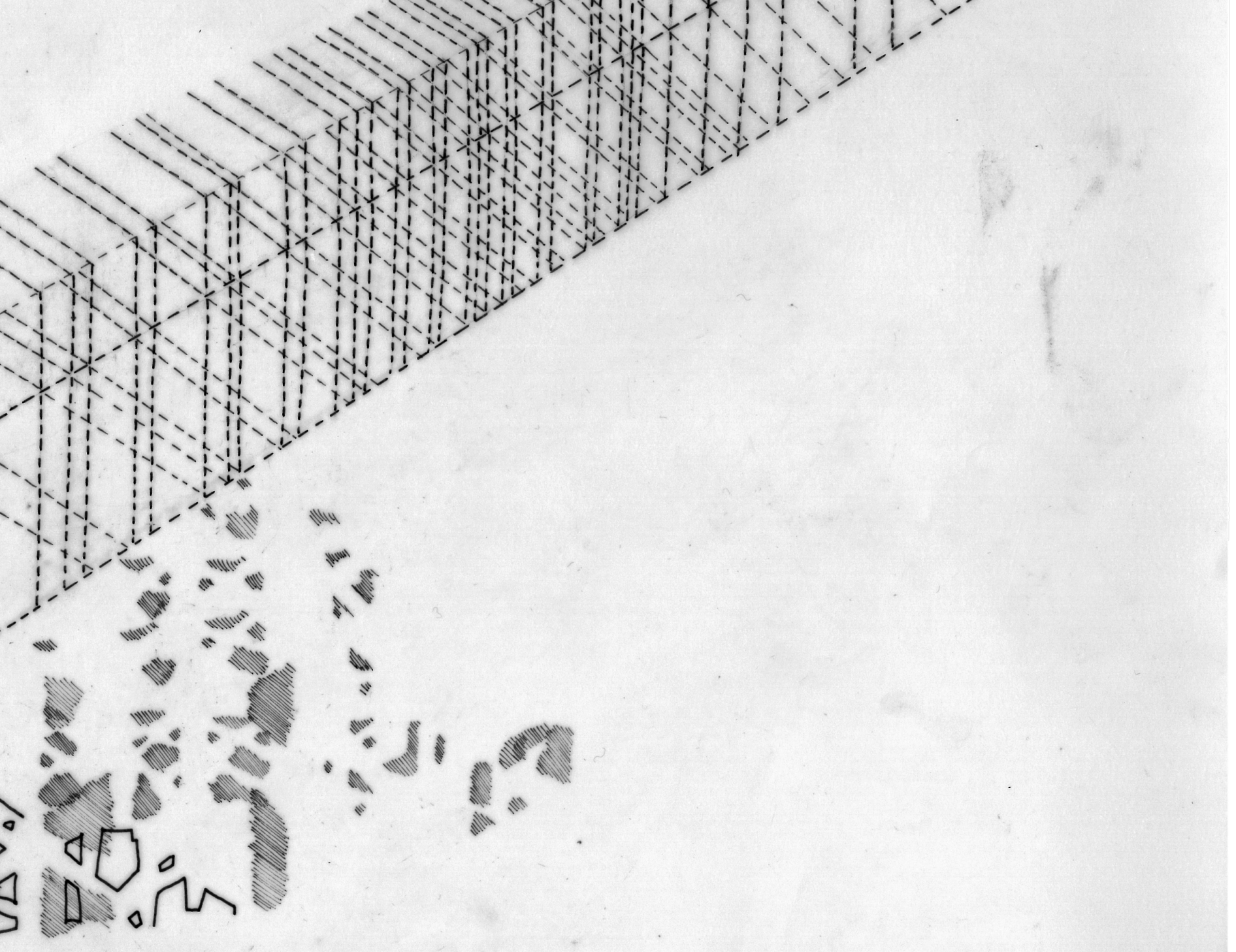




\section{Site Model}

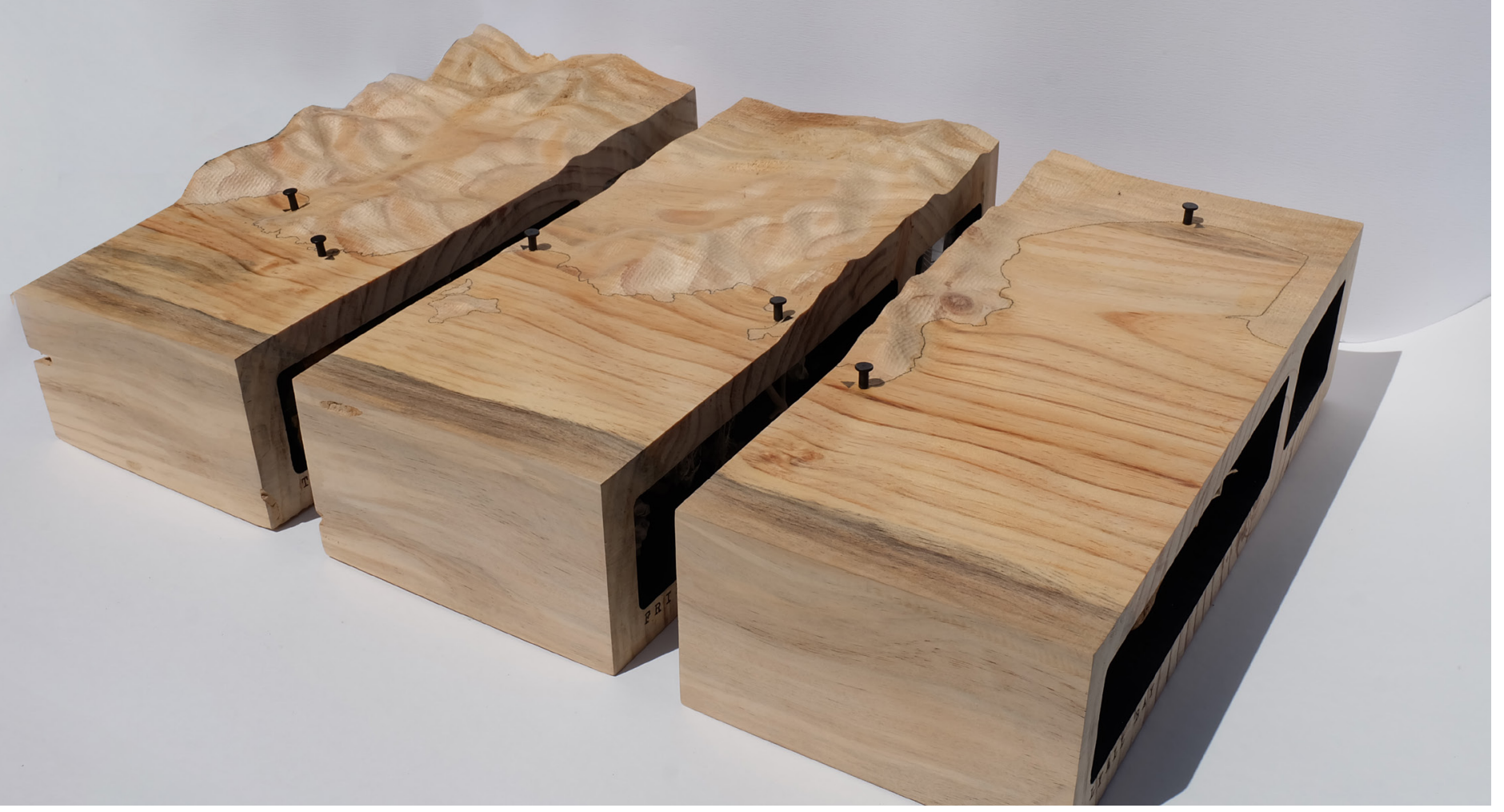

Fig 6.05. Series of images of overall site model

This physical site model developed an understanding of colour, texture and form of the landscape. Each section celebrates collected artefacts from the site visits. This revealed correlations between sites and the individual distinctiveness of a particular site.

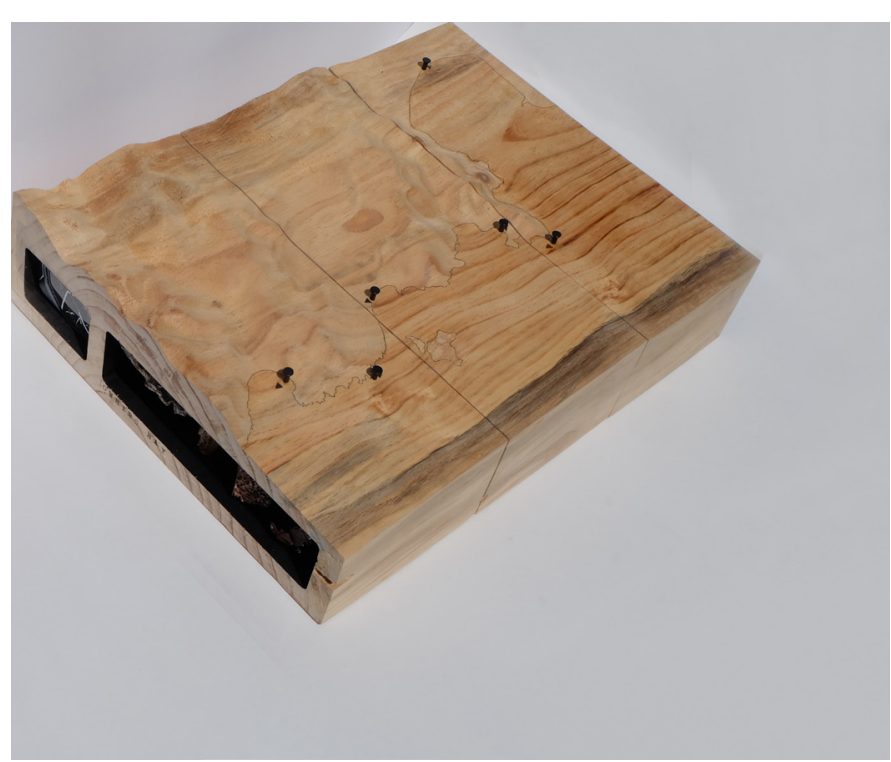



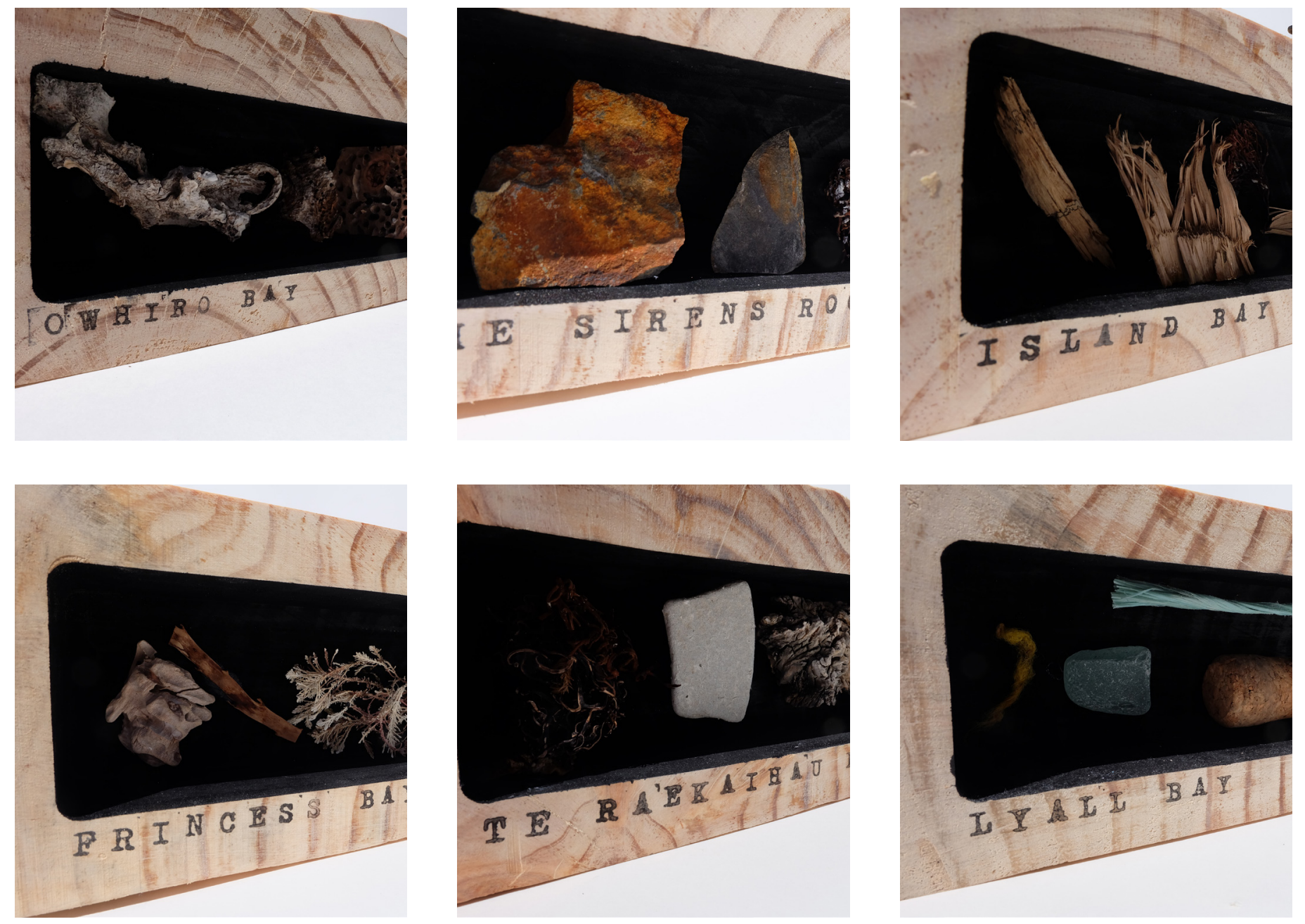

Fig 6.06. Series of images of collected materials and artefacts from each site 


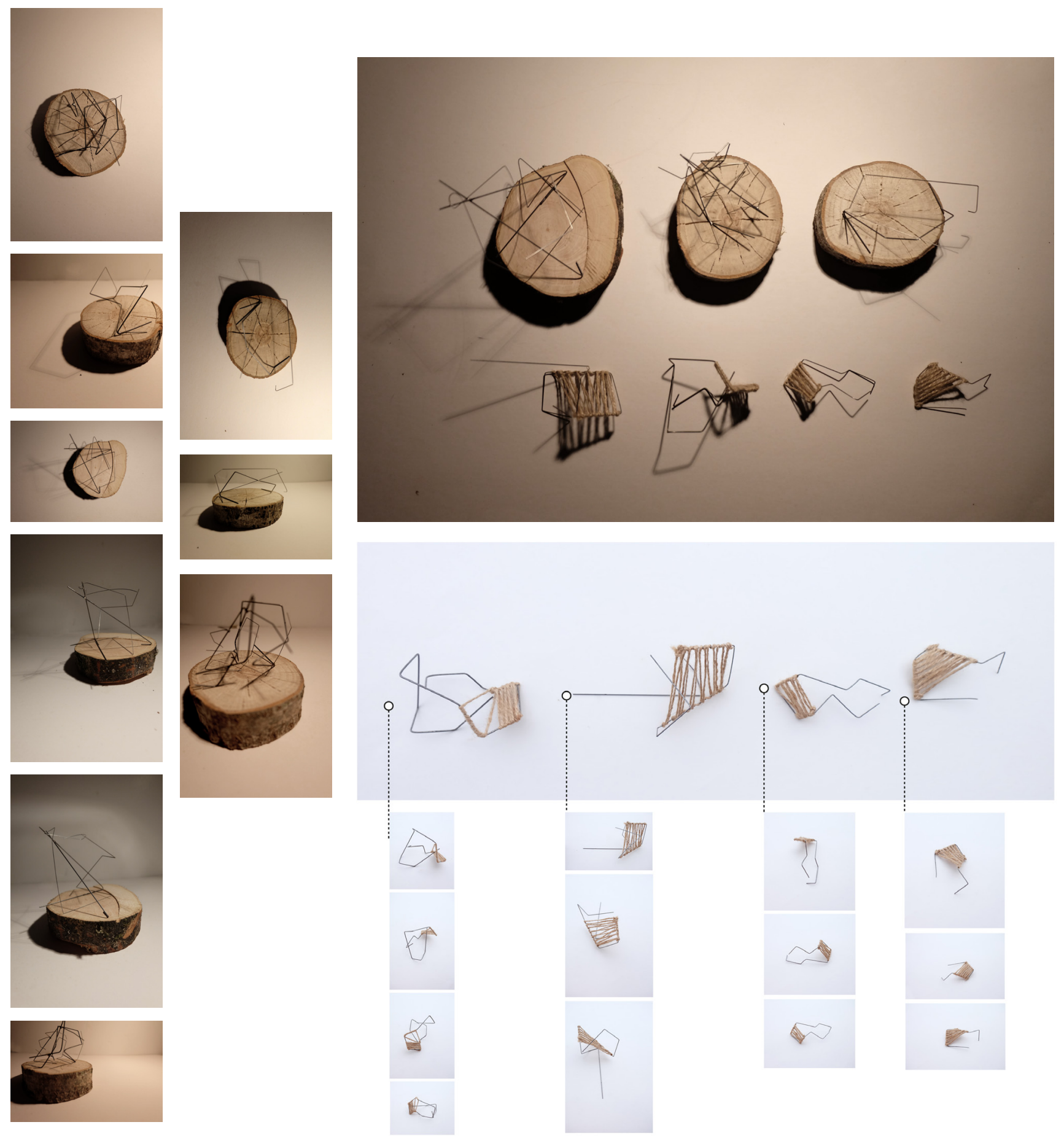

Fig 6.07. A collection images of initial exploration into form, protection and density 

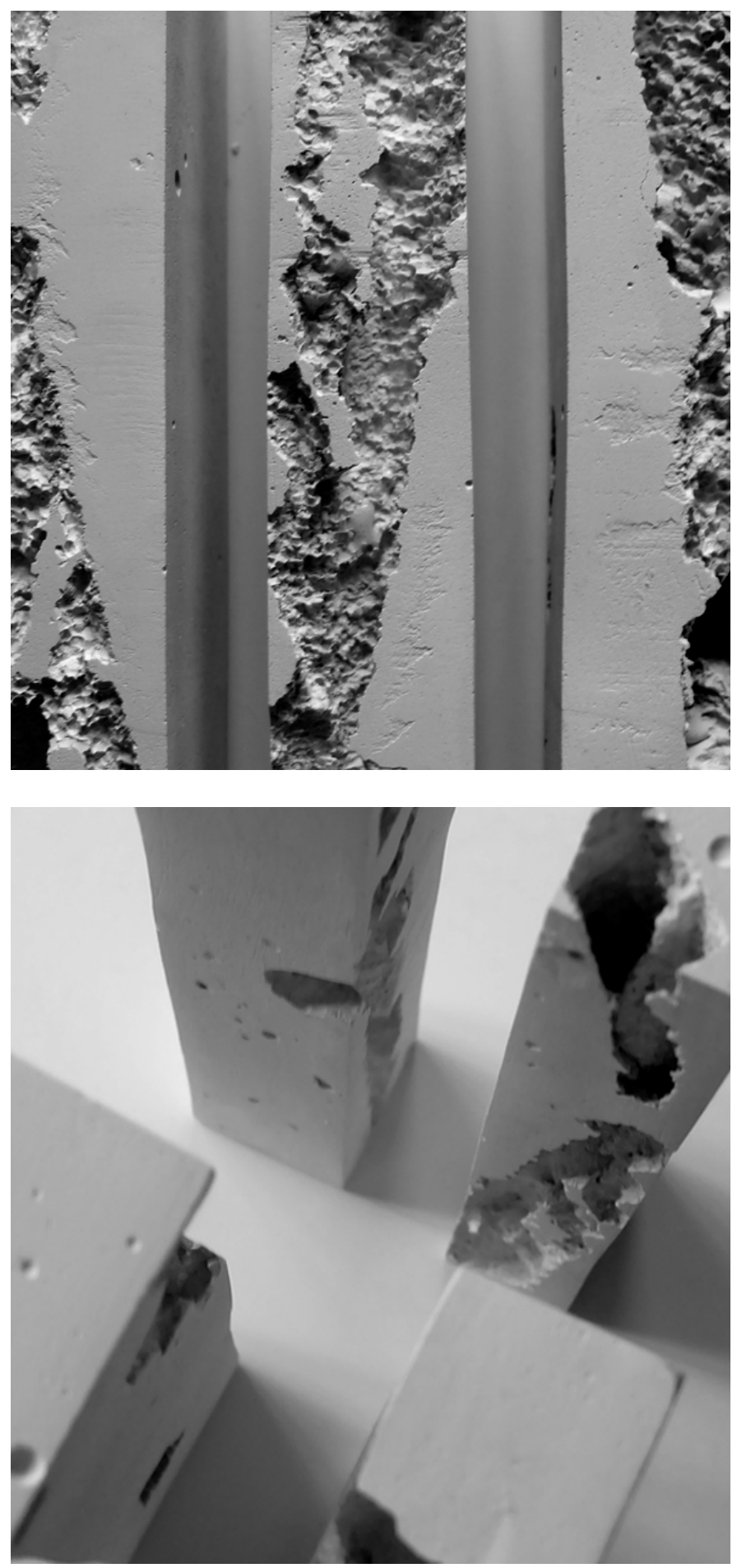

Fig 6.08. Material test exploring corrosion and revealing of interior space 


\section{Graphing Experiential and Physical site elements}

This series of diagrams look at highlighting the contrasting contextual response of each site. Each diagrams ranks the sites in response to the tangible and un-tangible aspects of the sites. Therefore highlights the key drivers and relationships for each site. This understanding reinforces and develops upon the conceptual design filters for each of the shelters. Thus initiating the connections between a response to their site and to each other, as individual pieces of architecture that are to be read as part of a greater whole. 


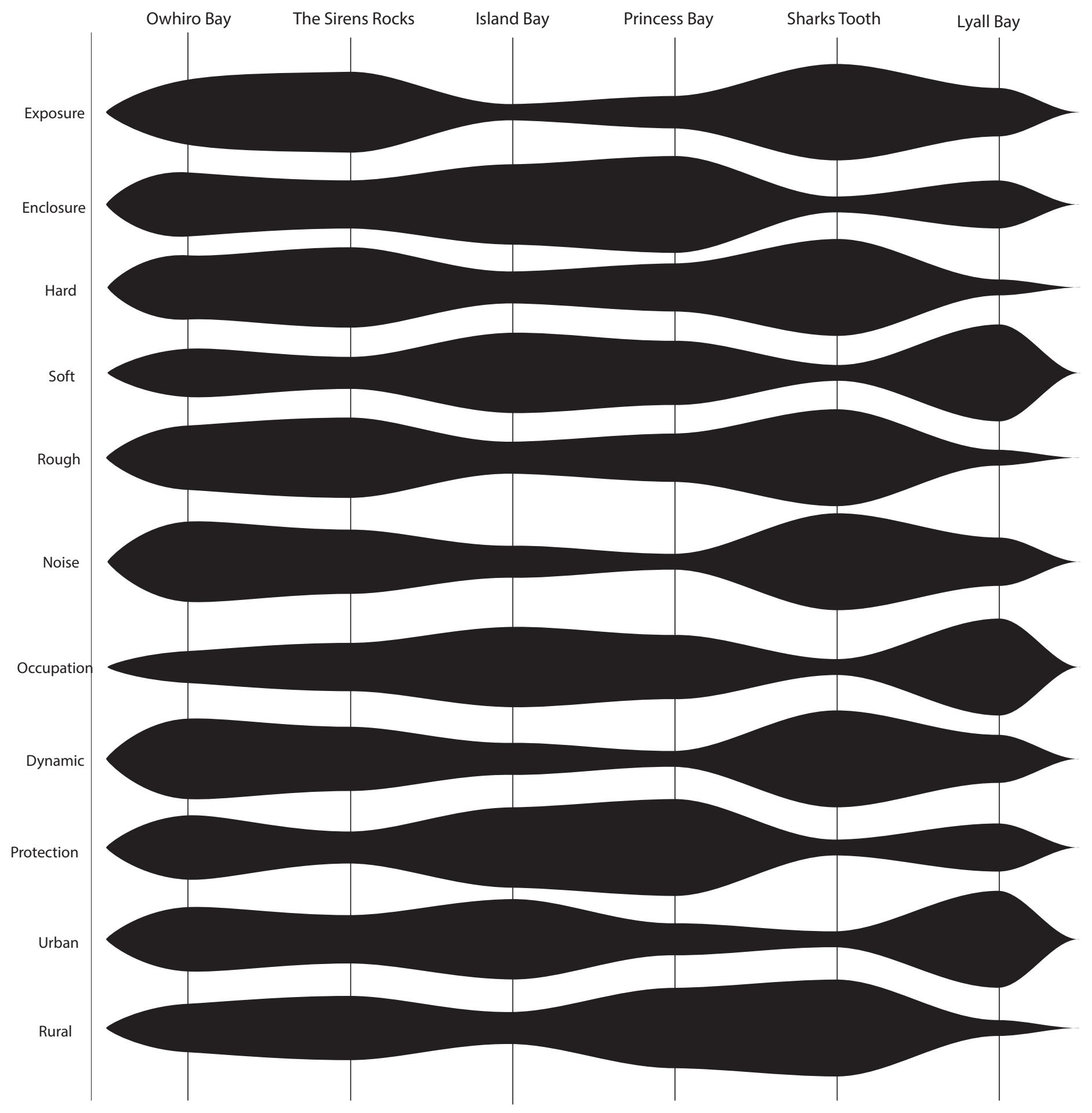

Fig 6.09. Diagram of physical and experiential responses to the sites 


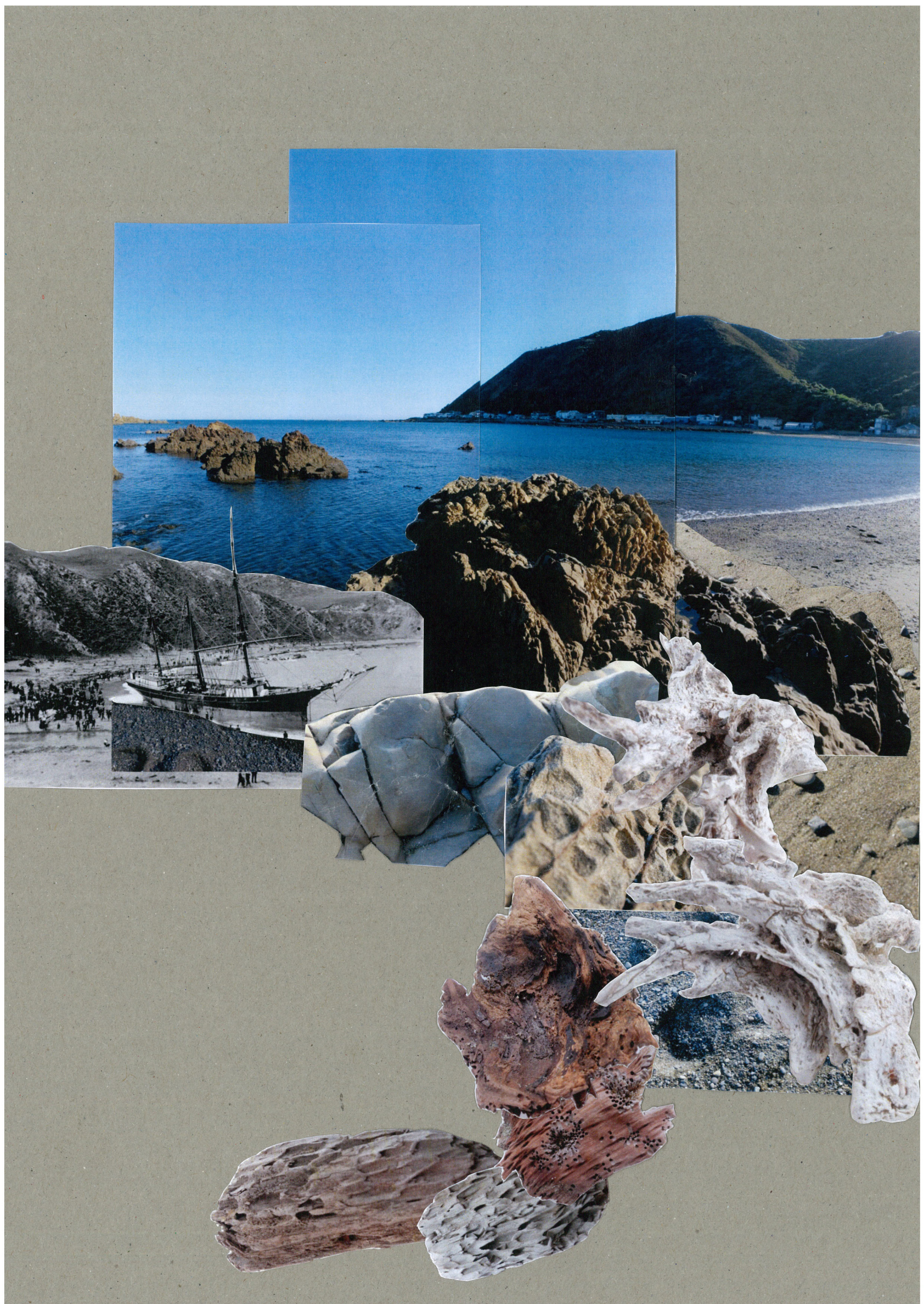

Fig 6.10. Collage of images, textures and fragments specific to Owhiro Bay 
Owhiro Bay is the first selected site. This somewhat sheltered bay is the last populated bay in the direction of Red Rocks. The beach is popular mainly with walkers. The site has had a strong historical narrative with seven shipwrecks taking place between 1874 - 1982. There were five incidents where ships have either been stranded or sunk at Owhiro Bay. Firstly, the Cyrus on March 7th, 1874. This was a three-masted barque ship from Canada. (Reserve) After running into navigation troubles in rough weather and becoming too close to shore, the ship struck rocks on the western side of the bay. Two of the ten crew members and the three passengers were lost. On that same day the Wellington, a full rigged ship, also ran into trouble in the severe weather and struck the rocks about $40 \mathrm{~m}$ from the Cyrus where two crew were lost. Both ships were broken up in the storm.

On October 13th, 1904 the La Bella went ashore in the bay after being overwhelmed by strong winds and almost all the sails being blown away the ship ran ashore stern first. The ship was later re-floated and towed to Wellington Harbour. (Reserve)

The Progress was the next ship to be lost at Owhiro Bay. On May 1st, 1931 the cargo steamer lost it propeller, due to the strong southerly winds and seas the anchors were not able to hold the ship in place and despite attempts to raise the sails and sail off shore the Ship struck the rocks. It broke in two almost instantly resulting in four crewmembers drowning. (Reserve)

The Final ship to sink in Owhiro bay was the steel hulled Yung Pen from Taiwan. After drifting onto the rocks by what is said to be poor navigation, the crew were rescued and the ship sunk close to the existing three wreaks that were already there. It later broke into two pieces with the hull section sinking with about $1 \mathrm{~m}$ of water covering it at low

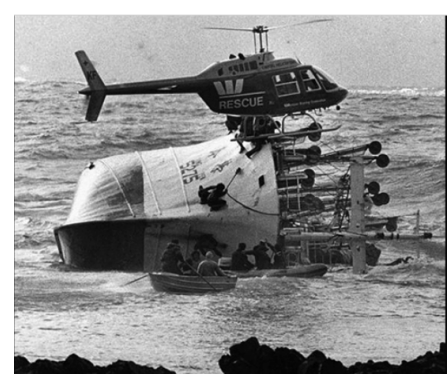

Fig 6.13. Yen Pen ship sinking tide, while the front section was pushed to within $15 \mathrm{~m}$ of the shore. This section was salvaged. (Reserve) This historical narrative is the key defining factor from the other sites.

The intervention at Owhiro Bay focuses on the narrative of the historical shipwrecks. The shelter takes the occupant through the narrative of the process of breaking down. Investigating the temporality vs permanent disintegrating and weathering process of the ship structures.

Brief

- Information panels about the shipwrecks

- $\quad$ Strong language of material weathering and disintegration

- $\quad$ Occupation of the tidal threshold

- $\quad$ Enhancement of sea/tidal movement 


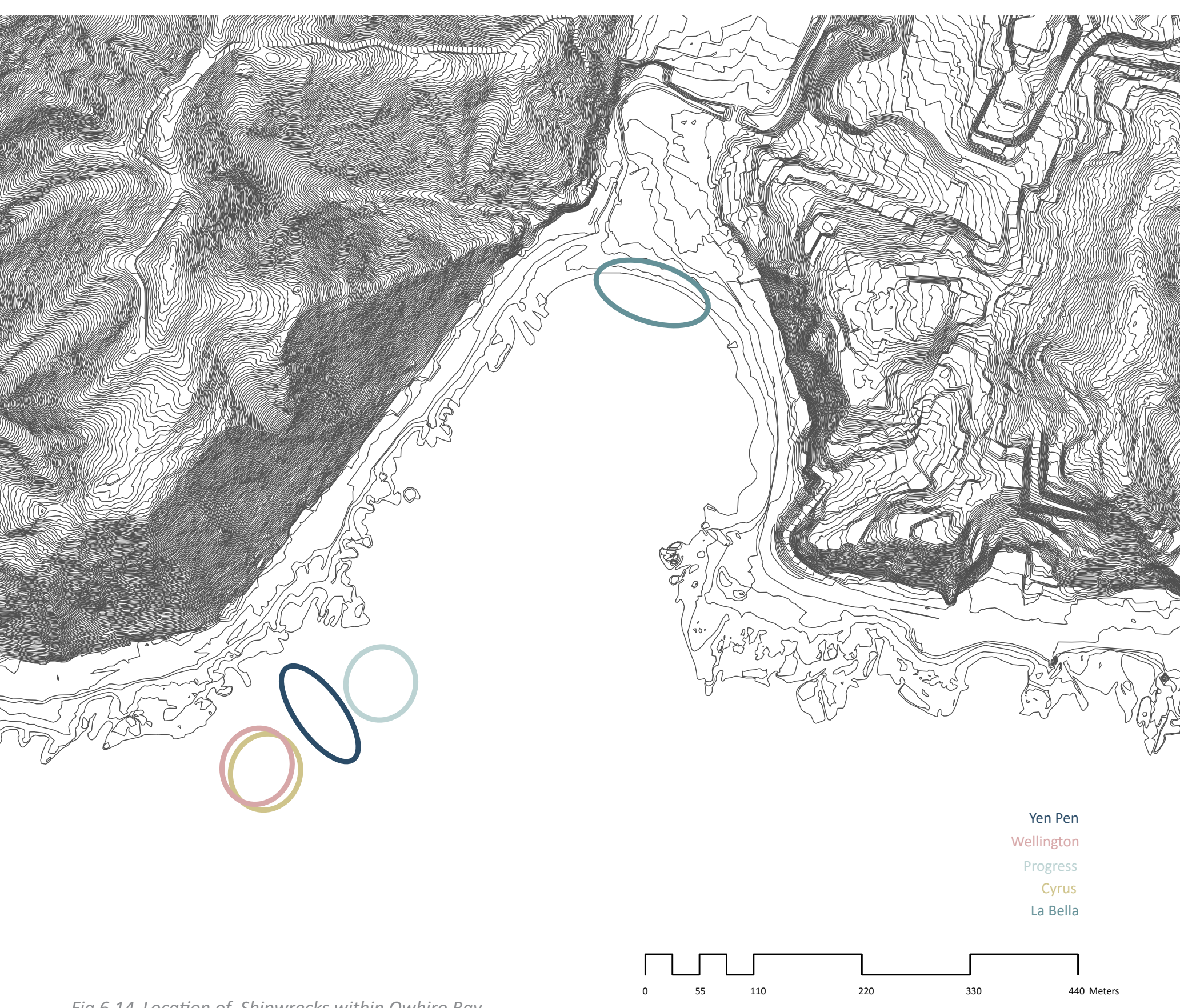

Fig 6.14. Location of Shipwrecks within Owhiro Bay 


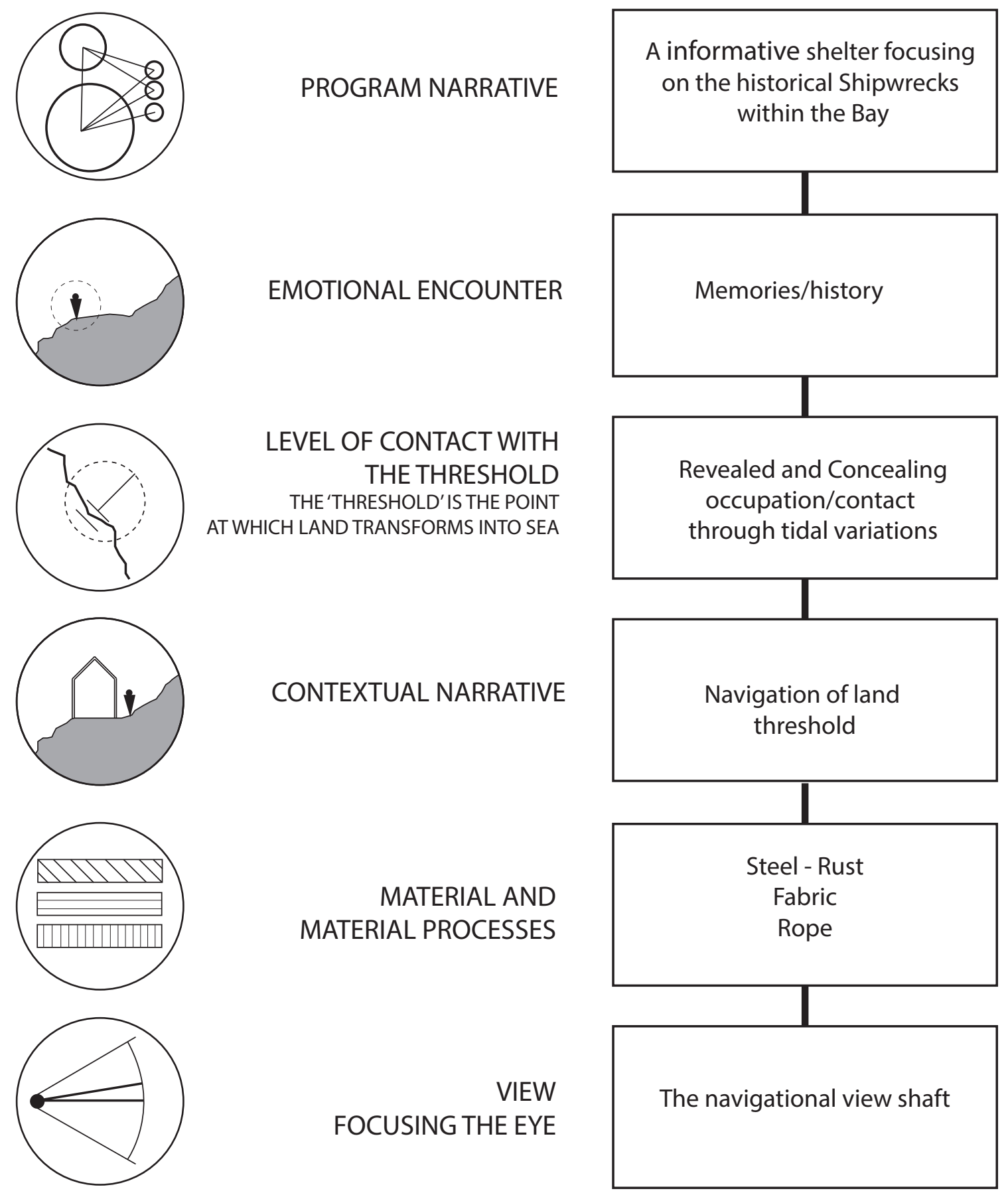




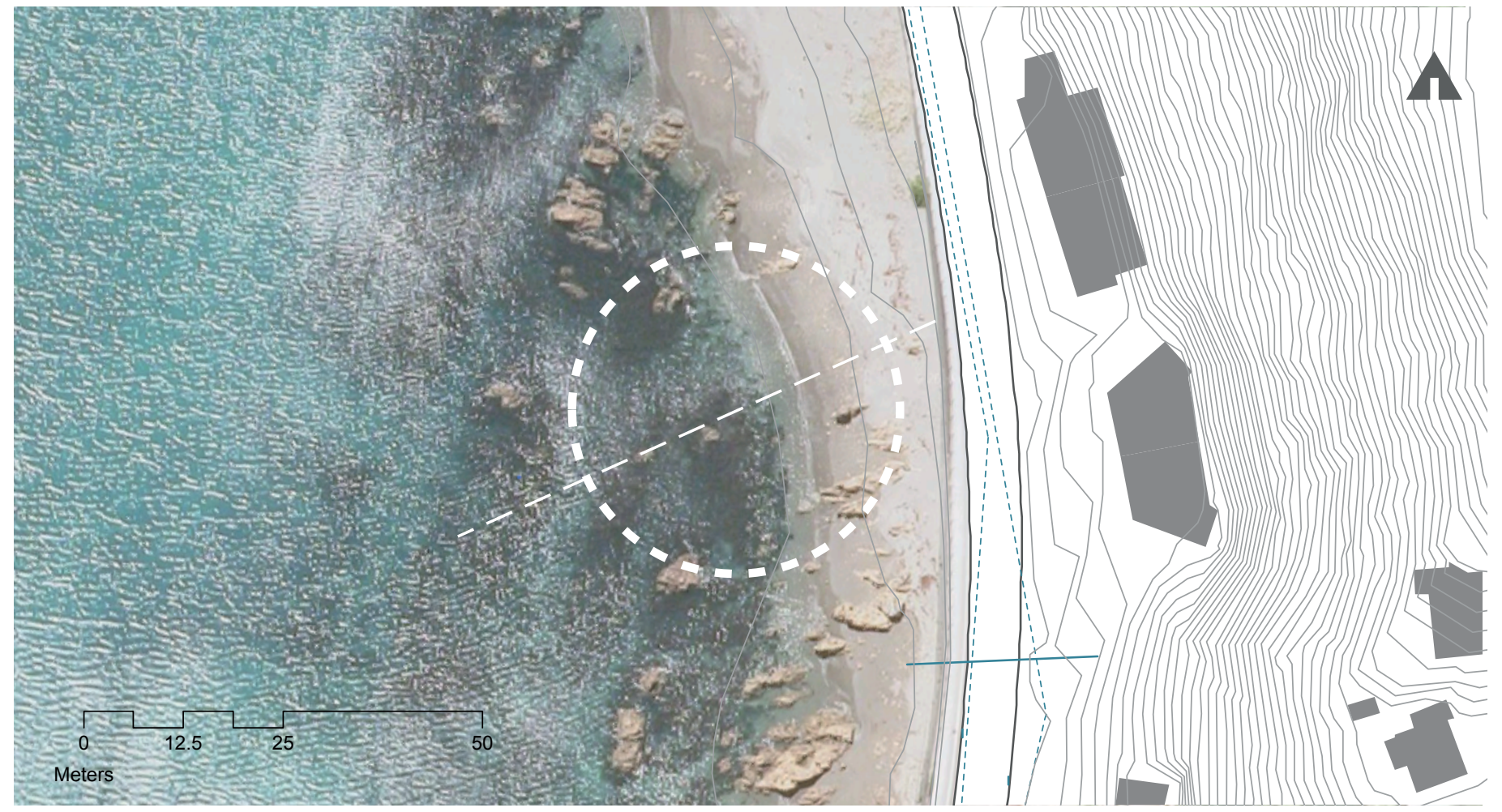

Fig 6.16. Site Plan - circle highlights the focus area of the site, the diagonal line represents the intuitive direction and section cut

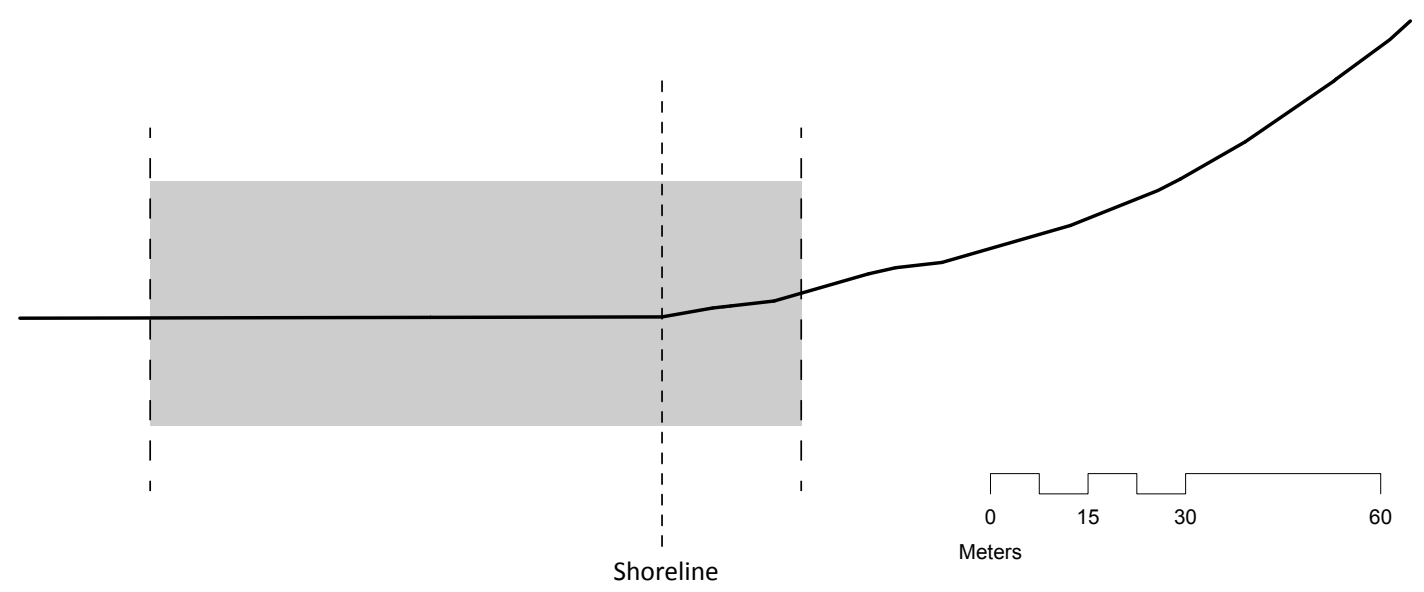

Fig 6.17. Diagrammatic section through site 


\section{Images of site}
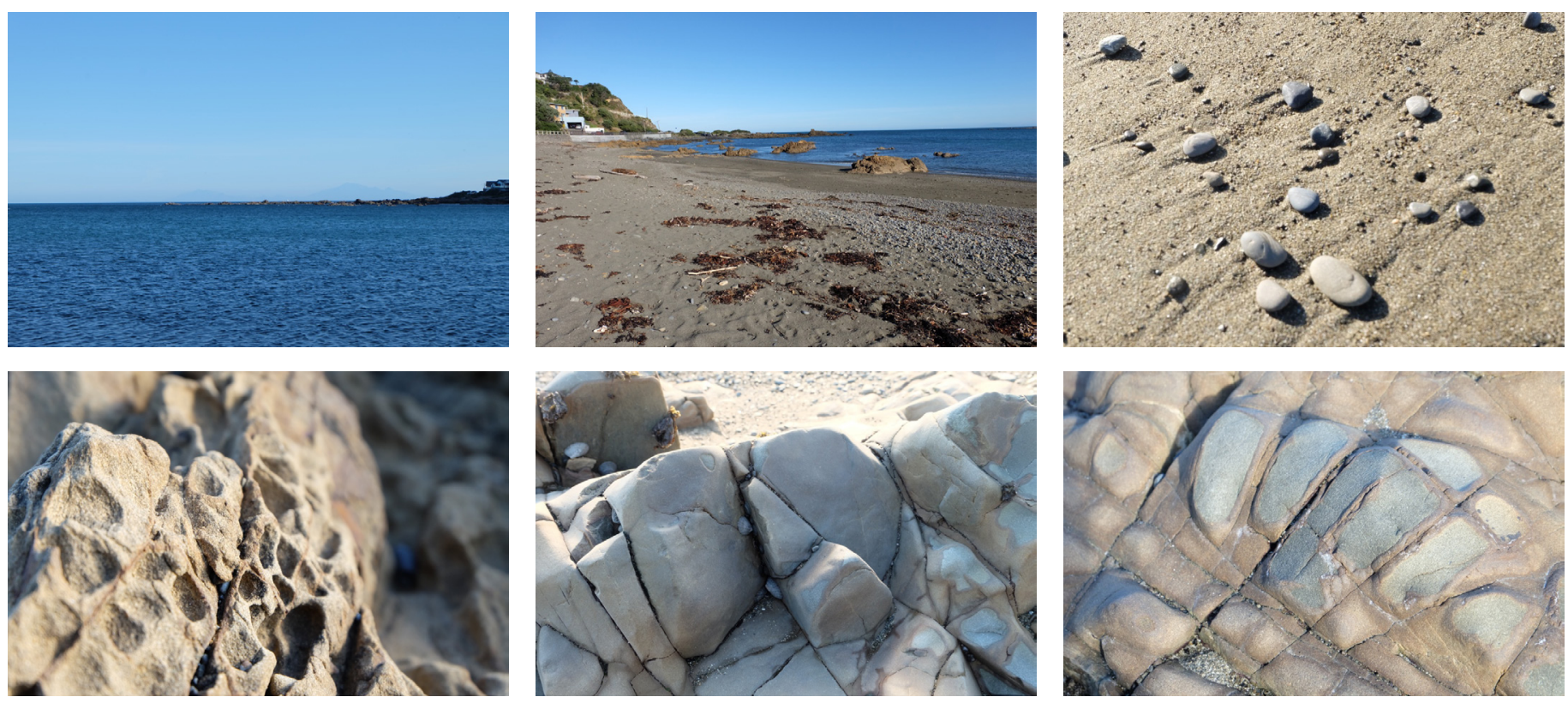

Fig 6.18. Collection of images from Owhiro Bay 

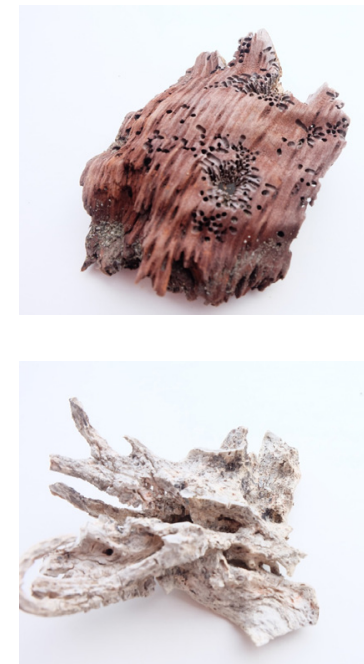

Fig 6.19. Found fragments
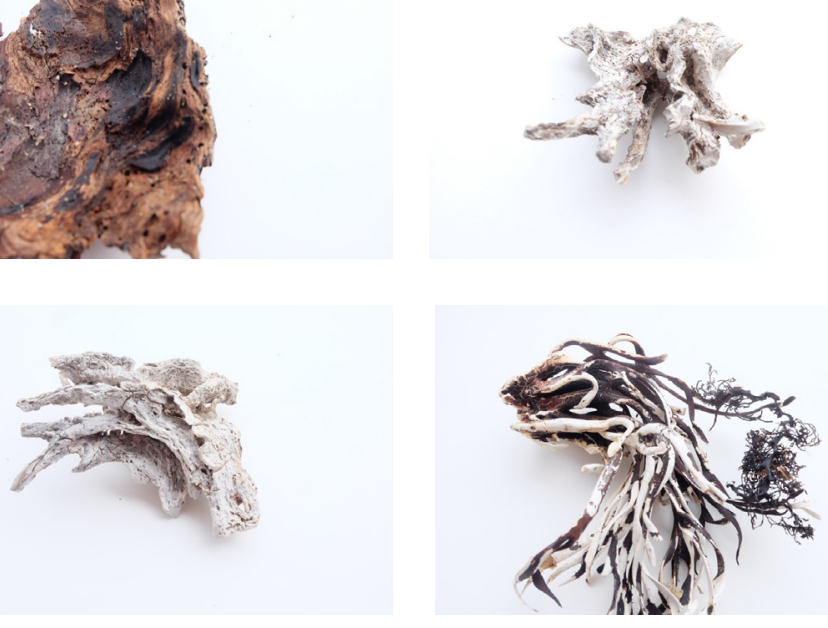
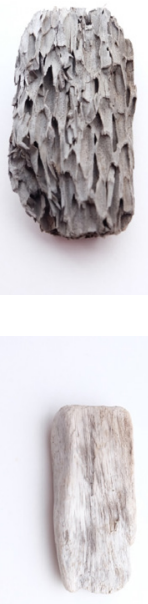

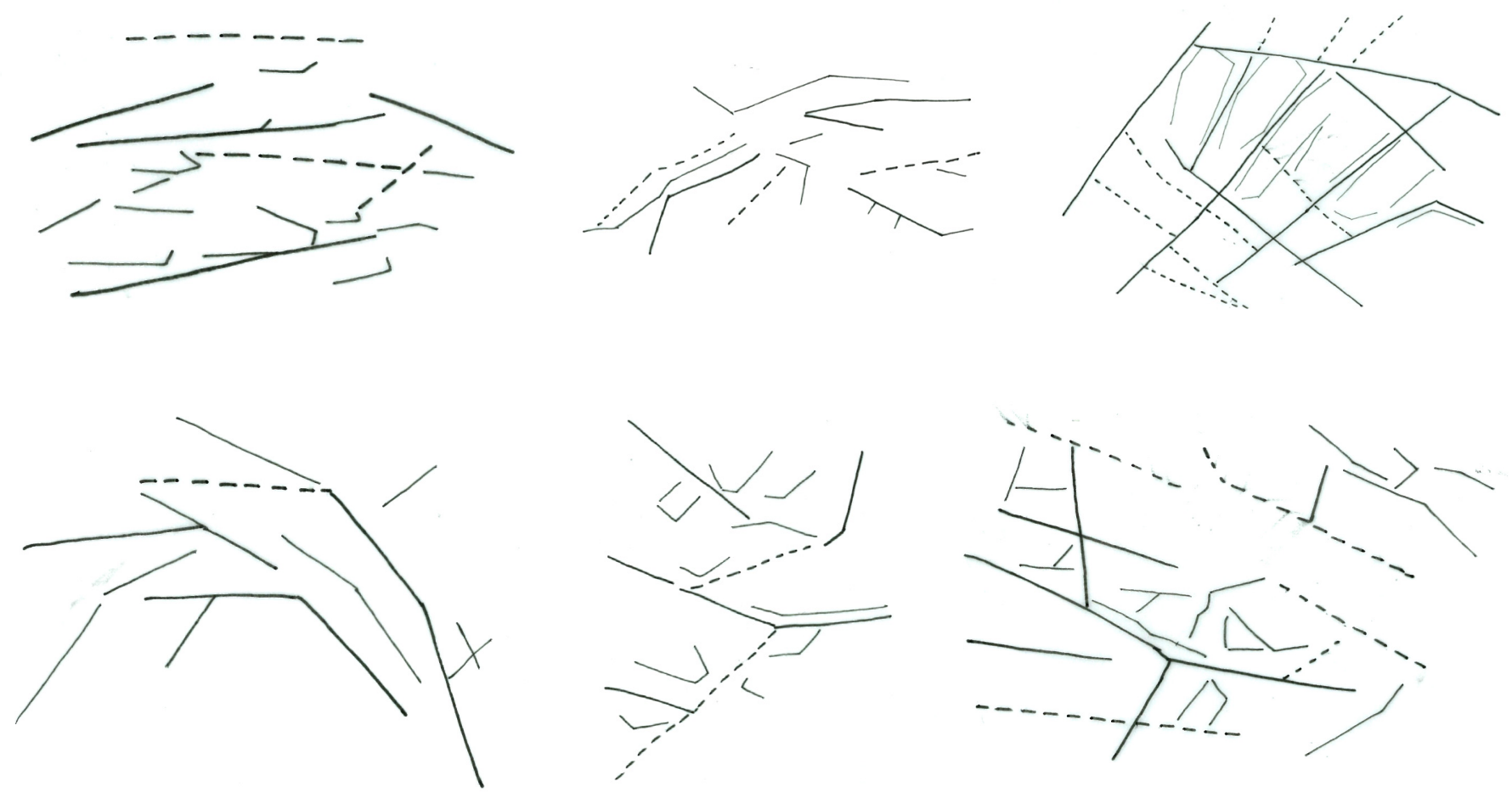

Fig 6.20. Initial form explorations 

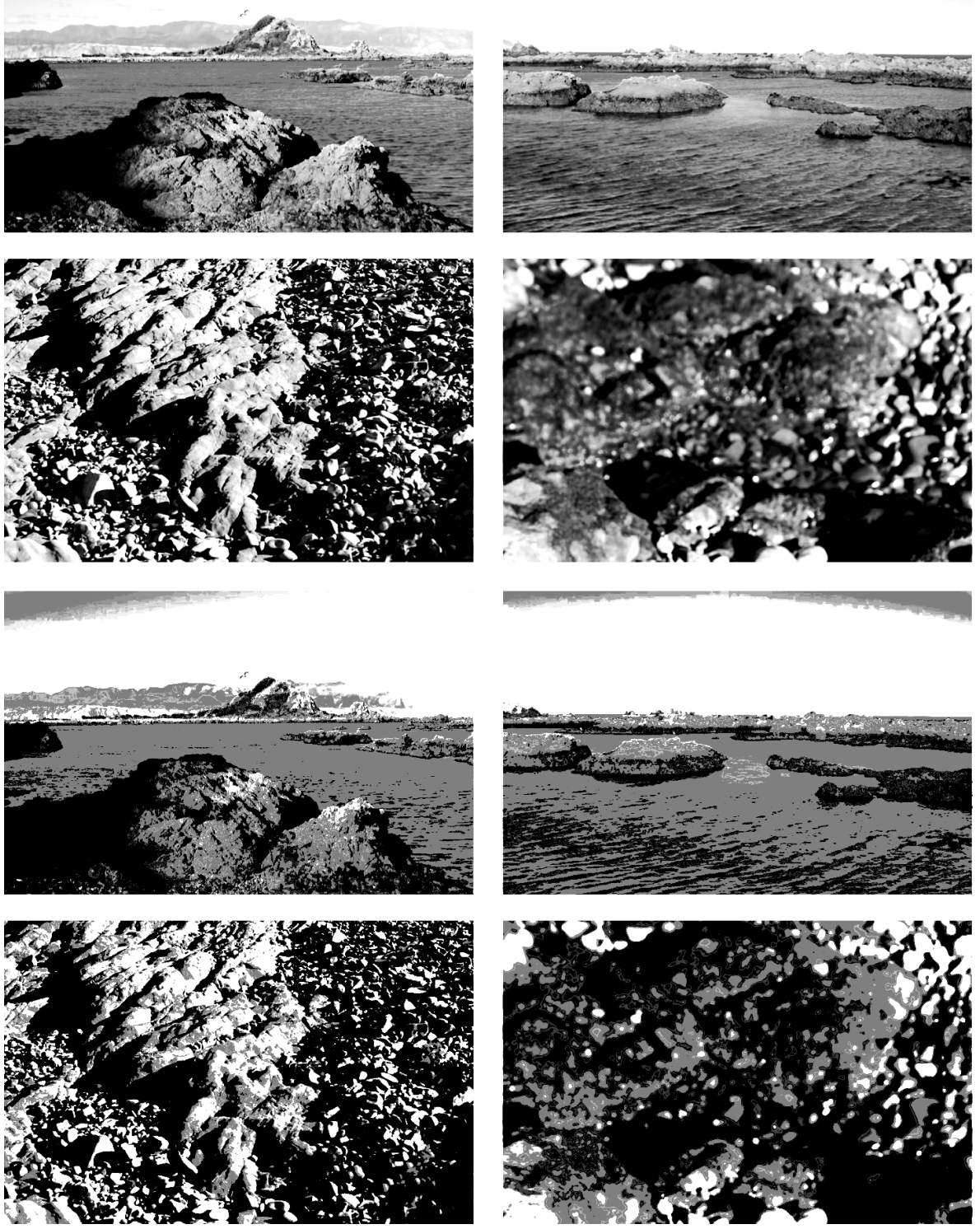
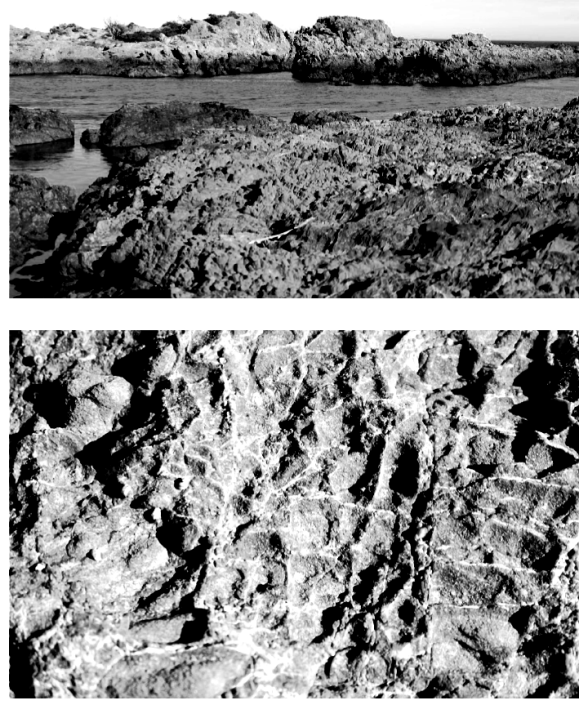
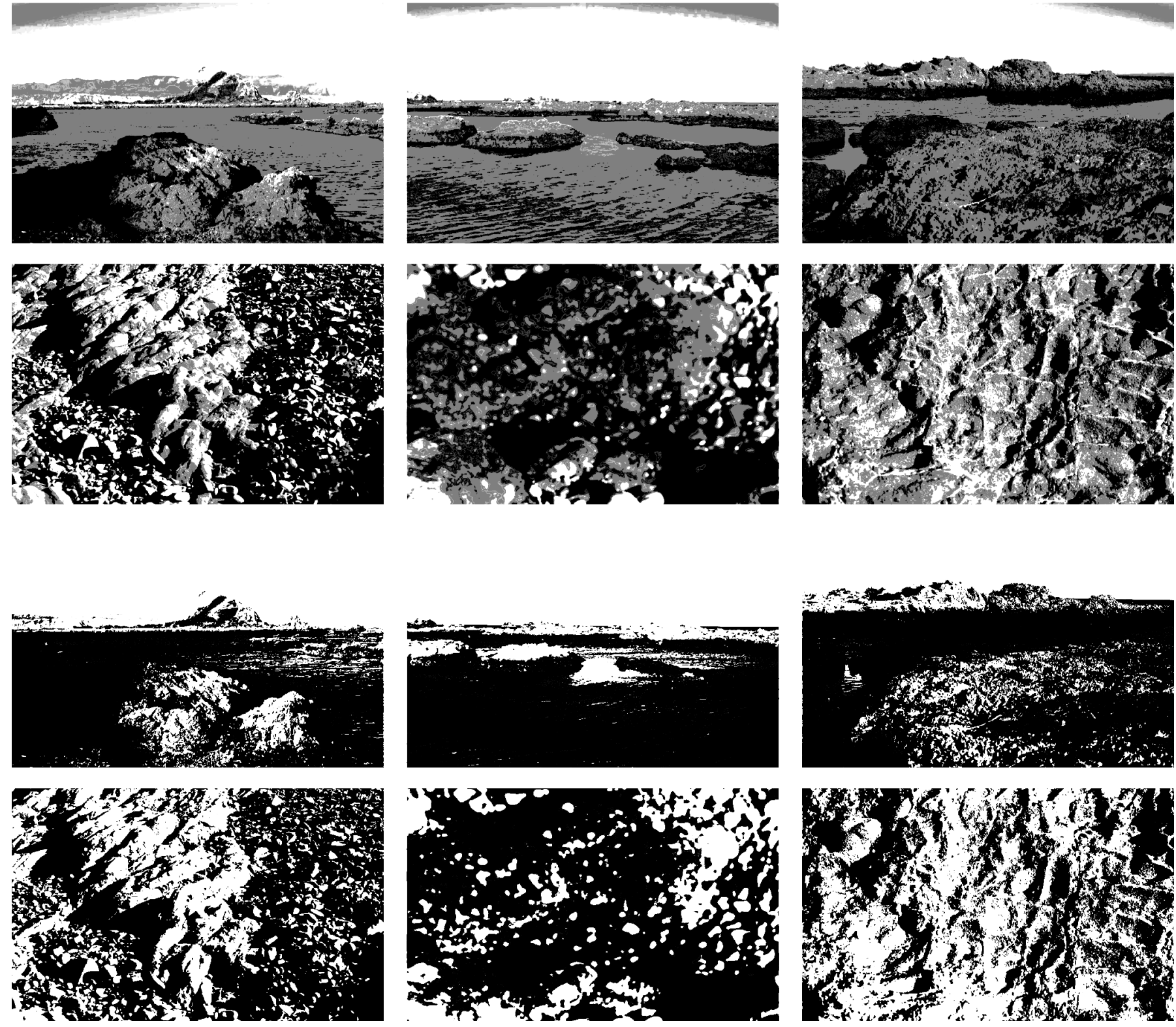

Fig 6.21. Graphic study of textures and views from the site 


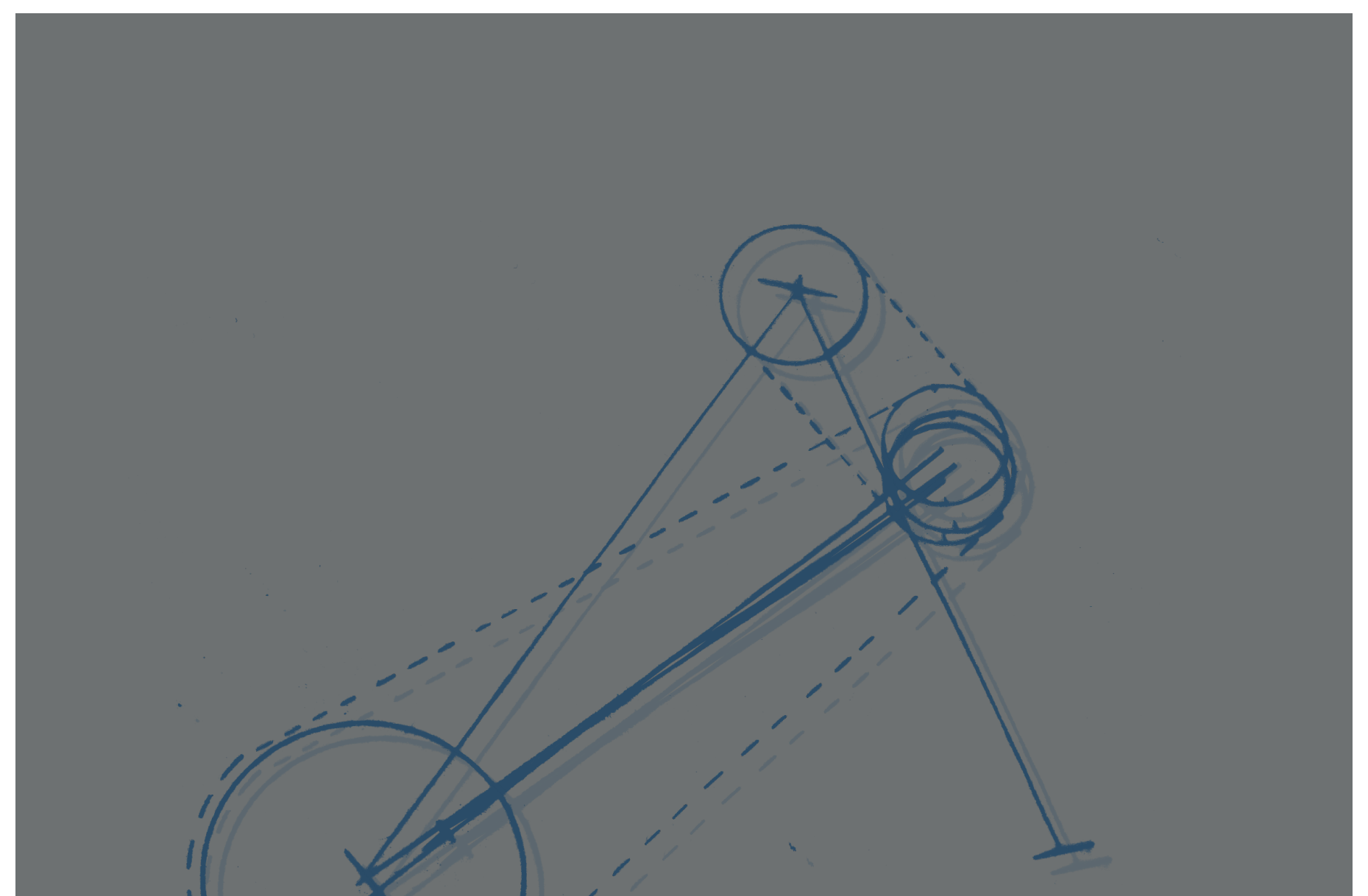

R

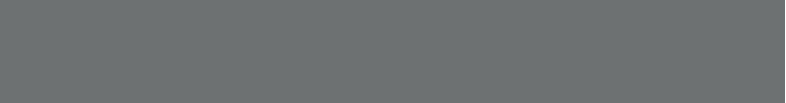




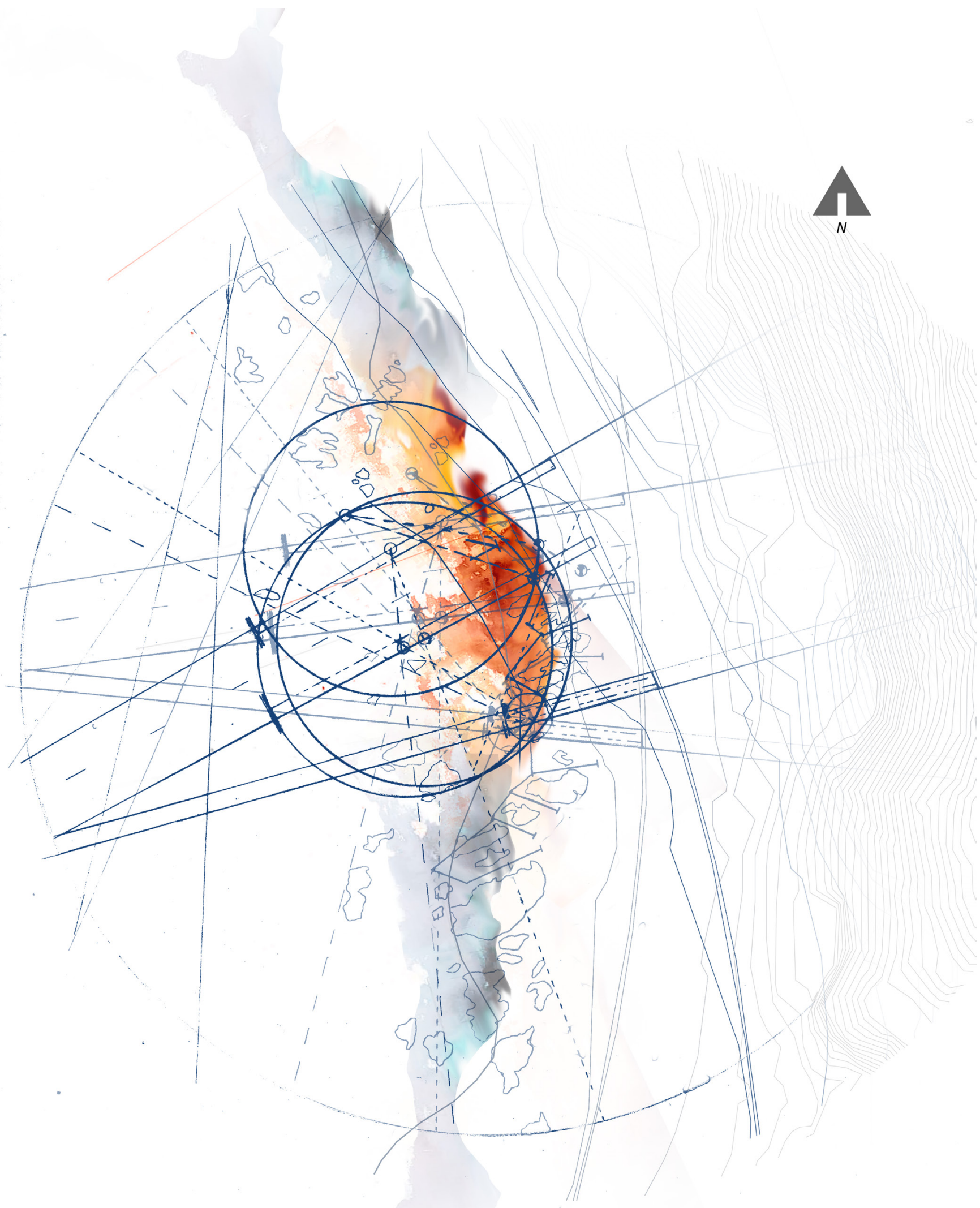

Fig 6.23. Detailed site analysis and drawing exploring key features such as site view shafts, axis and rock formations. 

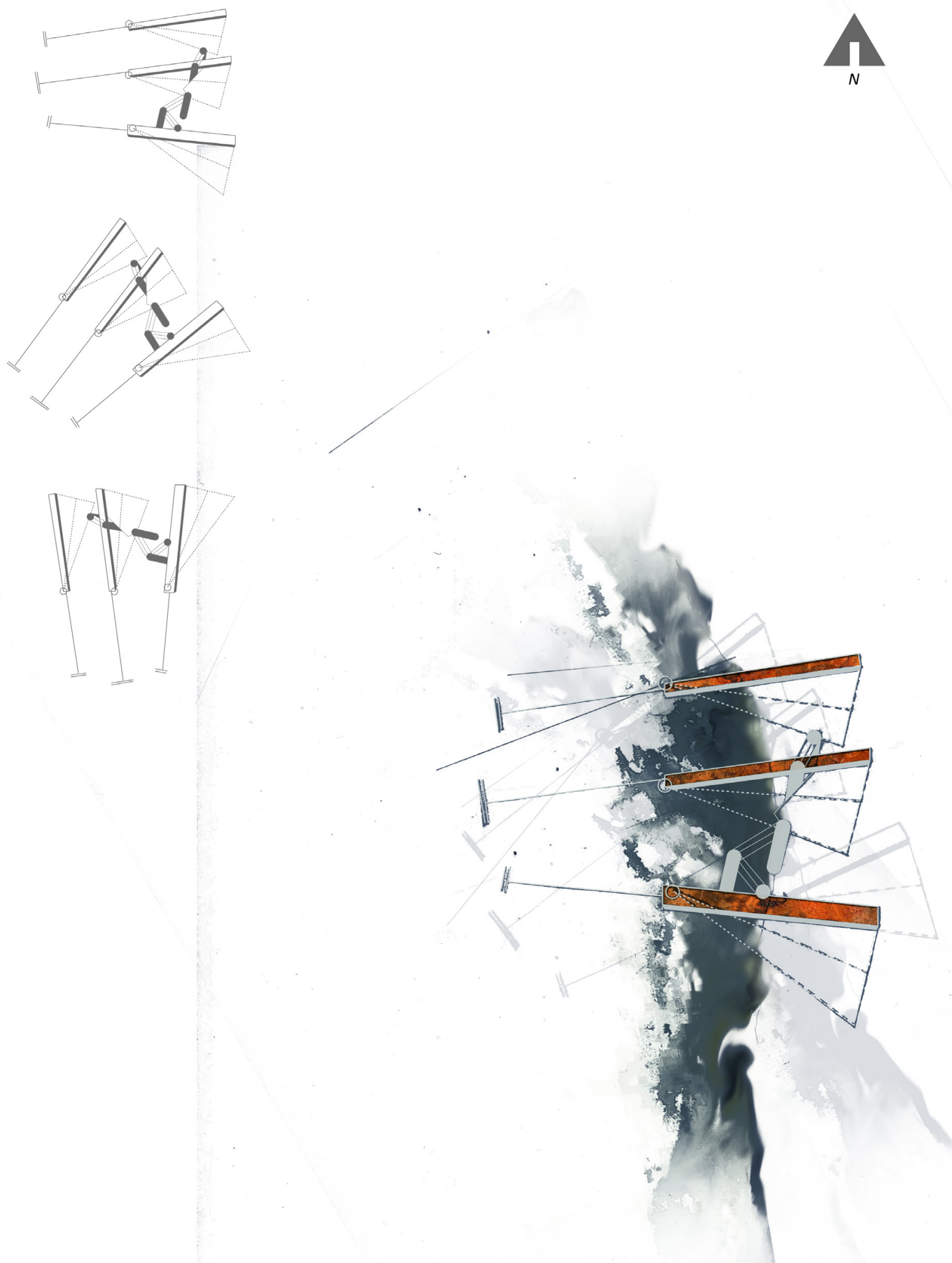

Fig 6.24. Initial form and layout of intervention 
The design of the Owhiro Bay intervention highlights and celebrates the historic shipwrecks. The aim of the design is to create an experience that explores the notion of navigation and concealment. The narrative derived from the failed navigation of the ships, which lead to the sea concealing their structures under the water. This narrative is explored through three channels constructed on the tidal threshold. The revealing and concealing of the forms of the architecture by the tidal variations allows the occupier to inhabit and experience the intense spatial conditions that contributed to the downfall of the ships. The channelling of the sea will also amplify the movement of the water developing an intense experience of revealing and concealing. 


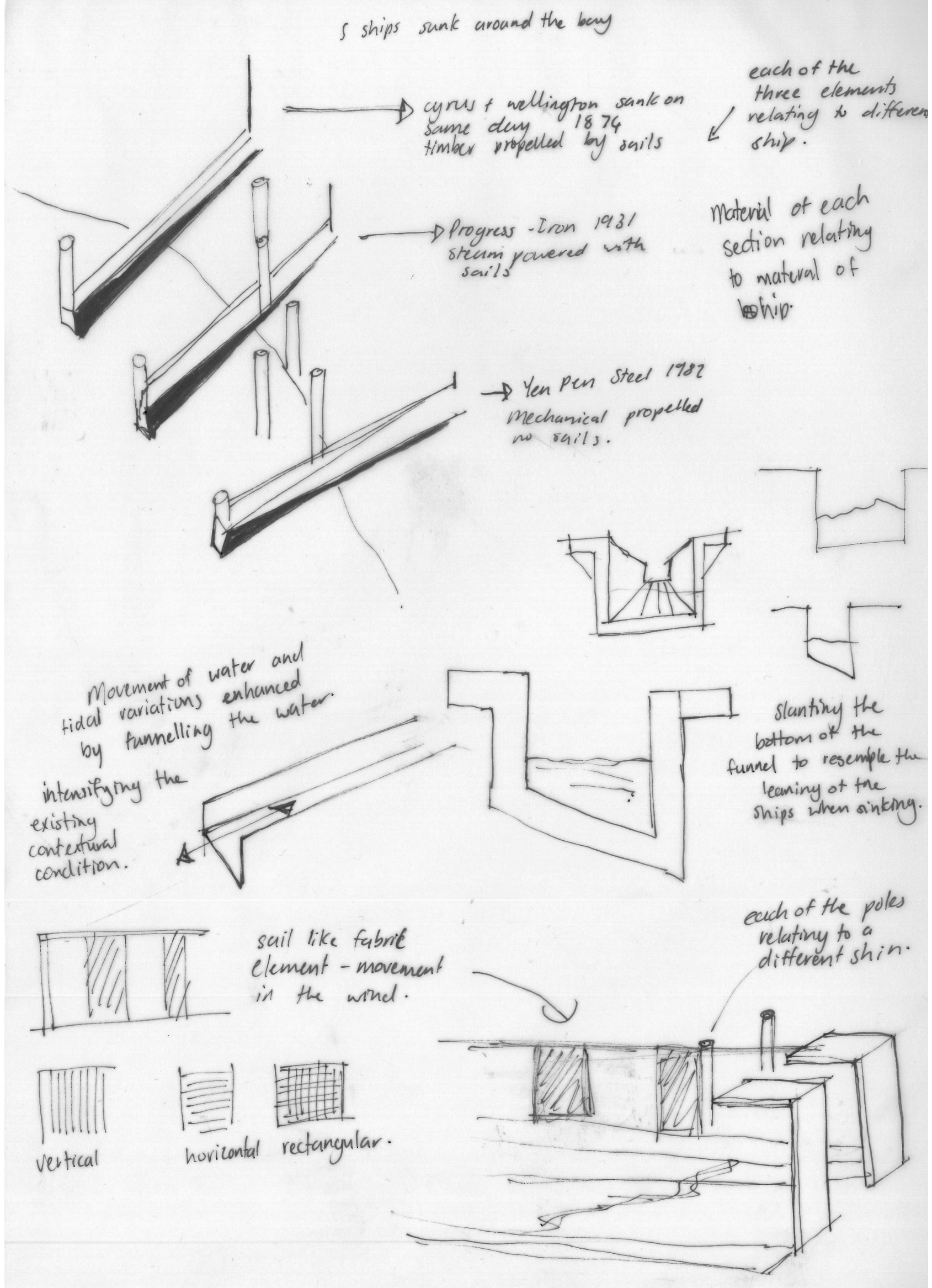




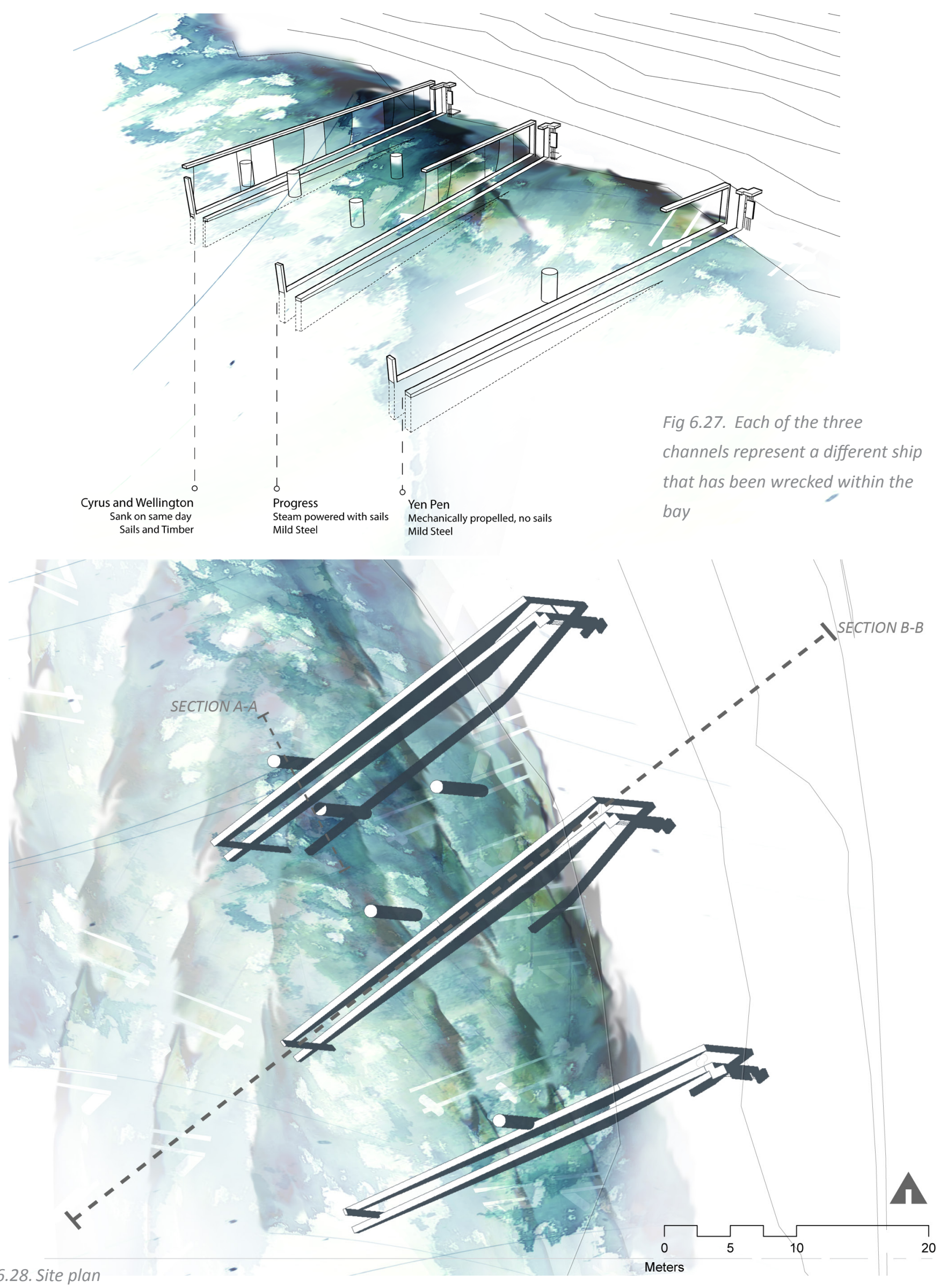

Fig 6.28. Site plan 


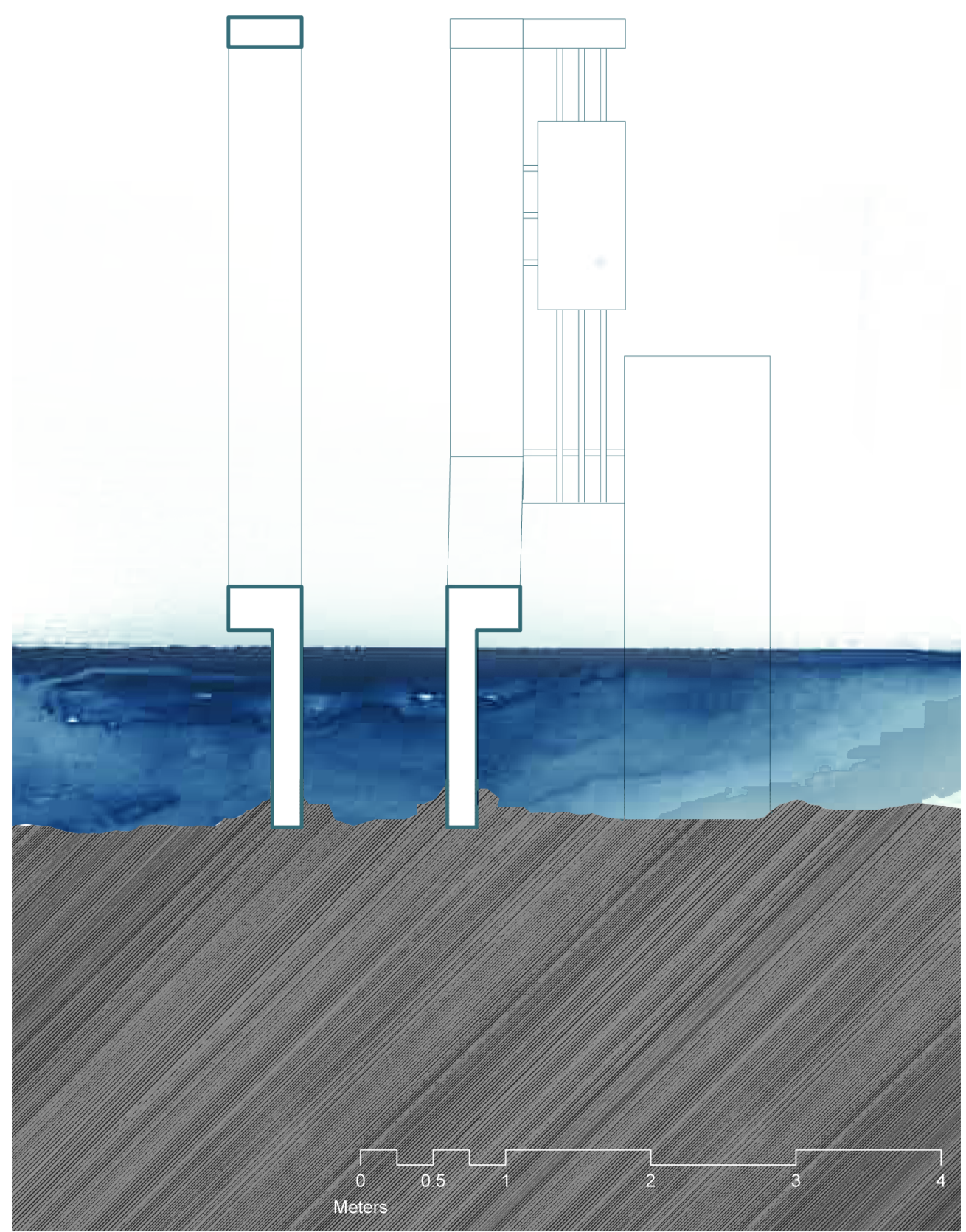

Fig 6.29. Section A-A highlighting the channel design to intensift the movement of water 
Fig 6.30. Section B-B highlighting the 'sails'. New Zealand flax used to create ropes that the make an open weave fabric for the sail element of the design. The open weave will prevent wind loading.

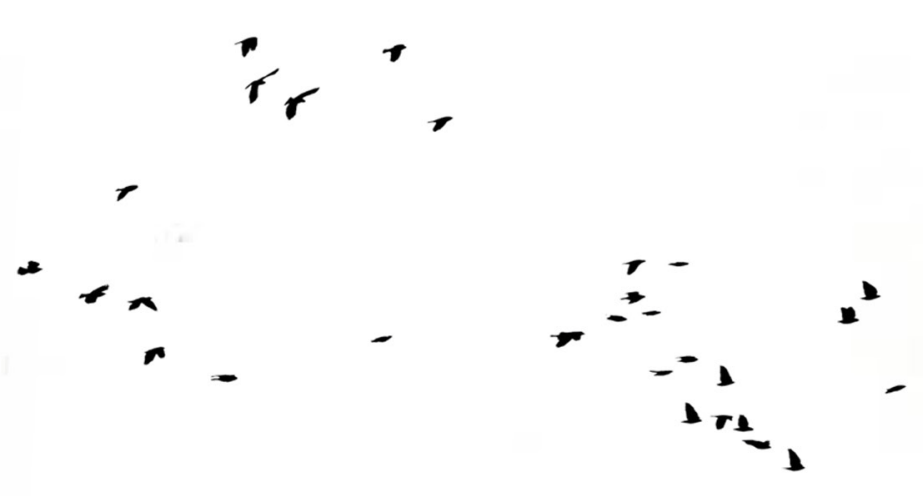





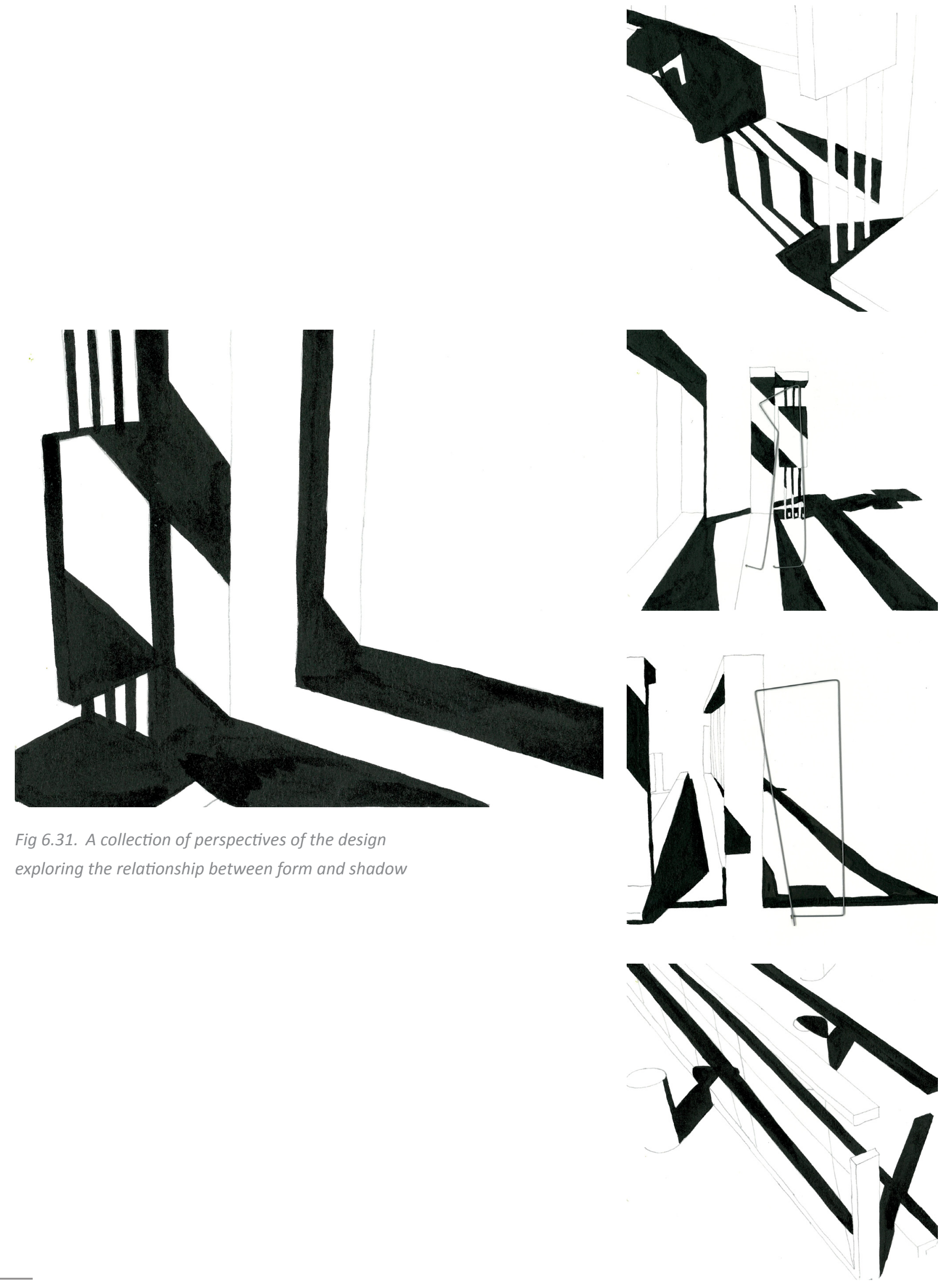




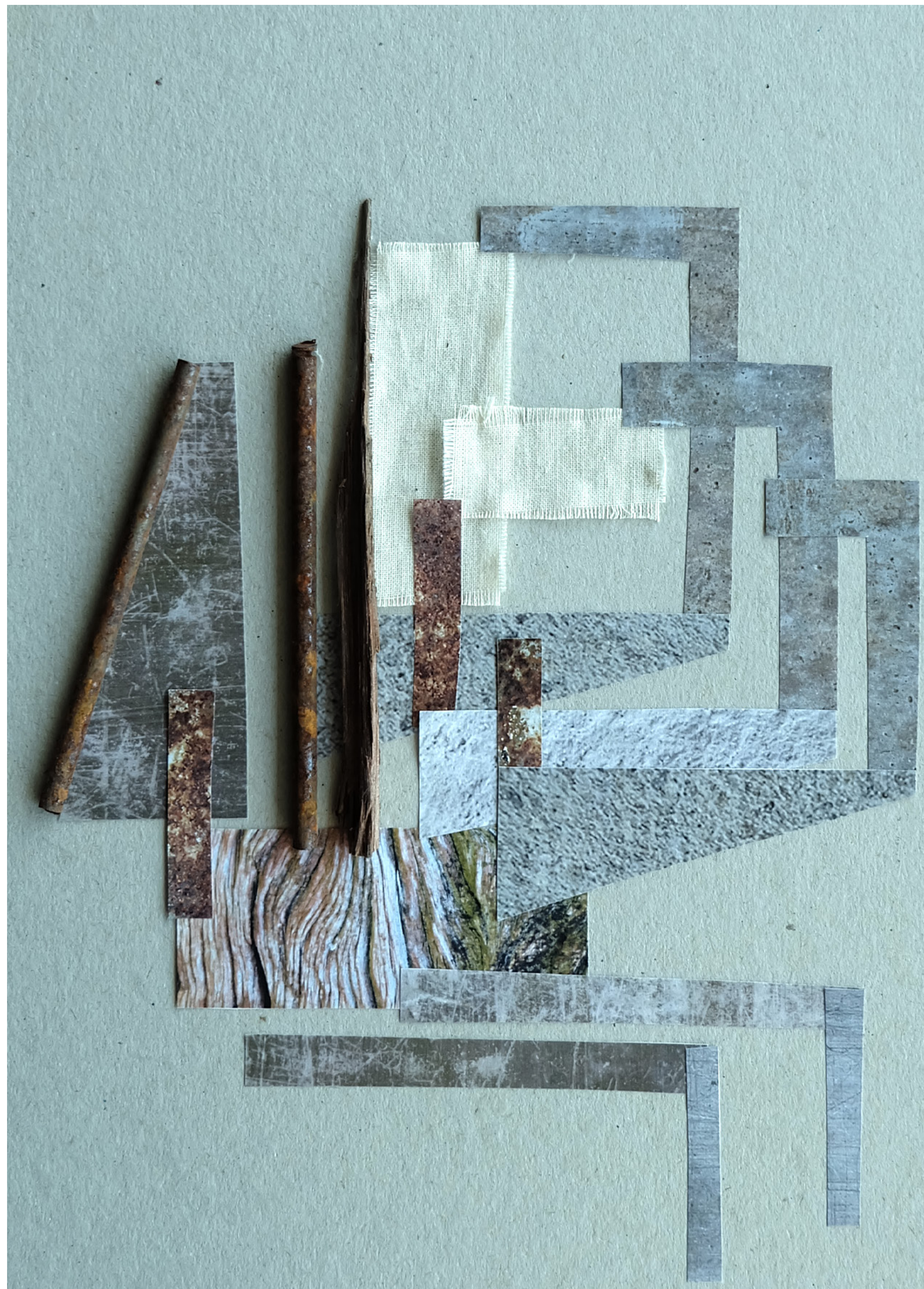




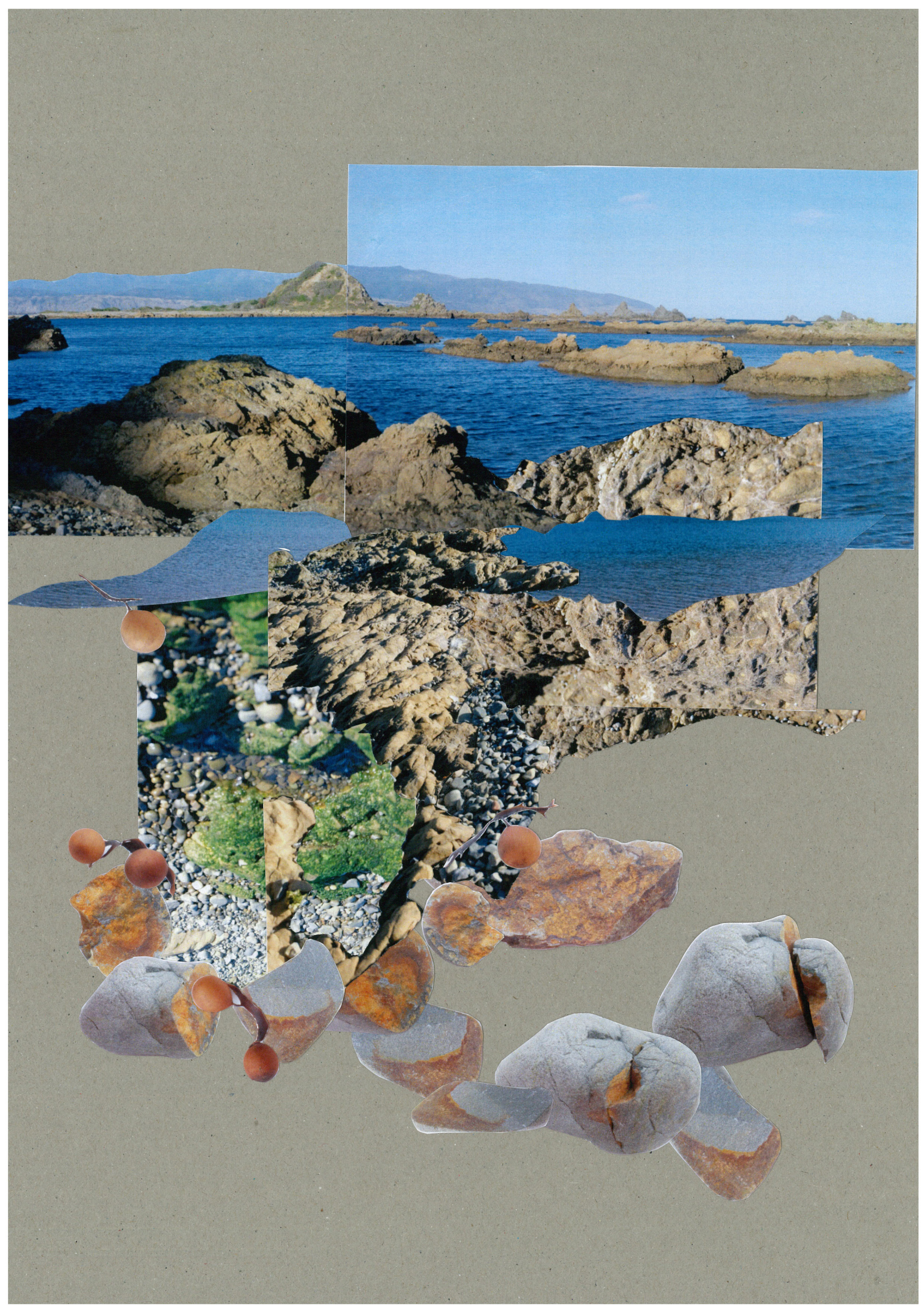




\section{Sirens Rocks}

This is the first site where you gain a sense of the power and force of the sea and what lies beyond. Making your way over the fractures in the rock formations there is a sense of excitement and anticipation. This journey takes you from a sense of safety and groundedness to weightlessness and suspense. This experience is a key element of the site that will be explored through the design process. When standing out on the platform, human scale seems reduced. The expansive uninterrupted view of the horizon is confronting and inspiring. The constant rhythm of the sea crashing against the rocks reveals the power of the surrounding water and the reflective surface of the water appears to hide what lies beneath, creating a sense of mystery. On rough days it is not possible to access the platform of rocks, however, depending on the conditions, this site provides an empowering and intense experience of the coastline.

This site is popular with divers. Below the water's surface the seabed features long rocky reefs extending out to sea. ("The Wellington Dive Guide") The topography of large channels and gravel flats under the sea is just as varied as above the surface.

The shelter at Sirens Rocks focuses on the experience that is created from the intensity of the site. The shelter investigates transcending the threshold between land and sea; the journey taken by divers. The programmatic needs and the experiential qualities of the journey are explored through the architecture.

\section{Brief}

- $\quad$ Place for people to sit and watch snorkelers in shallow area

- $\quad$ Ramp for divers to enter and exit the water

- Handrail for stability when entering and exiting the water

- $\quad$ A place to sit to take off /put on diving gear e.g. mask and flippers

- $\quad$ Pathway to a second diving platform

- $\quad$ Second diving platform to have suitable access for rougher sea conditions

- Material language of weathering

- Intensification of site experience through density and transparency of view paths 


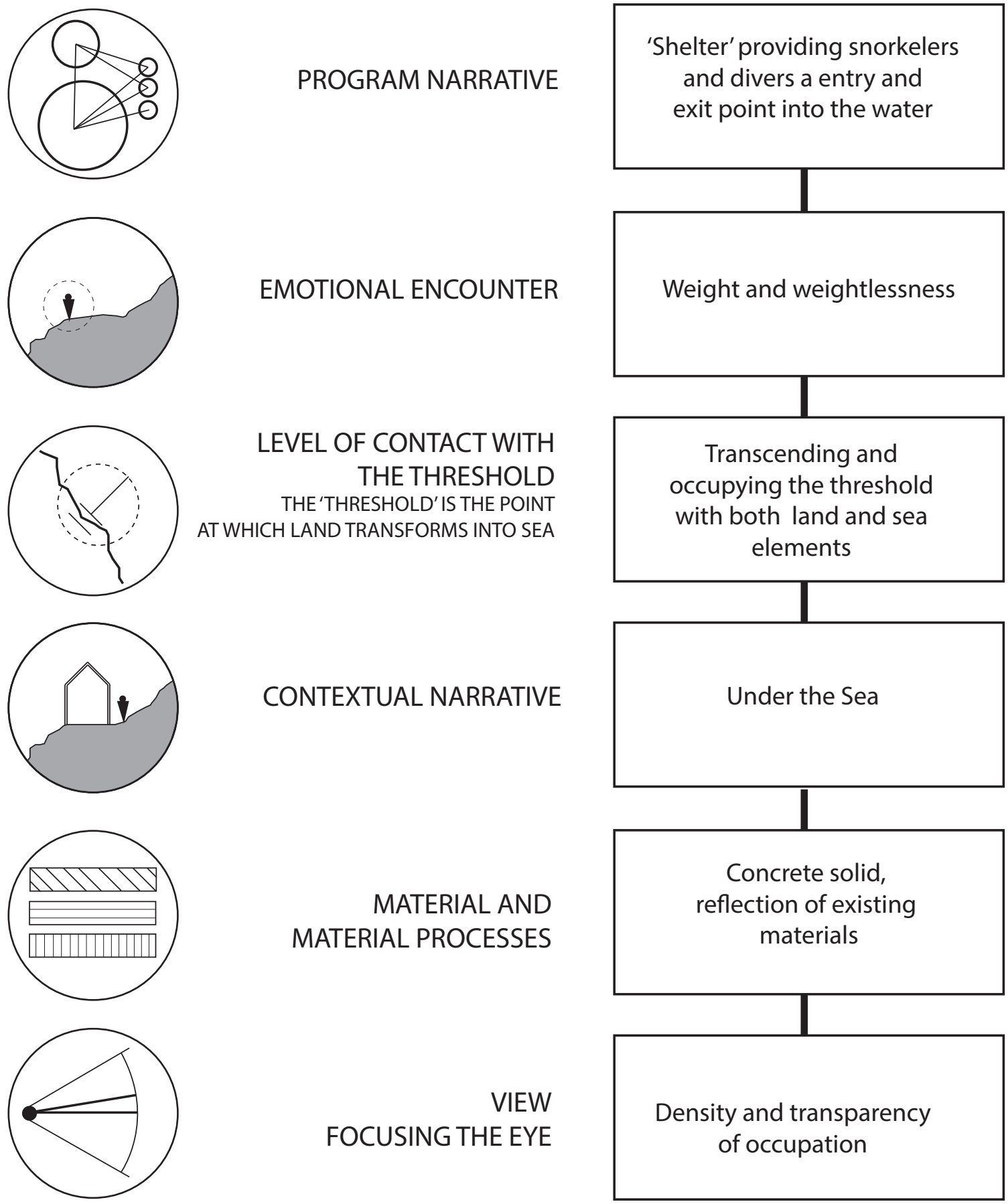




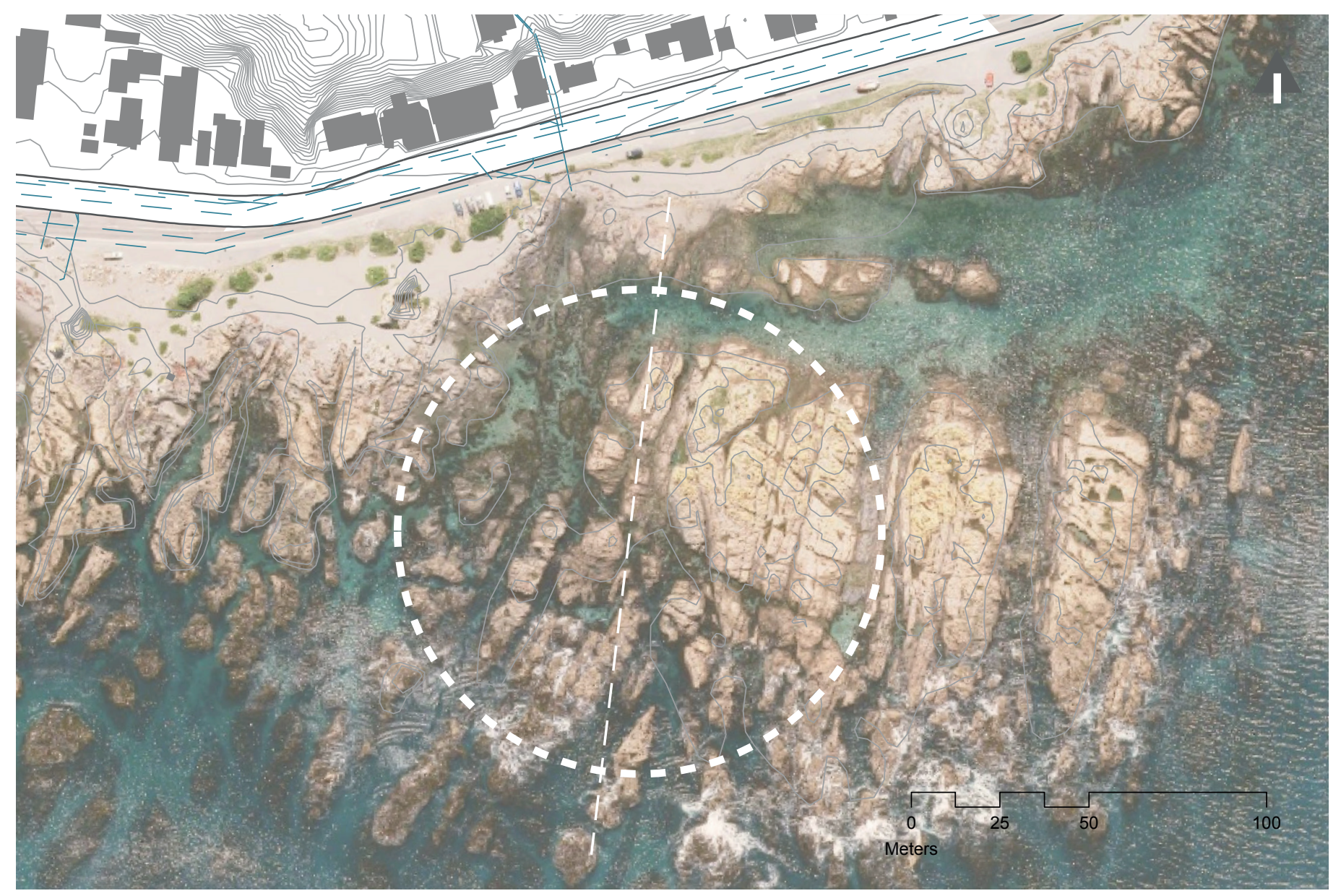

Fig 6.35. Site plan - circle highlights the focus area of the site, the diagonal line represents the intuitive direction and section cut

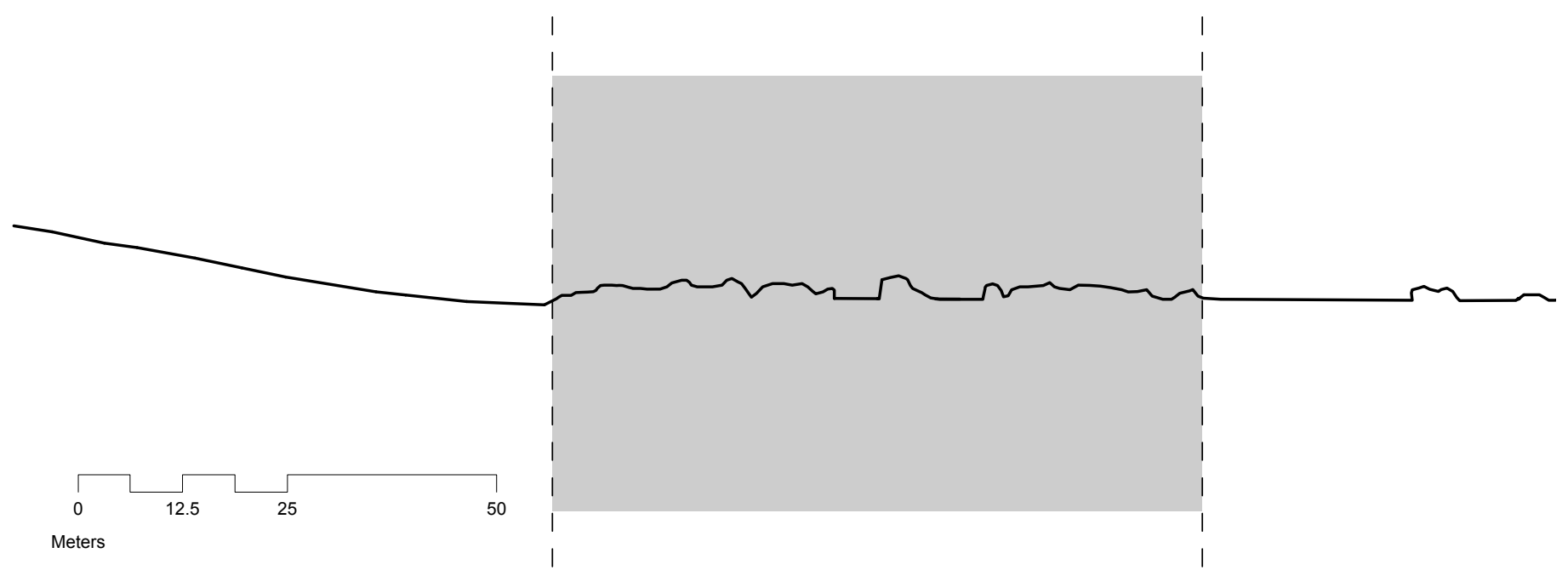

Fig 6.36. Diagrammatic section through site 
Images of site
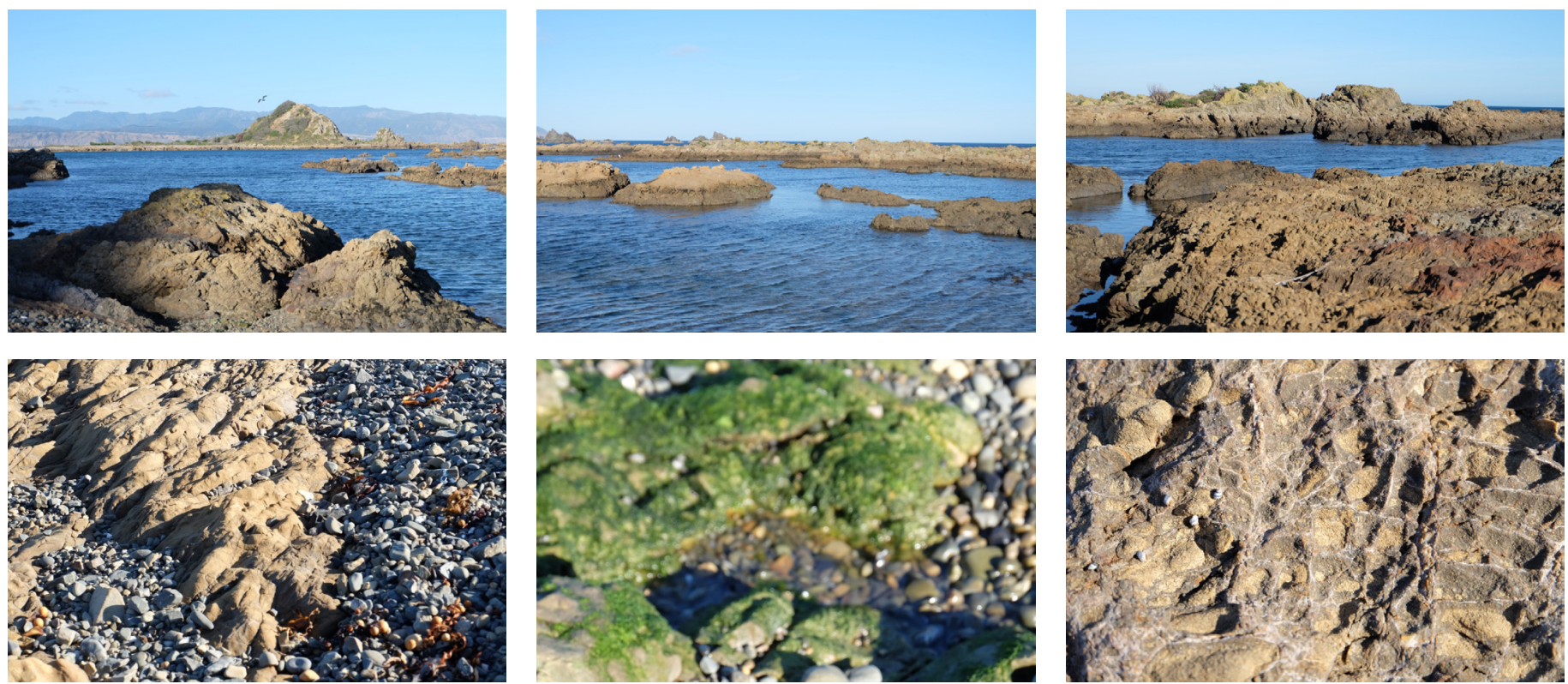

Fig 6.37. Collection of images from Sirens Rocks 

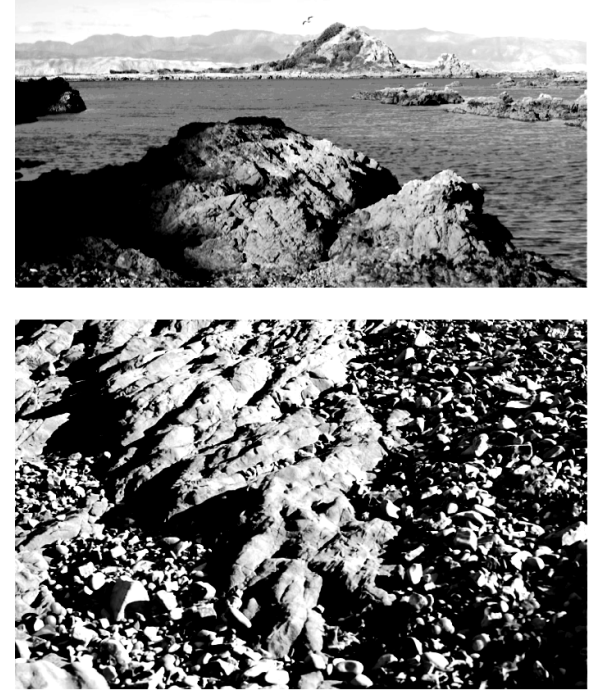

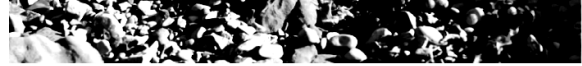
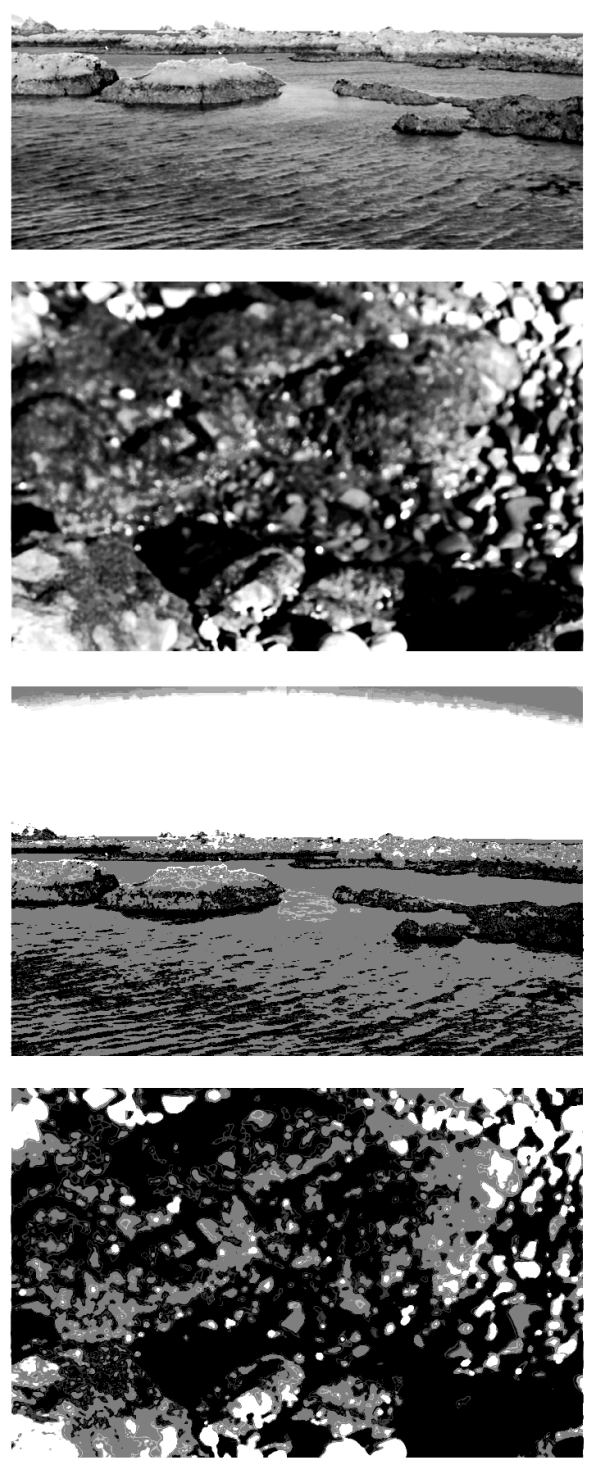
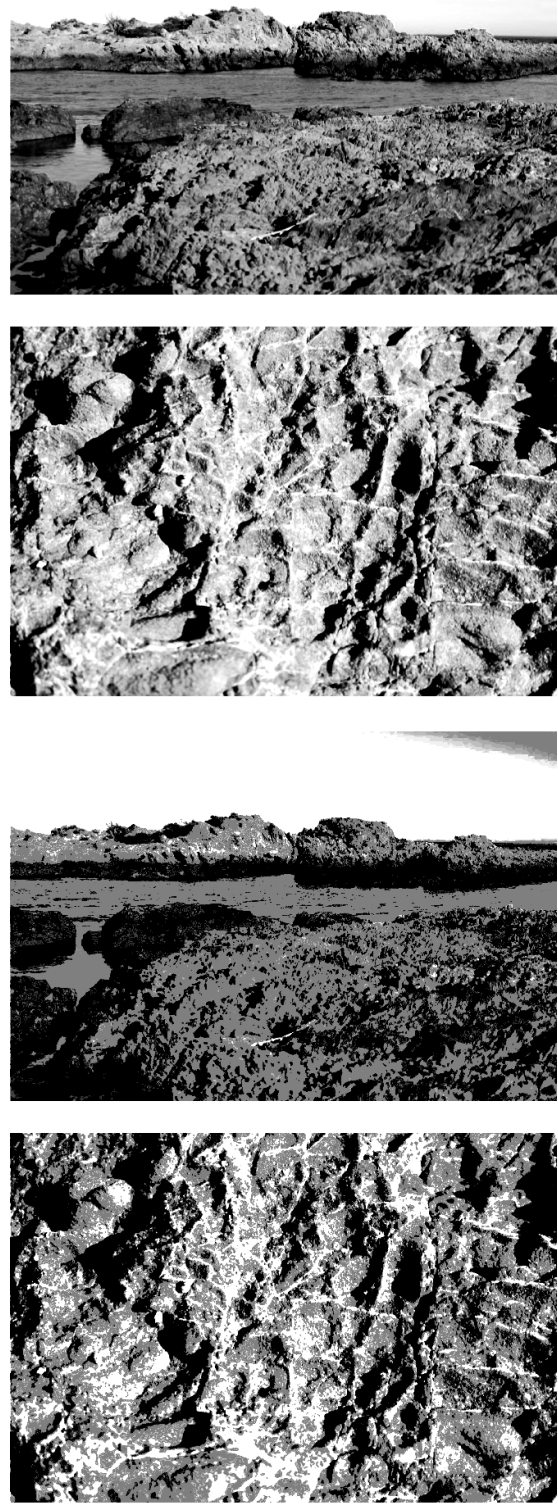
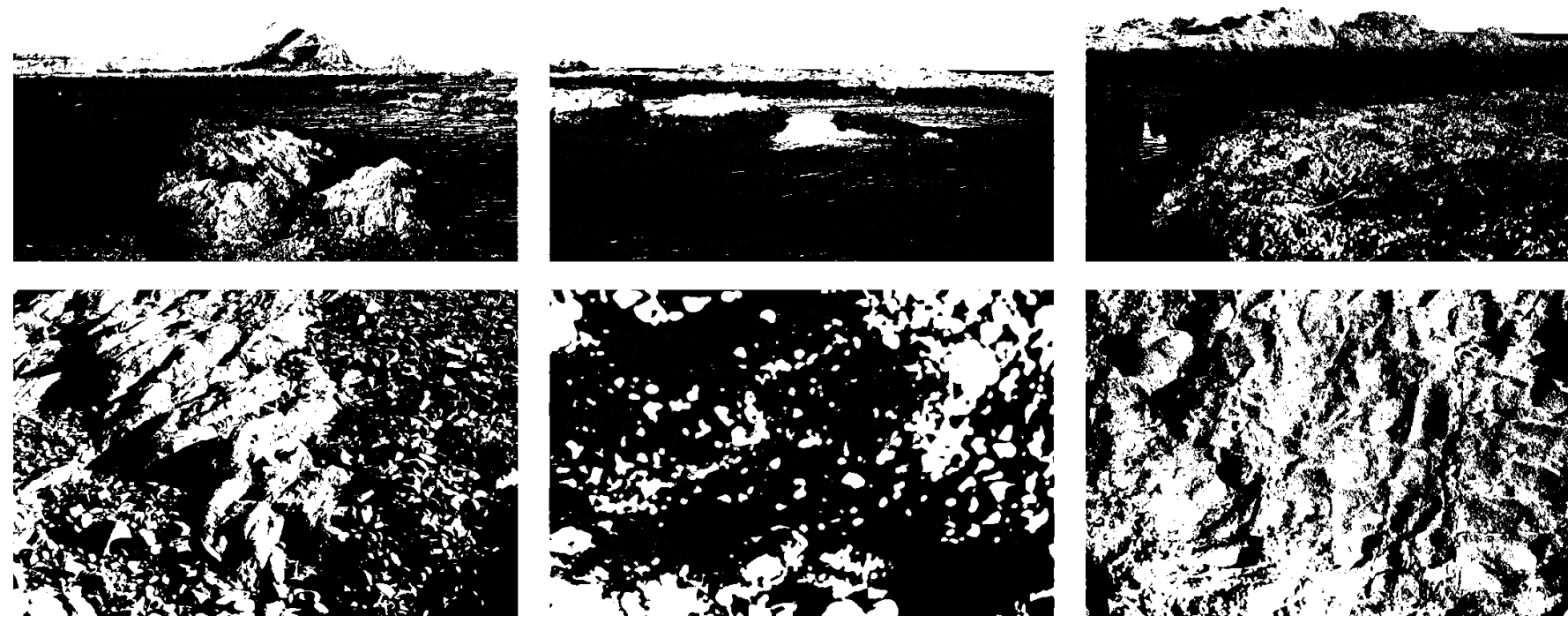

Fig 6.38. Graphic study of textures and views from the site 

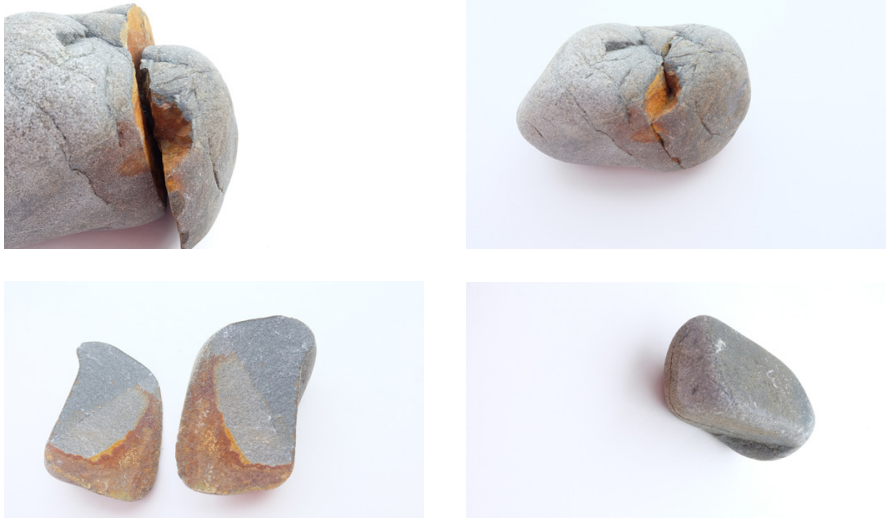

Fig 6.39. Found fragments
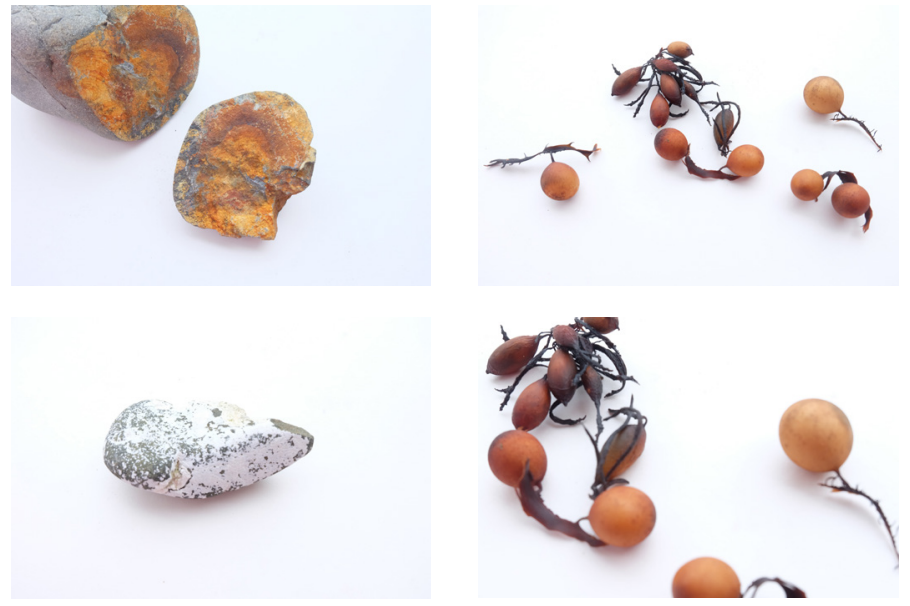

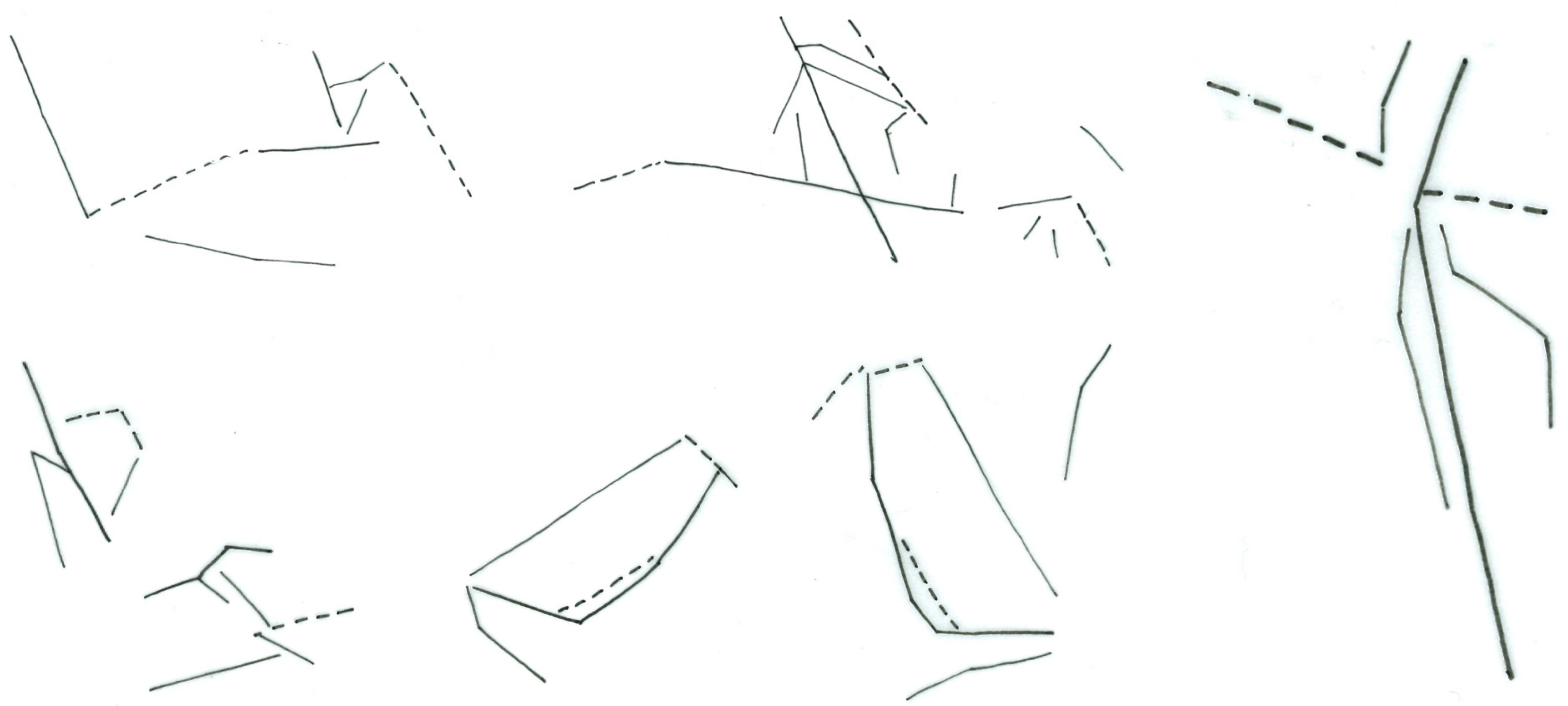

Fig 6.40. Initial form explorations 


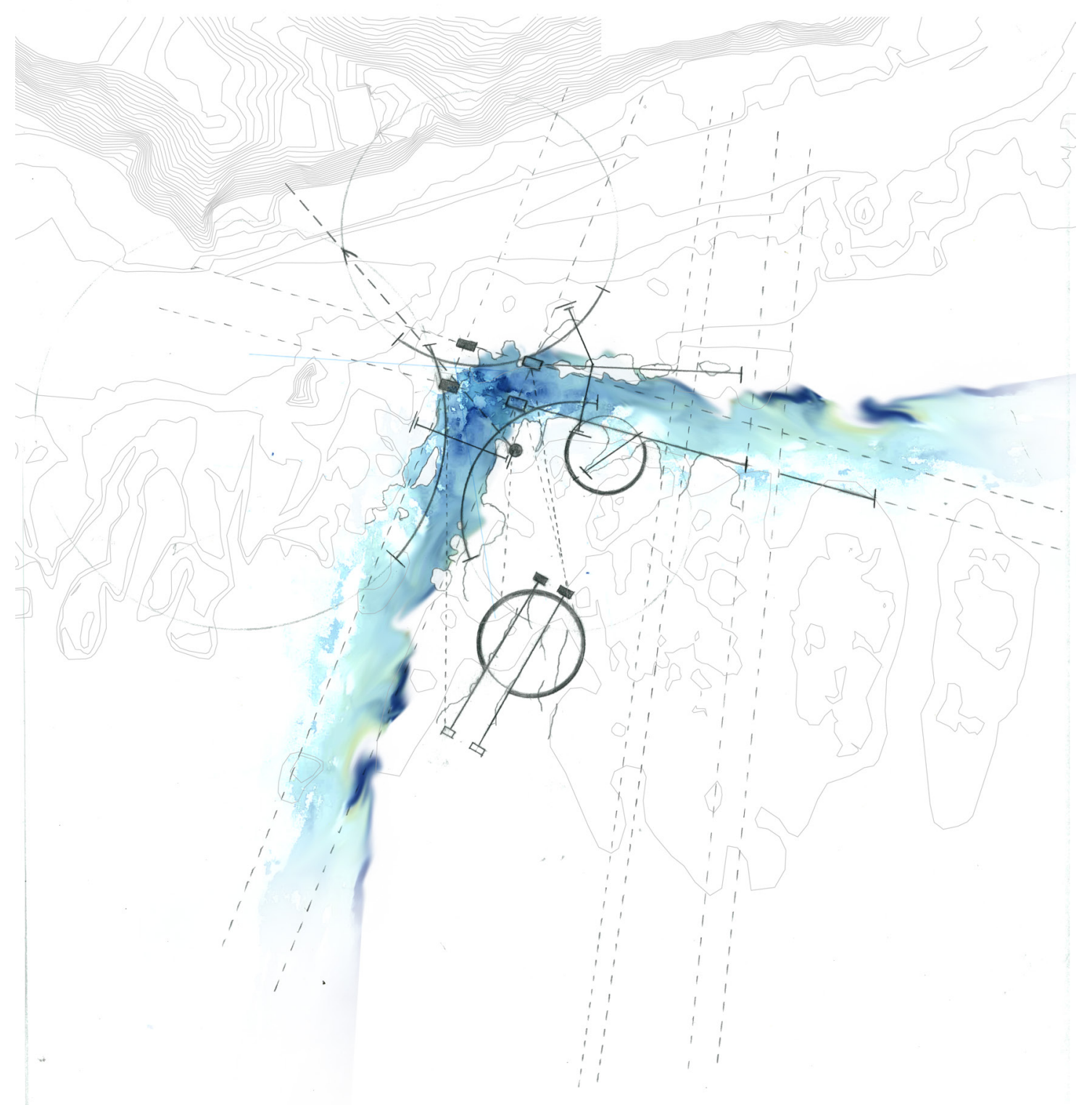

Fig 6.41. Detailed site analysis exploring axis, topography shafts and key points of entry 


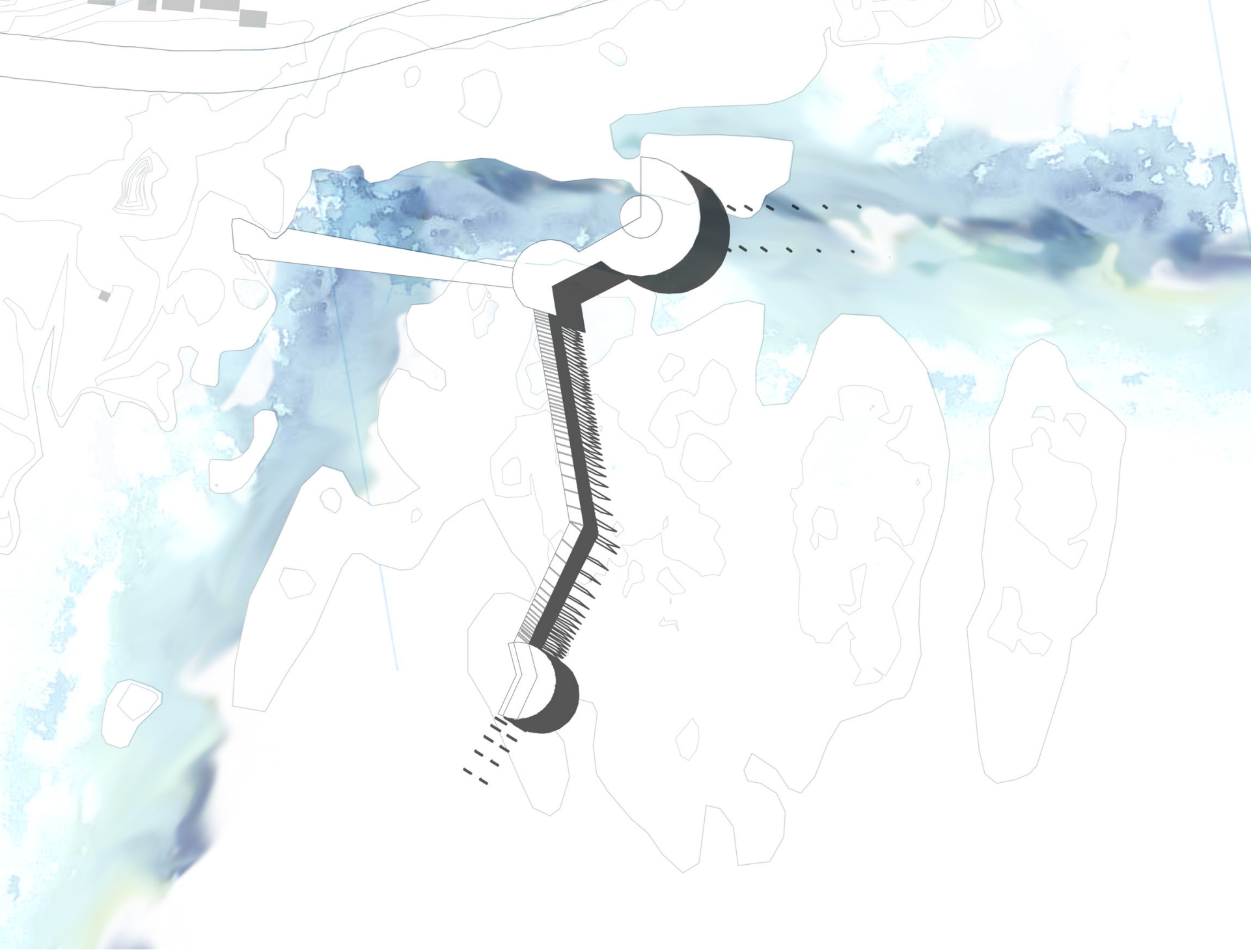

Fig 6.42. First design iteration

This initial design develops two divers' entry points into the water. Each of the points feature different diving conditions so that people with varying abilities can use the platforms. The route connecting the two platforms explores the notion of density and transparency through the column configuration.

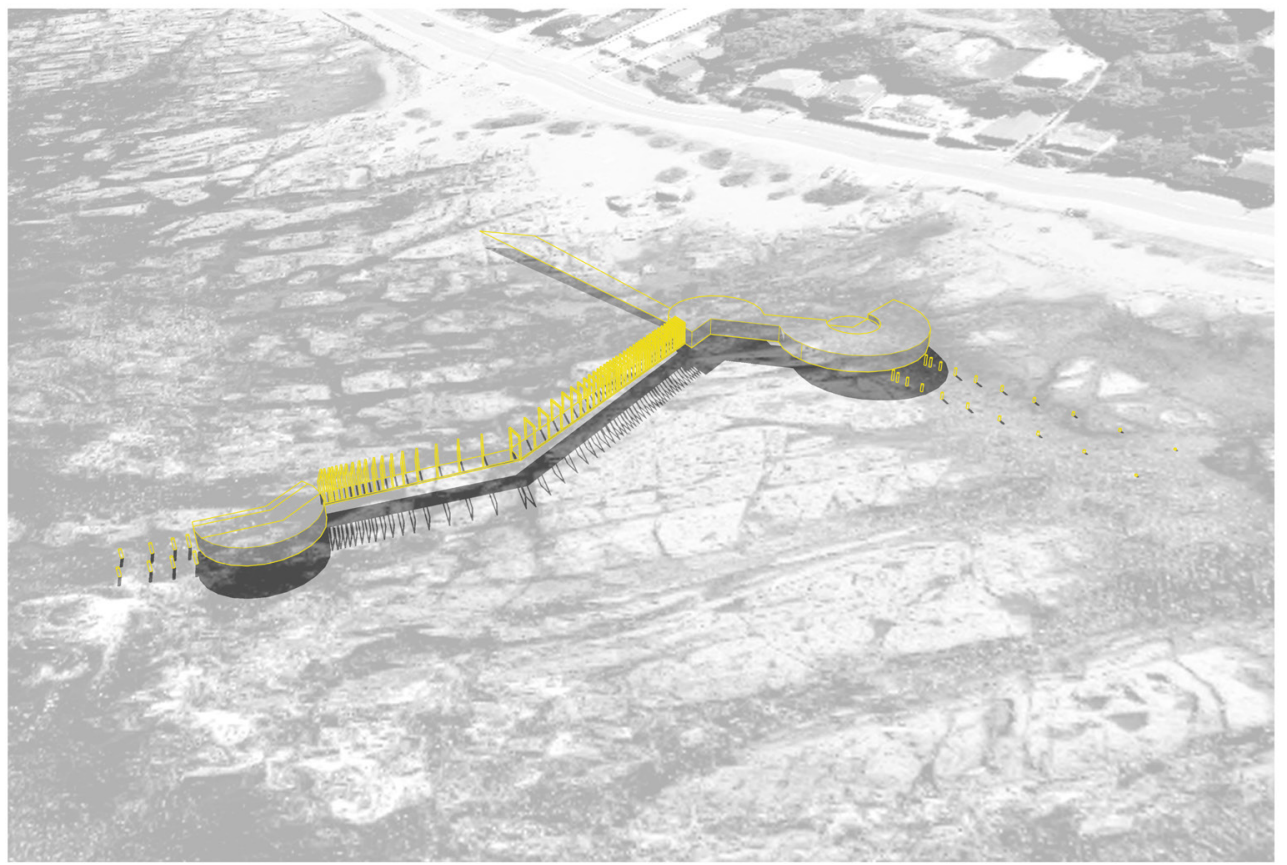

Fig 6.43. First design iteration perspective 


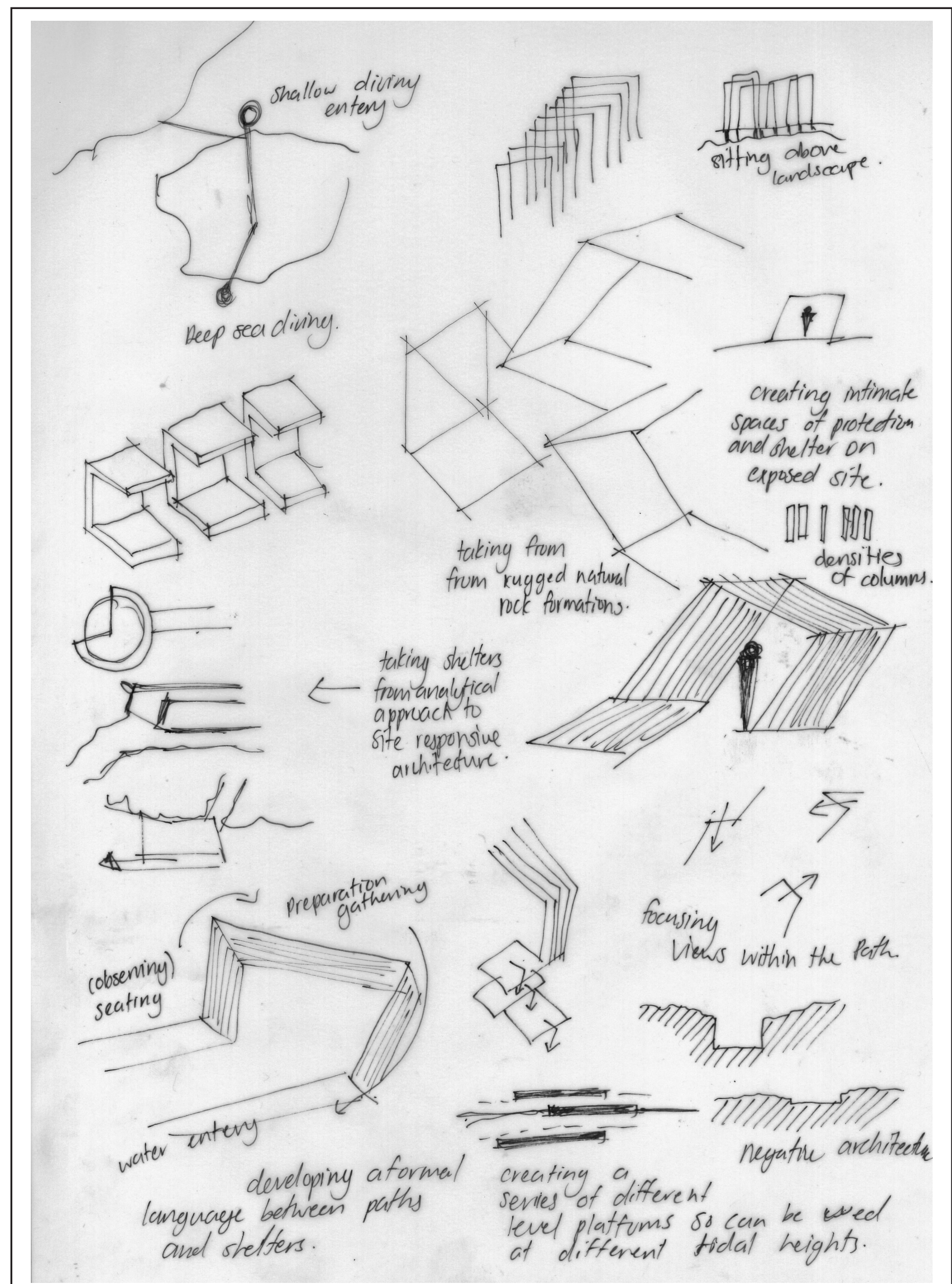




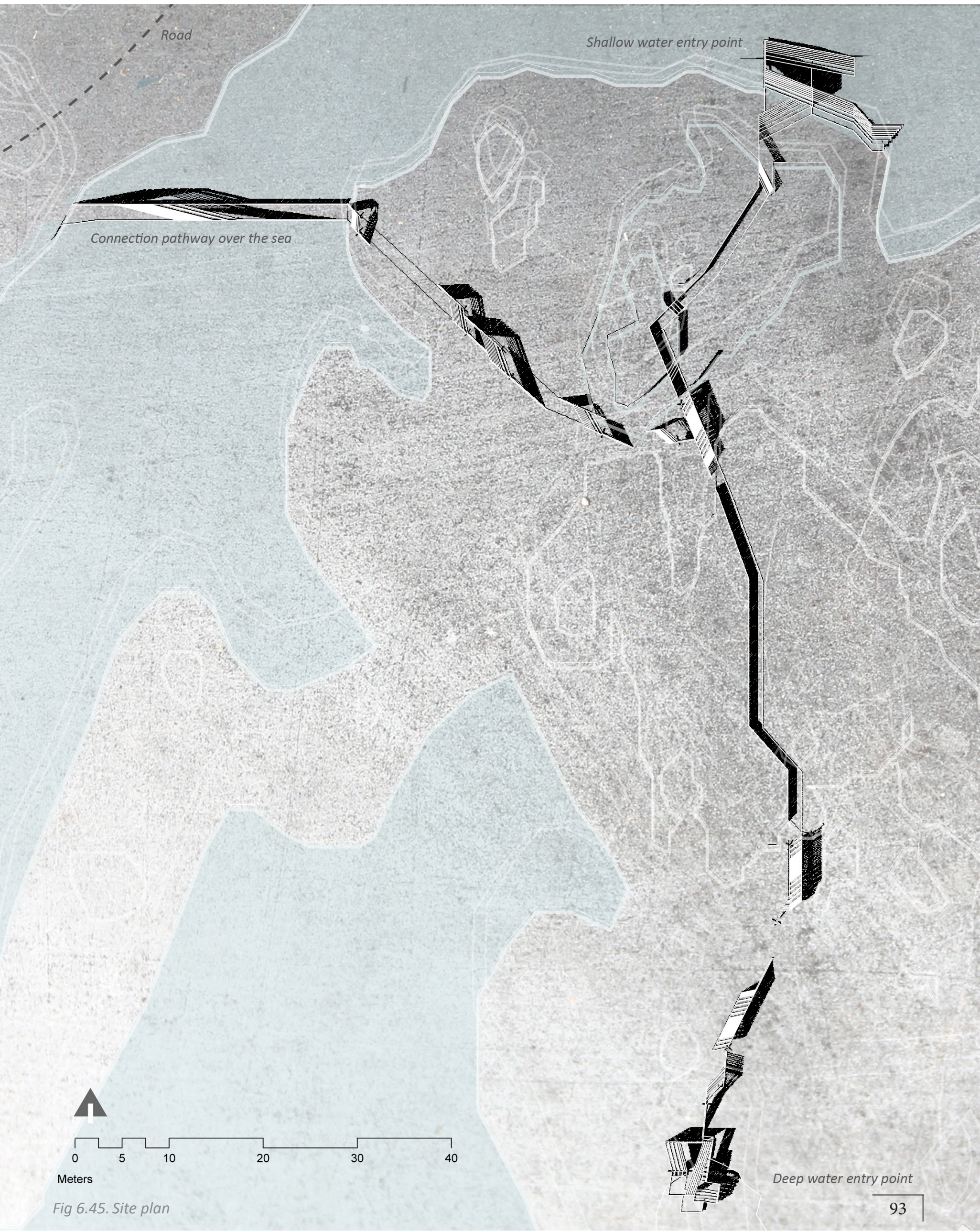




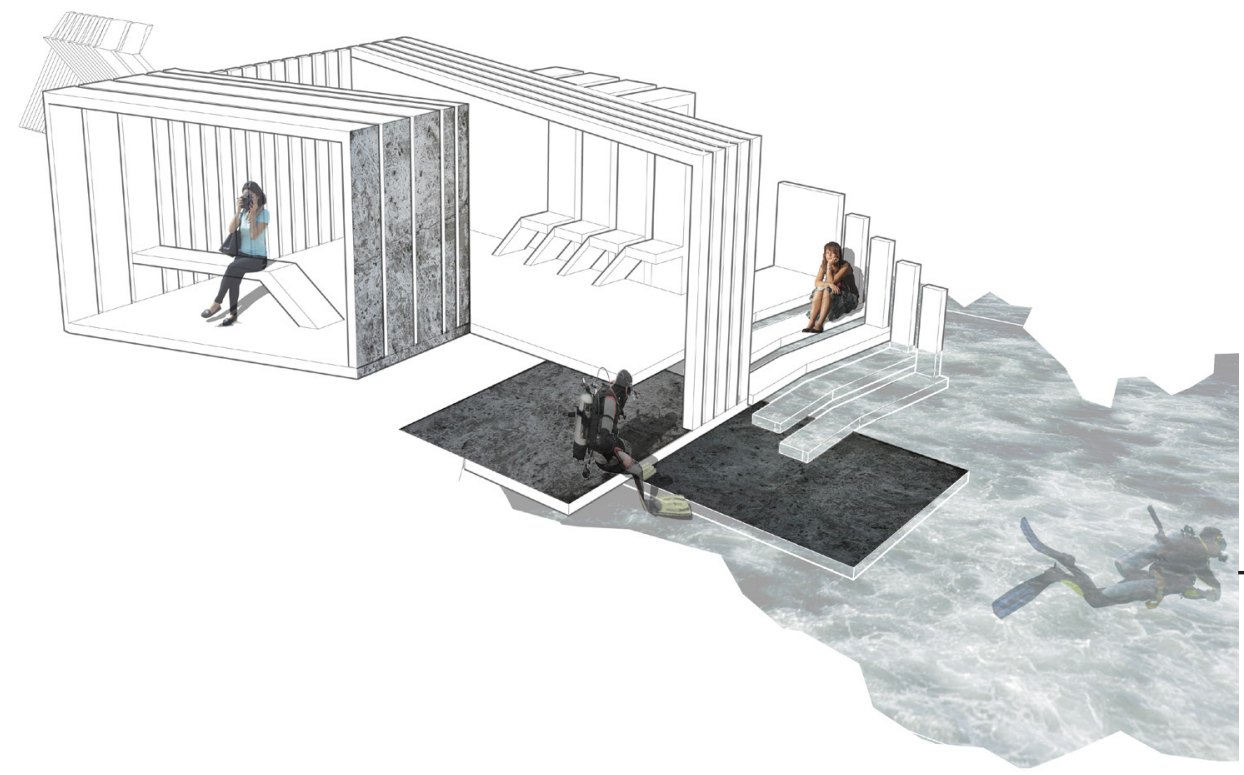

Fig 6.46. Deep water entry shelter

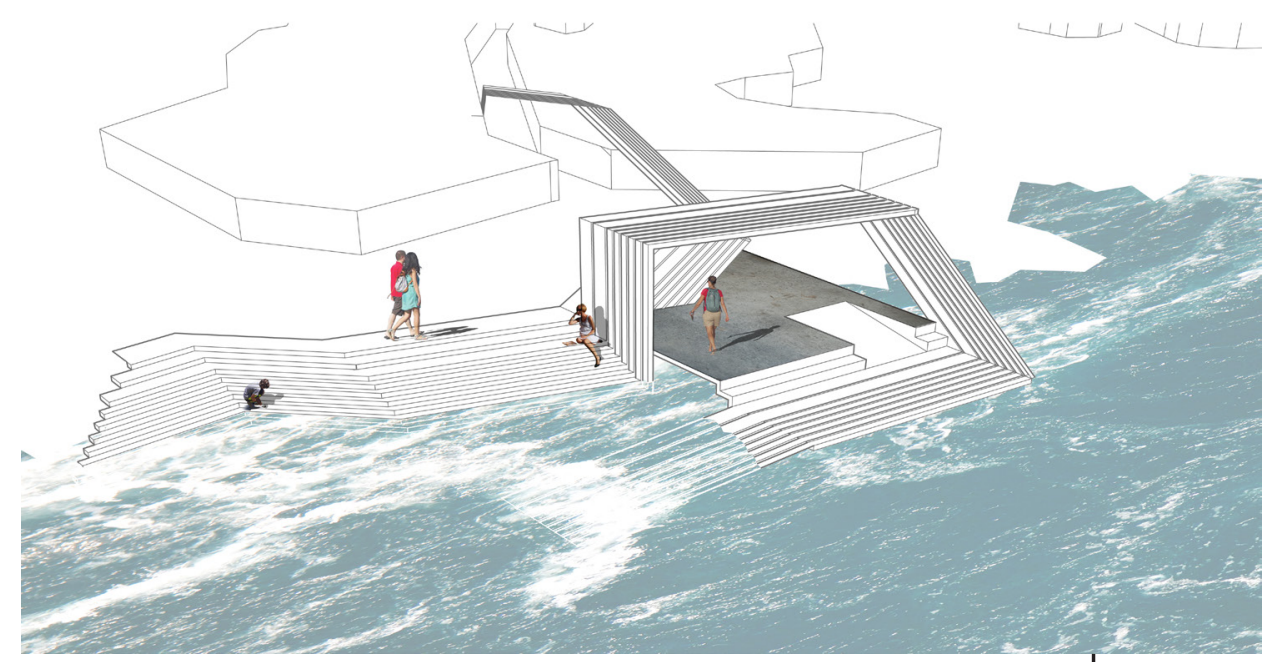

Shallow water entry point

Fig 6.47. Shallow water entry shelter
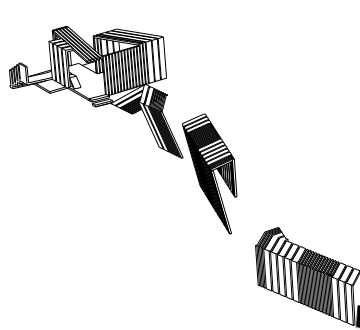
The shelter on the Sirens Rocks explores the experience of the journey taken by the divers. As the diver moves from land to sea they transcend the threshold of weight and weightlessness. The design of the shelter focuses on three key elements, the shallow diving point, the deep-sea diving point and the connection paths.

The entry points are designed to visually indicate to the user the experience from being the observer to the observed. The architecture folds up and around leading the users into the water.

The shallow diving point investigates the observation of the observer (the diver observing under the water). Working with the existing rock formations the platform leads to a shallow and protected small bay, which is a good place for people to learn to dive and snorkel.

The deep-water entry point highlights the movement of the sea threshold. Driven by this movement a series of platforms have been devised for divers to use to enter the water. The differing vertical heights allow for the shelter to be used at varying tidal heights.

Movement channels have been cut into the rocks creating a suggested pathway between the shelters. Through the use of 'negative' architecture, the connection path becomes a journey of density and transparency. This experience has been intensified in the formation and placement of the folding 'positive' architecture. These forms 'pop' up out of the rocks revealing intimate spaces of protection and shelter in an exposed site. The forms frame views of the architecture and surrounding landscape.
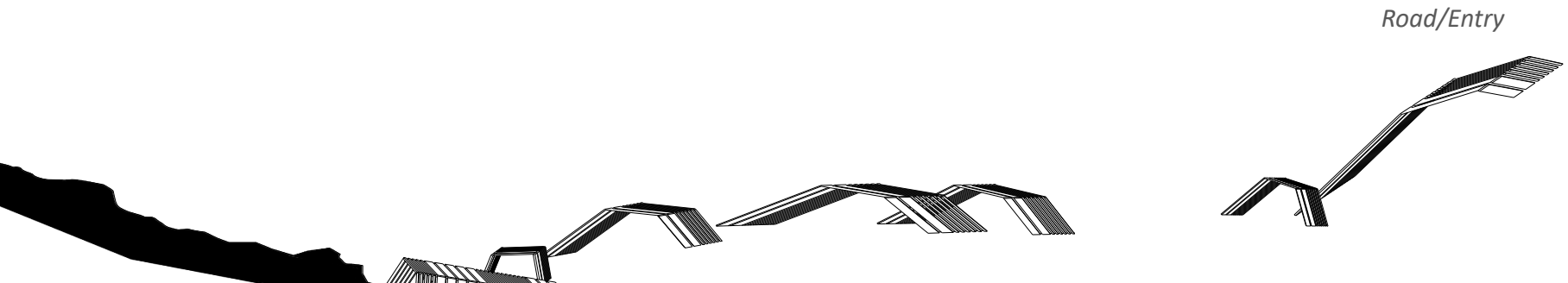

Fig 6.48. Overview of intervention 
Fig 6.49. A collection of perspectives of design features and experiences

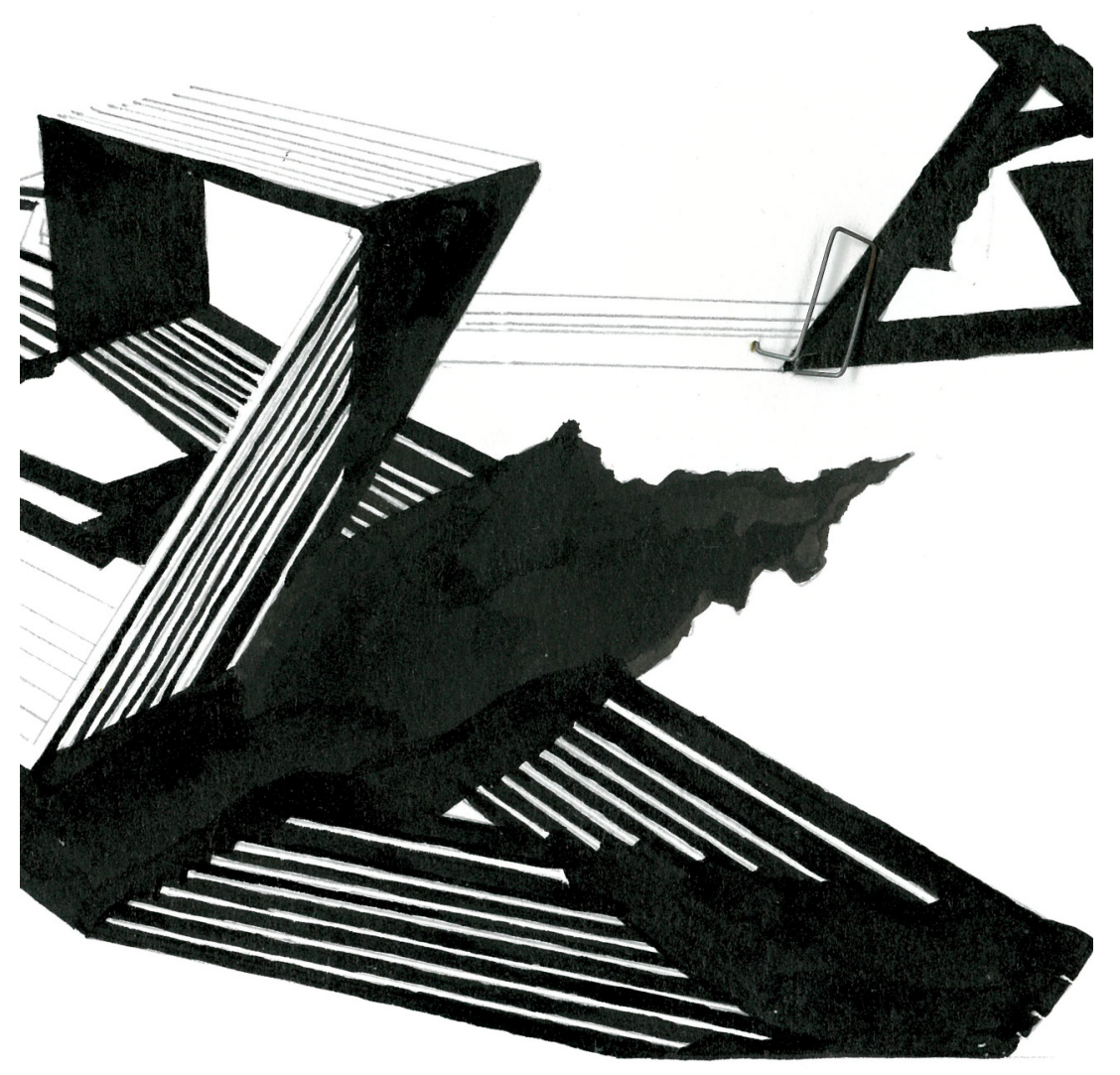

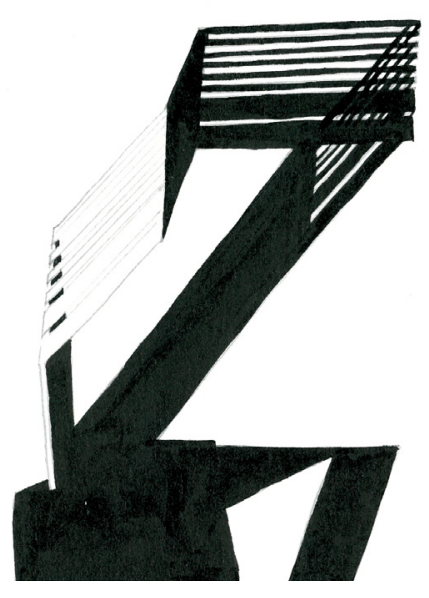
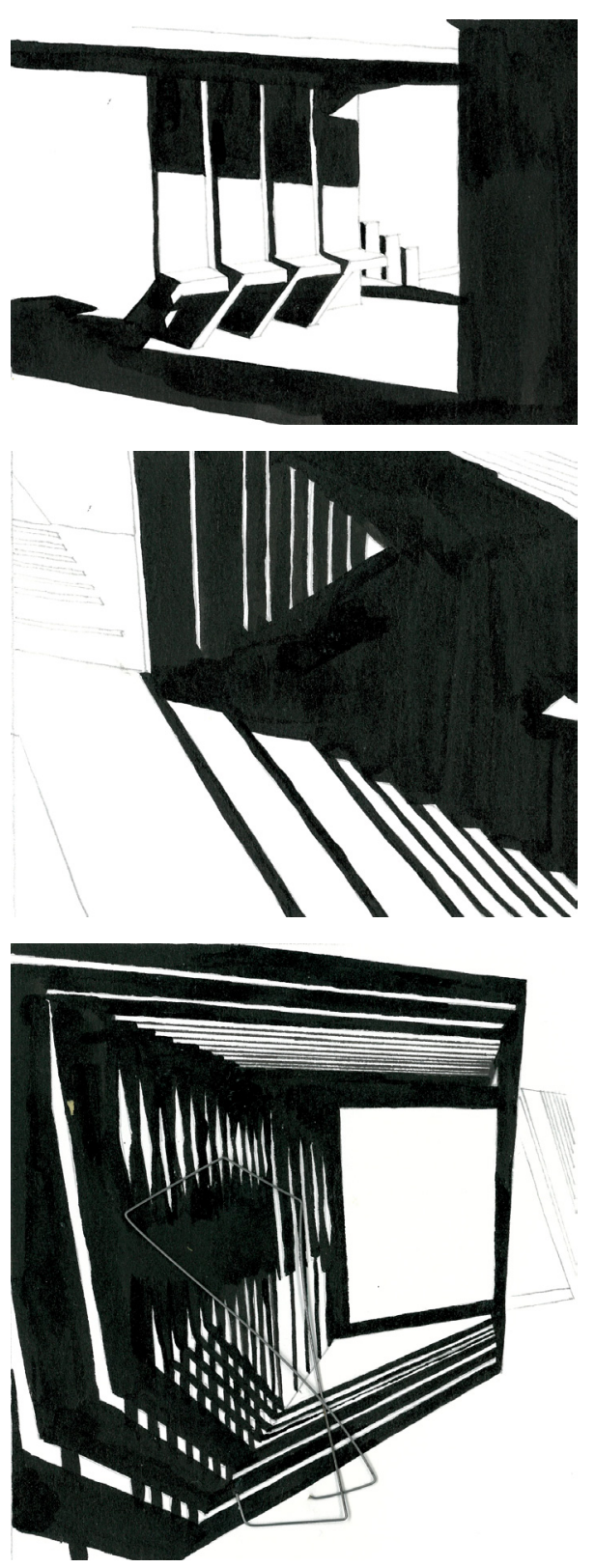


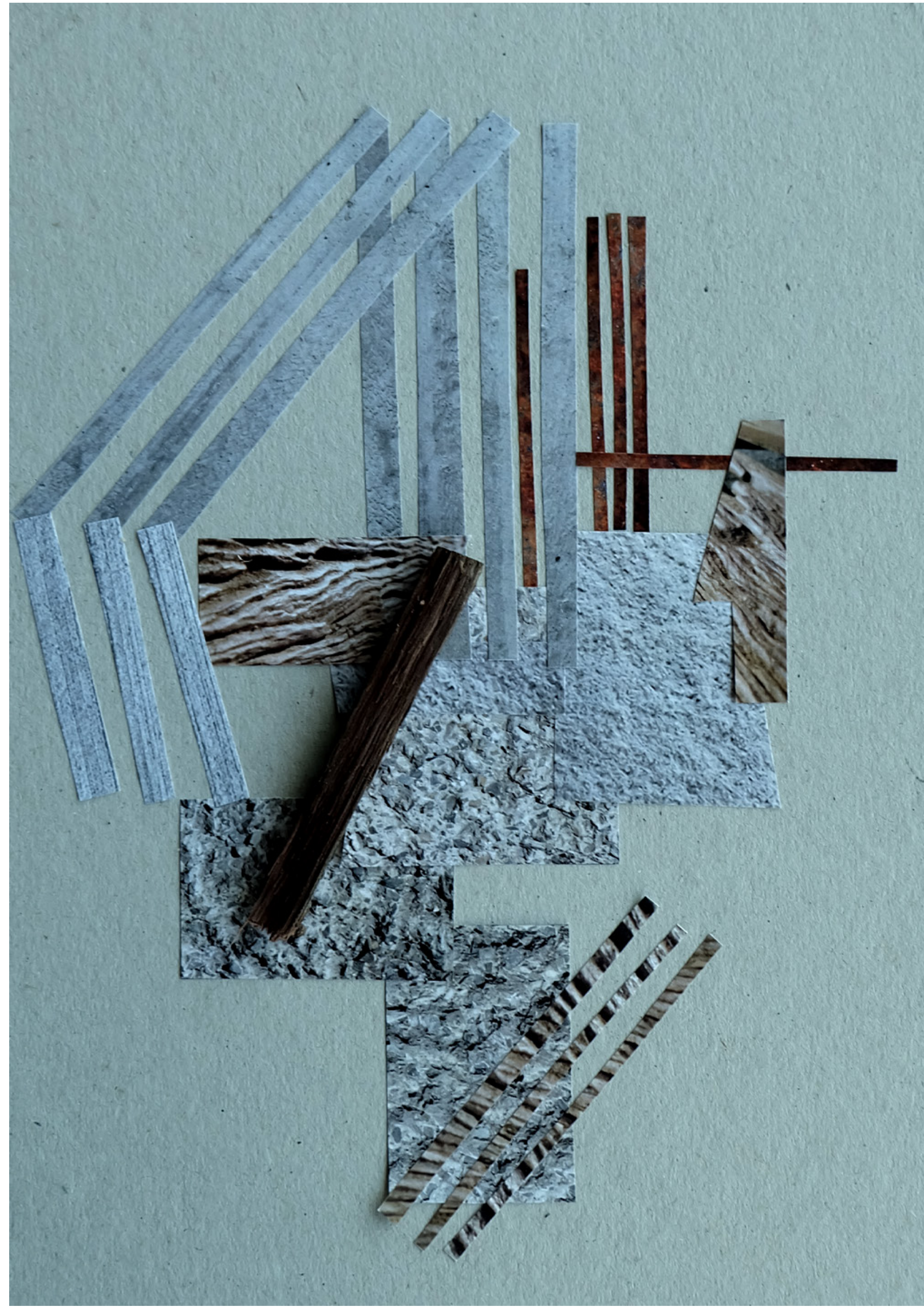




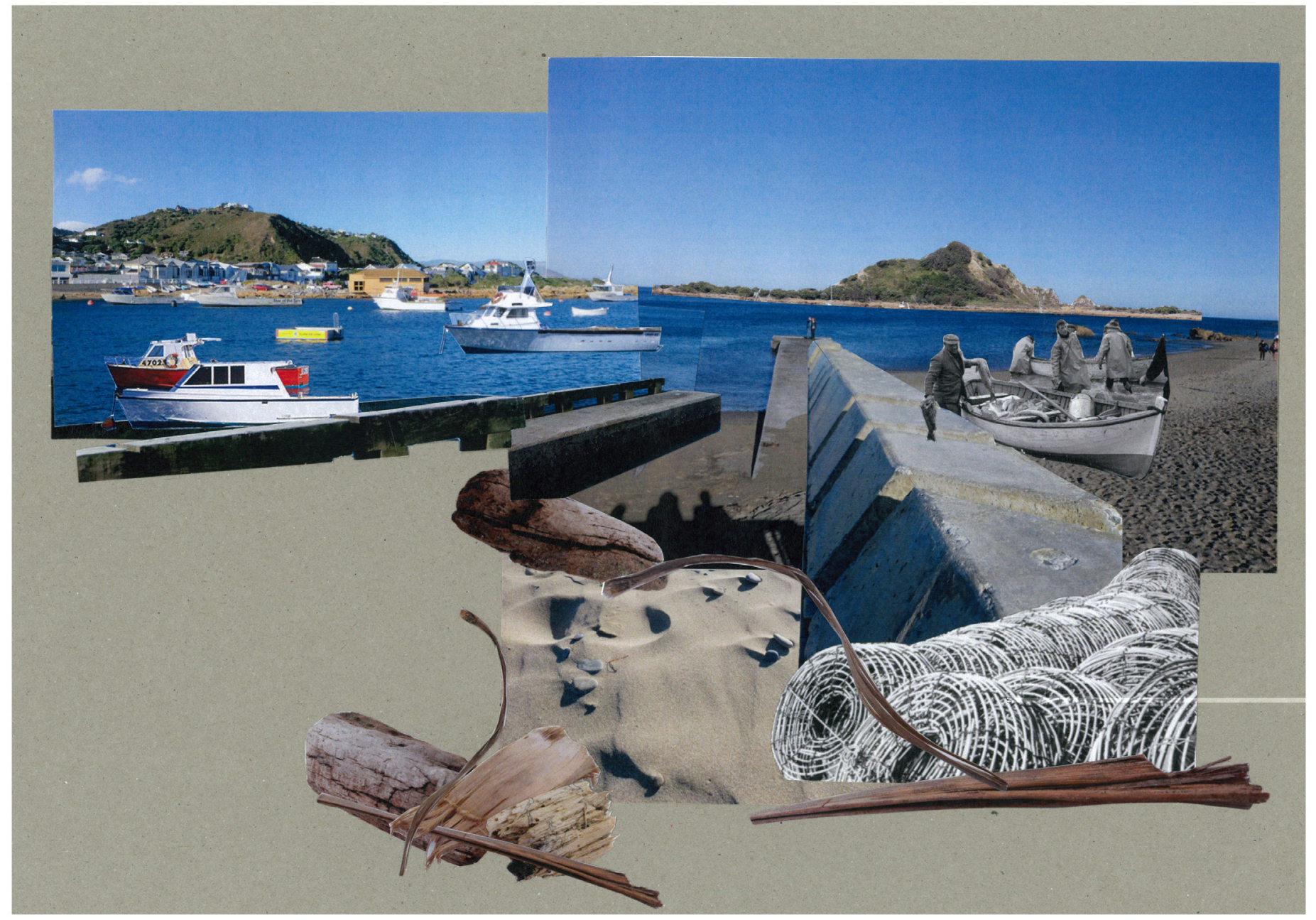

Fig 6.51. Collage of images, textures and fragments specific to Island Bay 


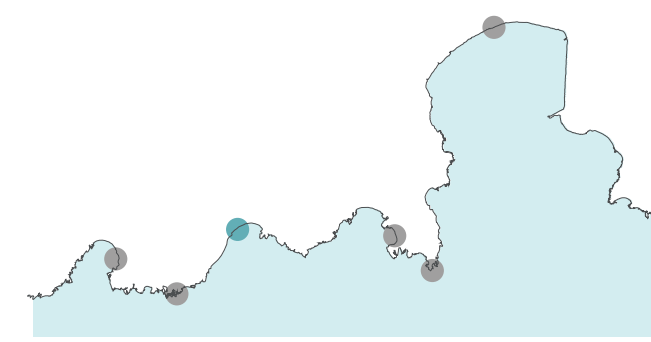

\section{Island Bay}

The beach at Island Bay has long been treasured by the people of Wellington. In a sense it represents protection and safety. It is one of the only places along this stretch of coastline where it is sheltered enough to anchor boats. This has resulted in a large fishing community becoming established here. Another distinguishing feature of Island Bay is Tapu Te Ranga Island in the middle of the bay. This was also a place of refuge and protection used by local Maori and is considered to have 'considerable heritage values as a traditional refuge' (Council).

This site is one of the calmest sites due to its sheltered outlook. The sandy beach stretches seamlessly out into the water where there is little distinction between water and land. Visitors to the site are lead through the remains of the original sand dunes to the beach. There is a strong sense of protection and safety at this site highlighted by the outlook of the island and fishing boats anchored peacefully in the bay.

The shelter at Island Bay investigates the notion of protection through material and form. The process of fishing and the materials and boats that are used as vehicles to investigates these ideas.

\section{Brief}

- $\quad$ Design a series of structures that provide places for people to gather

- $\quad$ Explore the notion of cage from the crayfish pots and fishing nets

- $\quad$ Protective shelter from the sun, wind and rain

- Use the narrative of fishing through the selection of materials 


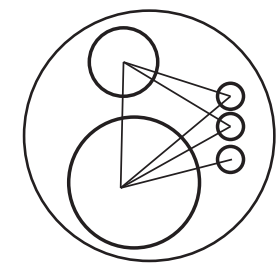

PROGRAM NARRATIVE
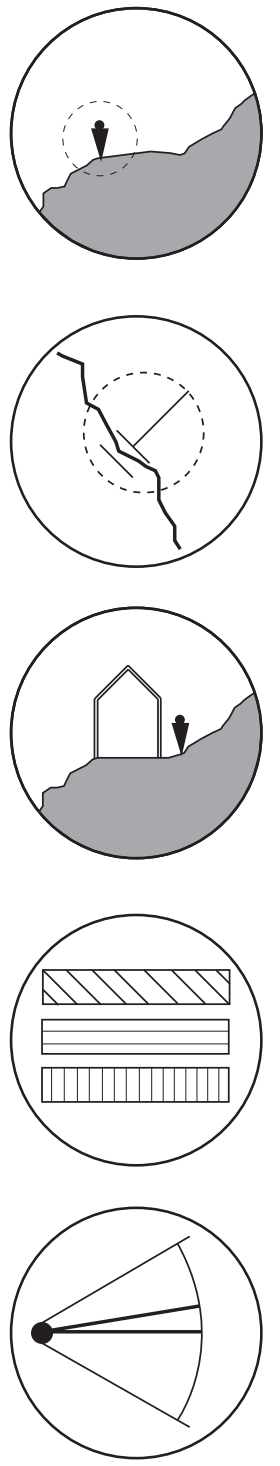

CONTEXTUAL NARRATIVE

LEVEL OF CONTACT WITH

THE THRESHOLD

THE 'THRESHOLD' IS THE POINT AT WHICH LAND TRANSFORMS INTO SEA$$
\text { AT WHICHLANDTRANSFORMS INTOSEA }
$$

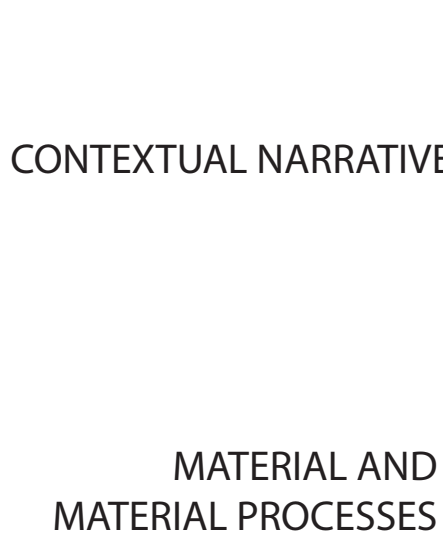

VIEW

FOCUSING THE EYE
Exploring retreat and protection throught the notion and cage and capture
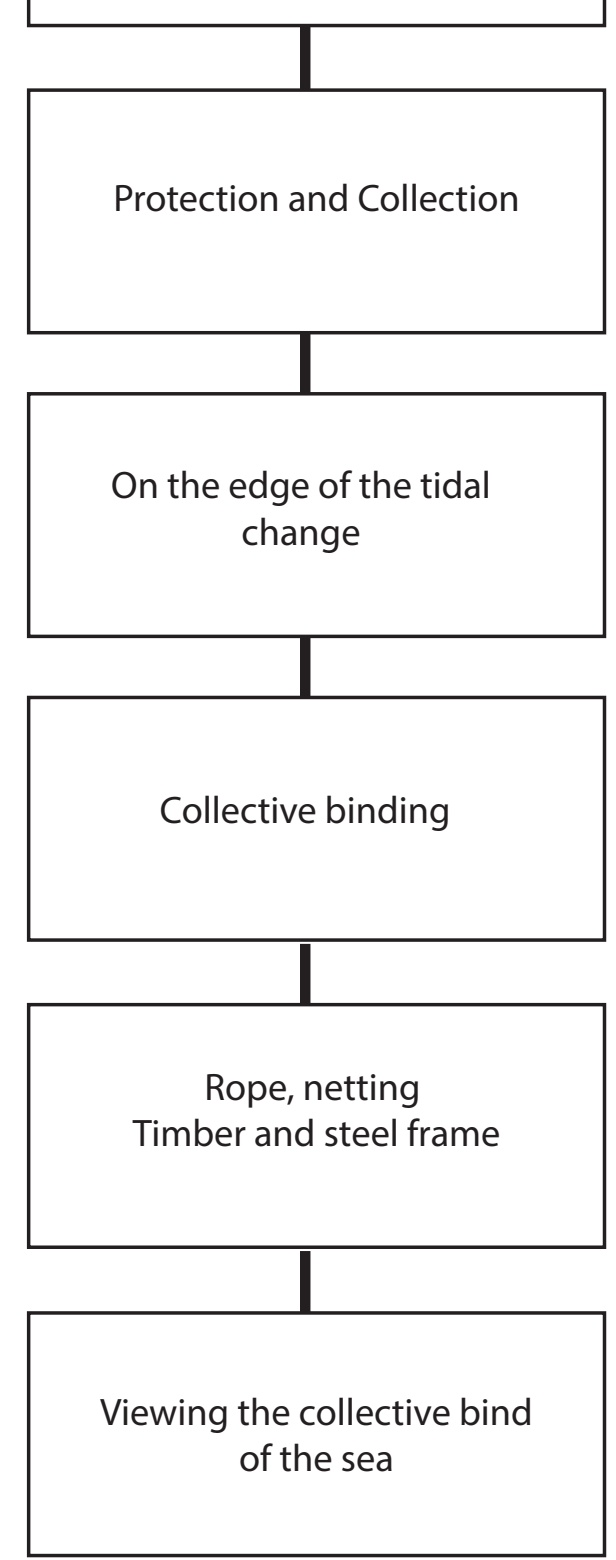


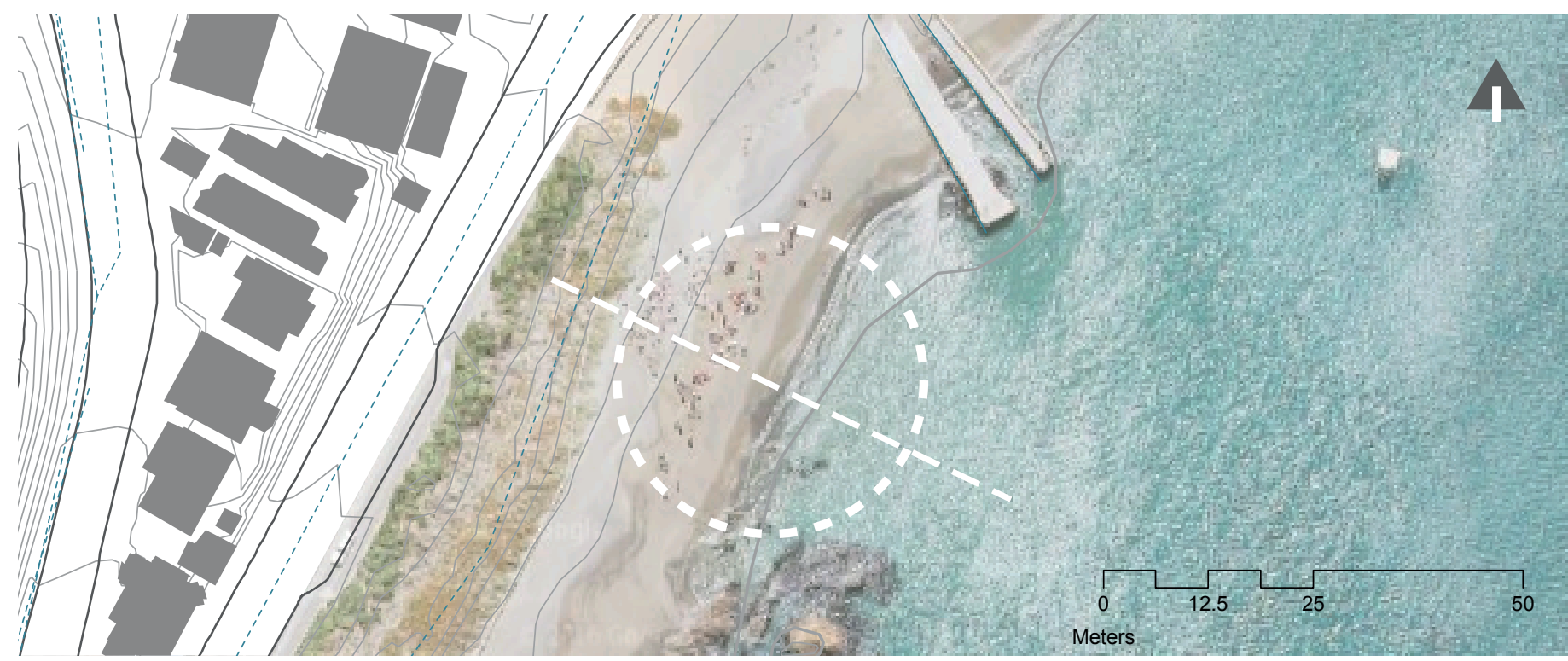

Fig 6.53. Site plan - circle highlights the focus area of the site, the diagonal line represents the intuitive direction and section cut

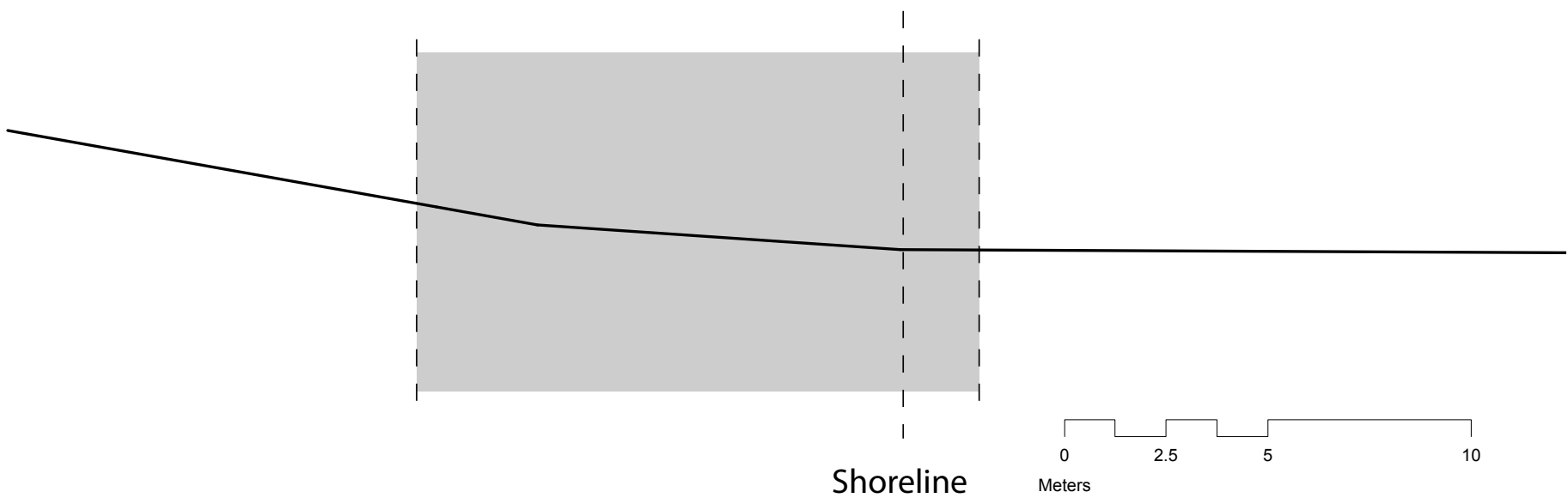

Fig 6.54. Diagrammatic section through site 


\section{Images of site}
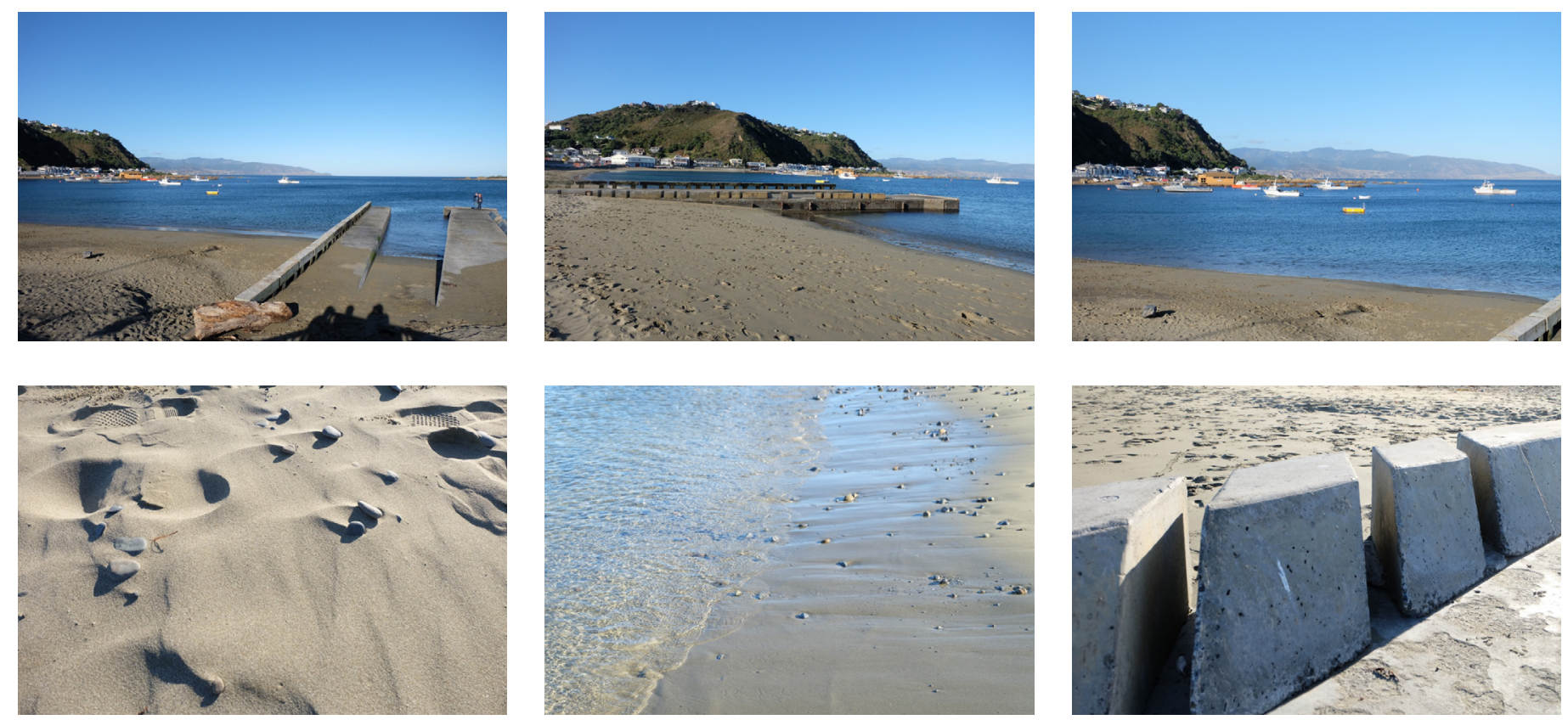

Fig 6.55. Collection of images from Island Bay 

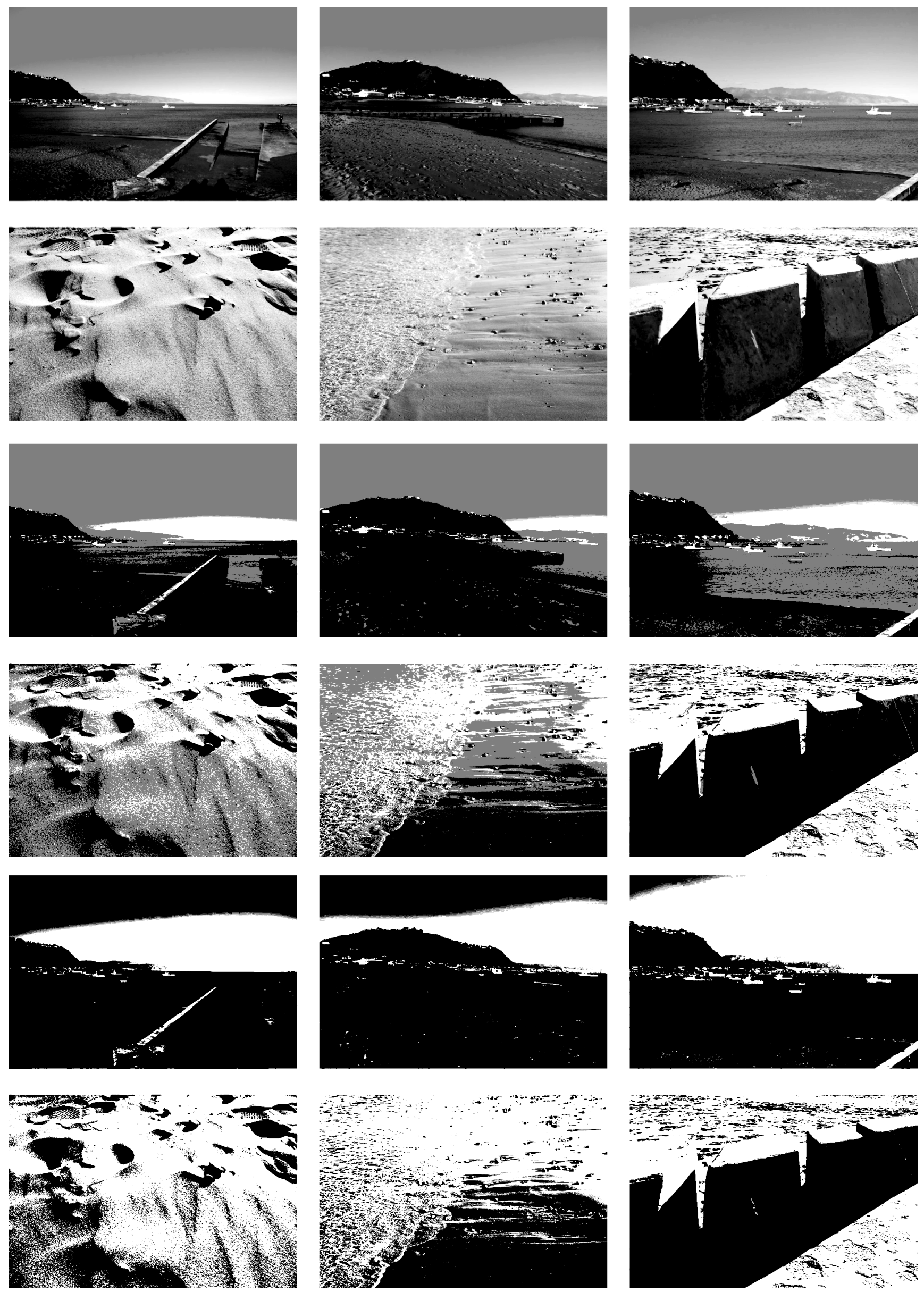

Fig 6.56. Graphic study of textures and views from the site 

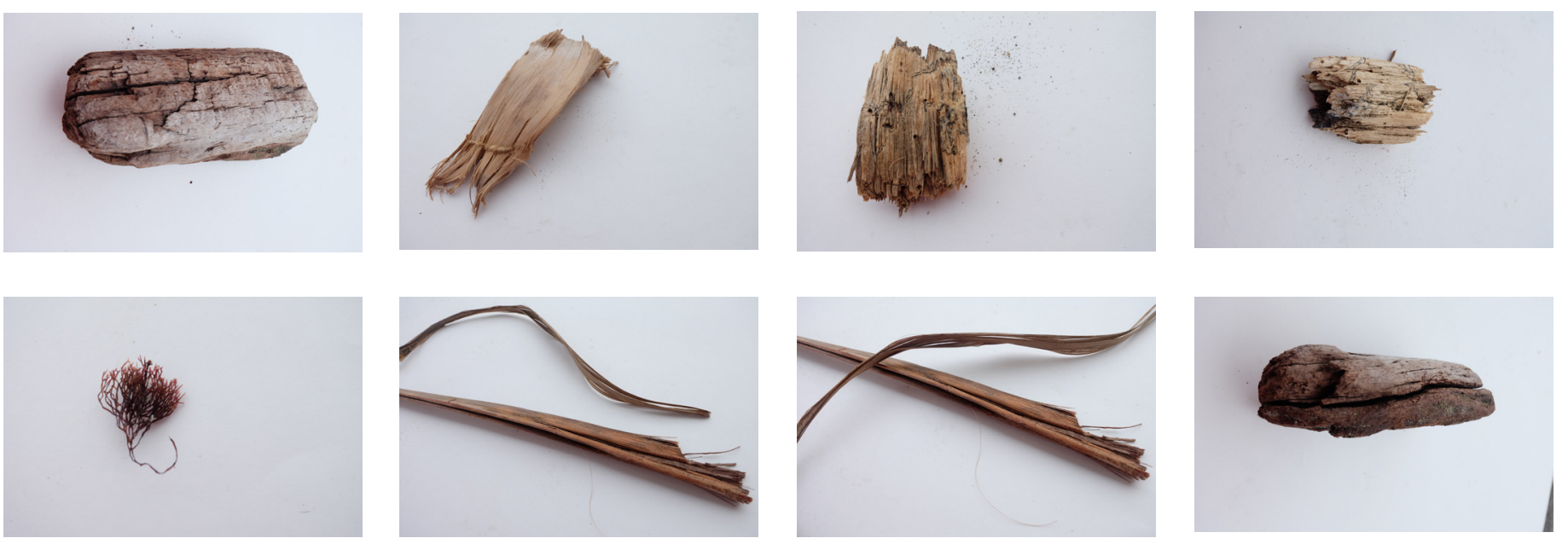

Fig 6.57. Found fragments 

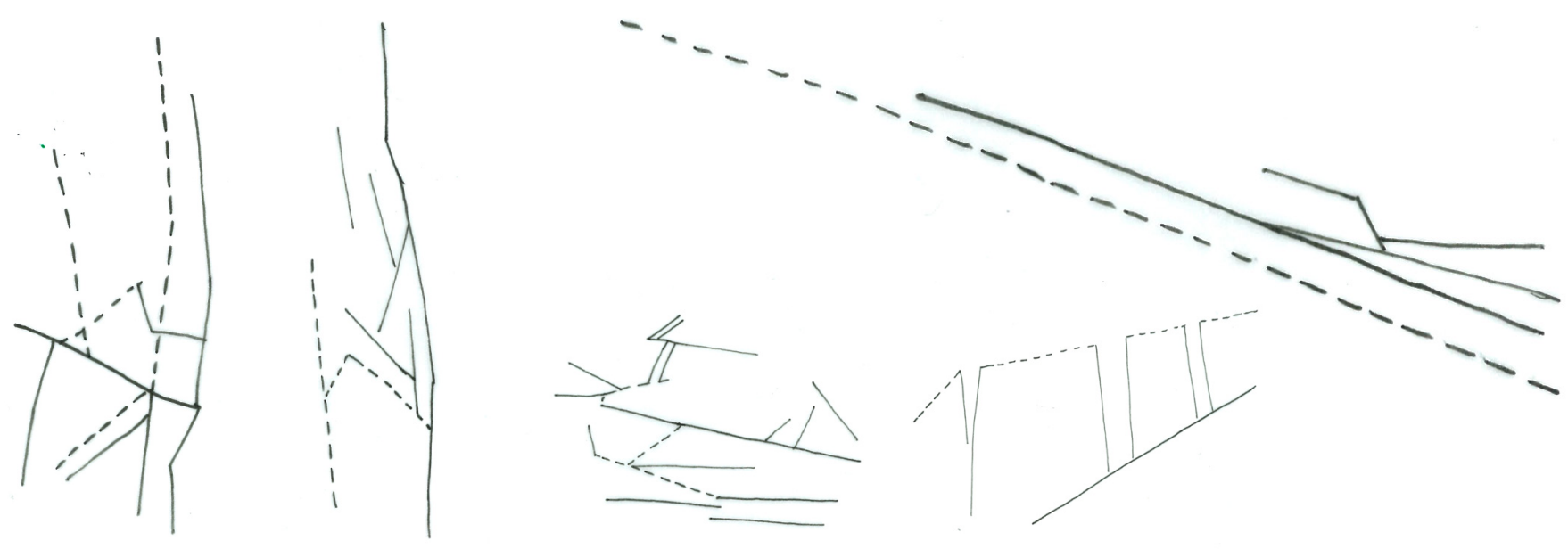

Fig 6.58. Initial form explorations 


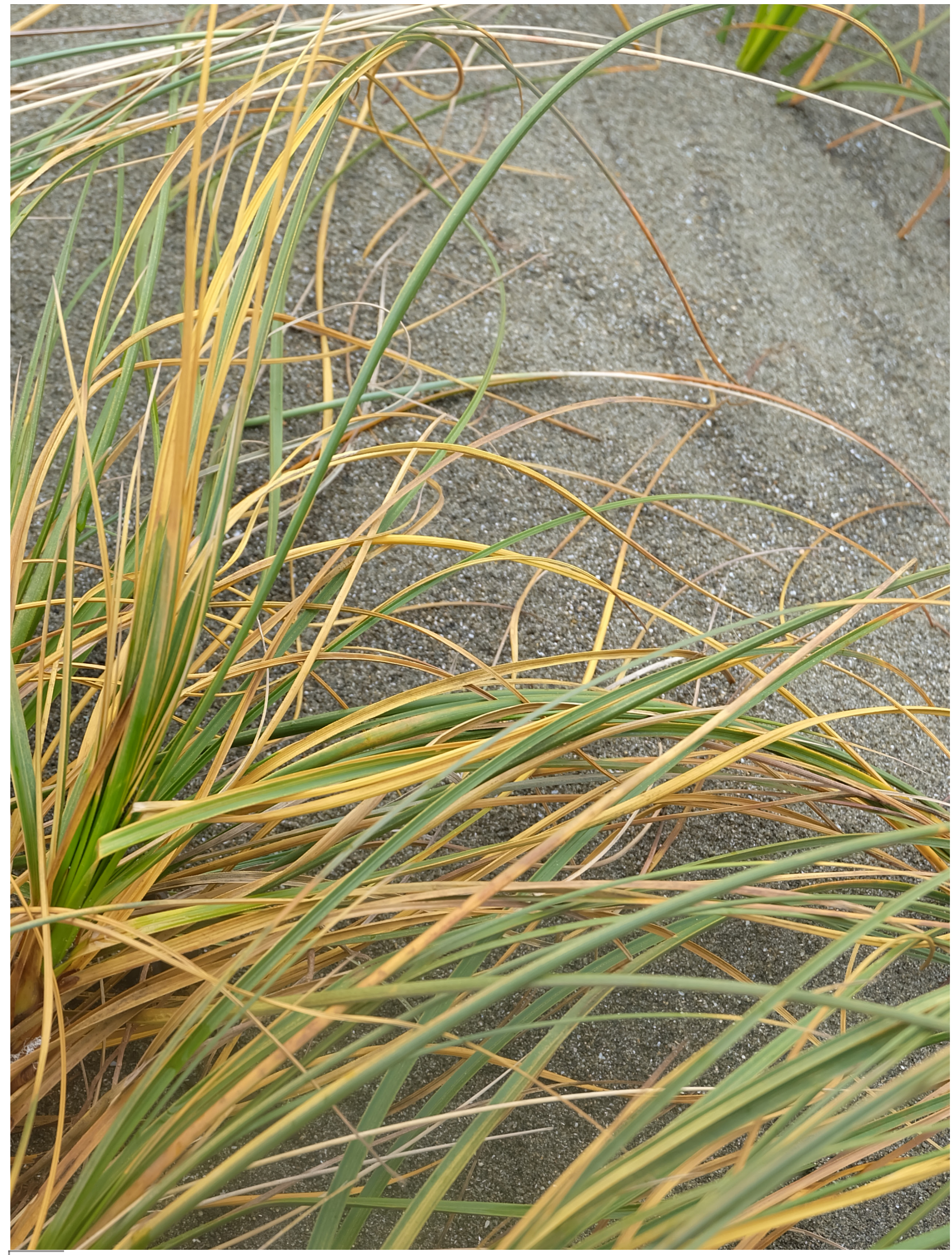




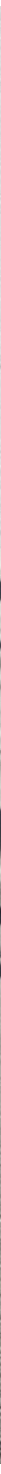

Fig 6.60. Collage of Island Bay design drivers

Fig 6.59. Photograph of site detail (opposite) 


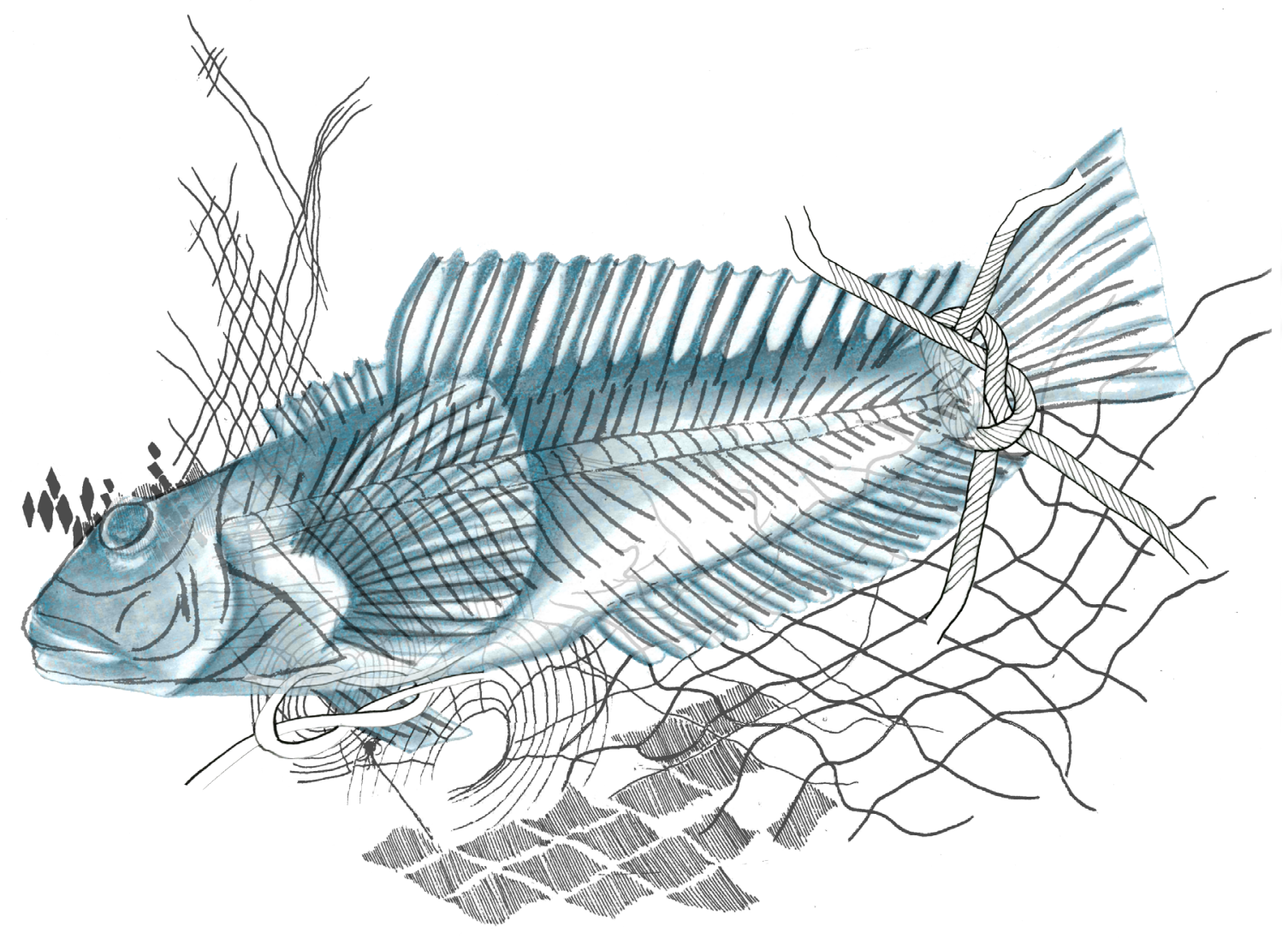

Fig 6.61. Drawing of commonly caught Blue Cod bound by fishing nets and ropes. This image represents the notion of cage and capture taken from the process of catching fish. 


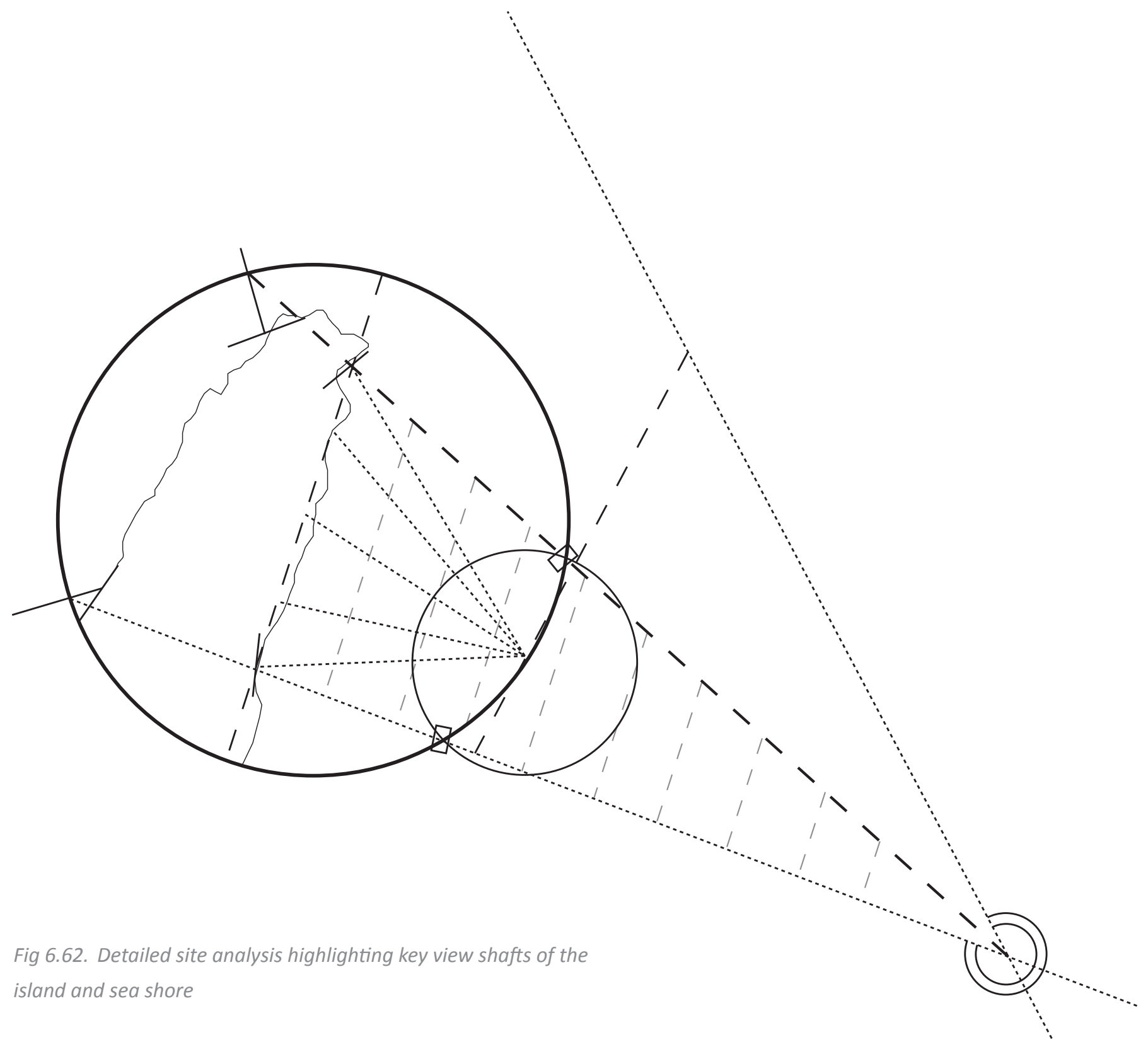

Fig 6.63. Laying the fish on the site revealing key structural relationships between fish and site

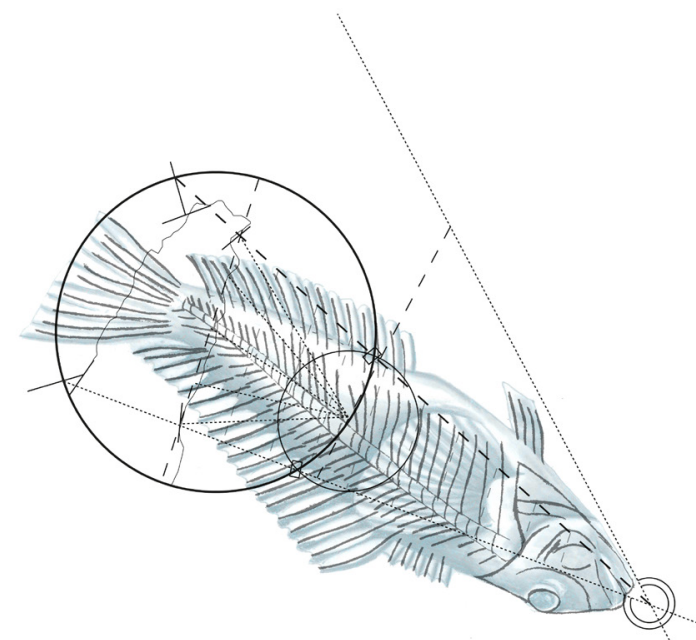



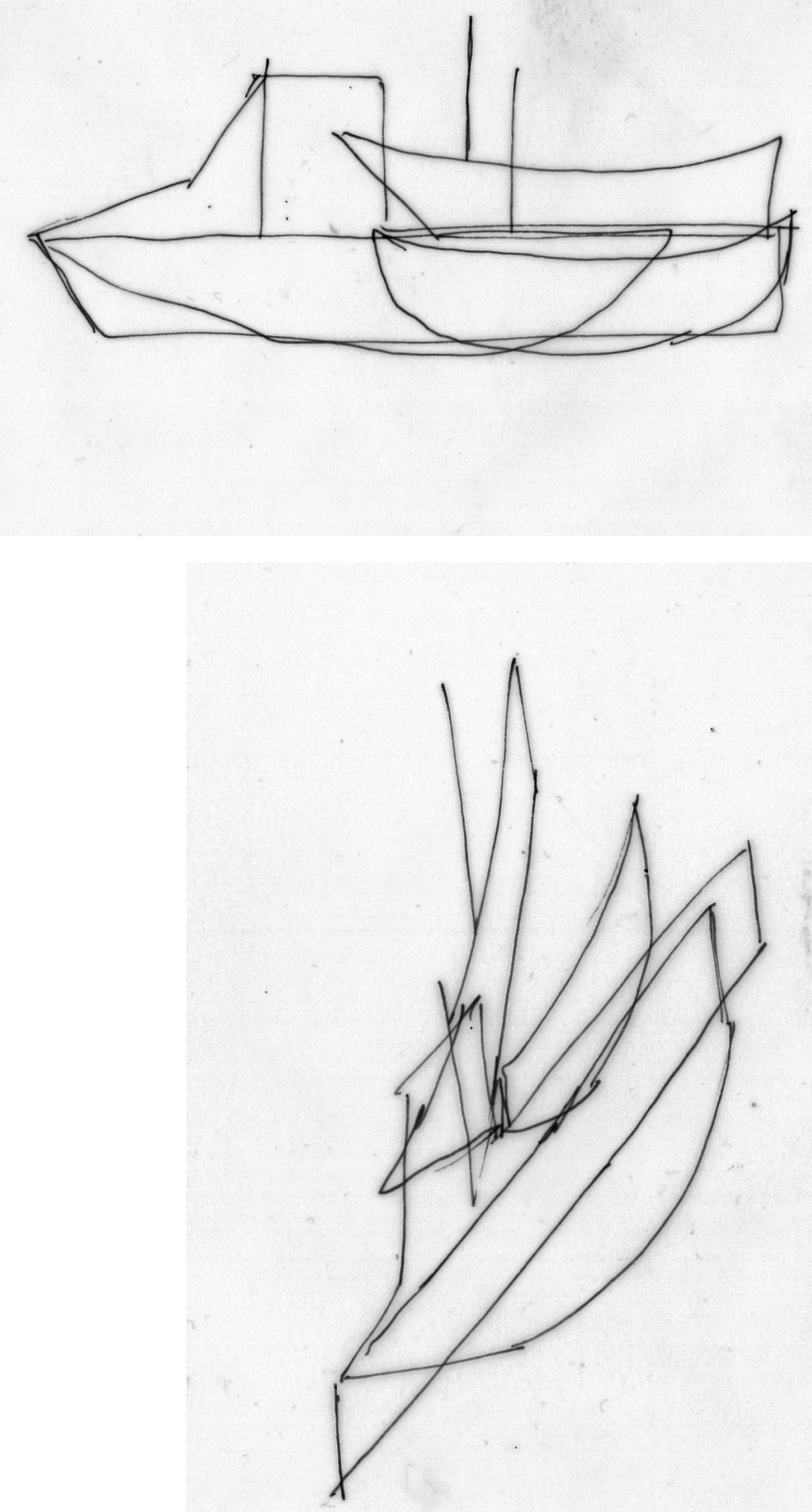

Fig 6.64. Line drawings of fishing boats found anchored in Island Bay. The boat structures create the primary structure of the architecture.
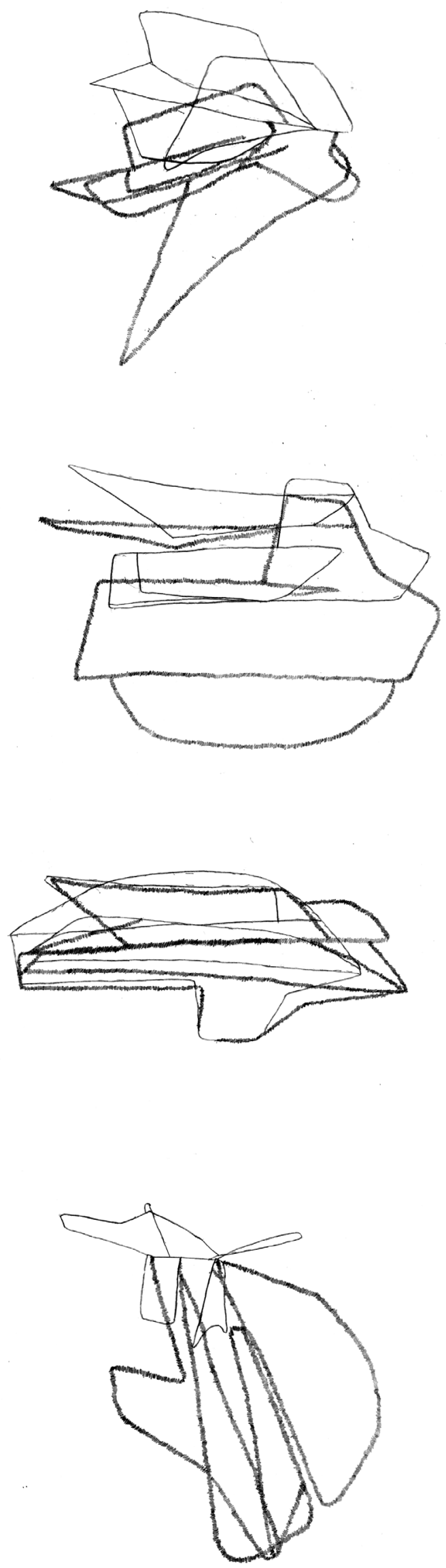

Fig 6.65. Iterations of different configurations of the primary structure 

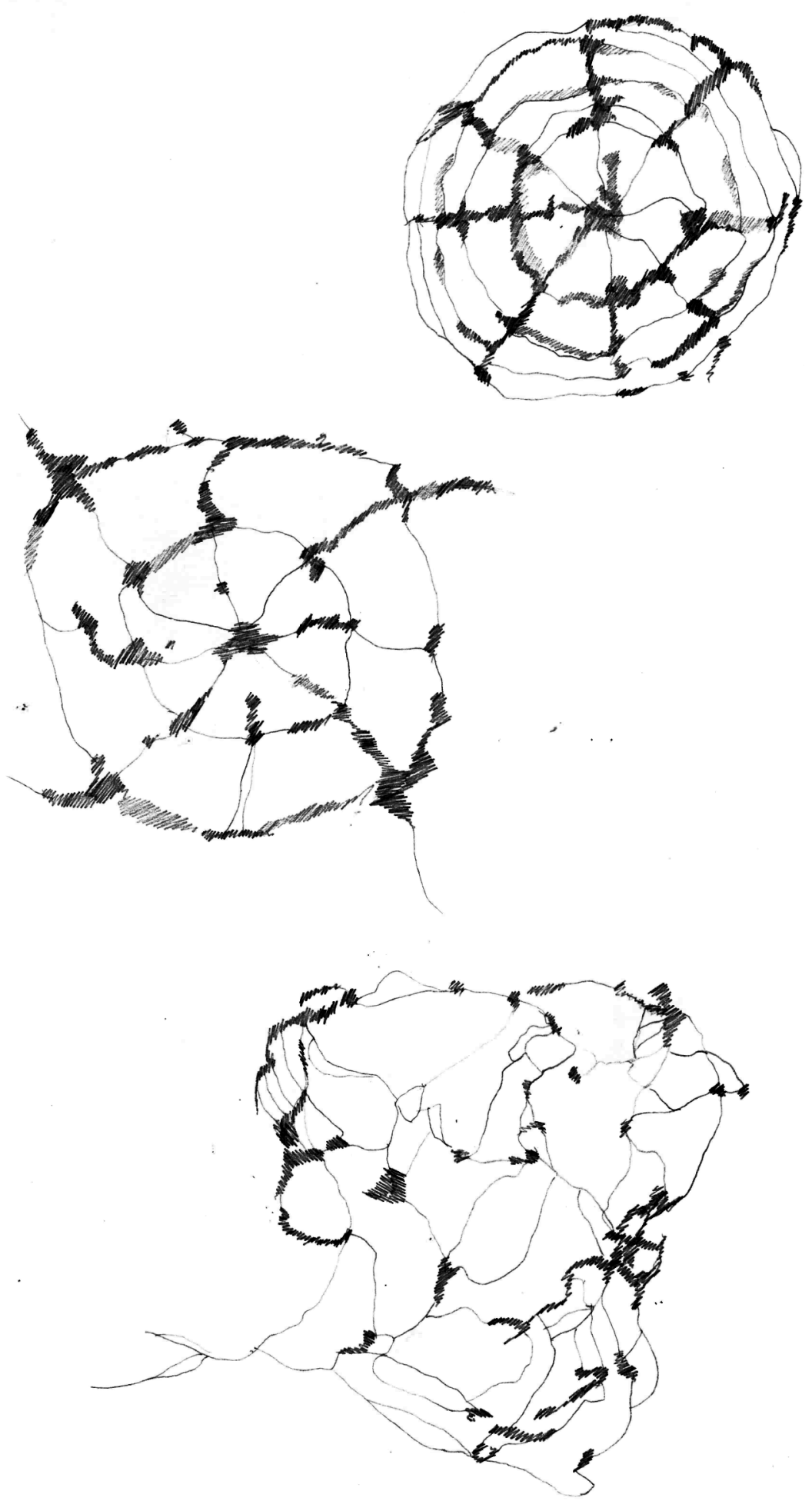

Fig 6.66. Drawing of different net configurations 


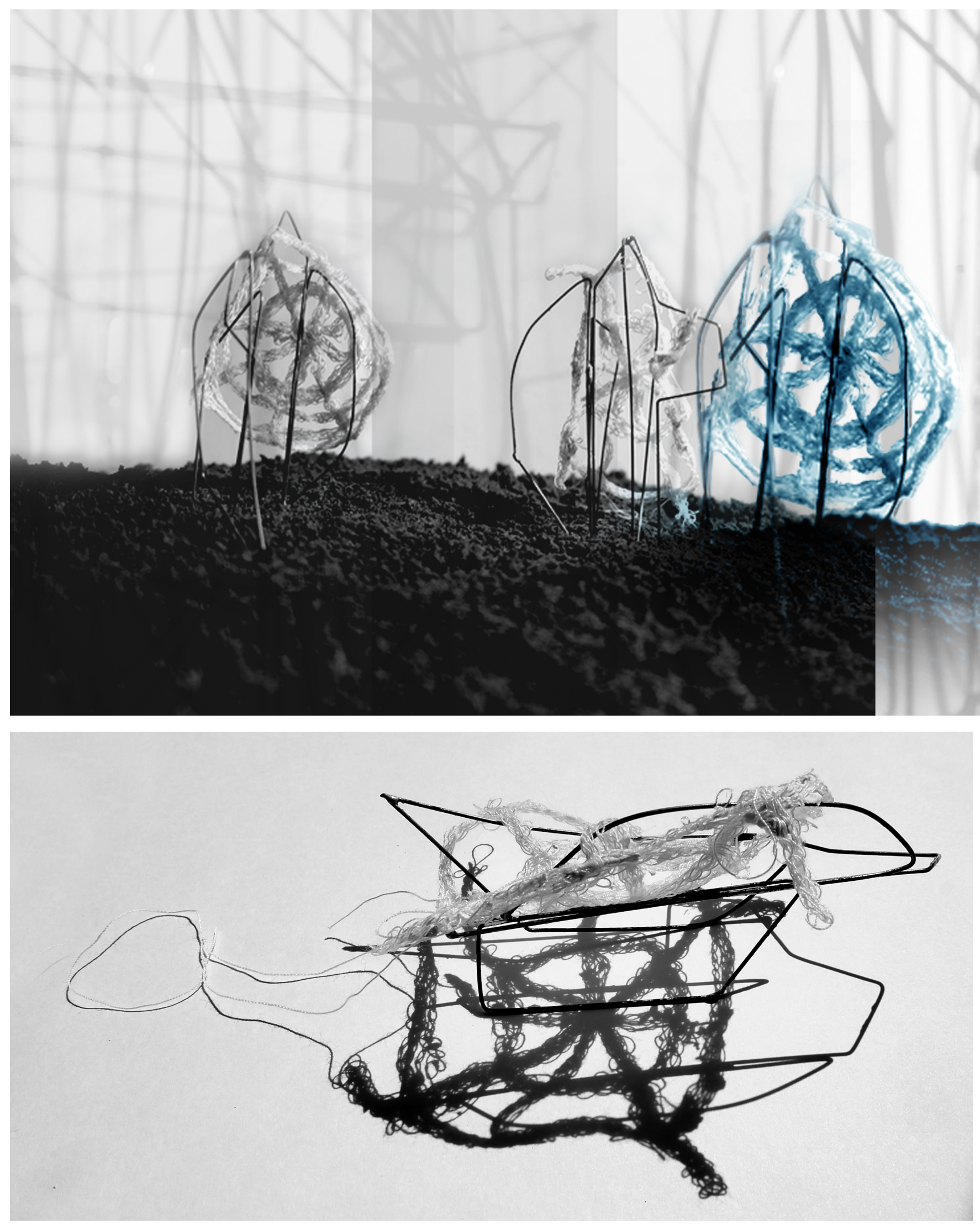




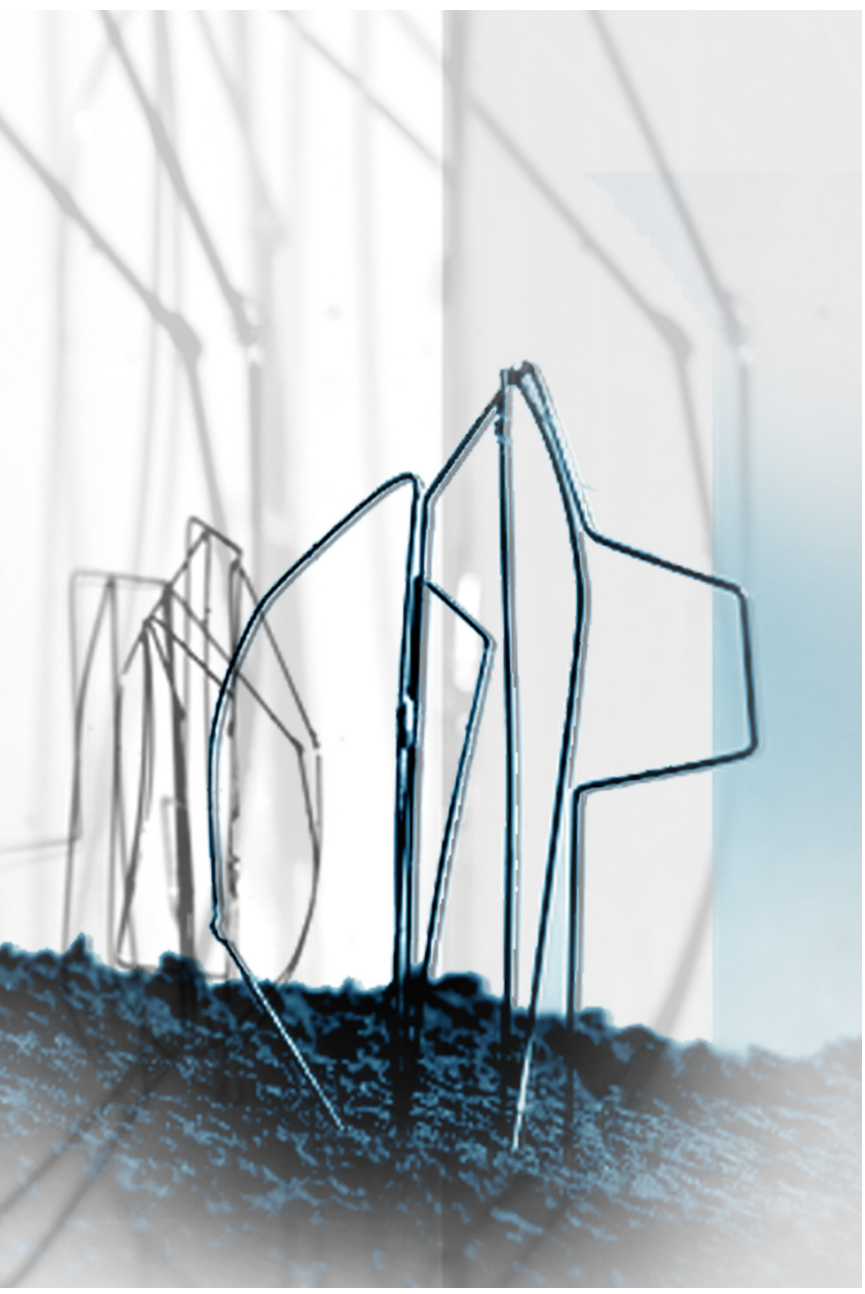

The interventions at Island Bay aim to explore the notion of protection and collection. Each of the designed structures look at creating a framework of architecture that people are attracted to, enhancing their experience of protection. Through layers of primary and secondary skin each of the structures will create a habitable space that encapsulates the users. The secondary skin is a progression from the flax sails used in the Owhiro Bay shelter. Made from nylon rope the skin provides shelter from rain, wind and sun. Contrasting experiences of protection will be created from the densities in the weaving of the skin (dense/ open).

Fig 6.67. Series of models of shelters
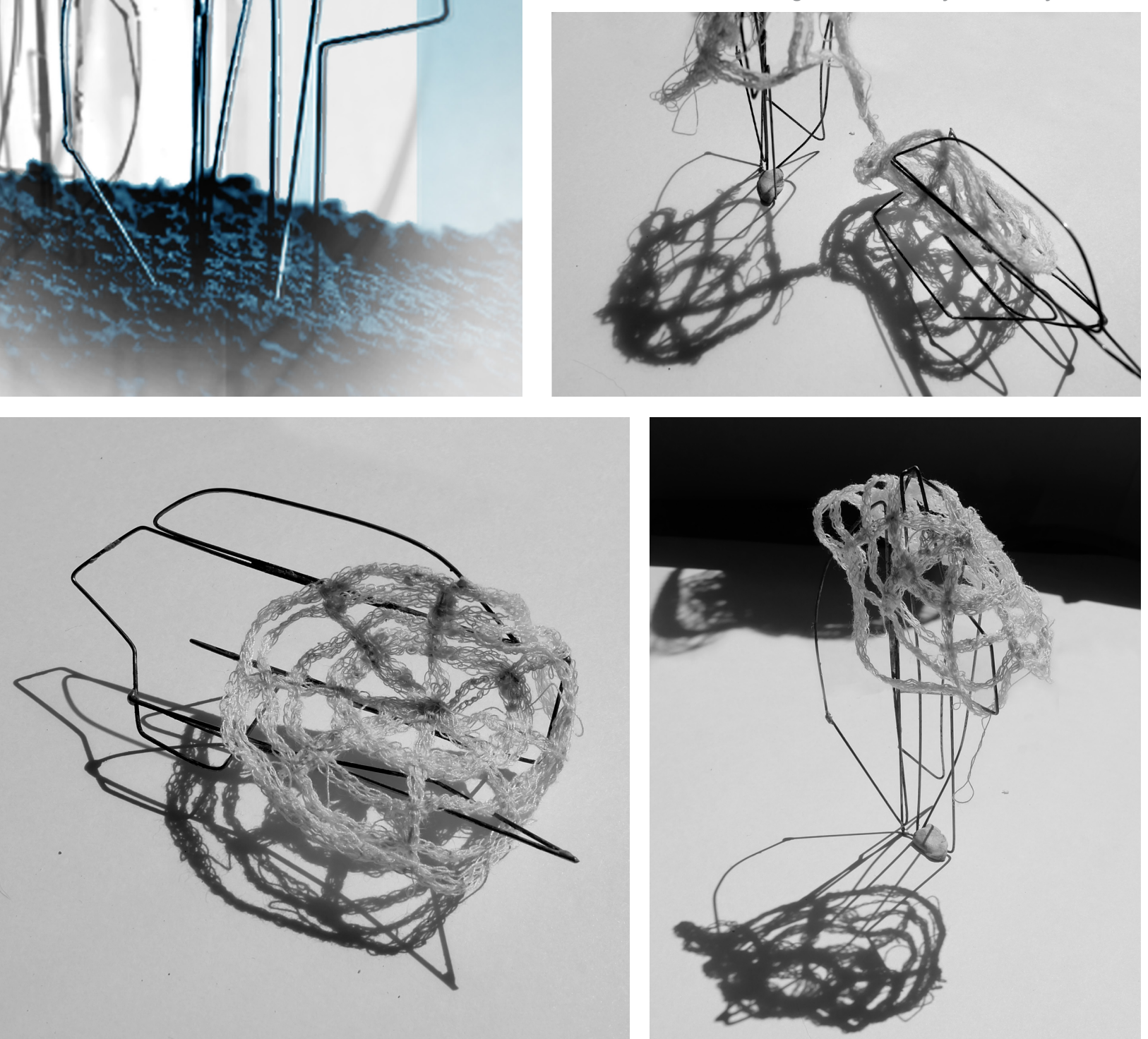


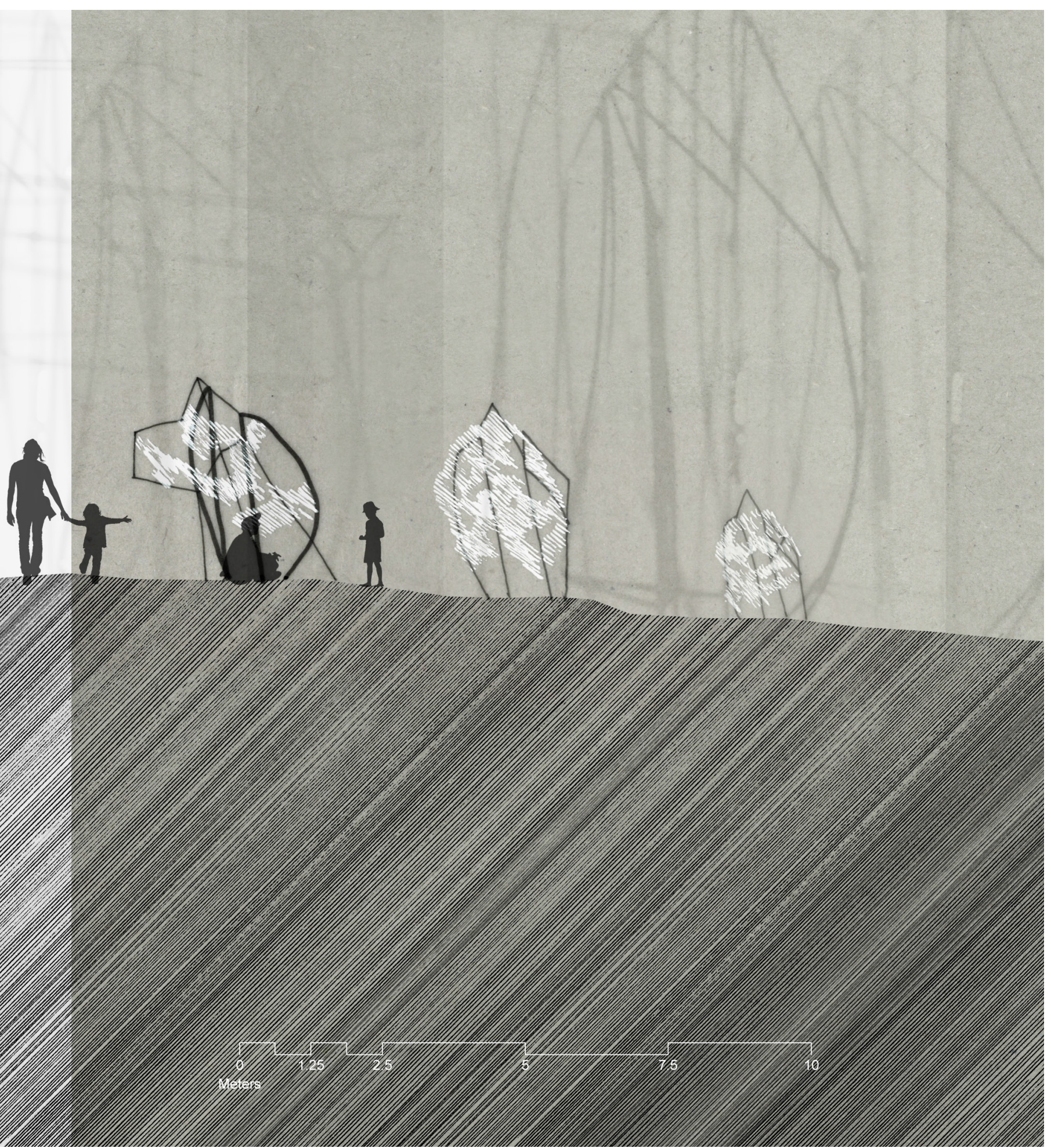

Fig 6.68. Overall section

Fig 6.69. Detailed section of one structure exploring the notion of habitable space that encapsulates the user through a metaphorical cage created by the primary structure and secondary netting skin (opposite) 
A

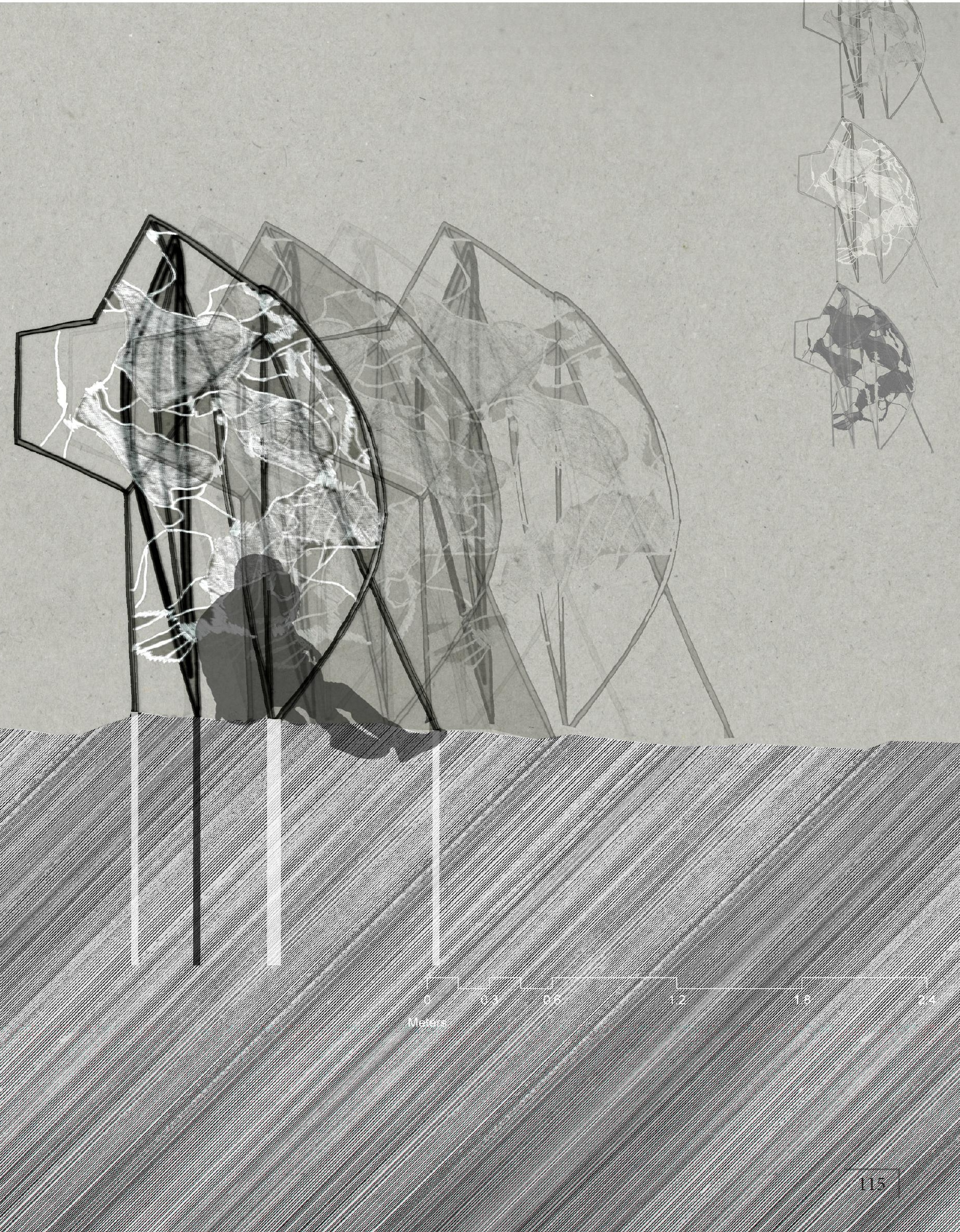




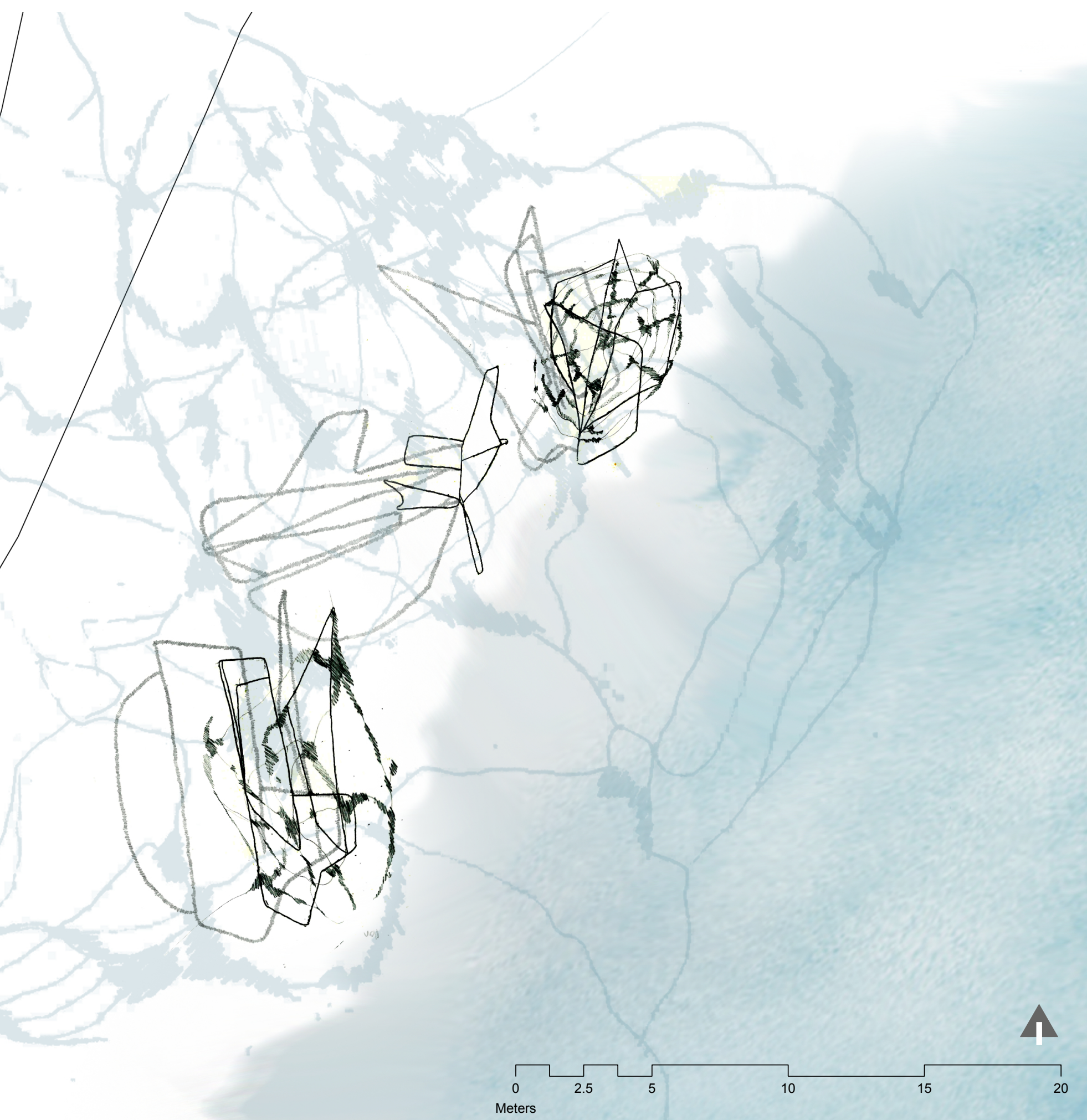

Fig 6.70. Site plan 


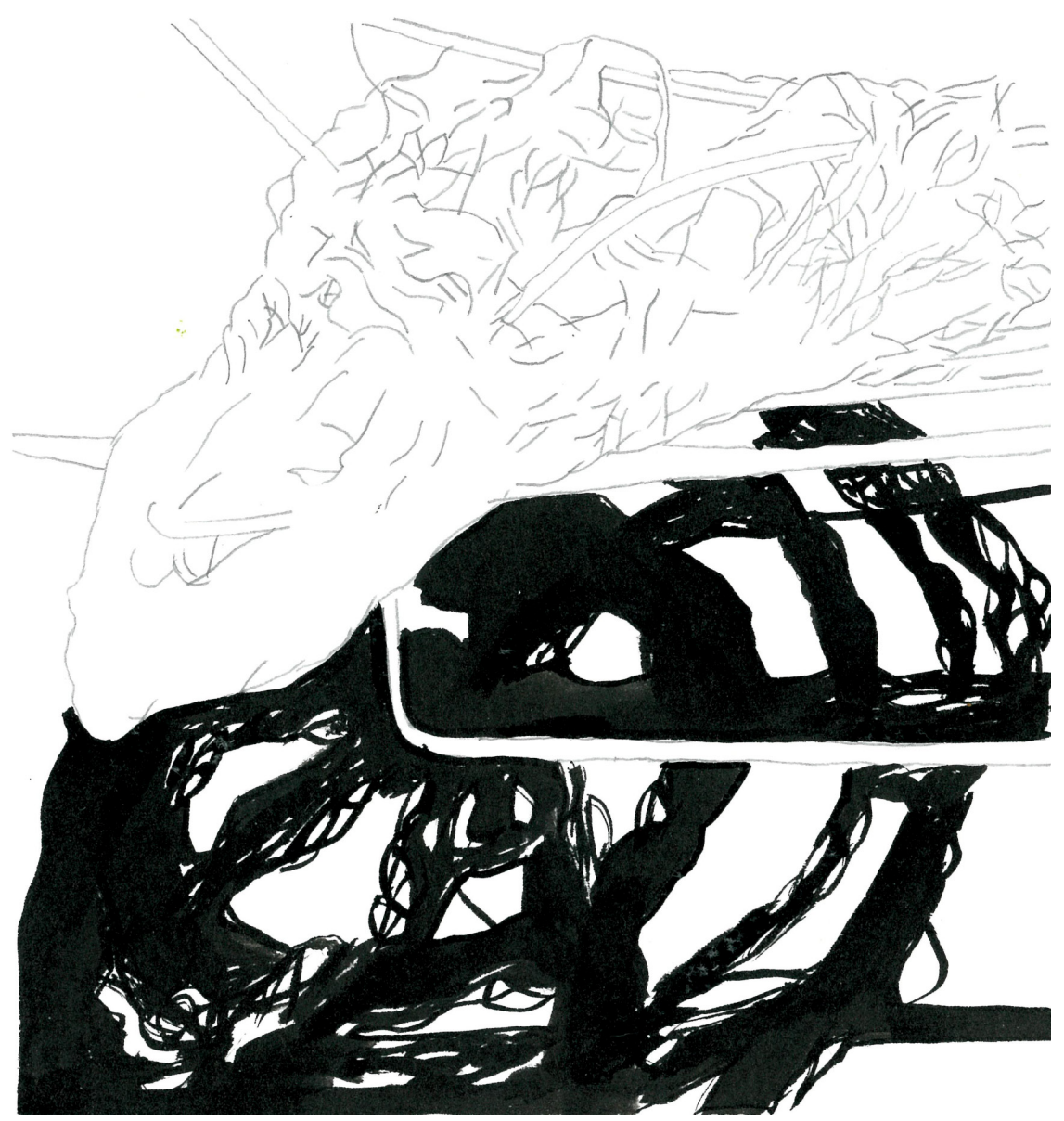

Fig 6.71. A collection of perspectives of the design exploring the relationship between form and shadow
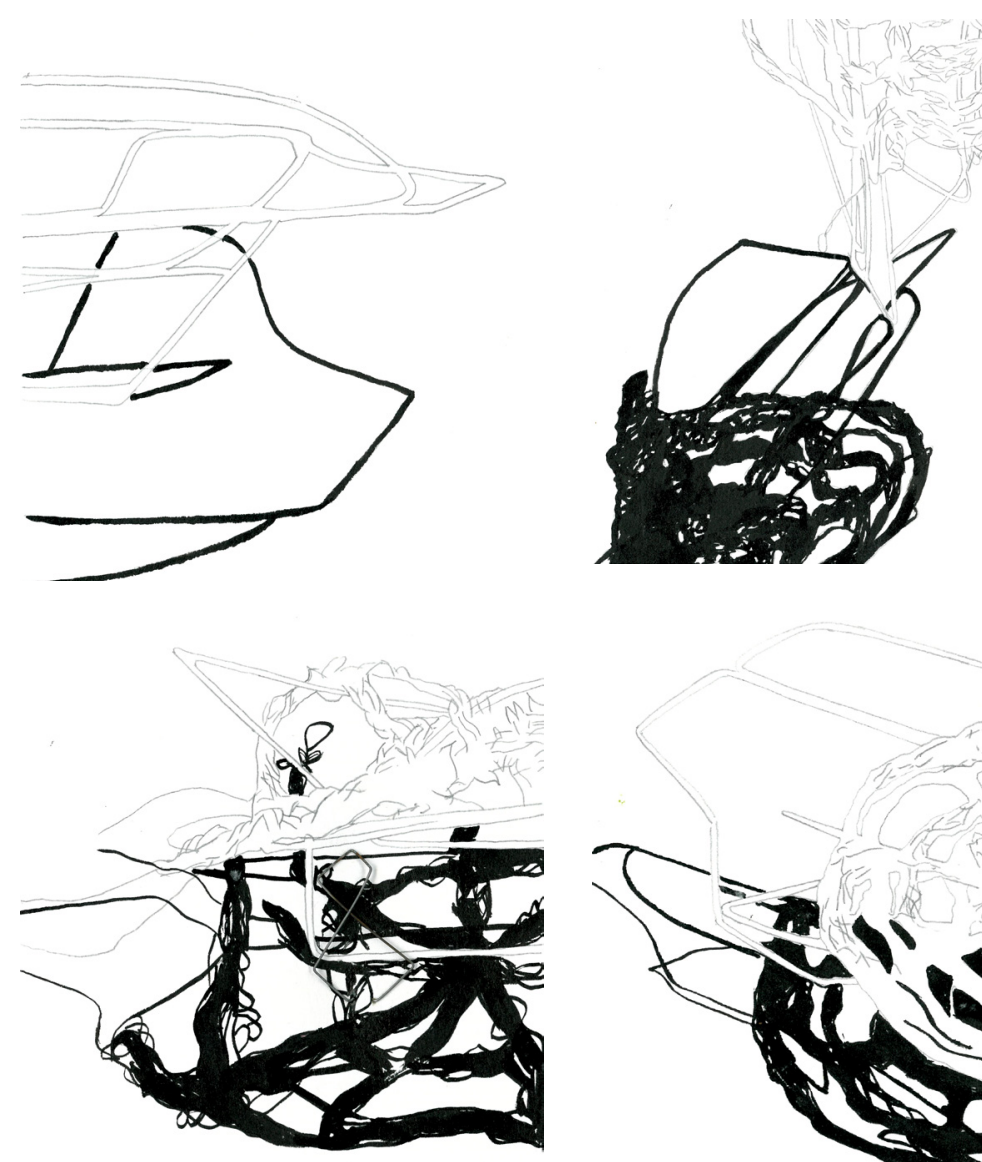


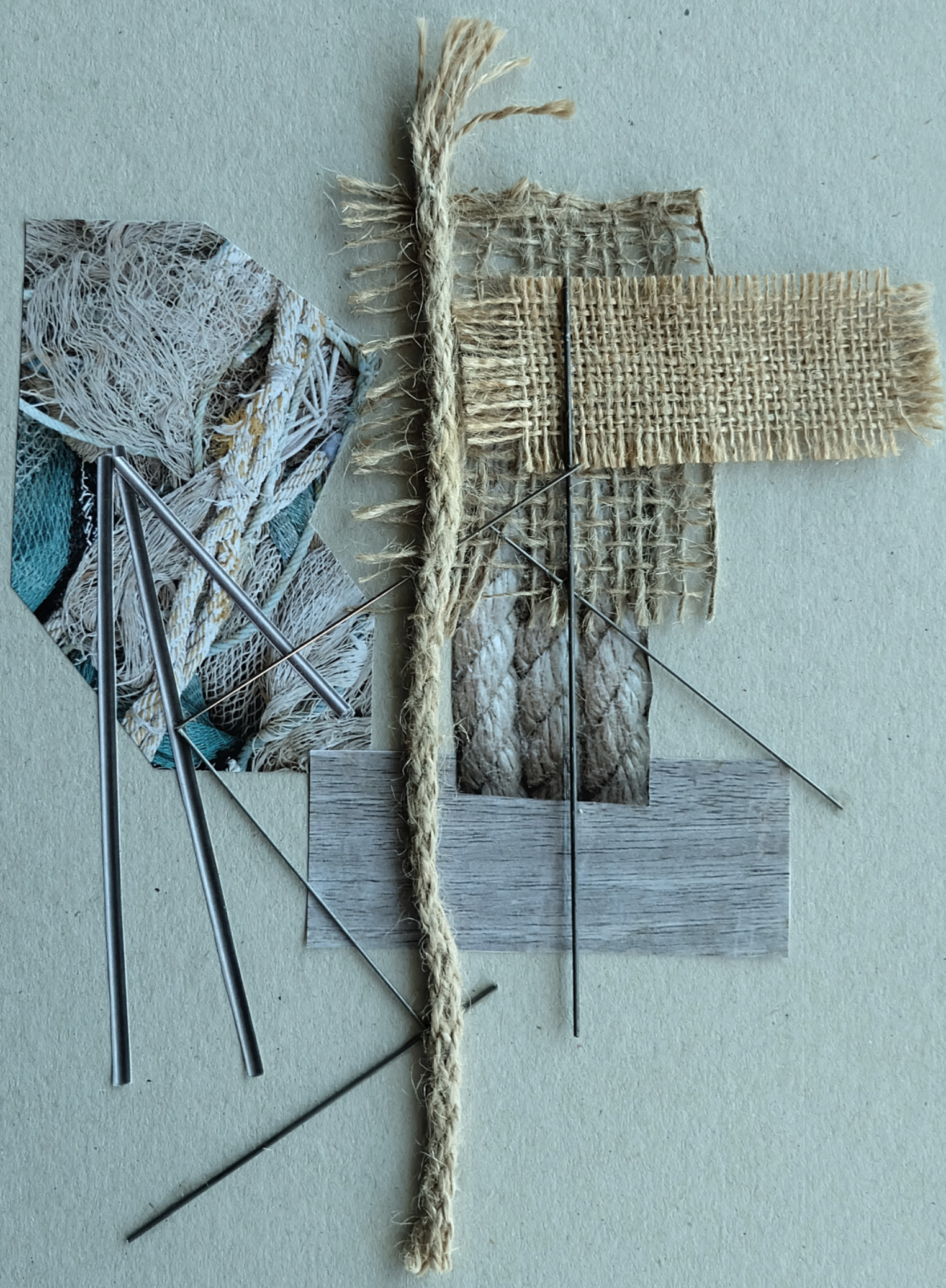




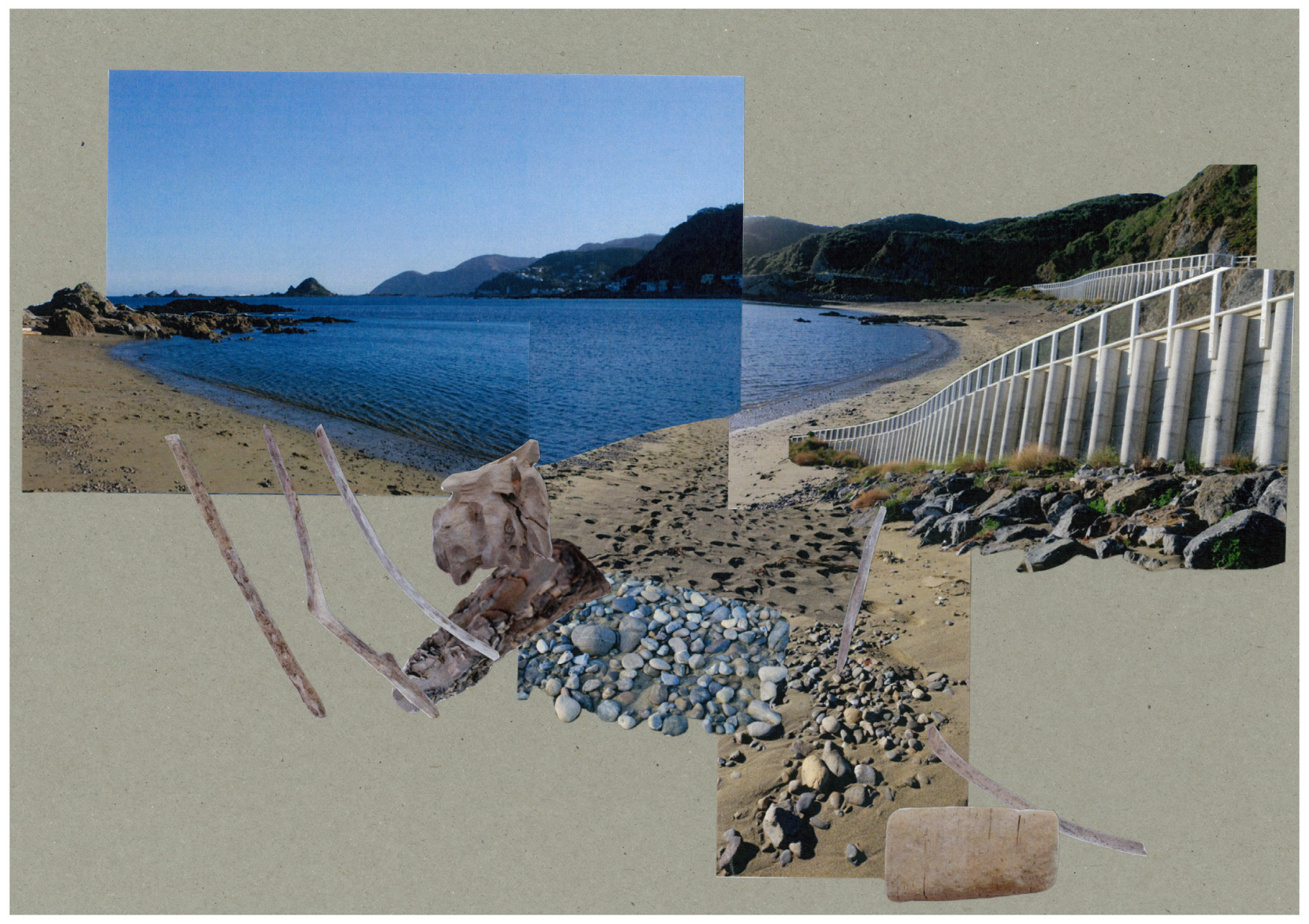

Fig 6.73. Collage of images, textures and fragments specific to Princess Bay 


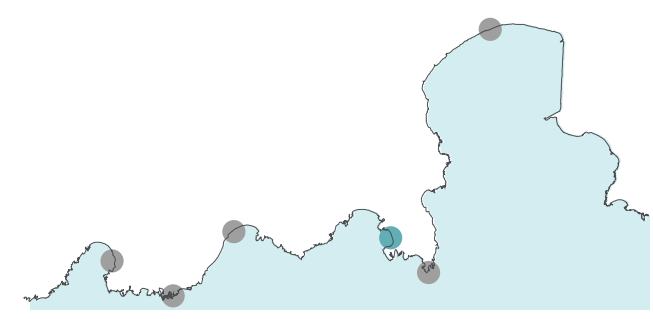

\section{Princess Bay}

It is the calmest and one of the most sheltered sites. The sandy private beach is a popular place to swim in the summer. Set below the road there is a sense of intimacy and protection created by the large retaining wall that has been constructed to prevent erosion from under the road. However this large concrete structure is a dominating force that overwhelms the human scale. This existing infrastructure is a key aspect of the site that will be explored through the design by questioning its ability to facilitate and enhance the notion of scale and occupancy.

One key aspect to the experience of the site is its direction and vertical experience. Facing the direction of the setting sun, it becomes a reflective space where the notion of time and space come into perspective. The setting sun can be experienced from either the beach or at the top of the retaining structure. This is a powerful experience that is a key driver for the design.

Brief

- $\quad$ Raised shelter for watching the sun set in the summer

- $\quad$ Place of reflection

- An un-interrupted view of the horizon

- $\quad$ Circulation between road and observation platform

- $\quad$ Explore light and shadow in highlighting the progression of time

- Seating for users to enjoy the view

- $\quad$ Form a barrier to acoustic and movement distractions from the adjoining road 


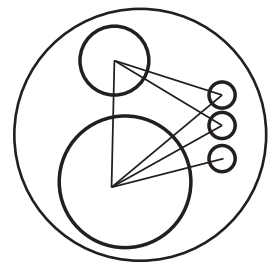

PROGRAM NARRATIVE

EMOTIONAL ENCOUNTER
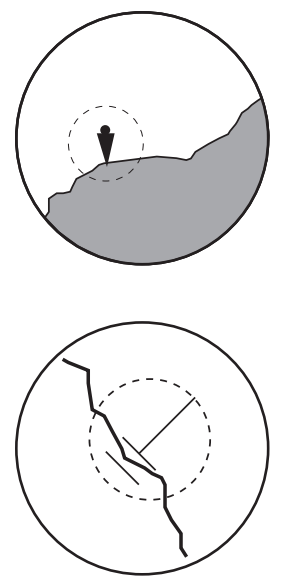

LEVEL OF CONTACT WITH

THE THRESHOLD

THE 'THRESHOLD' IS THE POINT AT WHICH LAND TRANSFORMS INTO SEA

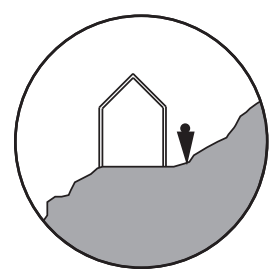

CONTEXTUAL NARRATIVE

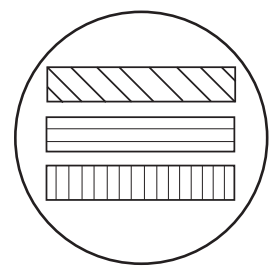

MATERIAL AND MATERIAL PROCESSES

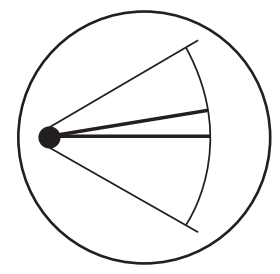

VIEW FOCUSING THE EYE 


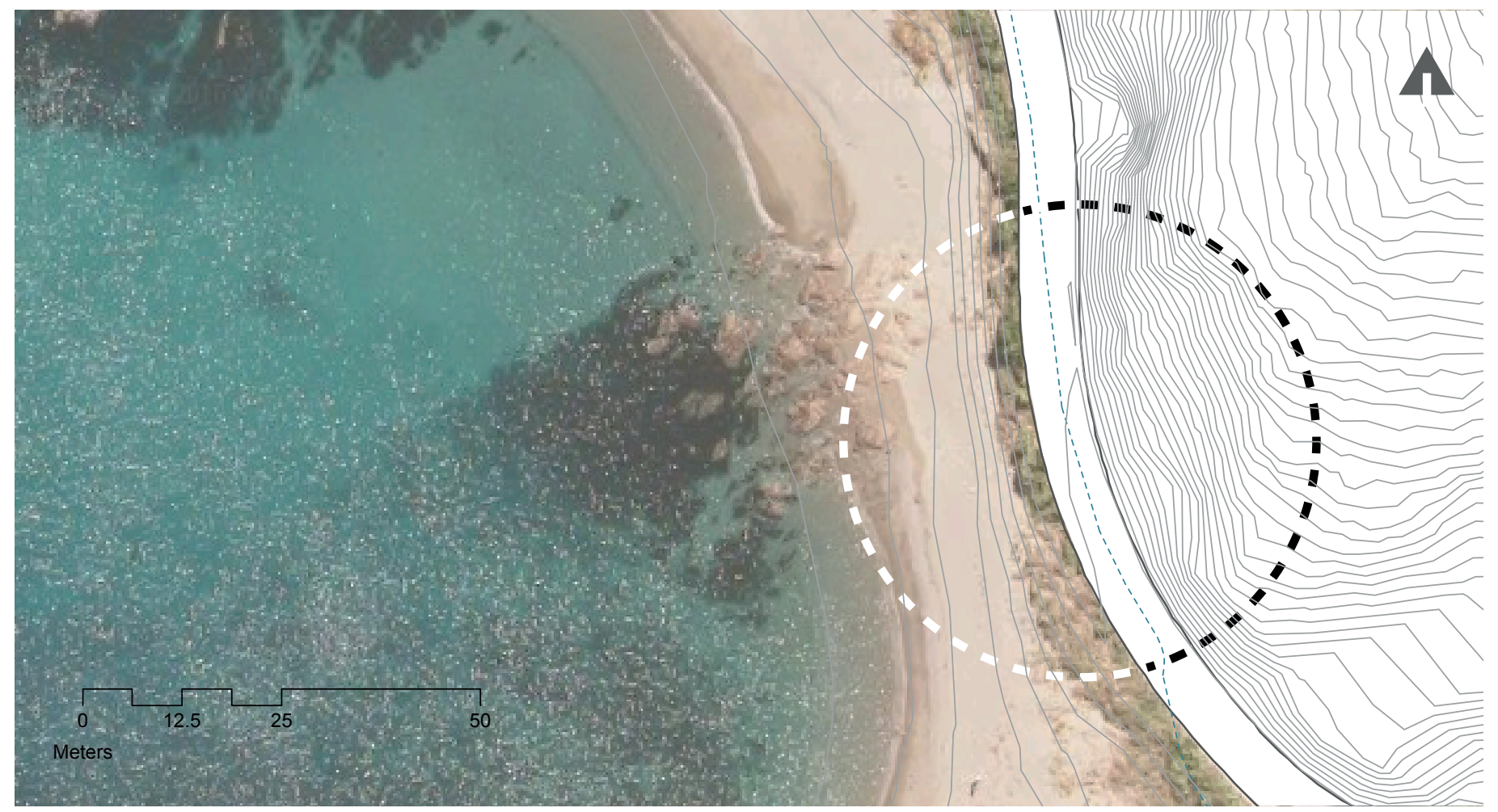

Fig 6.75. Site plan - circle highlights the focus area of the site, the diagonal line represents the intuitive direction and section cut

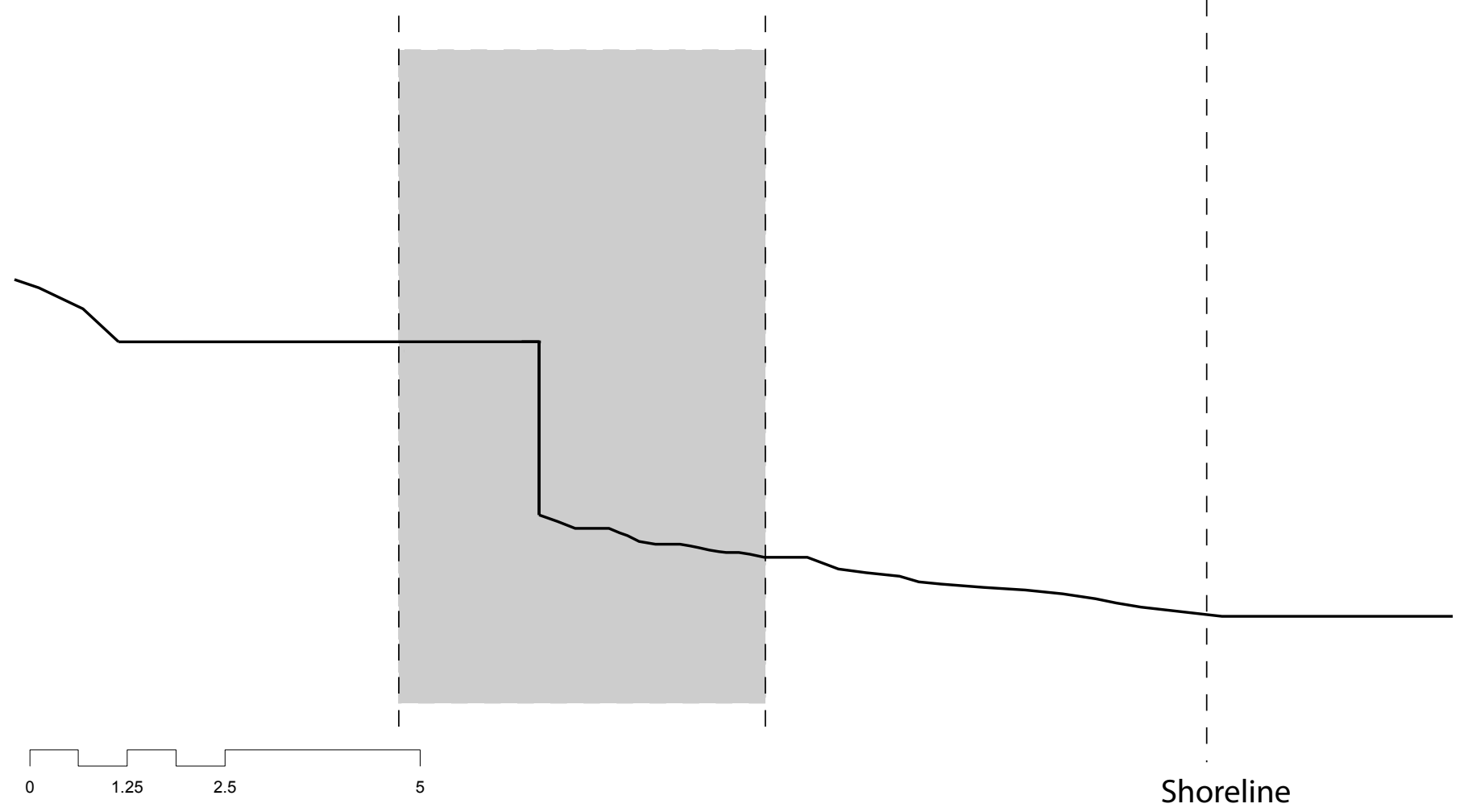

Meters

Fig 6.76. Diagrammatic section through site 


\section{Images of site}
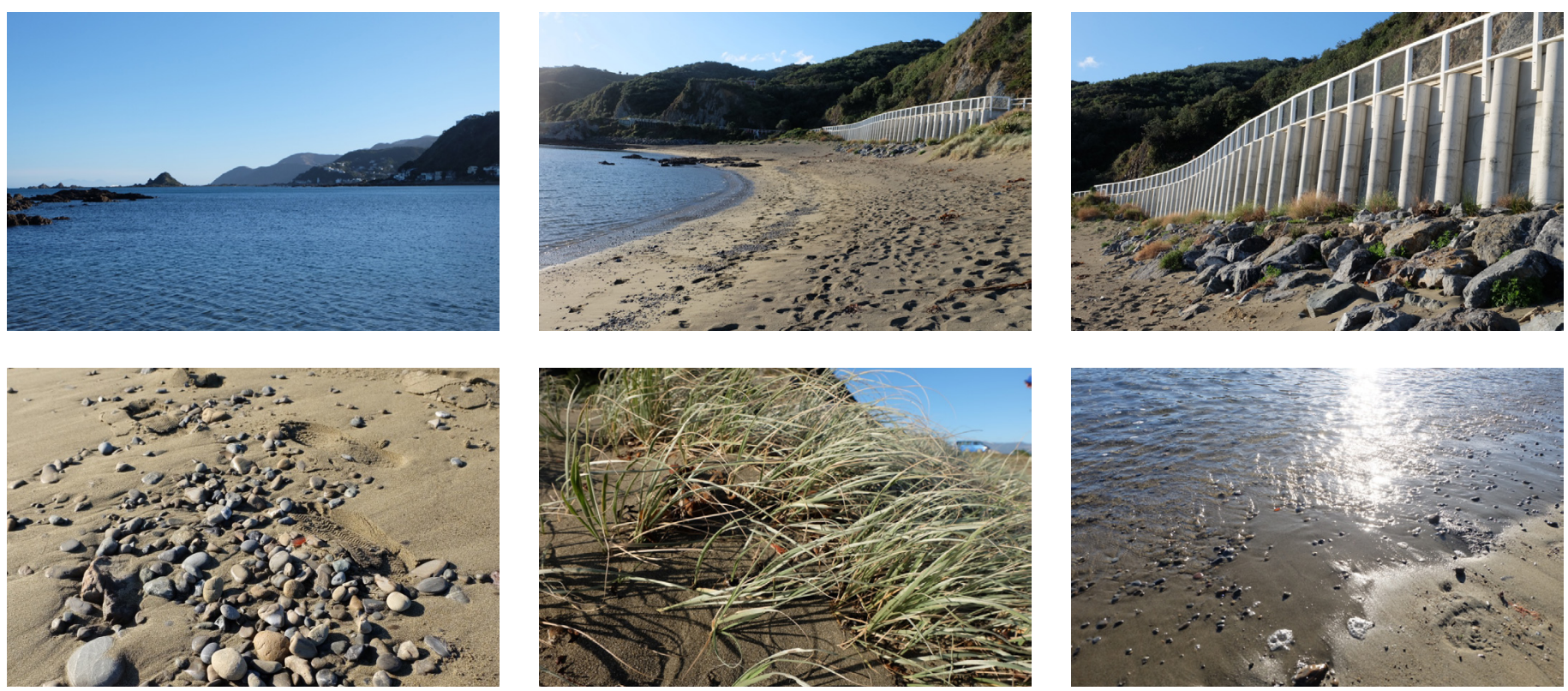

Fig 6.77. Collection of images from Island Bay 

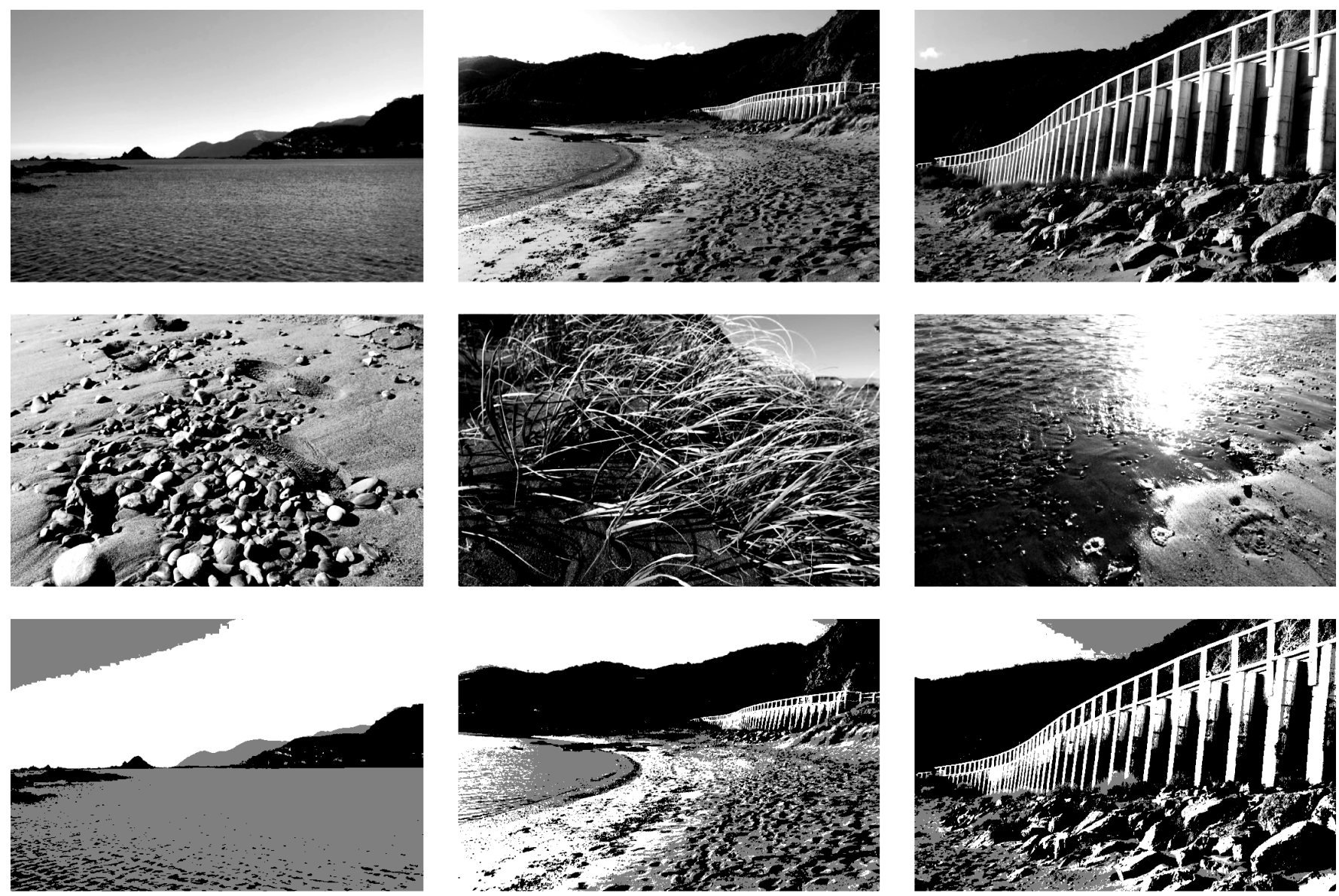

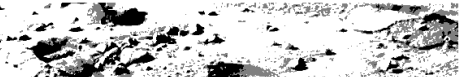
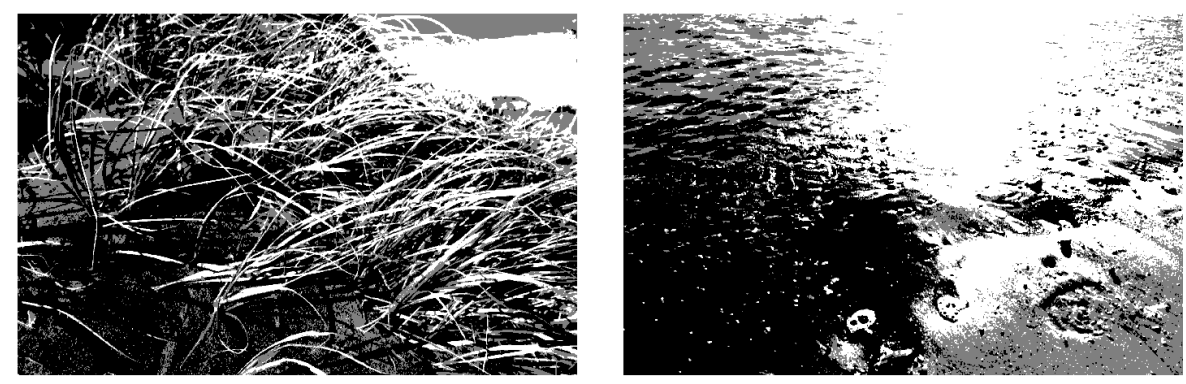

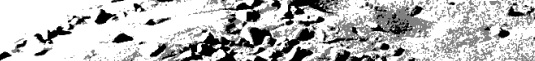

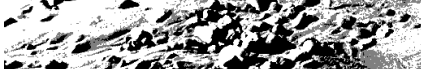
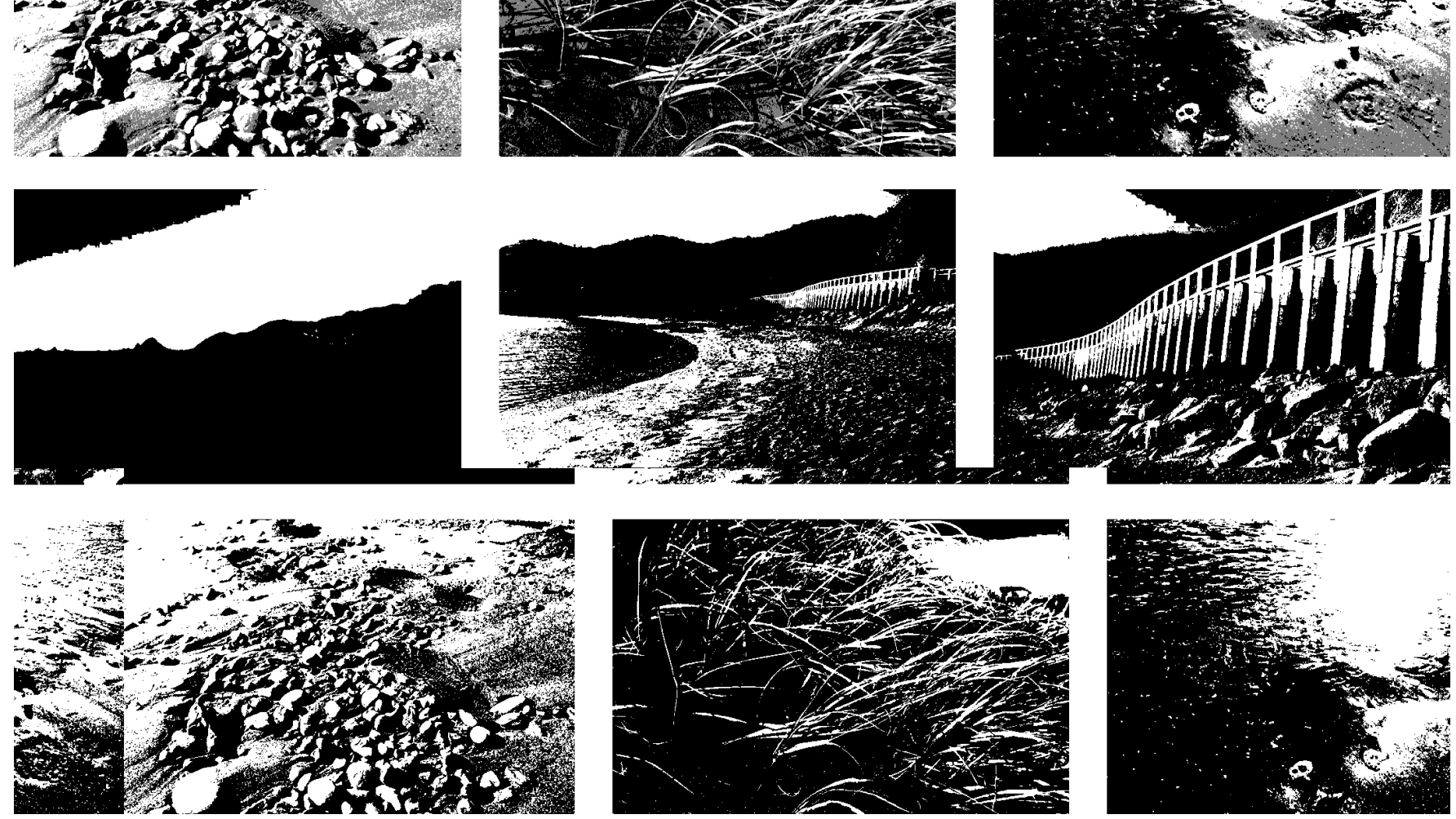

Fig 6.78. Graphic study of textures and views from the site 

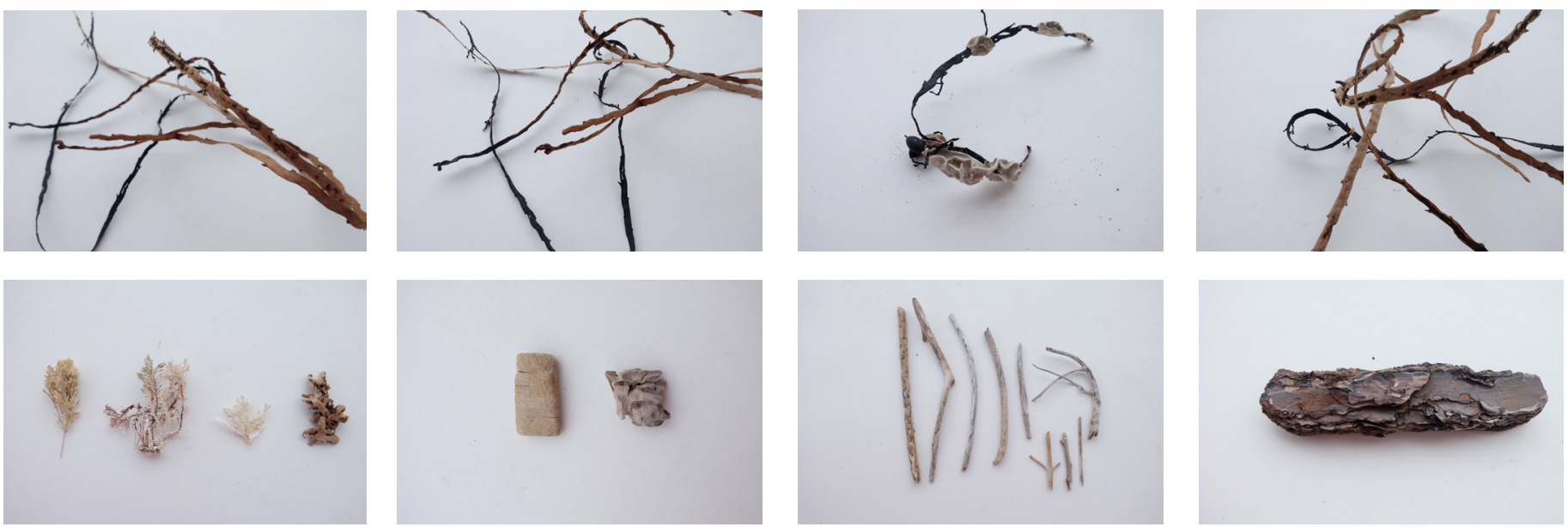

Fig 6.79. Found fragments 

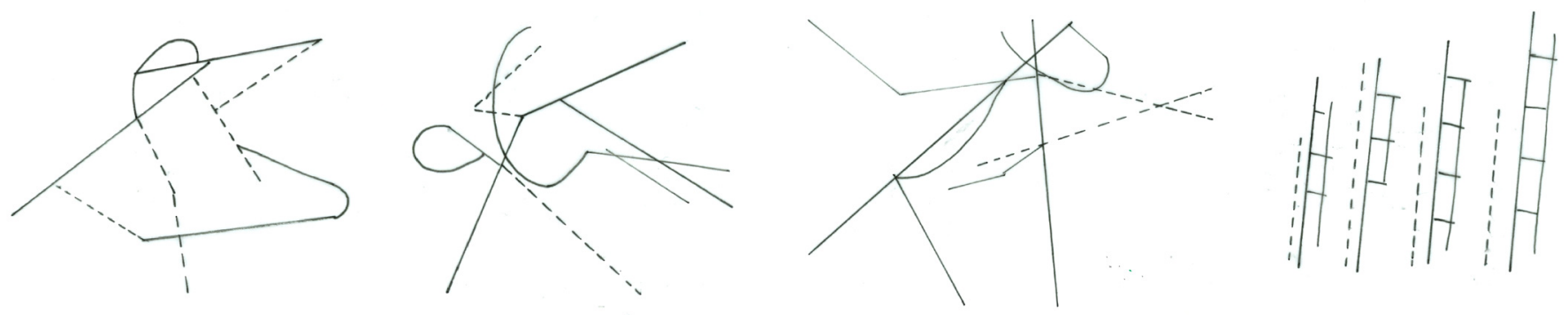

Fig 6.80. Initial form explorations 


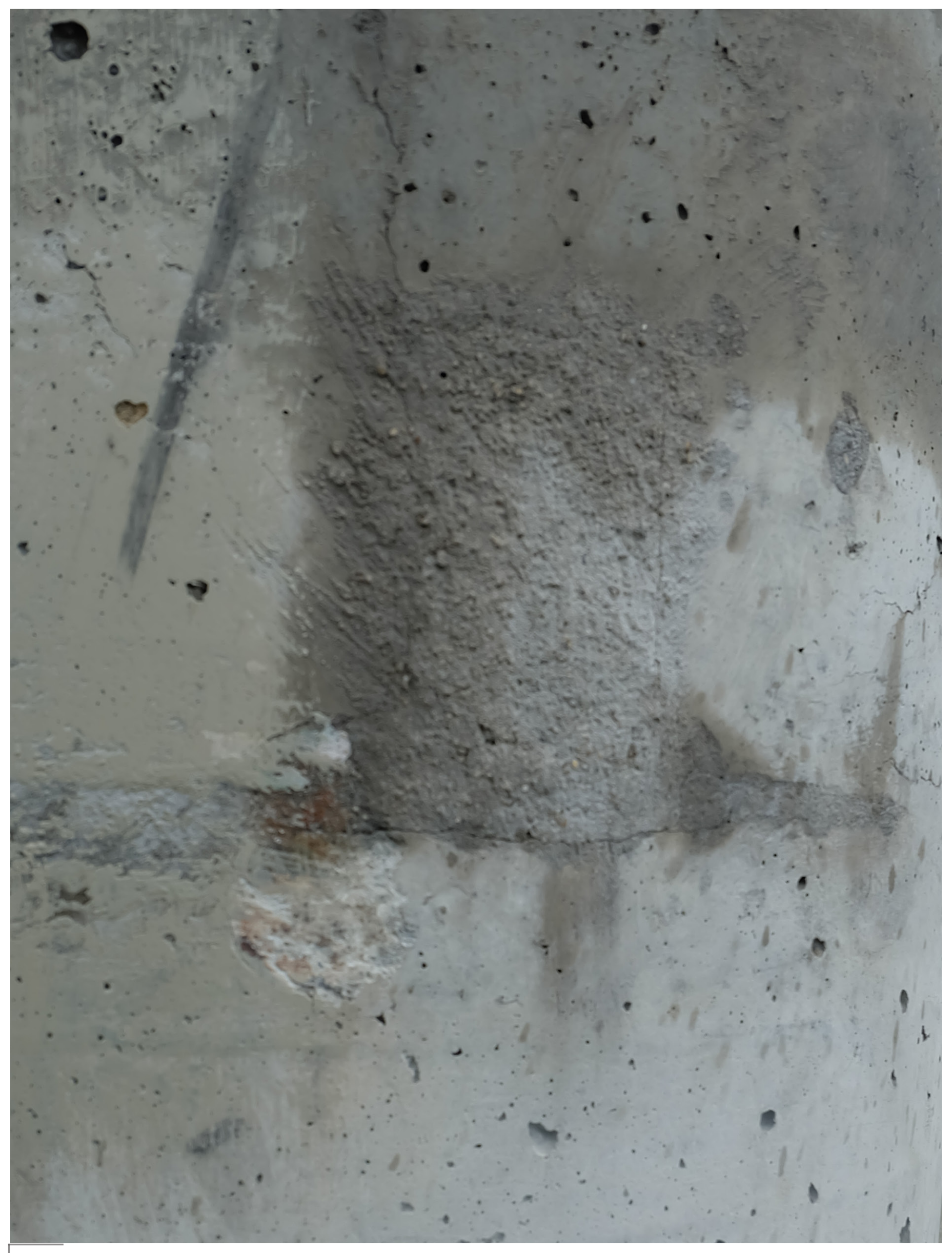




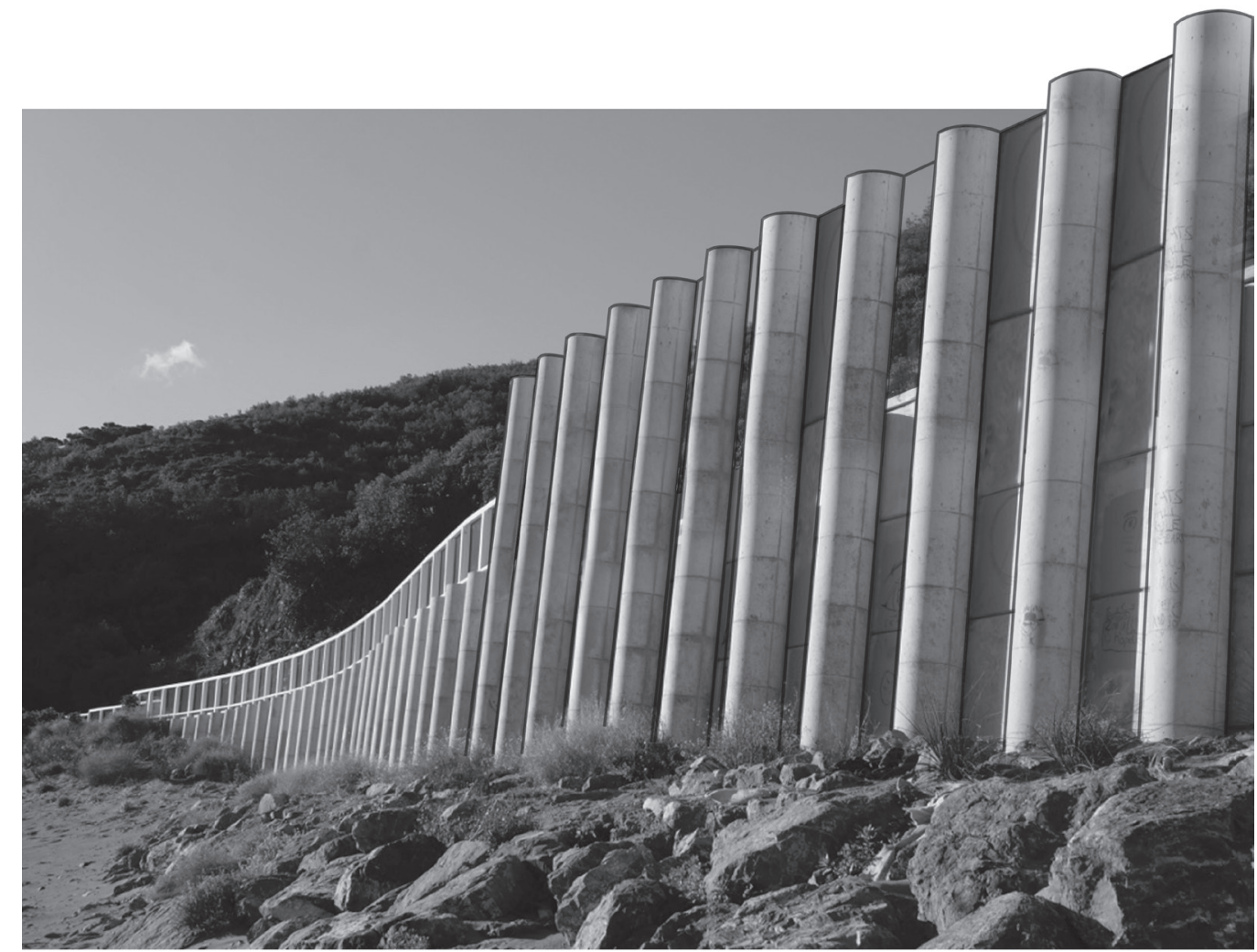

Fig 6.82. Extension of existing retaining wall creating a barrier from the acoustic and movement distractions from the road 


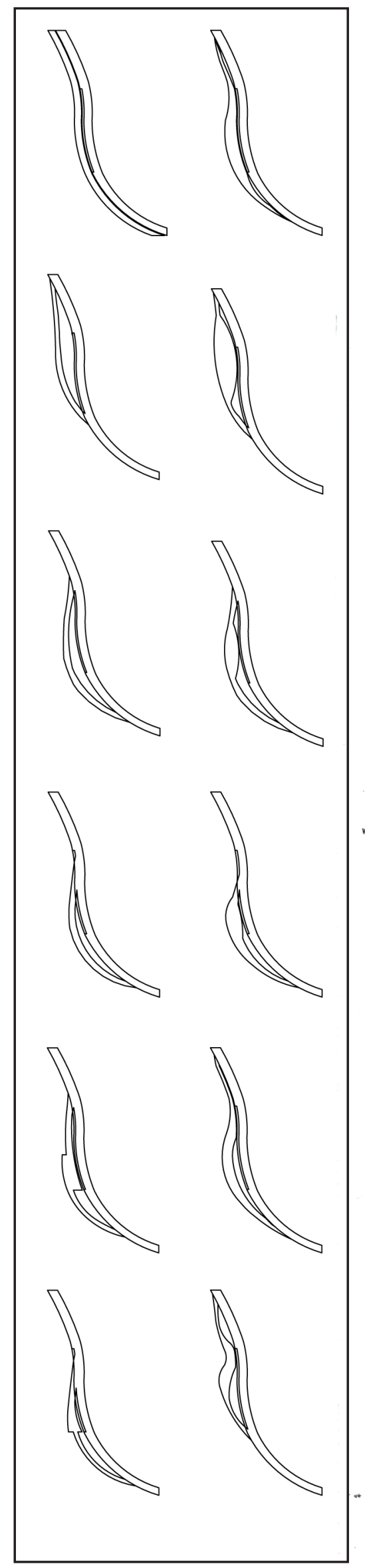

Fig 6.83. Design iterations of intervention location in relation to existing road

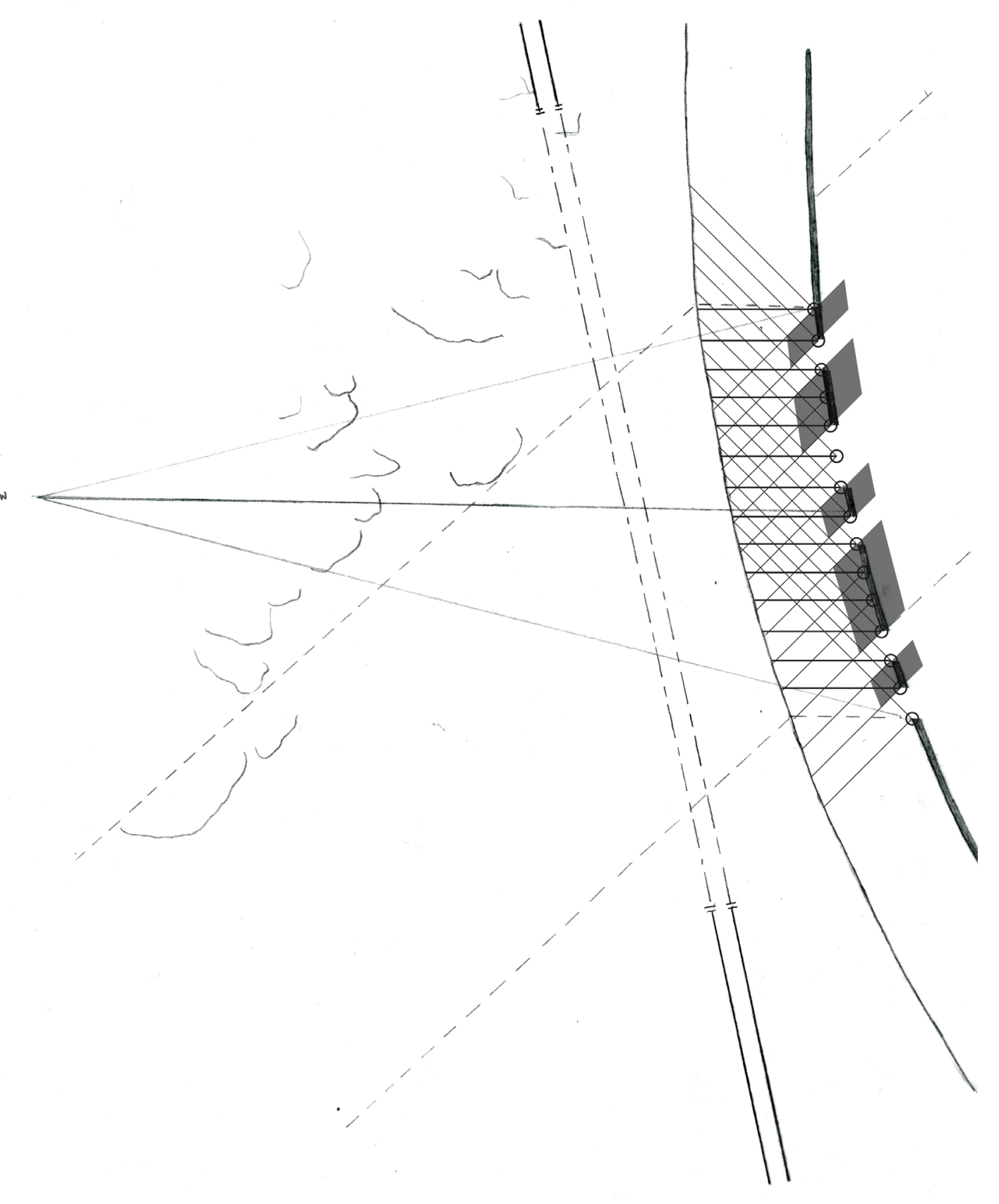

Fig 6.84. Detailed site analysis highlighting view shafts, possible density patterns of retaining wall and axis 


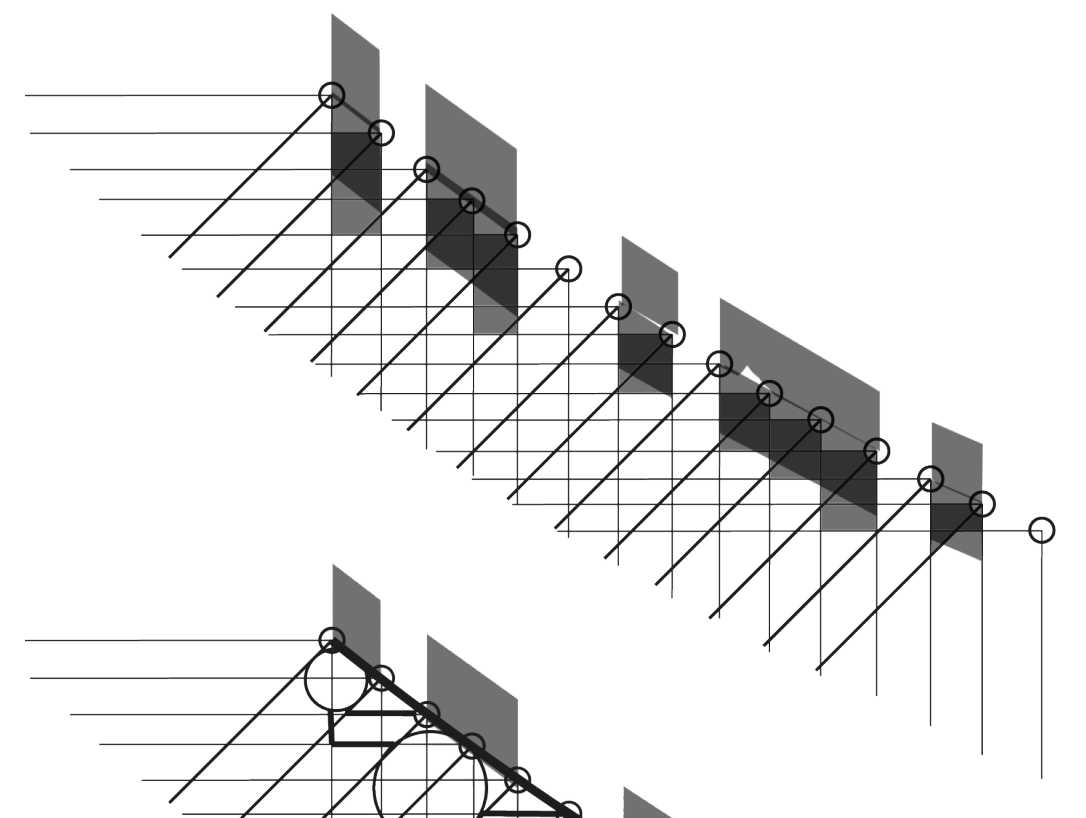

The design focuses on reflection and observation. The key design driver is the development of a contemplative space which encourages the user to focus in the horizon, allowing them to have an embodied experience of the surrounding contextual conditions. In achieving this a key design move has been made by extending the height of the existing retaining wall. This has developed an intensified level of privacy on the site from both noise and onlookers from the road. Unlike any of the other sites there is the ability to explore the vertical occupation of the site.

This iteration looks at using the existing columns of the retaining wall as nodal points from which platforms expand out. However there is an issue with scale and spatial arrangement in relation to each platform and the overall site.
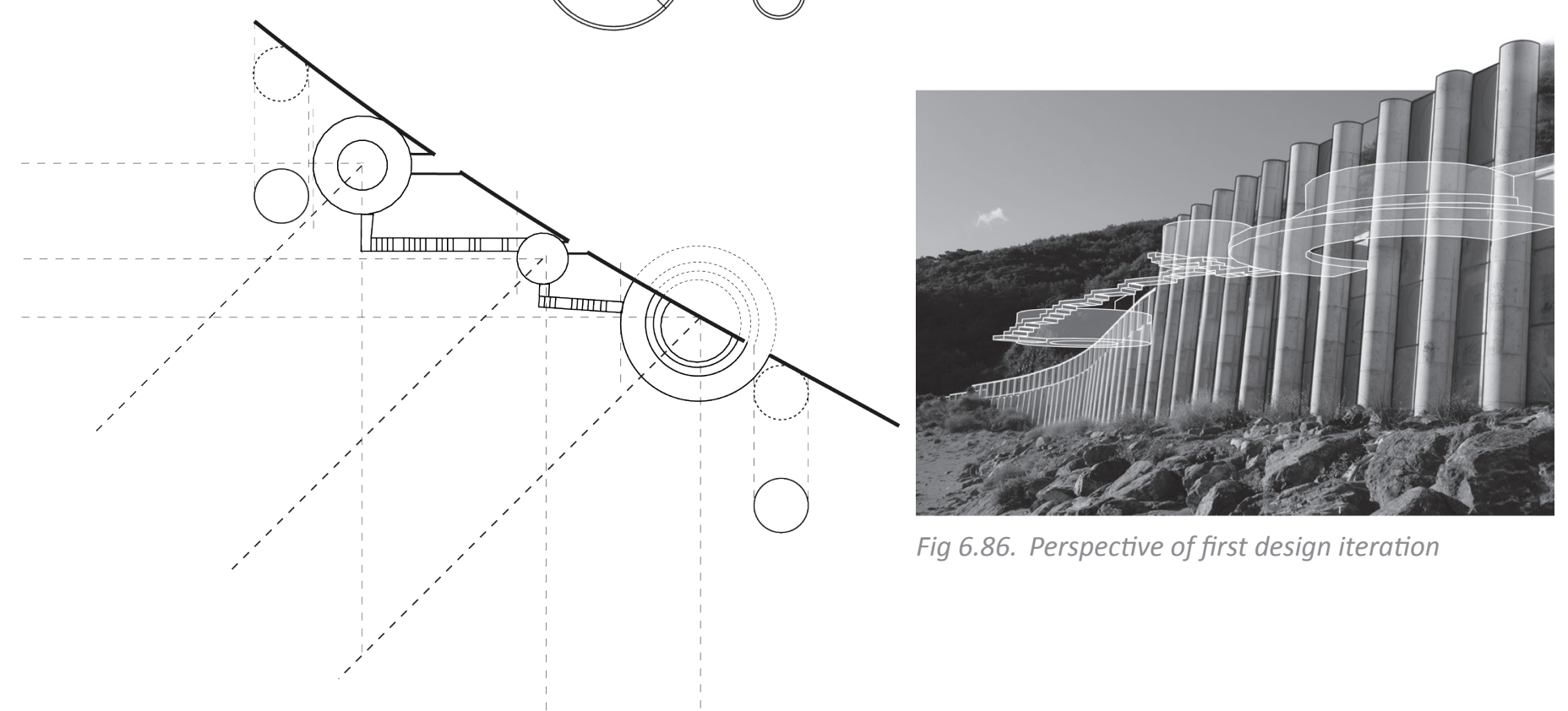

Fig 6.86. Perspective of first design iteration 


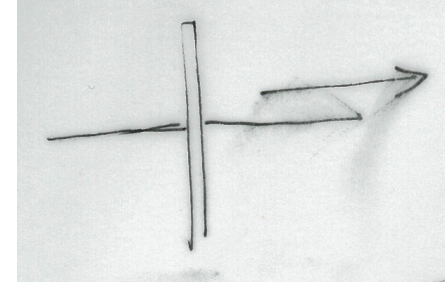

extending the existing retaining wall up.
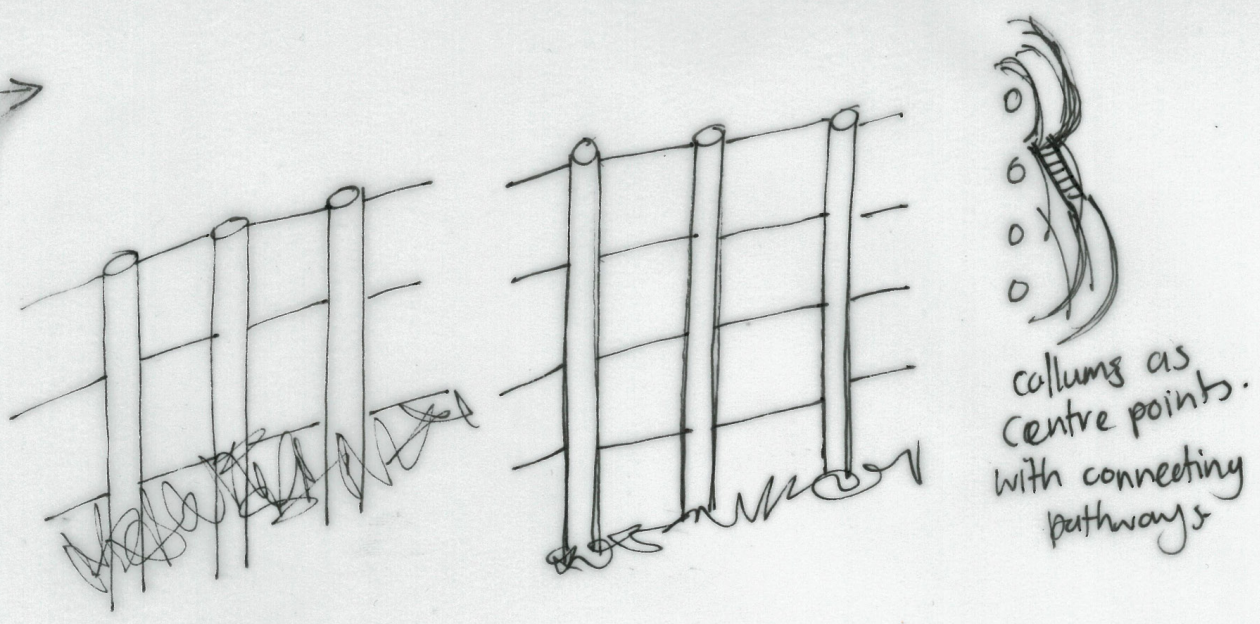
with connecting puthwoys.
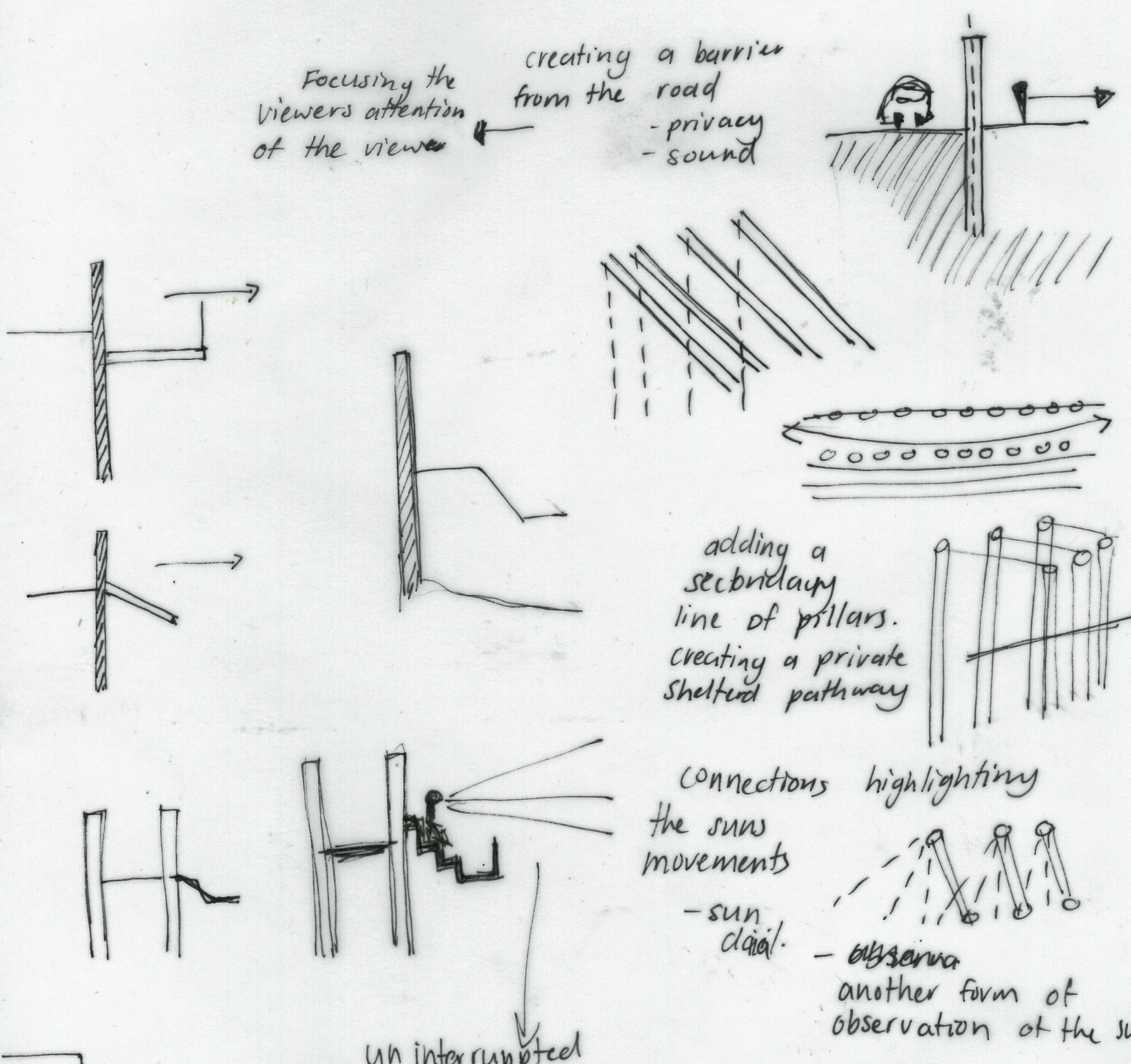
adding a
secbridayn
line of prllars.
creating a private
shelterd pathway

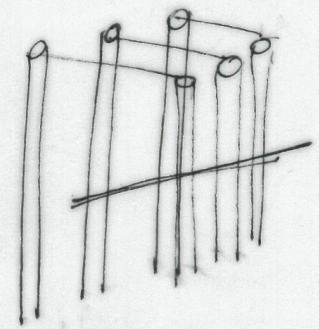

connections highlightiny

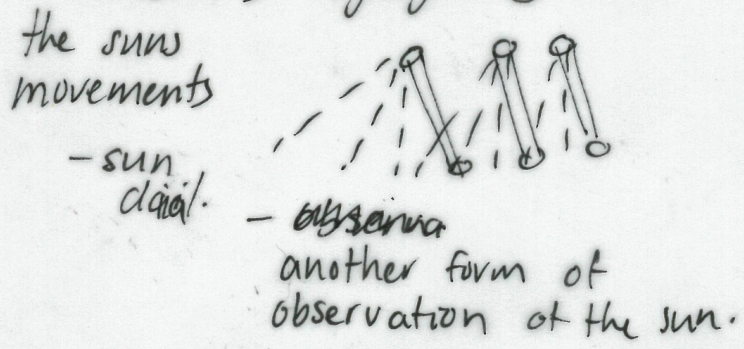



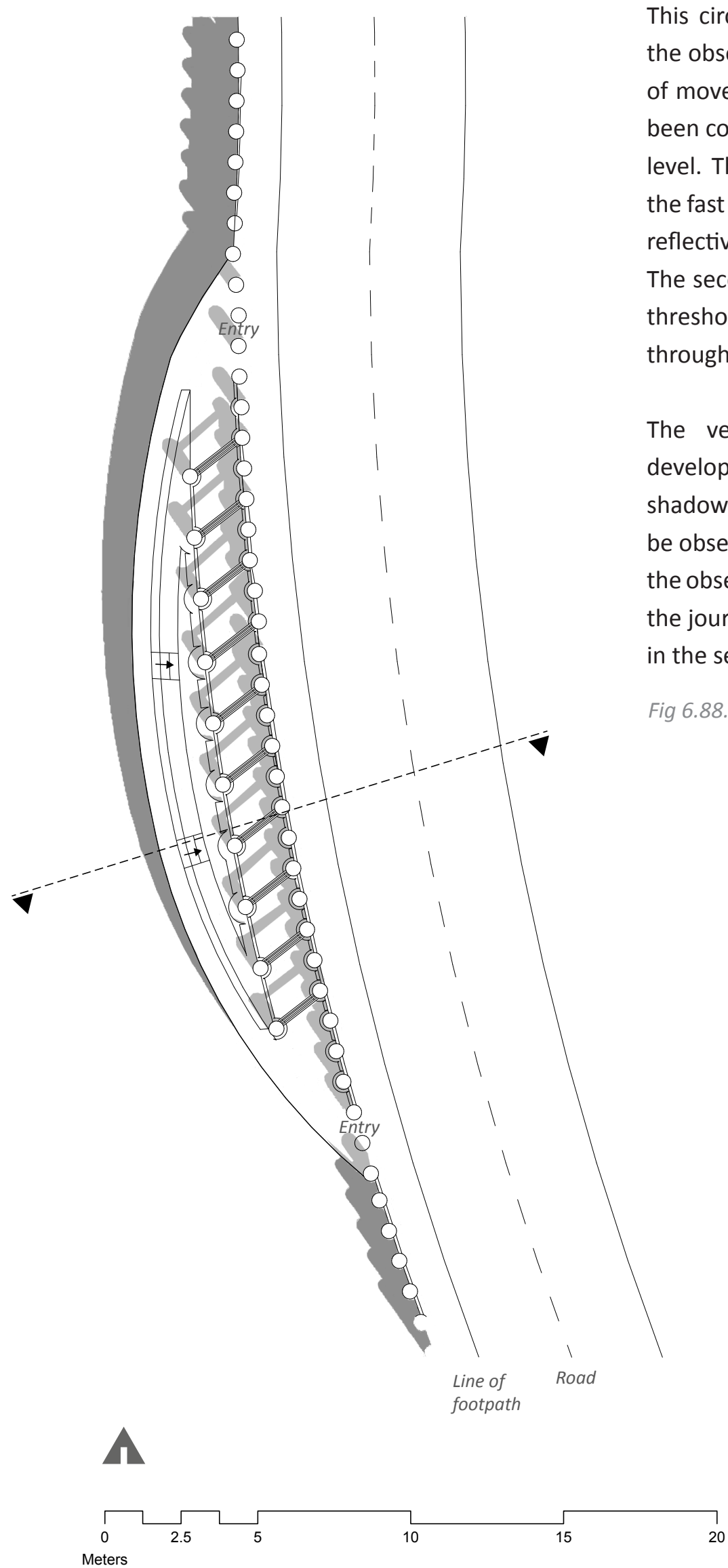

This circulation path between the wall and the observation platform creates a threshold of movement. The levels of movement have been considered in terms of speed and noise level. The aim is to separate the user from the fast movement of the road to the still and reflective space of the observation platform. The secondary line of columns develops this threshold allowing the users to transition through the levels of movement.

The vertical elements of the structure develop a strong language of light and shadow. The subtle movement of the sun can be observed through the projected shadows, the observation of time is highlighted through the journey of the shadow eventually ending in the setting sun.

Fig 6.88. Site plan

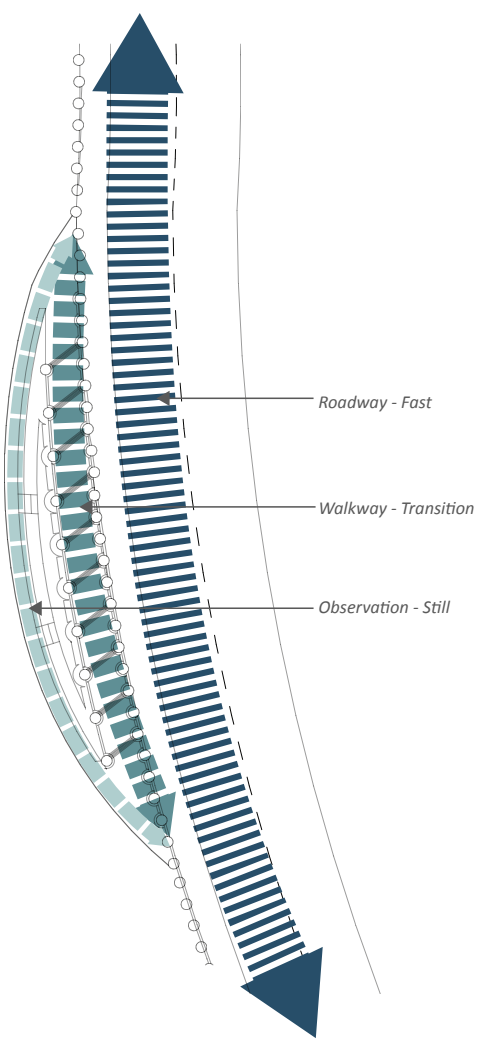

Fig 6.89. Levels of movement diagram 


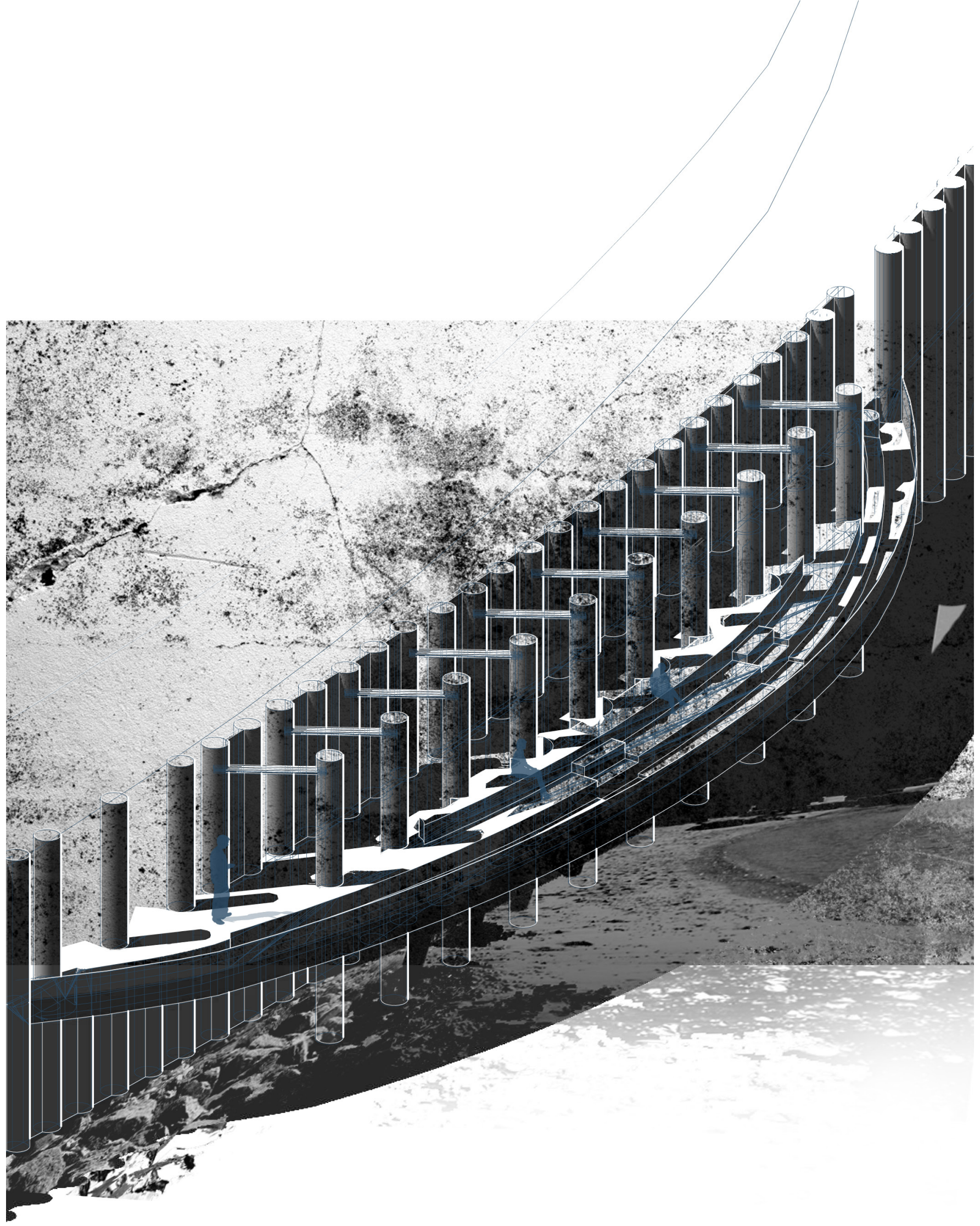

Fig 6.90. Perspective of overall intervention 


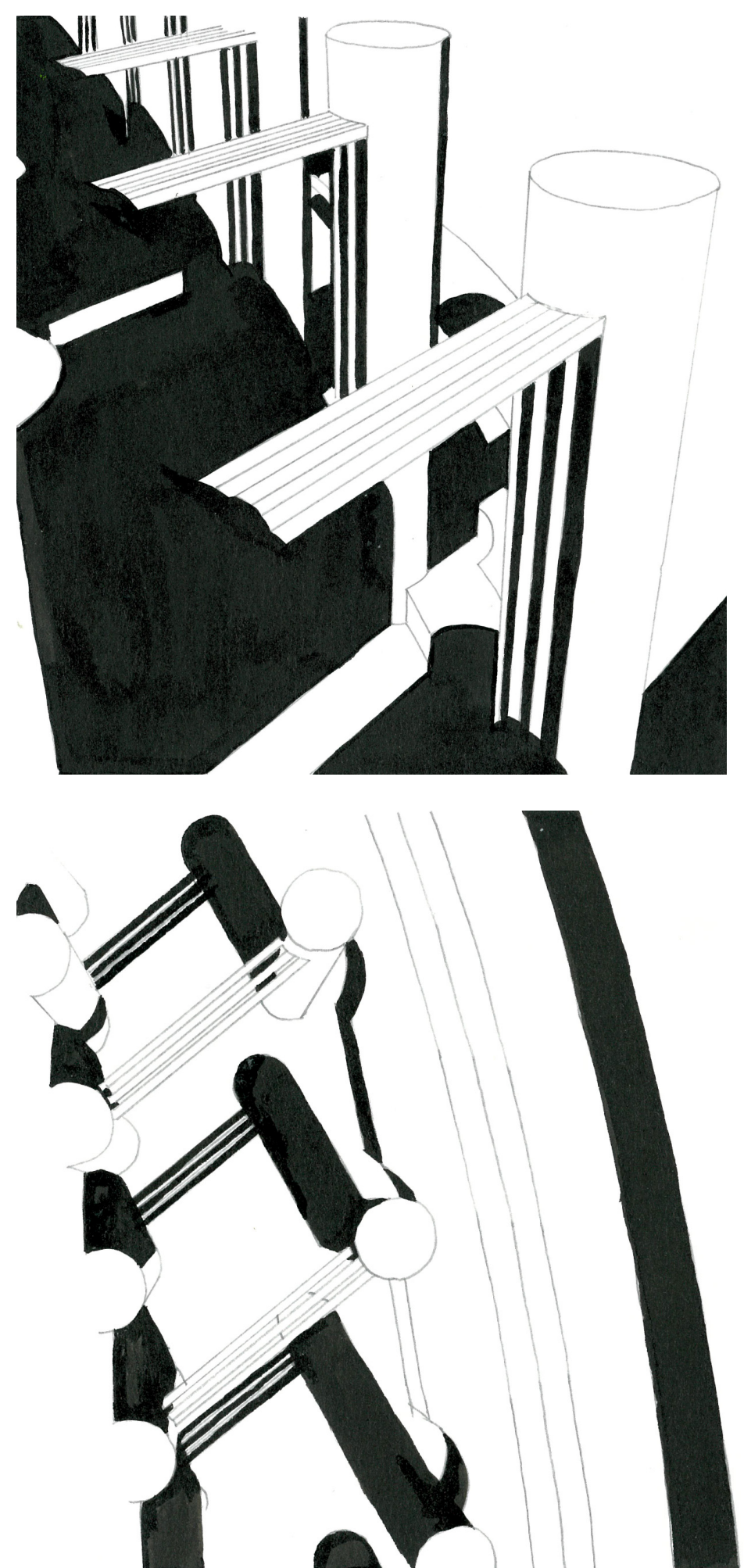

Fig 6.91. A collection of perspectives of the design exploring the relationship between form and shadow
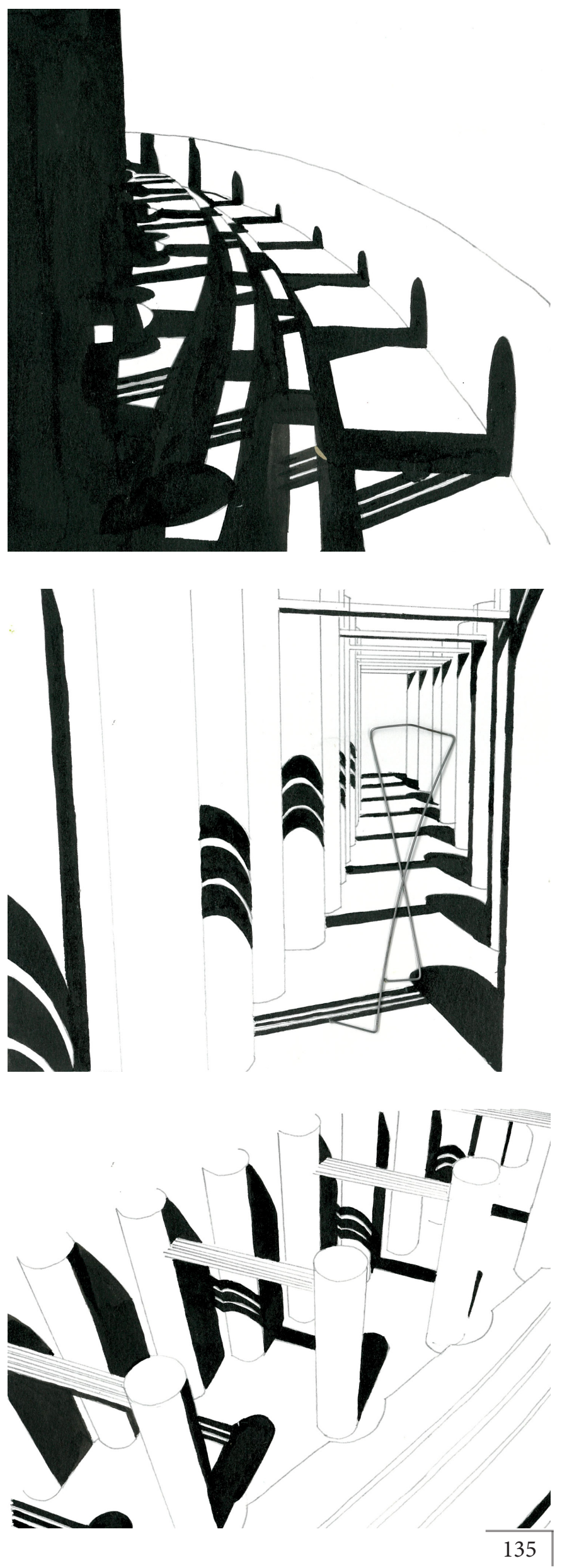


$$
\text { twe }
$$




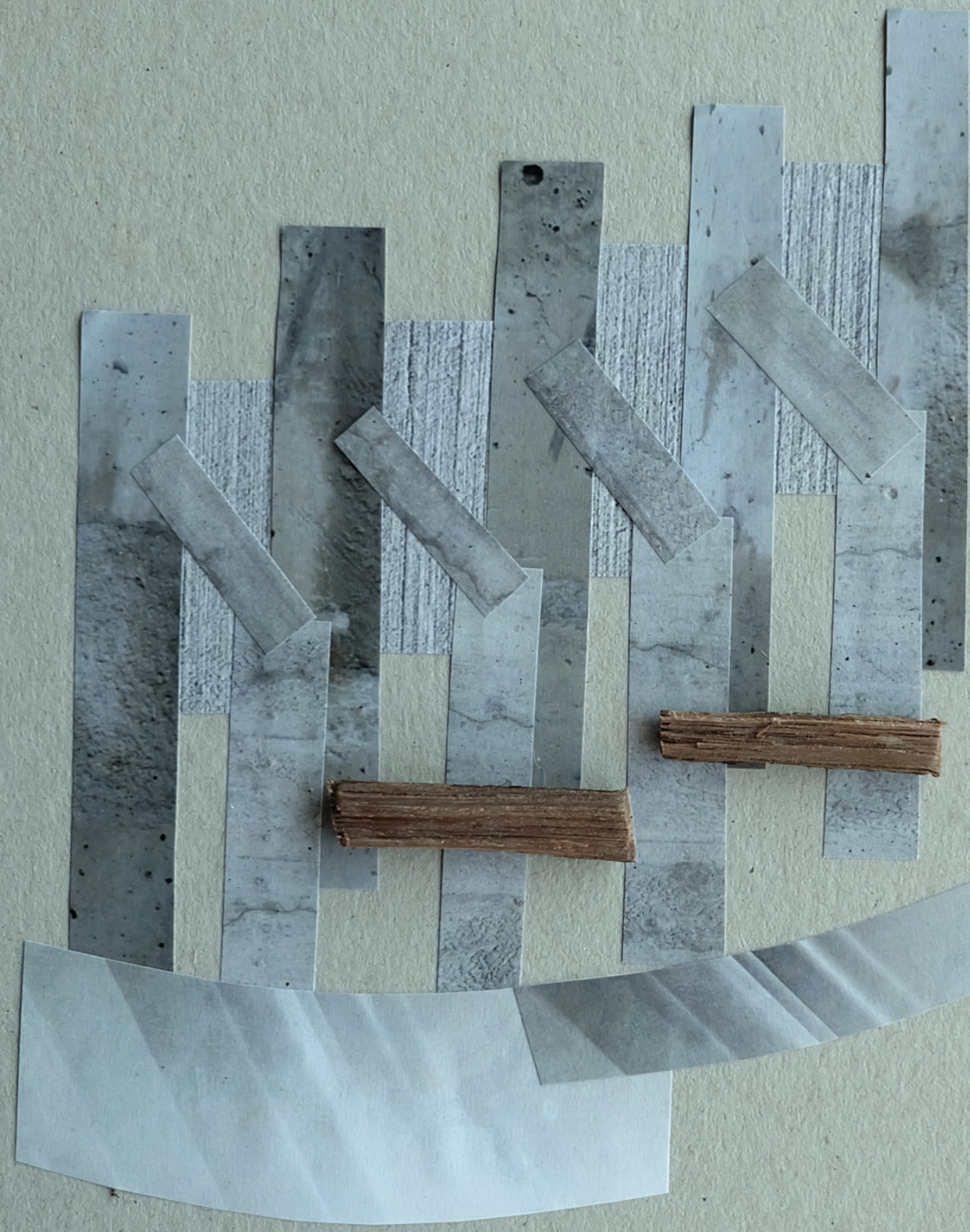




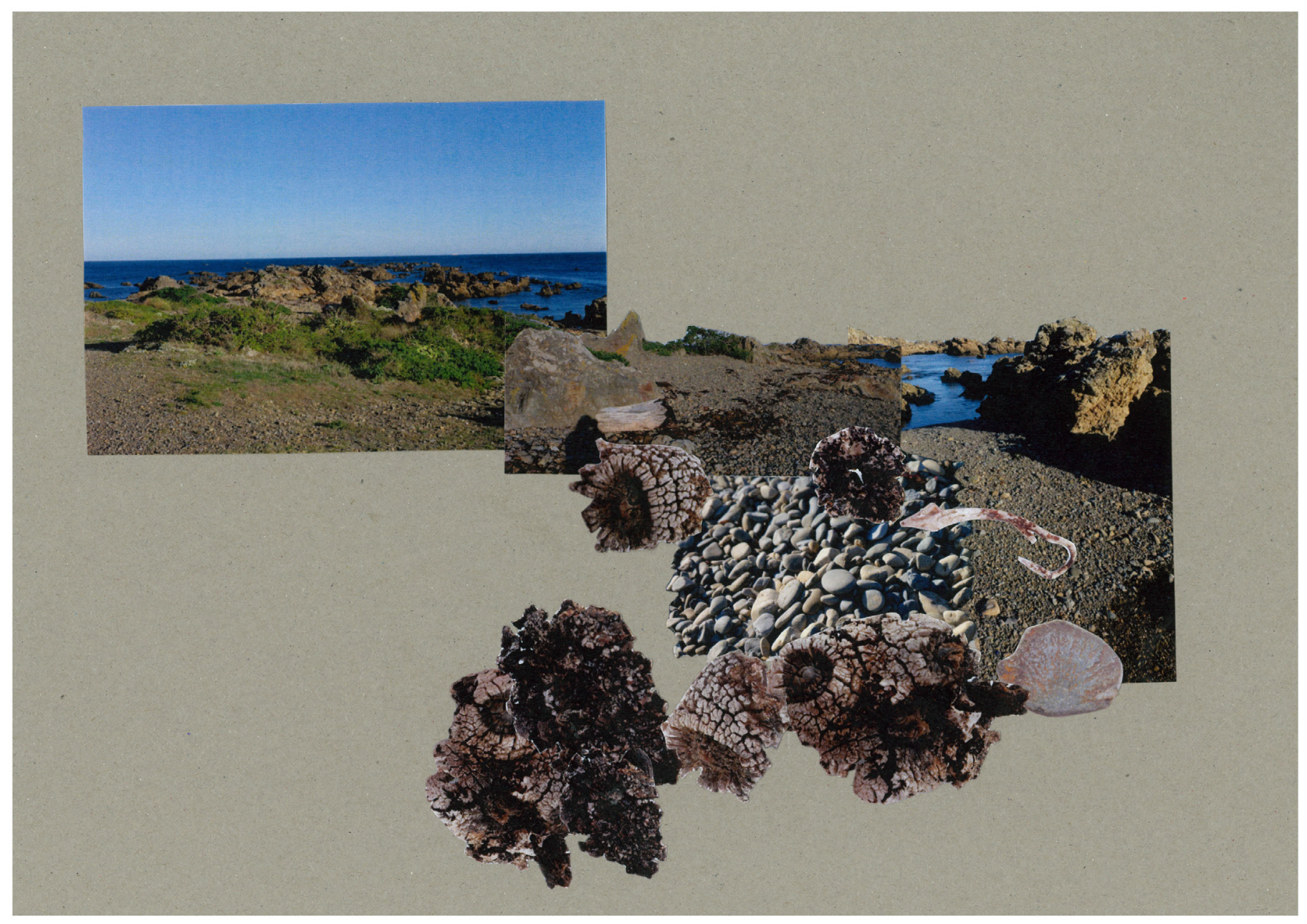

Fig 6.94. Collage of images, textures and fragments specific to Te Raekaihau Point 


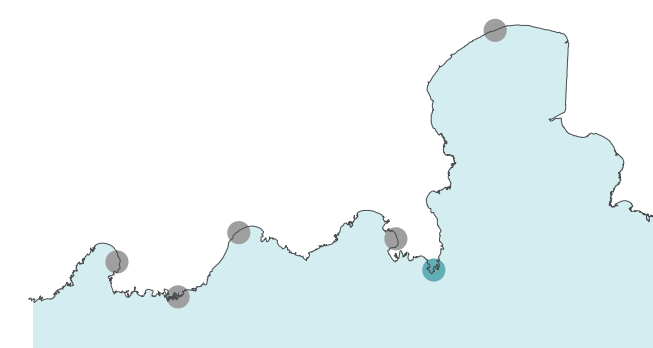

\section{Te Raekaihau Point - 'Sharks Tooth'}

Set out on Te Raekaihau Point this site is wild and untamed. There is a real sense of dynamic power on the site. The dramatic journey through the site reveals its ruggedness and highlights the untouched beauty of the coastline. You can become fully immersed in the spatial conditions of the site with the sensory triggers becoming intensified by the ever-changing context.

One of the key features of the site is the un-populated surroundings. This has made this spot popular with scenic photographers and astronomers. There is very little light pollution with no street lights or lights from houses nearby. This creates one of the best sites in Wellington for stargazing and night photography.

Brief

- Observation platform protruding out onto the point

- $\quad$ Place to sit and observe the night sky

- $\quad$ Shelter designed to view night sky in South, East and West directions

- $\quad$ Connecting pathway over the rocks

- $\quad$ Exploration of wind experience on the site

- Information on the night sky and the beginning of the Taputeranga Marine Reserve 


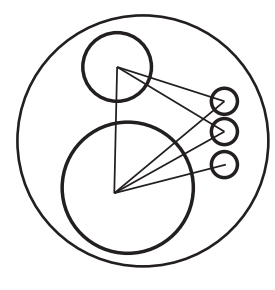

PROGRAM NARRATIVE

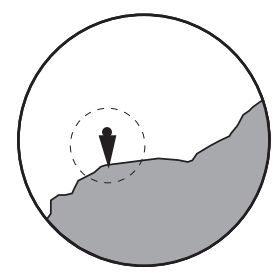

EMOTIONAL ENCOUNTER

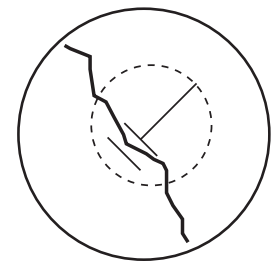

LEVEL OF CONTACT WITH

THE THRESHOLD

THE 'THRESHOLD'IS THE POINT AT WHICH LAND TRANSFORMS INTO SEA

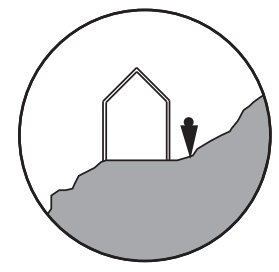

CONTEXTUAL NARRATIVE

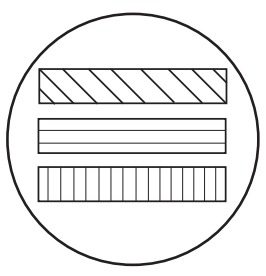

MATERIAL AND MATERIAL PROCESSES

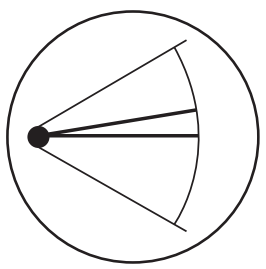

VIEW FOCUSING THE EYE

Observation/viewing Platform for star gazing information point as beginning point of the Mariene Reserve

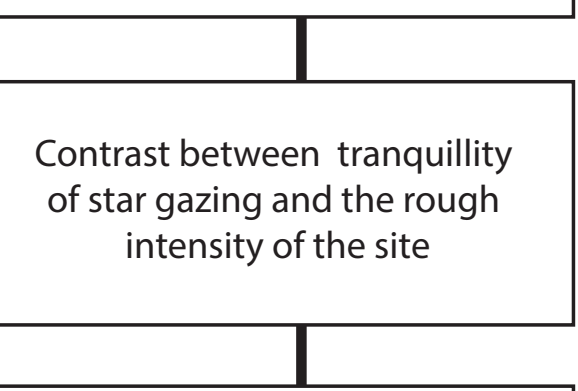

Lightly touching the threshold

Opening and Closing to the Sky

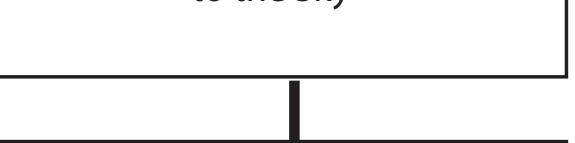

Salt Corrosion

Reflecting back to the sky

Opening up to the sky 


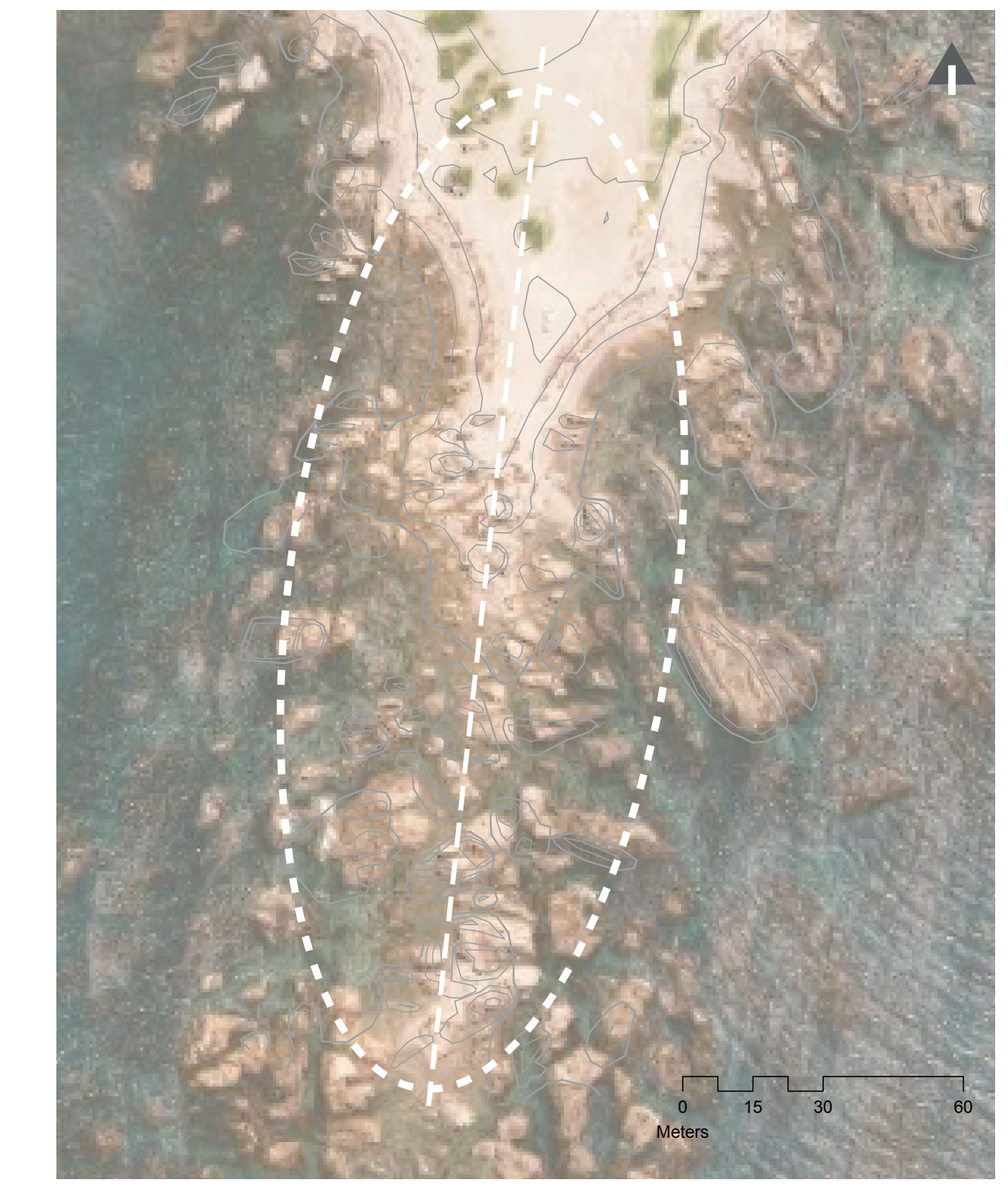

Fig 6.96. Site plan - circle highlights the focus area of the site, the diagonal line represents the intuitive direction and section cut

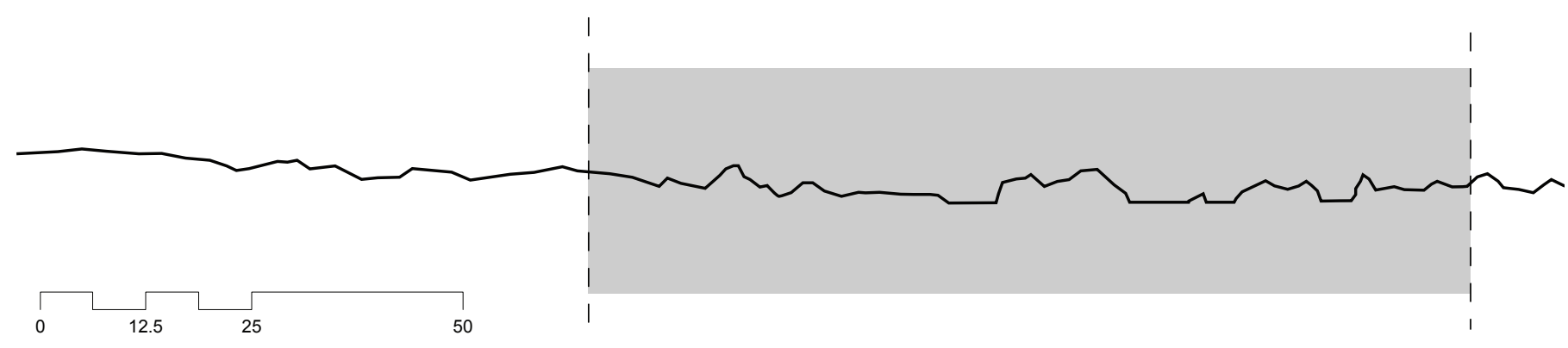

Meters

Fig 6.97. Diagrammatic section through site 
Images of site
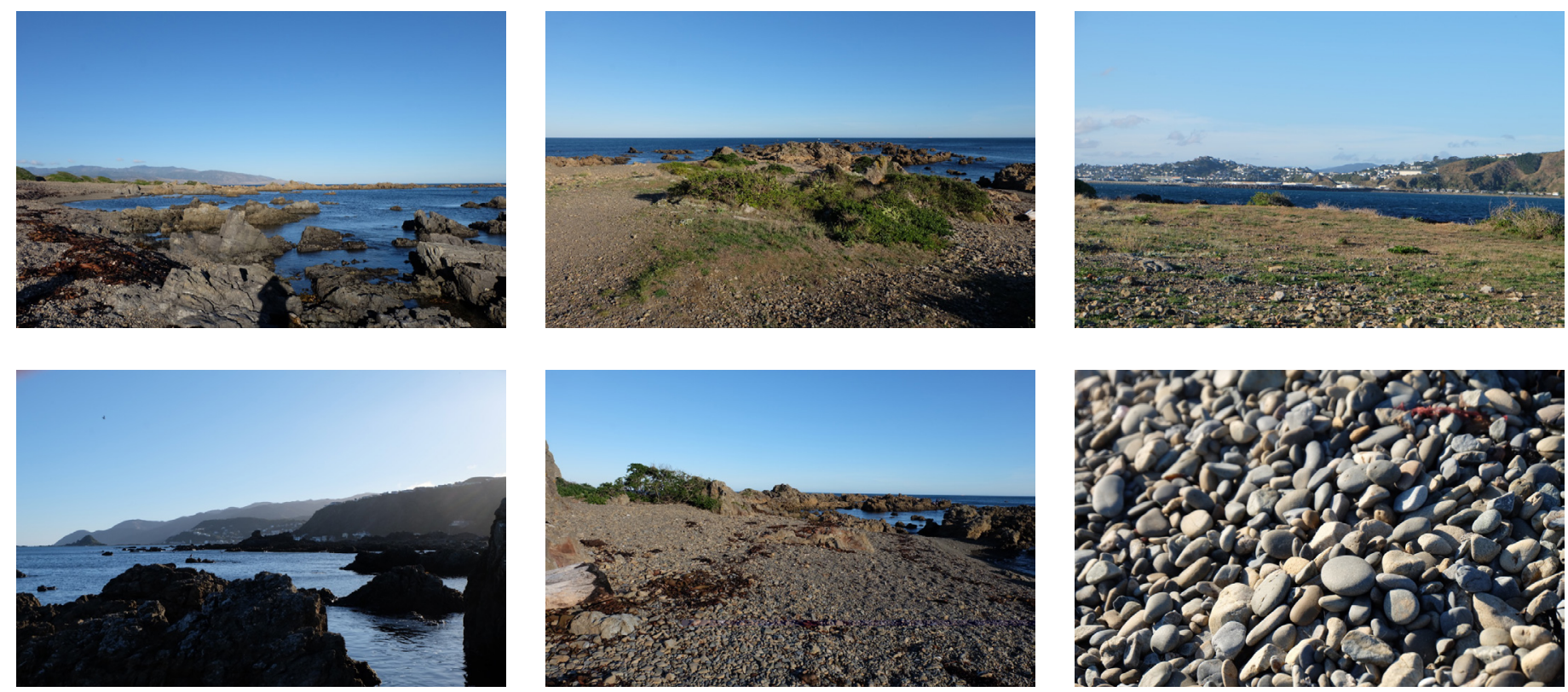

Fig 6.98. Collection of images from Te Raekaihau Point 

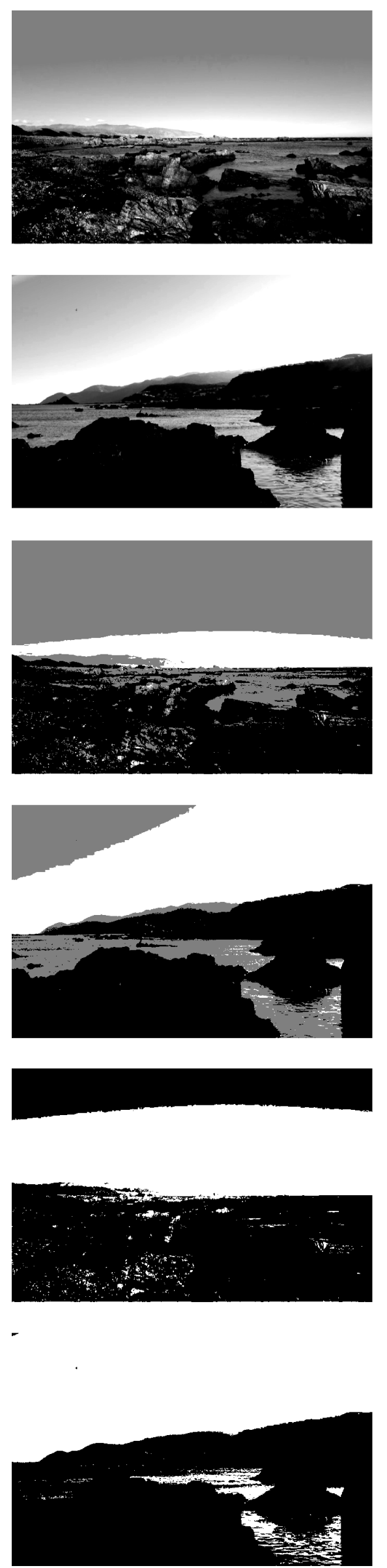
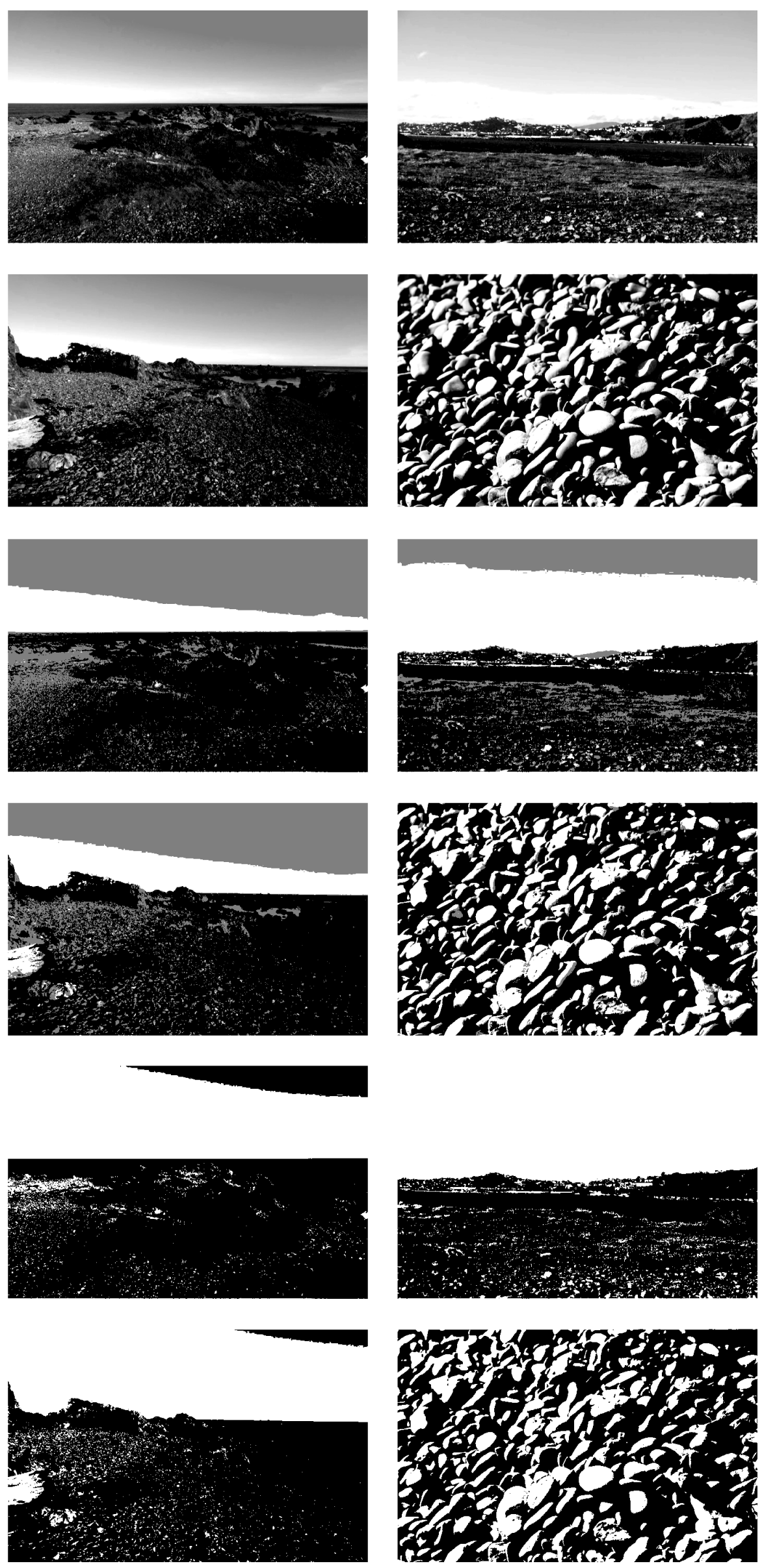

Fig 6.99. Graphic study of textures and views from the site 

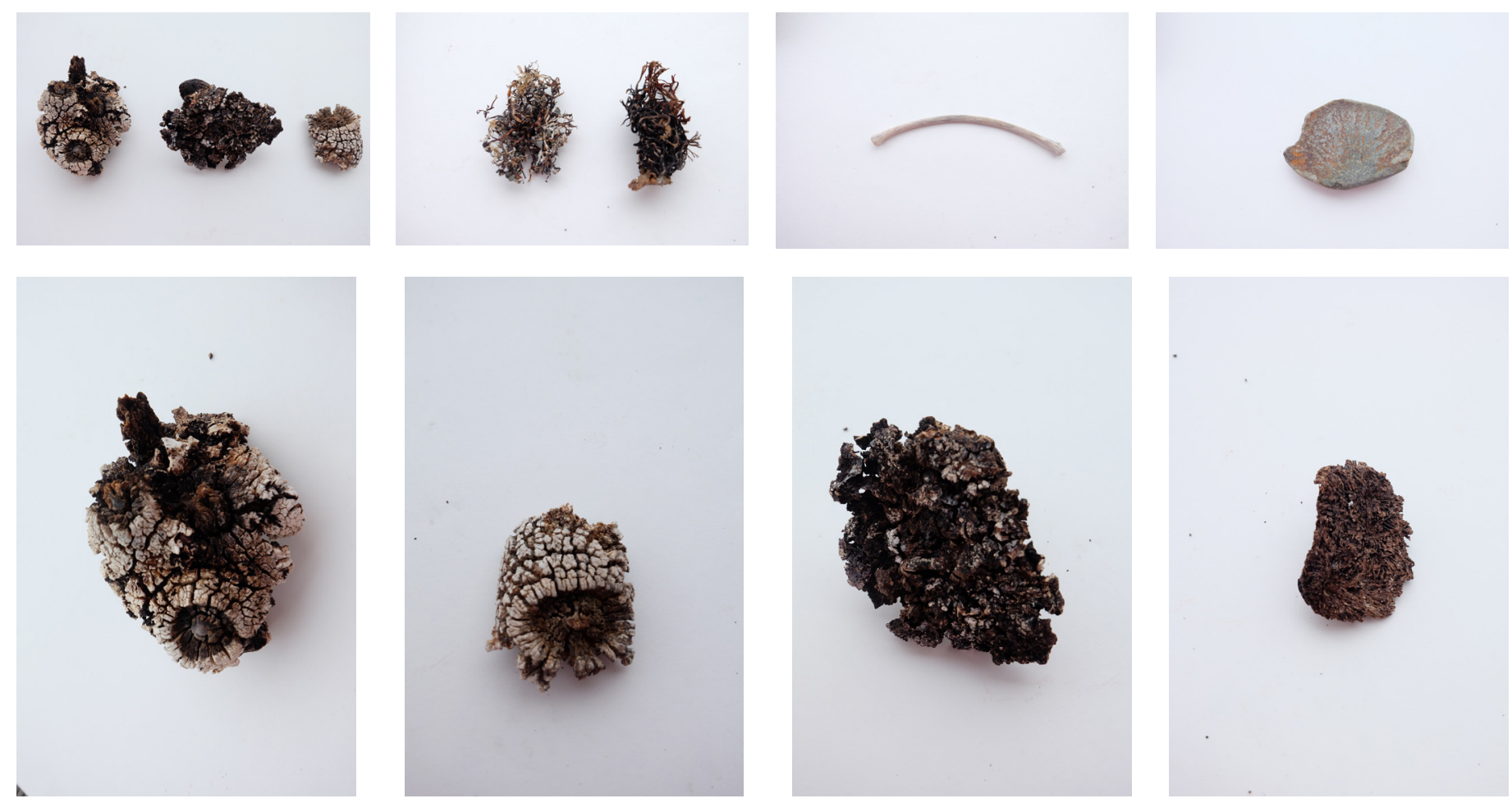

Fig.6.100. Found fragments 

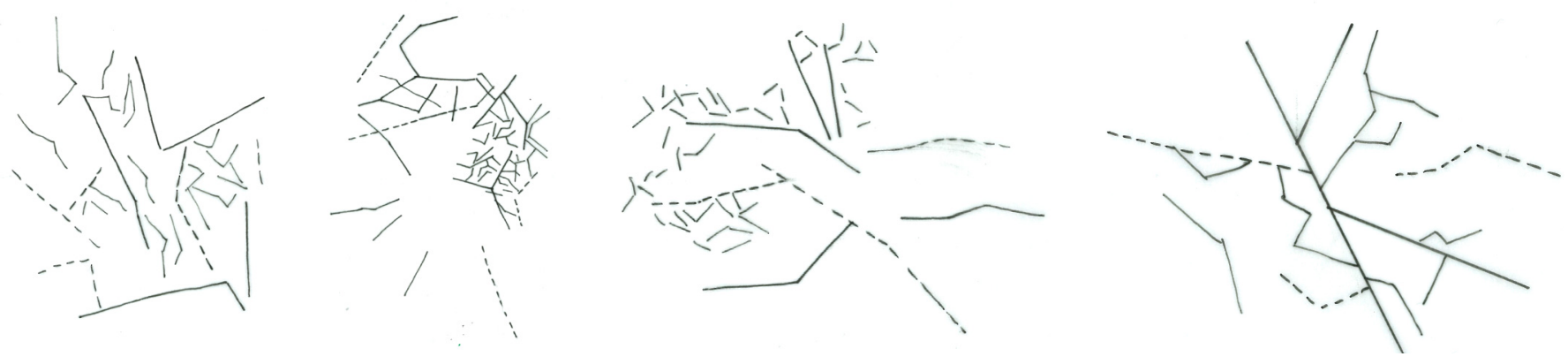

Fig.6.101. Initial form explorations 


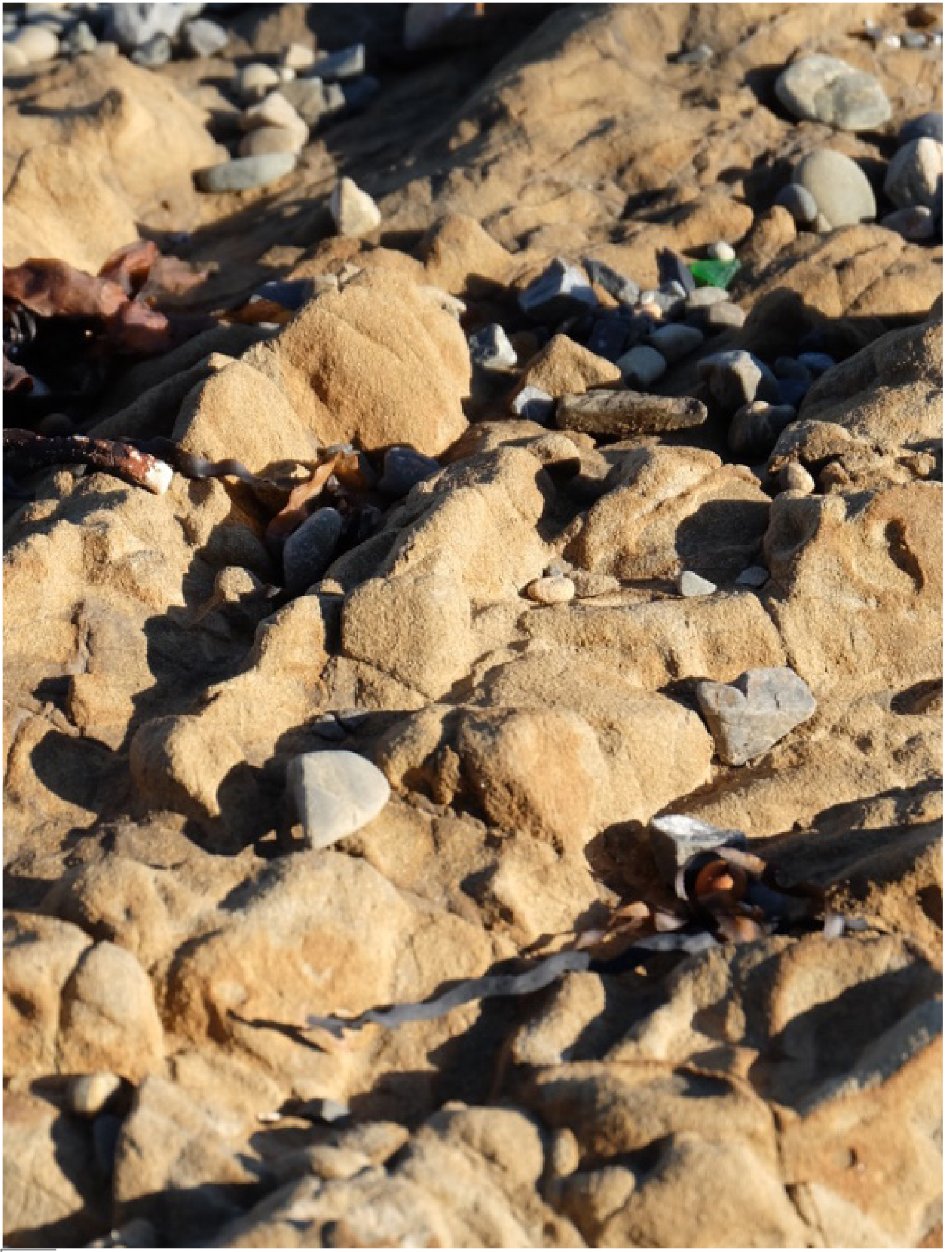




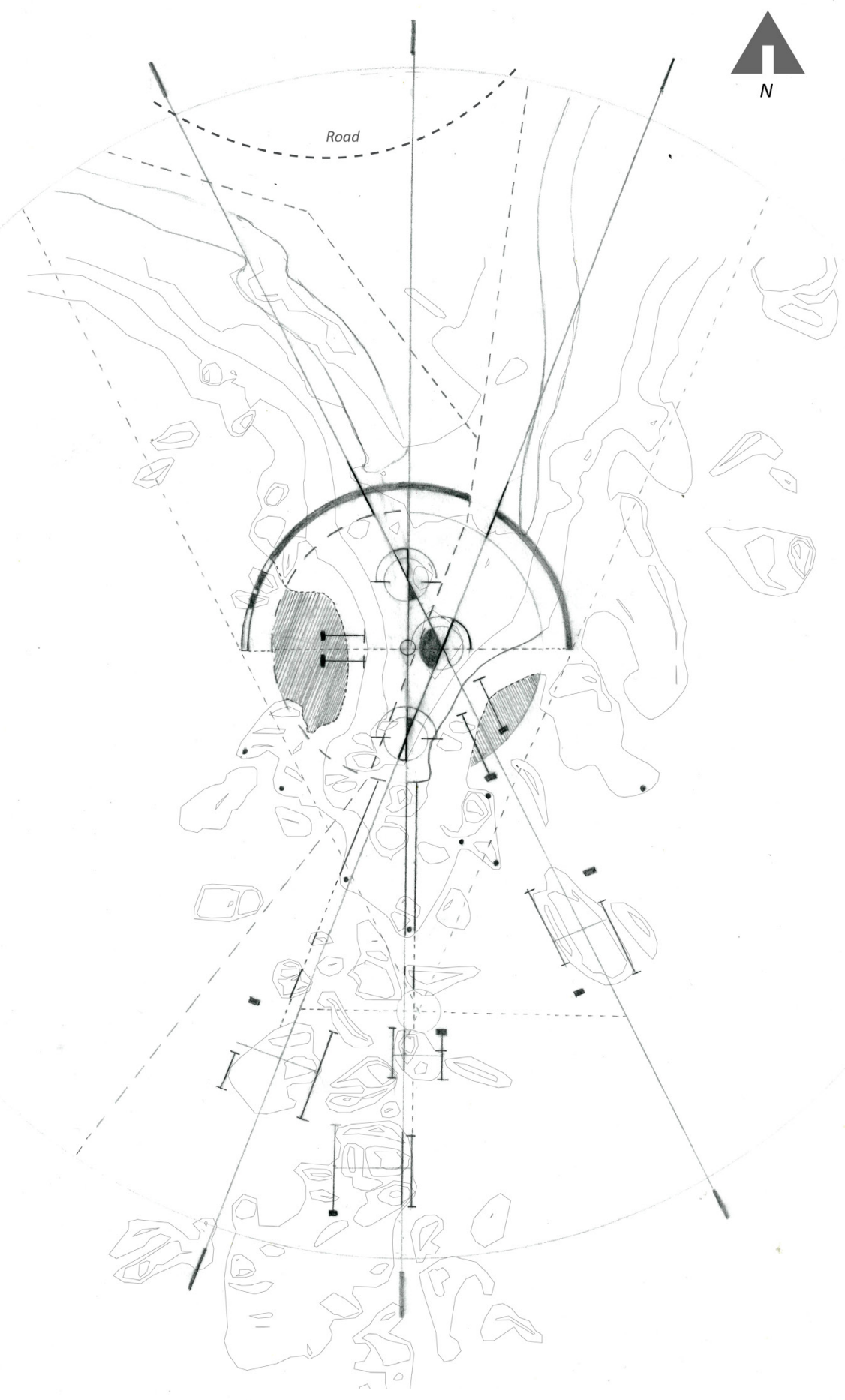

Fig.6.102. Photograph of site detail (opposite)

Fig.6.103. Detailed site analysis highlighting access points, axis and edge conditions 

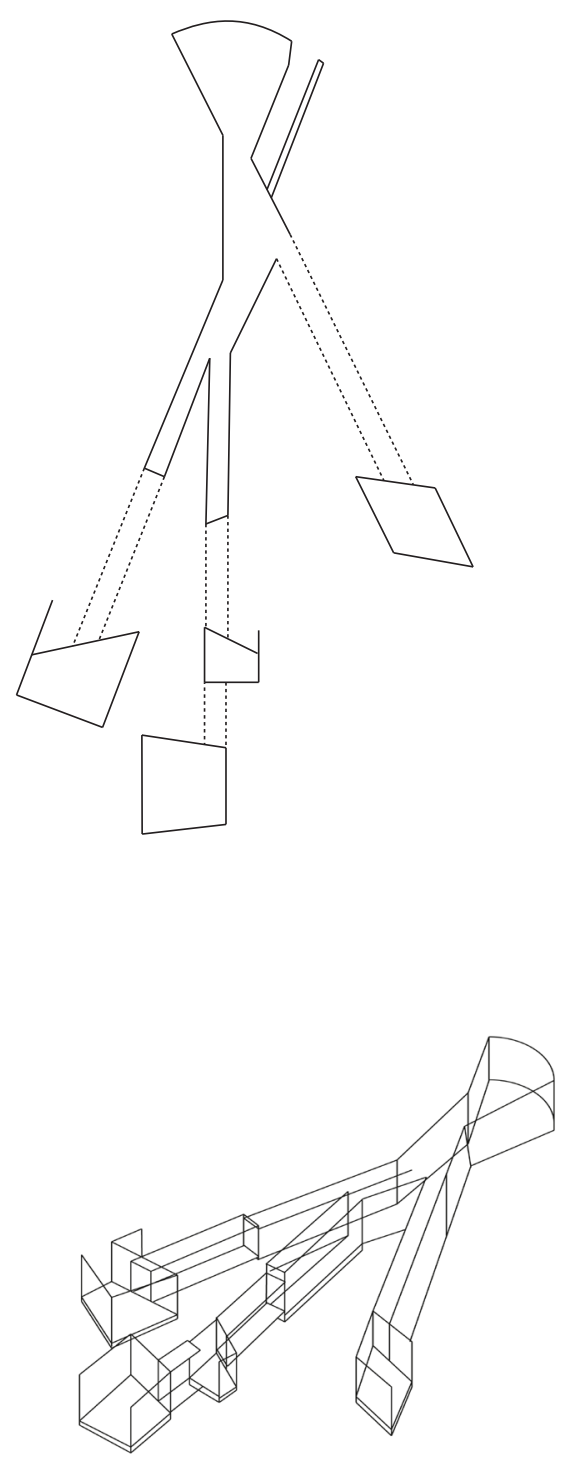

Fig.6.104. Initial form exploration from site analysis 
The initial design of the Sharks Tooth site is based upon the narrative of opening and closing to the sky. In developing the spatial experience of the intervention three sections of the design have been developed, which take you through a series of experiences, resulting in an intensified and focused experience of the night sky. There are three paths that can be taken each leading to a view of a direction of the night sky, south, east and west. As the occupier moves further through the intervention the spaces become more open both horizontally and vertically finally ending in an uninterrupted view of the sky and the adjoining horizon direction in which that particular platform is designed for viewing. This journey is designed to create a sense of anticipation and intensification of experience of the sky.

1. Closed - completely to all senses and experiences of the site ant night sky

2. Transition - horizontal opening out to the site but closed off to the sky

3. Open - vertical opening to the sky and horizontal opening facing the direction of the desired night sky, south, east and west

\section{1}

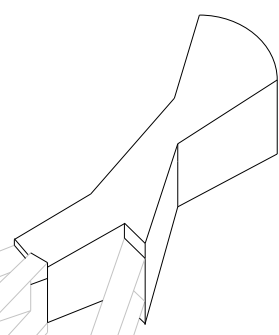

O

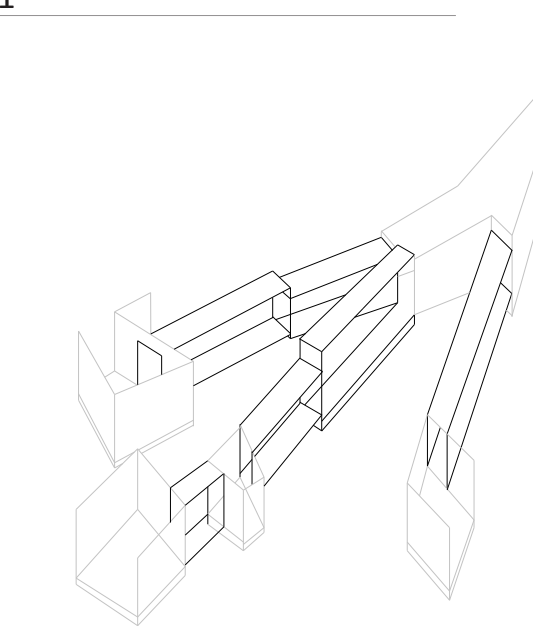

O 2
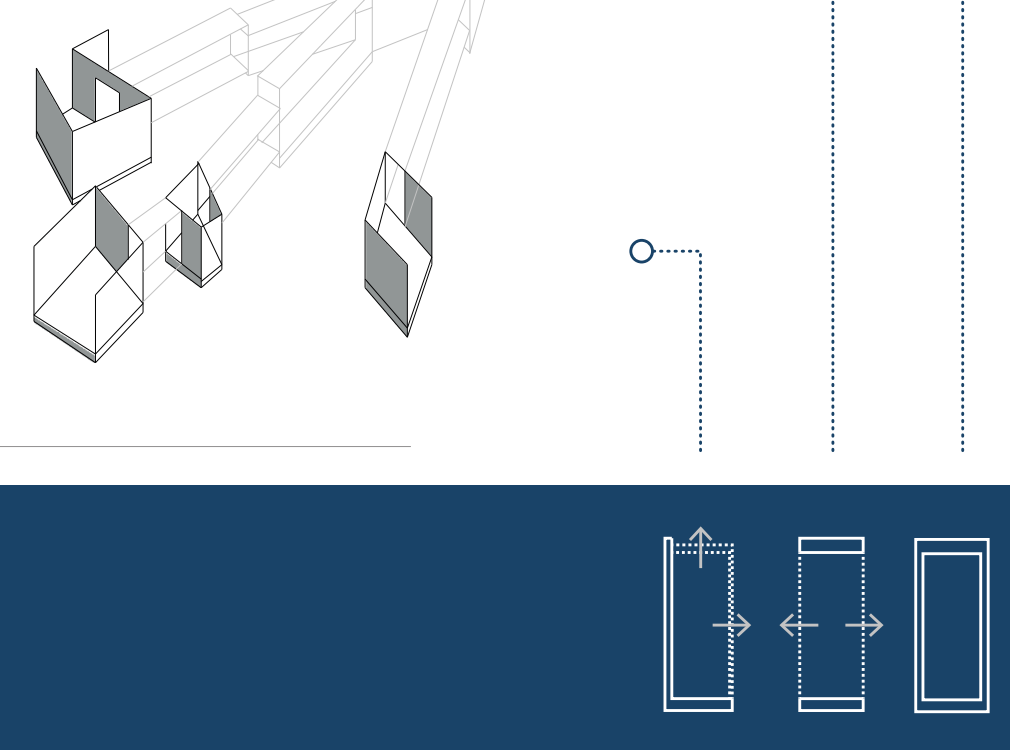


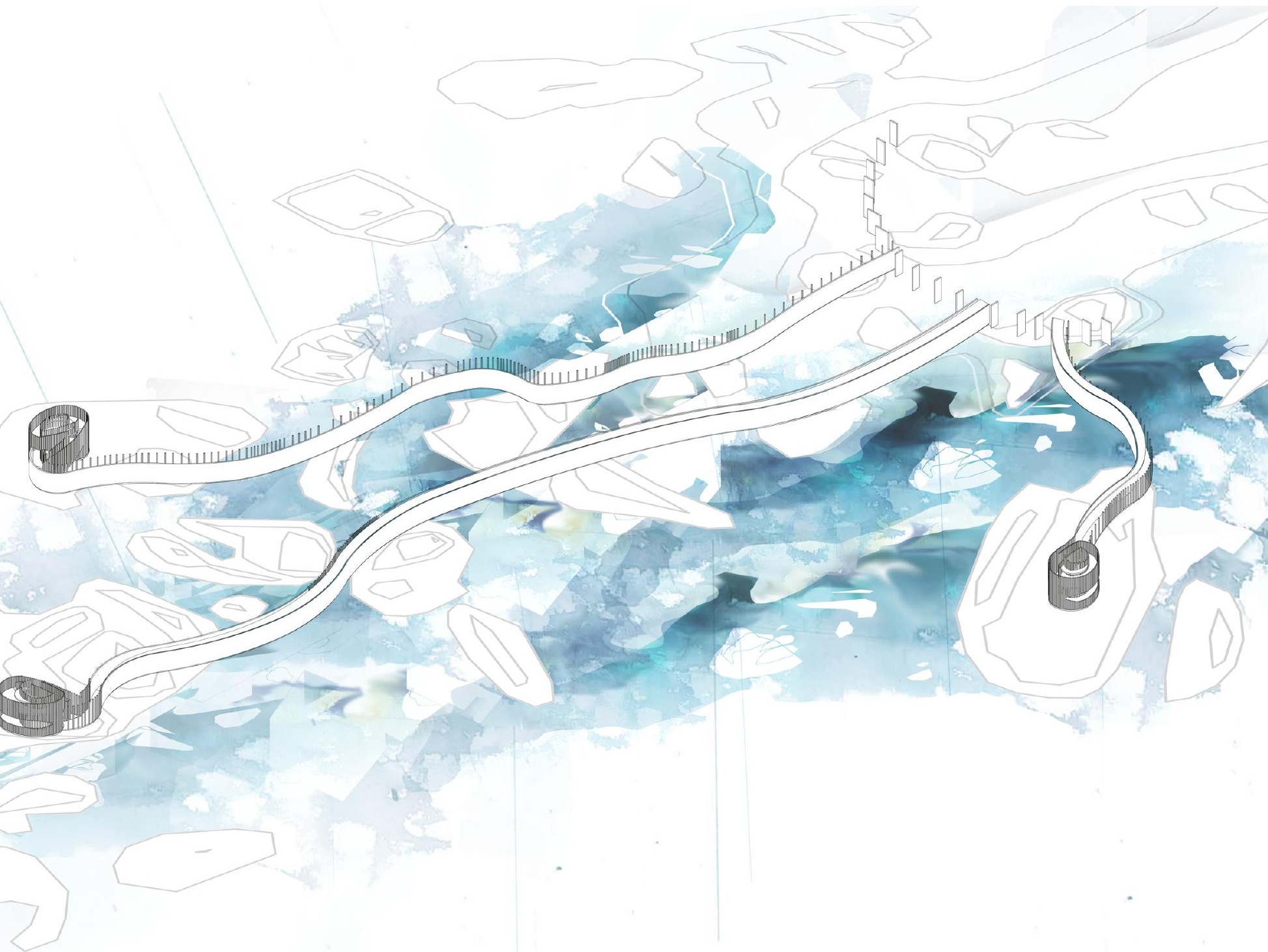

Fig.6.106. Overall perspective of intervention

Developing from the initial form exploration, the design was developed to further emphasise the context of the interventions and the relationship between context and architecture. The initial designs were rectilinear and foreign to the landscape. A more organic structure evolved that better integrated with the existing natural rock formations.

Each of the pathways are designed to develop an intensified experience of both architecture and context. Separately the pathways focus on a particular view shaft in both the vertical and horizontal direction. The densities and placement of the vertical columns have been devised to directionally focus the viewer on the horizon view plane that transitions the eye from land to sky. These pathways take the occupier on a journey of discovery from land to sea to sky.

One of the key contextual experiences of this particular site is the strength of the wind. Using this experience a vehicle for intensification, the pathways aim to both funnel and/or provide protection from the prevailing winds through the orientation and densities of the vertical components. This creates a contrast of experiences between protection from and vulnerability to the wind. 


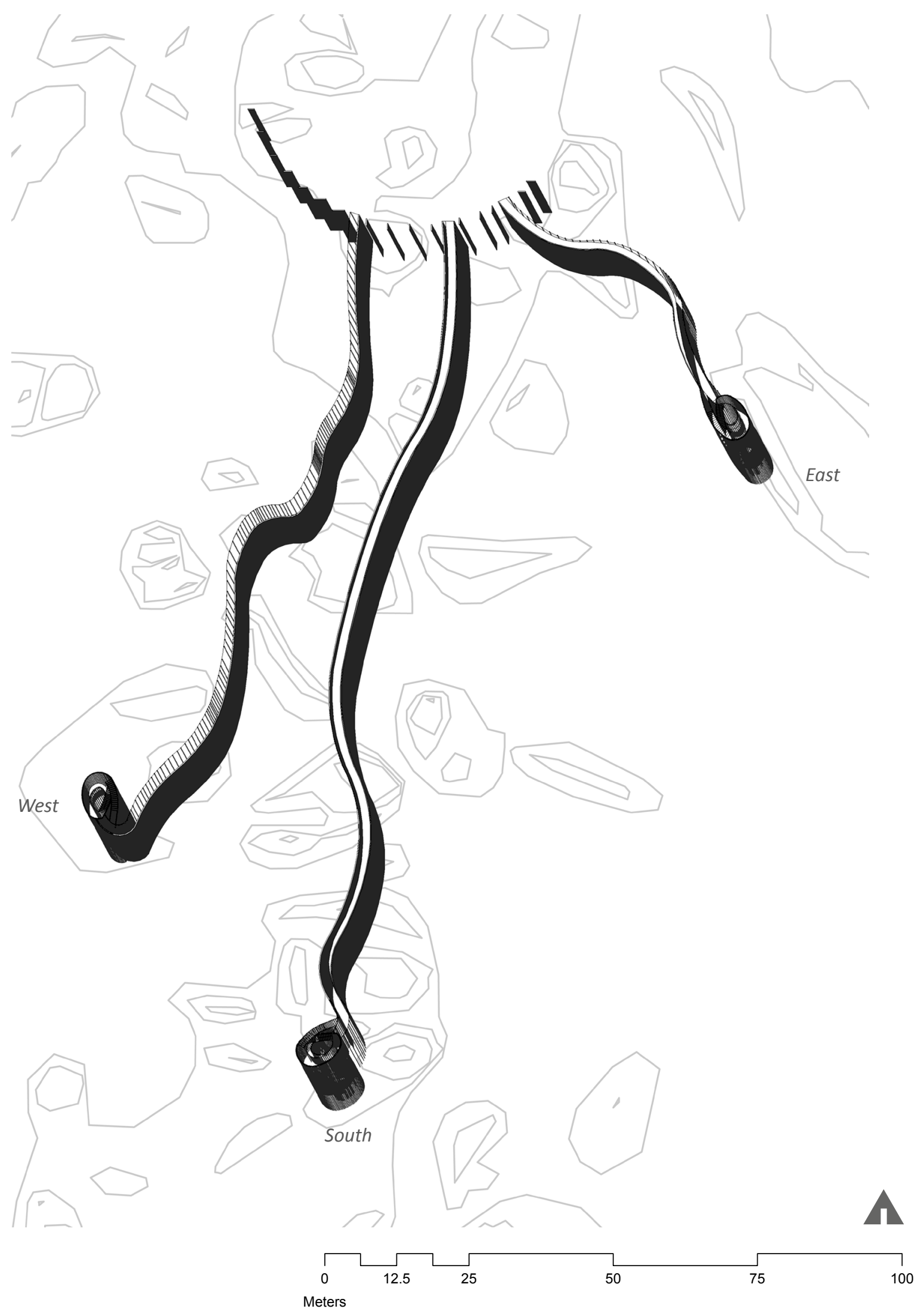

Fig.6.107. Site plan 

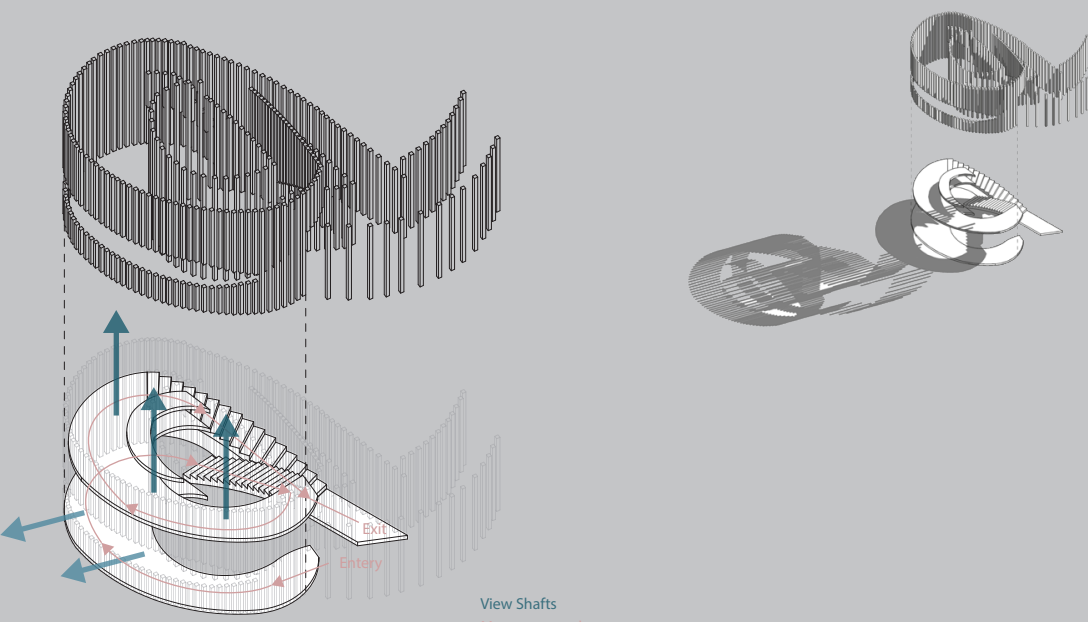

Fig.6.108. Diagram of observation platform

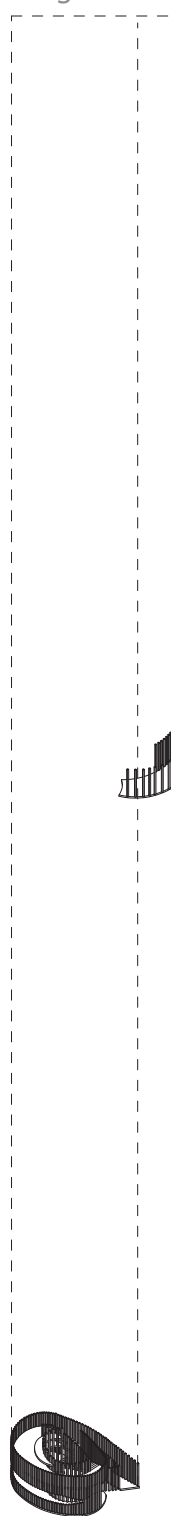

Fig.6.109. Exploded diagram of the three section of the design 


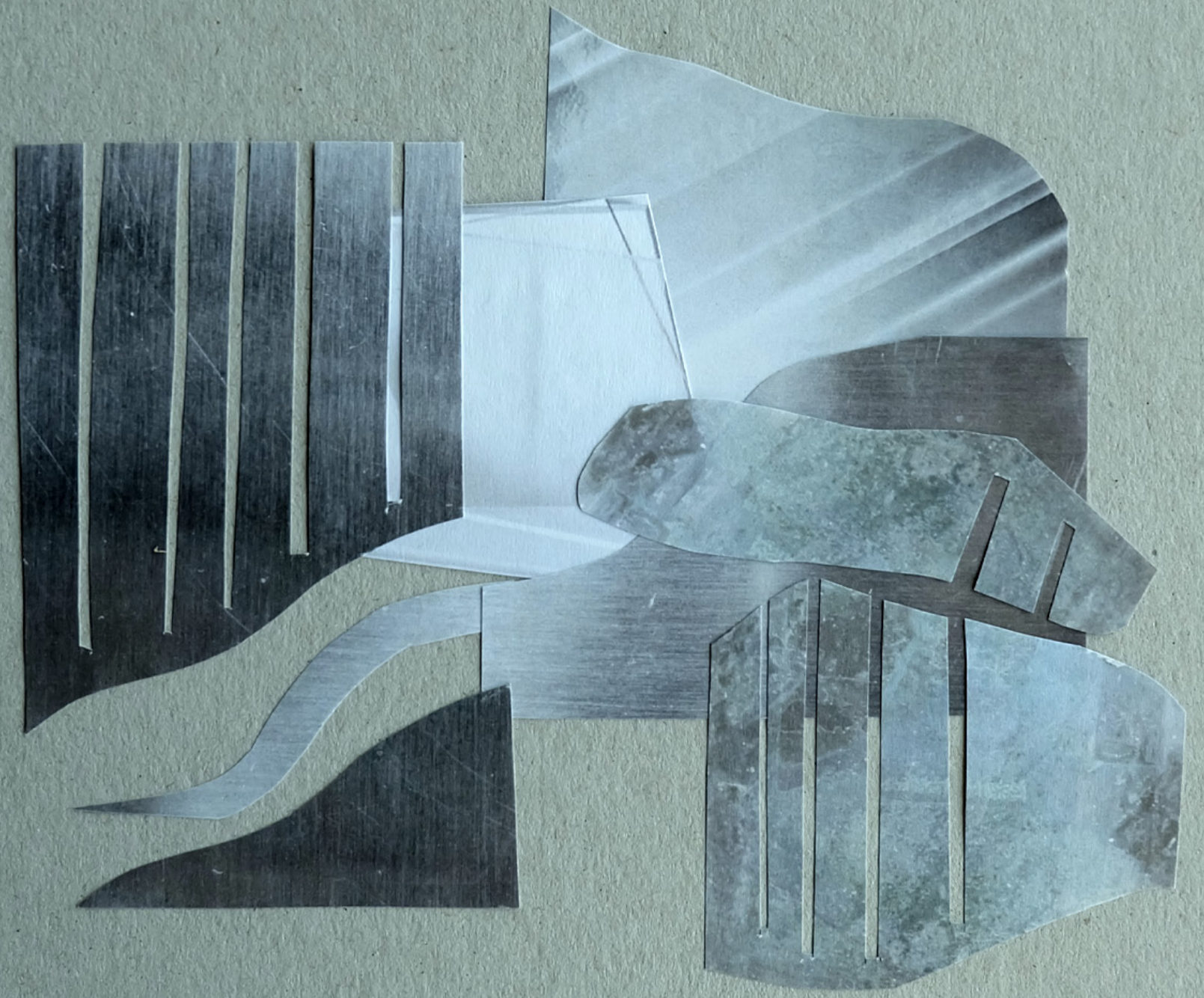



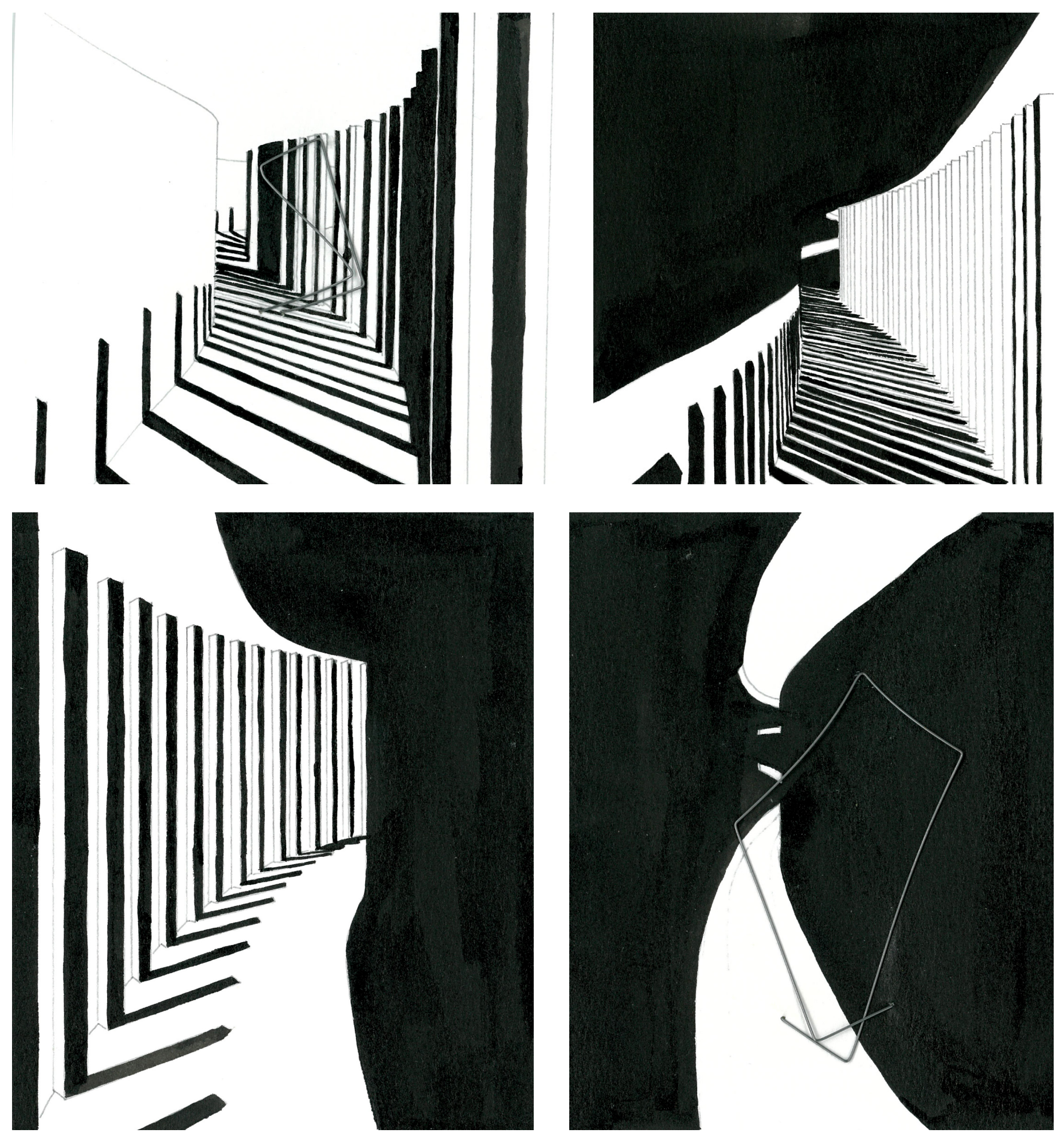


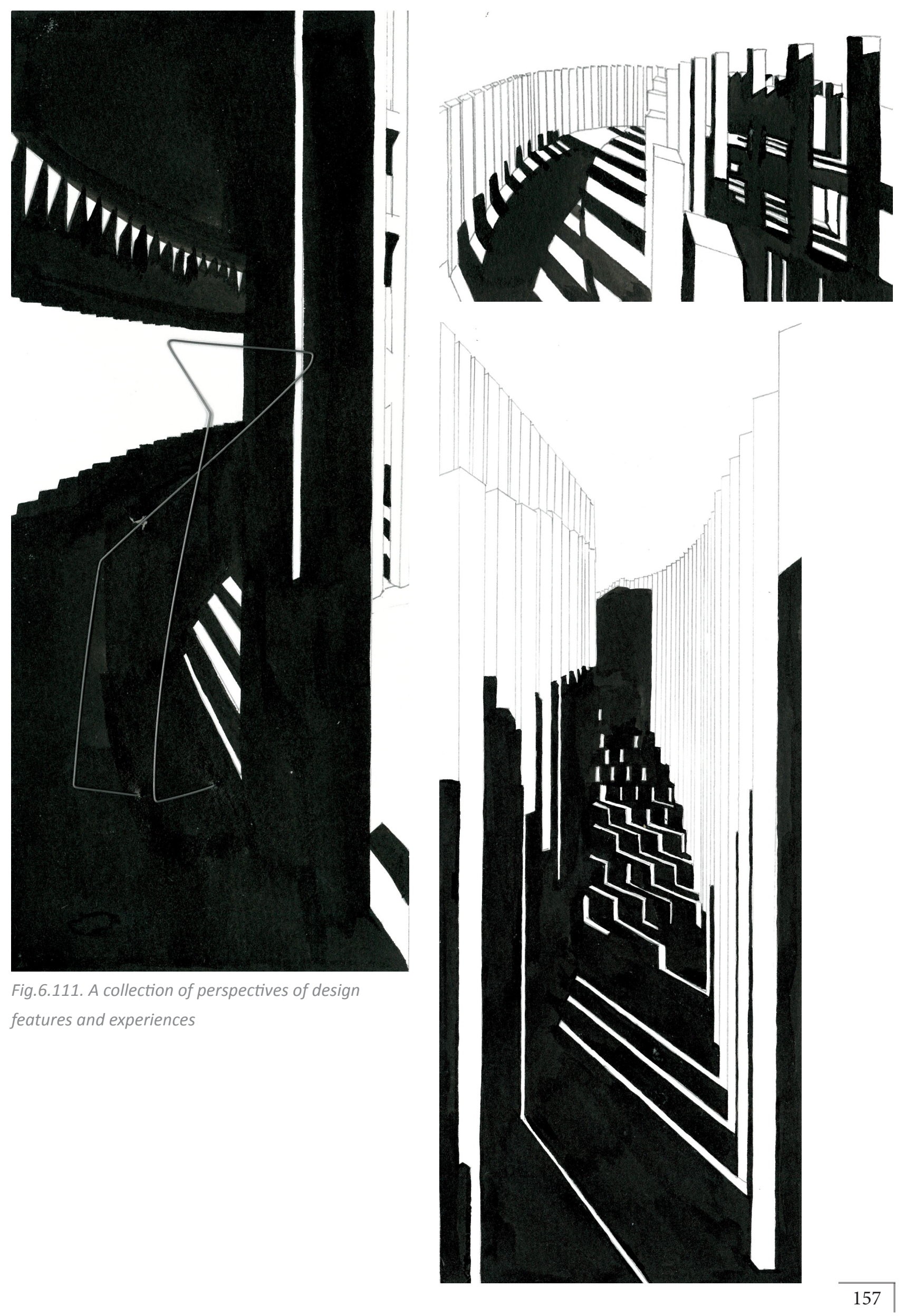




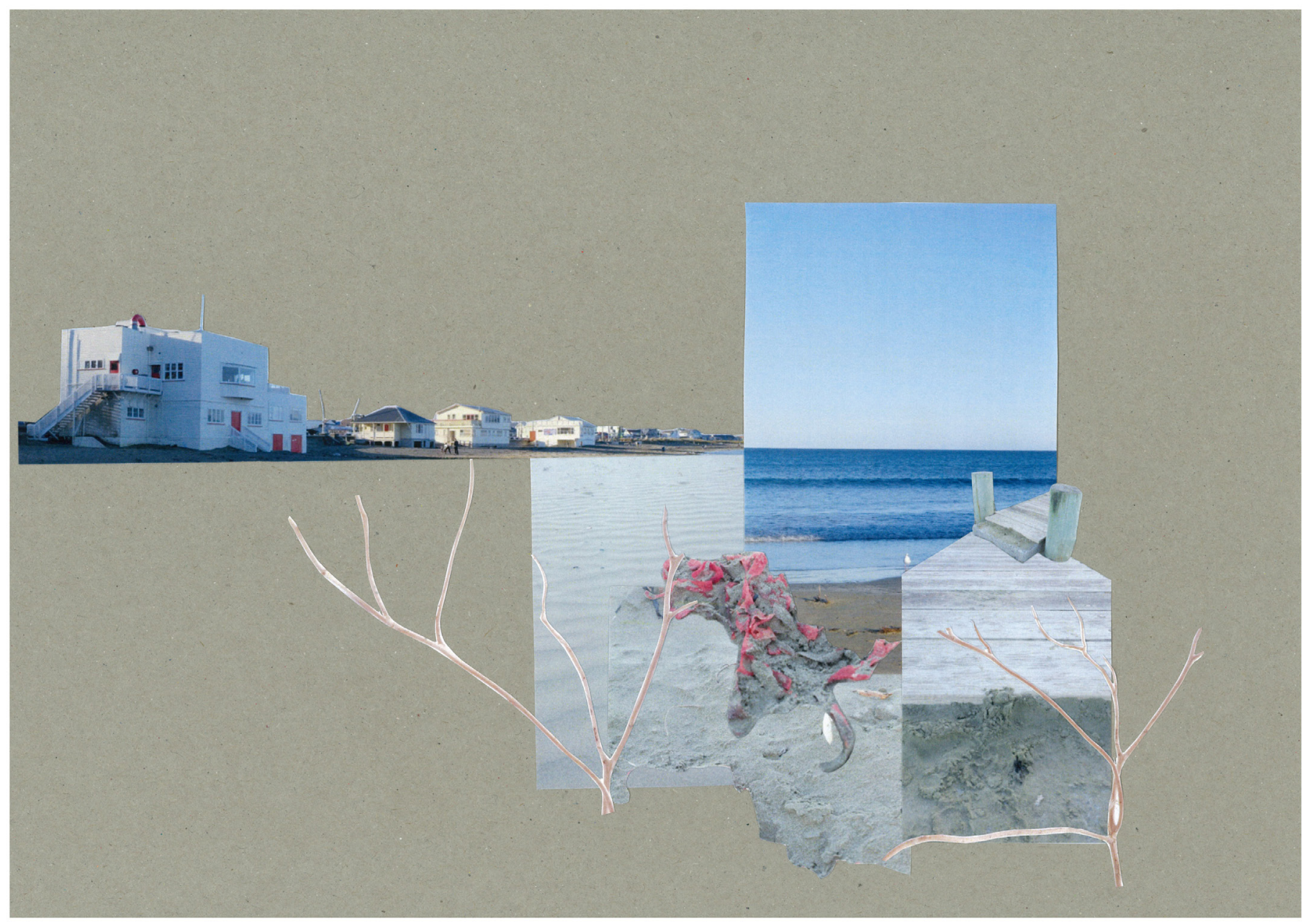

Fig.6.112. Collage of images, textures and fragements specific to Lyall Bay 


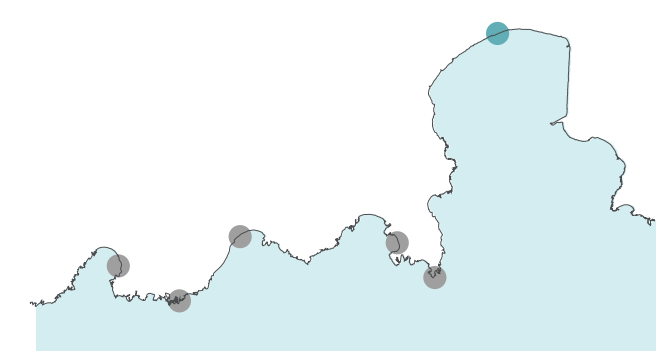

\section{Lyall Bay}

The final site is at Lyall Bay. This site is the closest to a populated area. The beach is one of the most well used beaches in Wellington and is very popular with surfers. Lyall Bay has a long history of surf lifesaving. Here the surf lifesaving building has crossed the divide of the road and has been built on the beach. At the site, there is a sense of battle between natural and manmade environments. As the urban infrastructure expands the natural environment seems to 'fight' to keep hold.

The shelter at Lyall Bay focuses the tension between human occupation and nature. In all directions, evidence of the conflict can be seen. Both form and materials are used to explore this conflicting relationship that distinguishes this site.

Brief

- $\quad$ Shelter for family and beach users

- $\quad$ Cluster of structures that can be occupied by many groups of people

- Use of man-made materials such plastic and fibreglass 

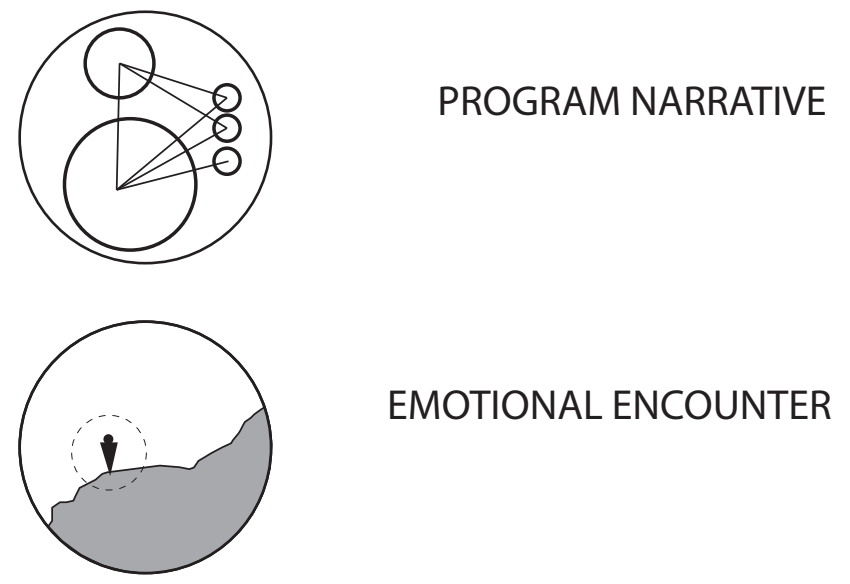

EMOTIONAL ENCOUNTER

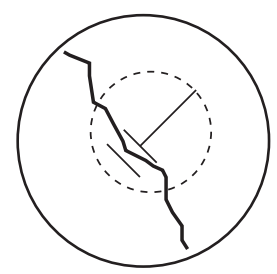

LEVEL OF CONTACT WITH

THE THRESHOLD

THE 'THRESHOLD' IS THE POINT AT WHICH LAND TRANSFORMS INTO SEA

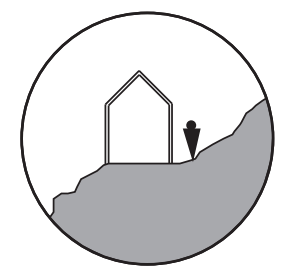

CONTEXTUAL NARRATIVE

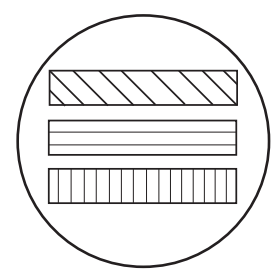

MATERIAL AND MATERIAL PROCESSES

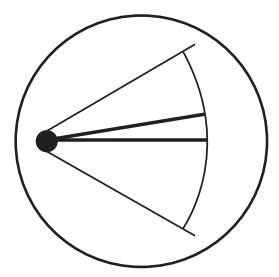

VIEW FOCUSING THE EYE

Feedom and Anticipation

On the edge of the tidal change of surfers

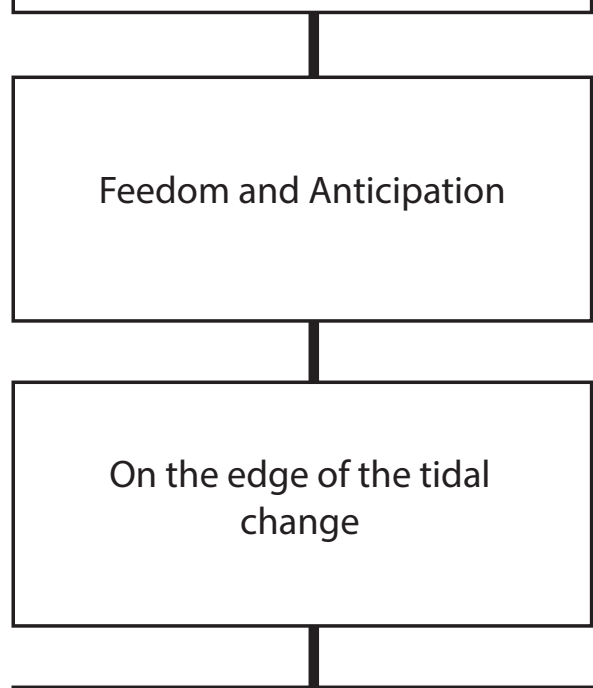

Natural vs Man Made

Spontaneous vs Regulation

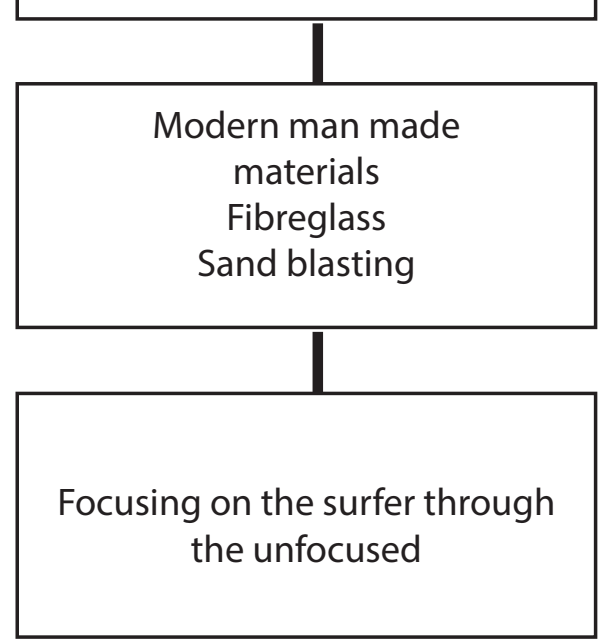




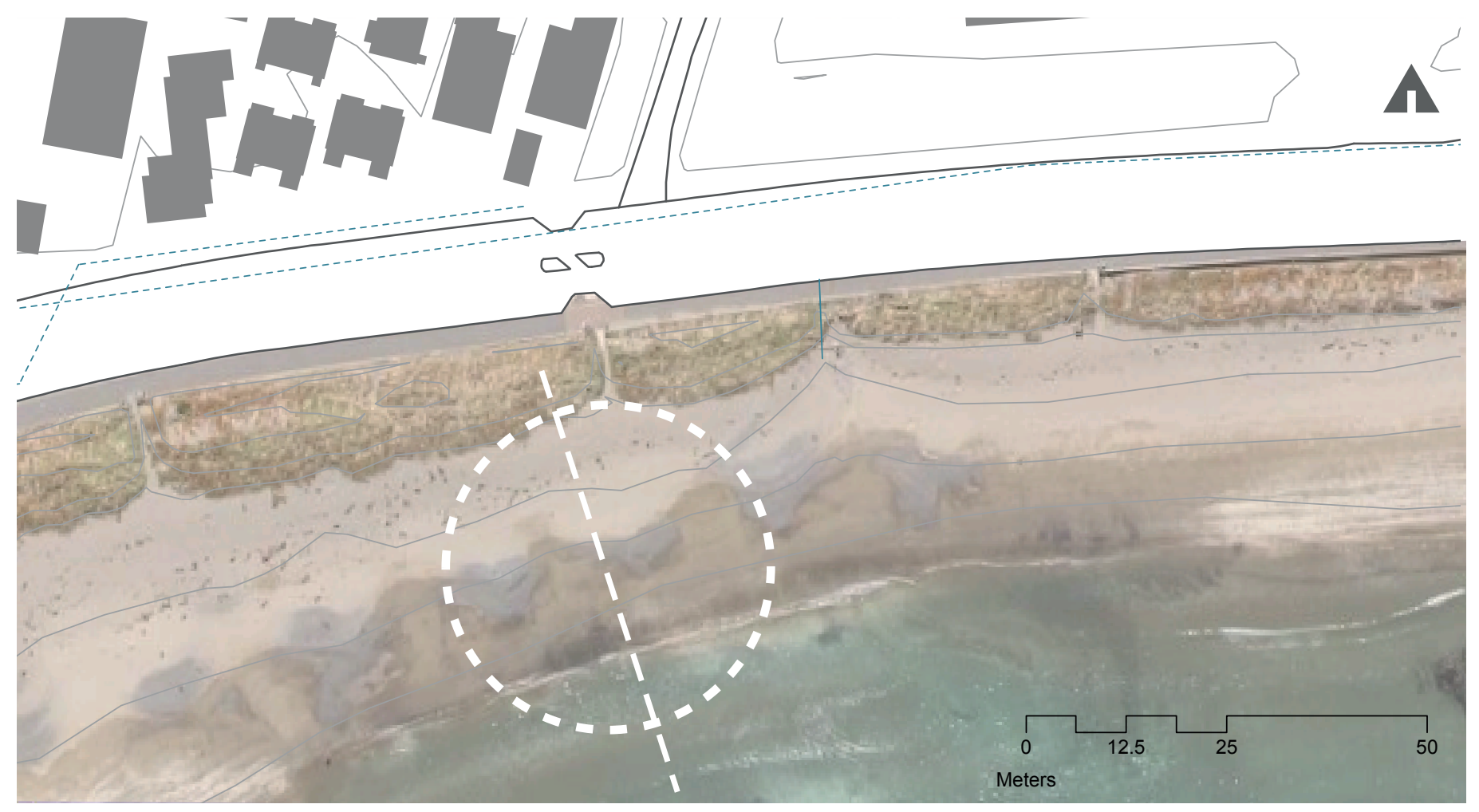

Fig.6.114. Site plan - circle highlights the focus area of the site, the diagonal line represents the intuitive direction and section cut

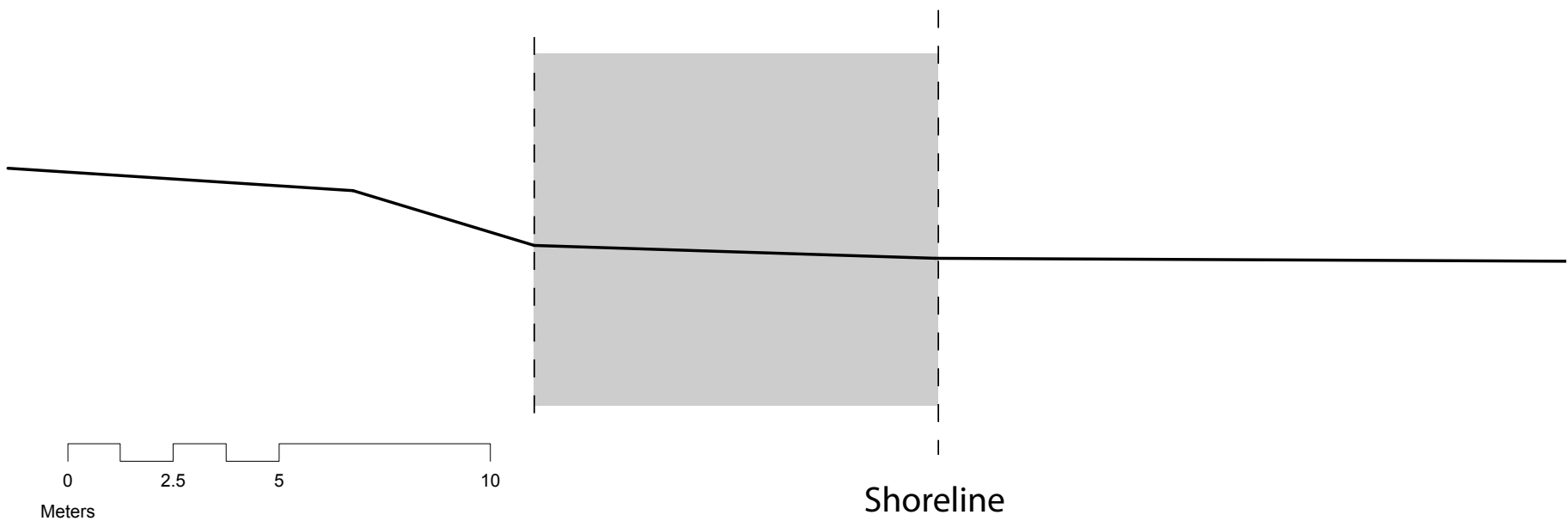

Fig.6.115. Diagrammatic section through site 


\section{Images of site}
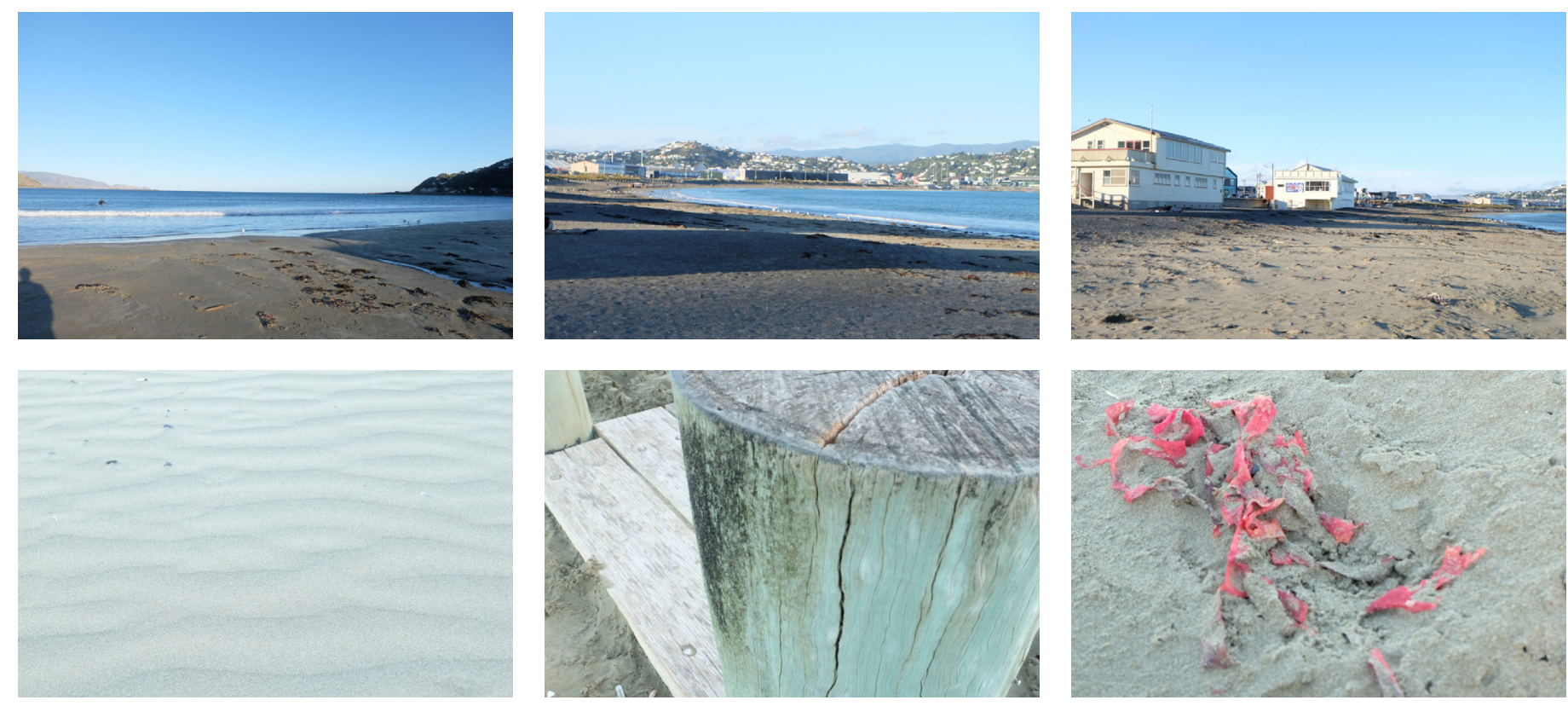

Fig.6.116. Collection of images from Lyall Bay 

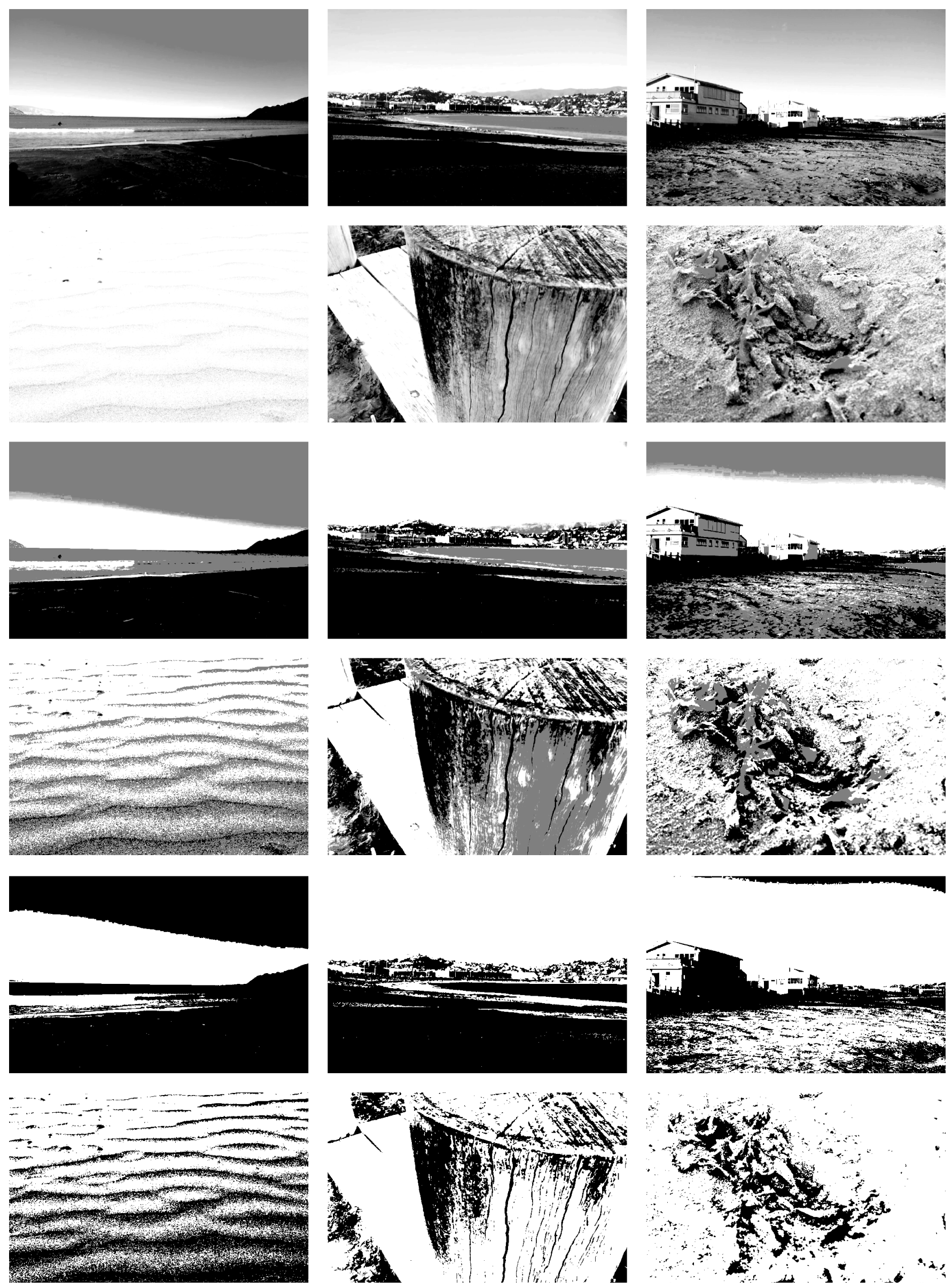

Fig.6.117. Graphic study of textures and views from the site 

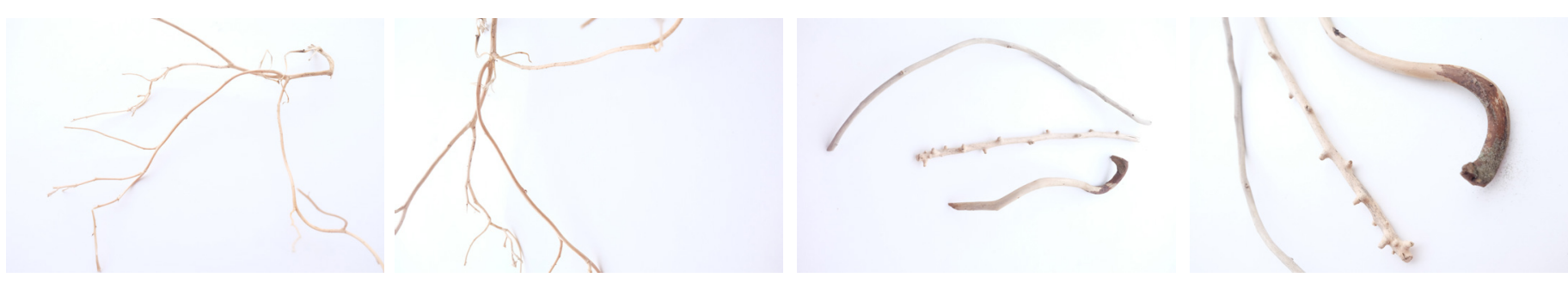

Fig.6.118. Found fragments
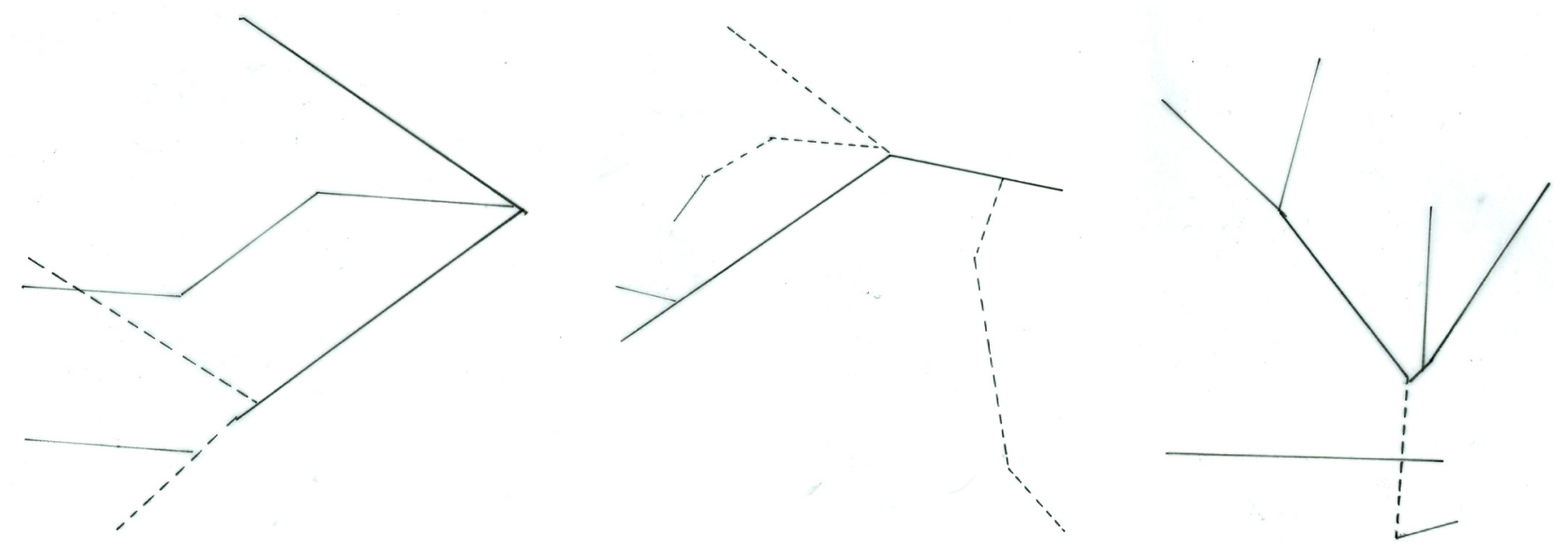

Fig.6.119. Initial form explorations 


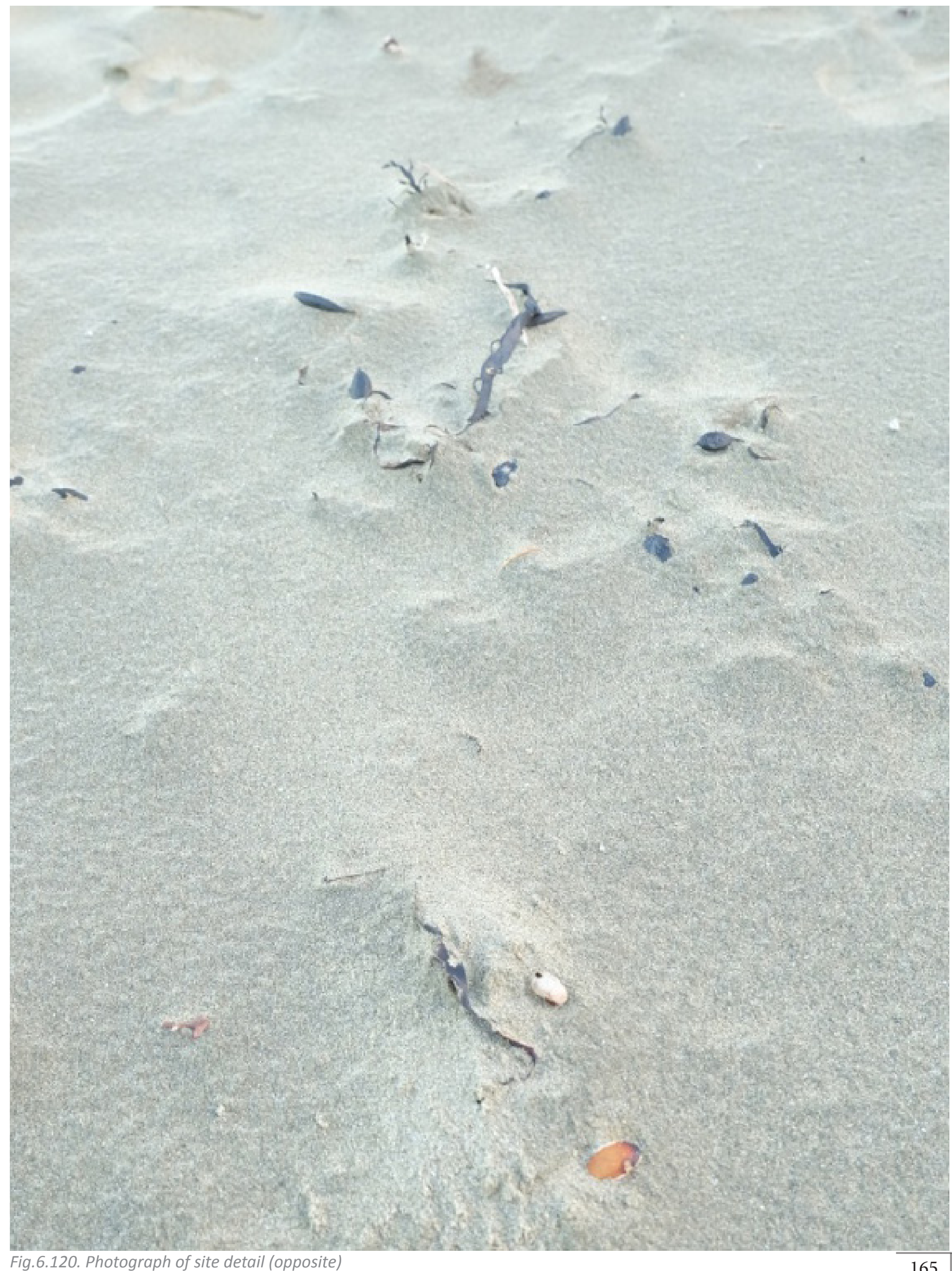


Nodal points and axis leading to the sea

Axis and man-made grid layout

Key intersections of grid lines and the divide between industrial and residential areas

Figure ground of key grids and patterns
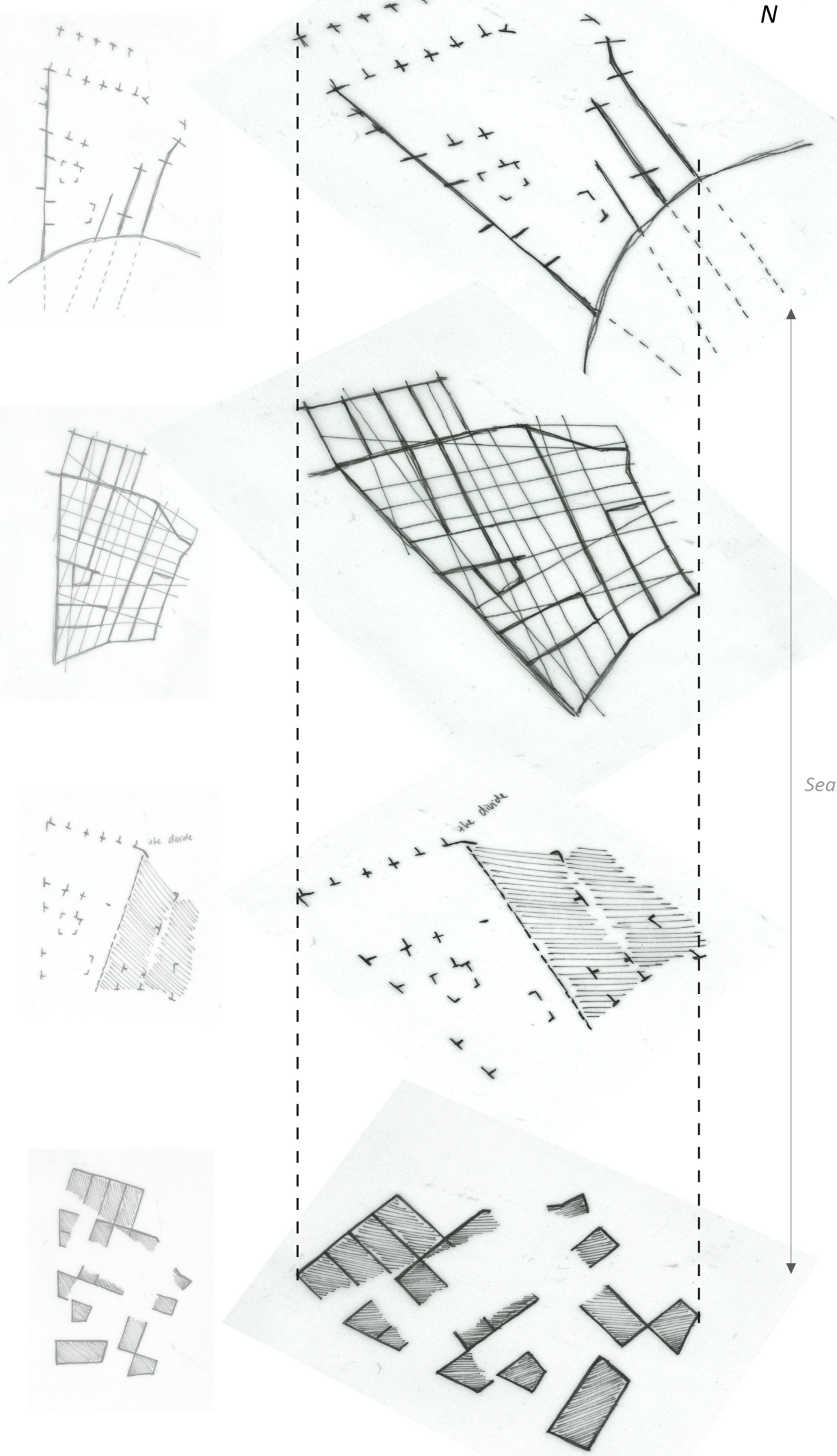

Fig.6.121. Sketched analysis of Lyall Bay context 

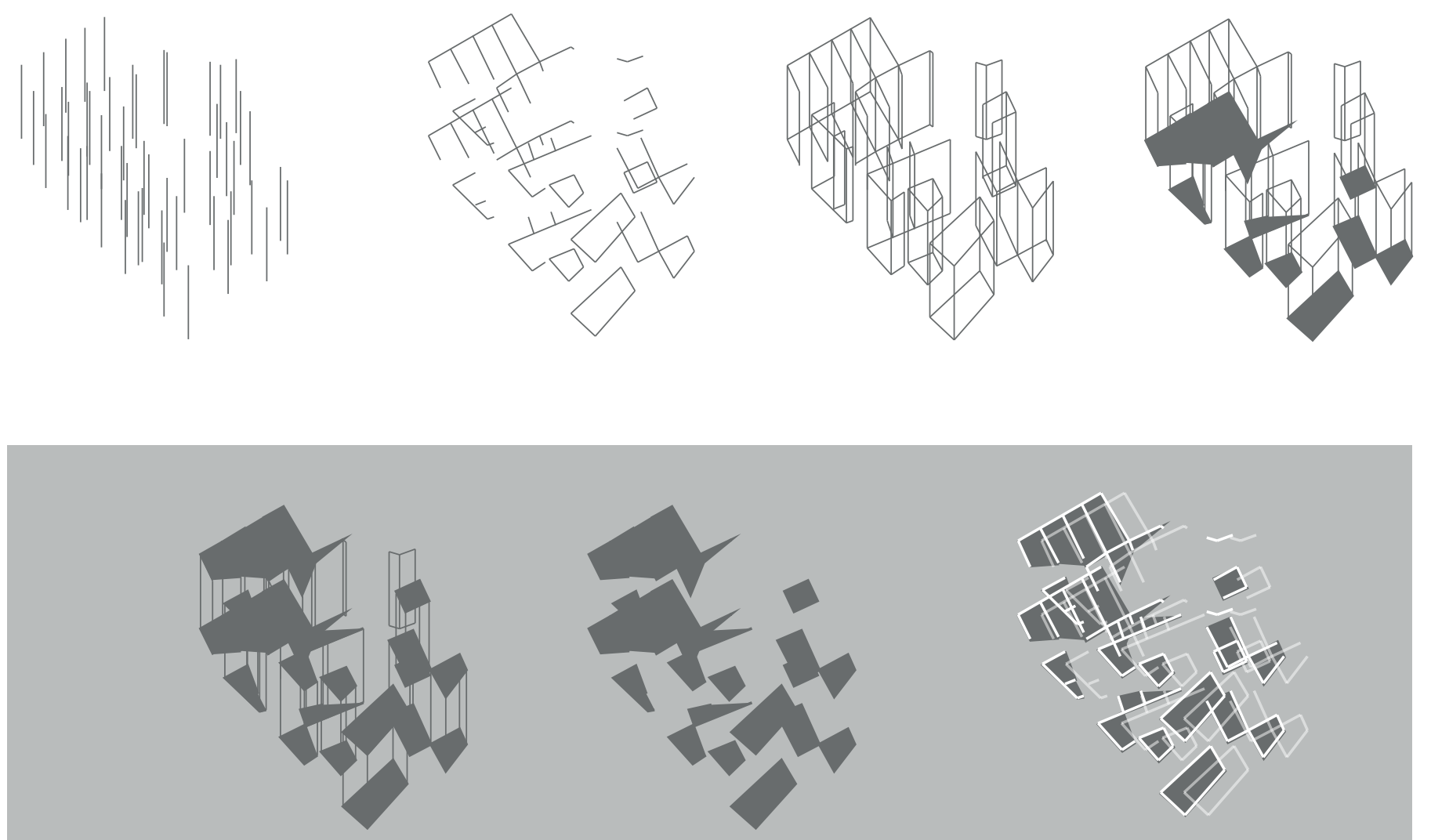

Fig.6.122. Graphic study of Lyall bay context 

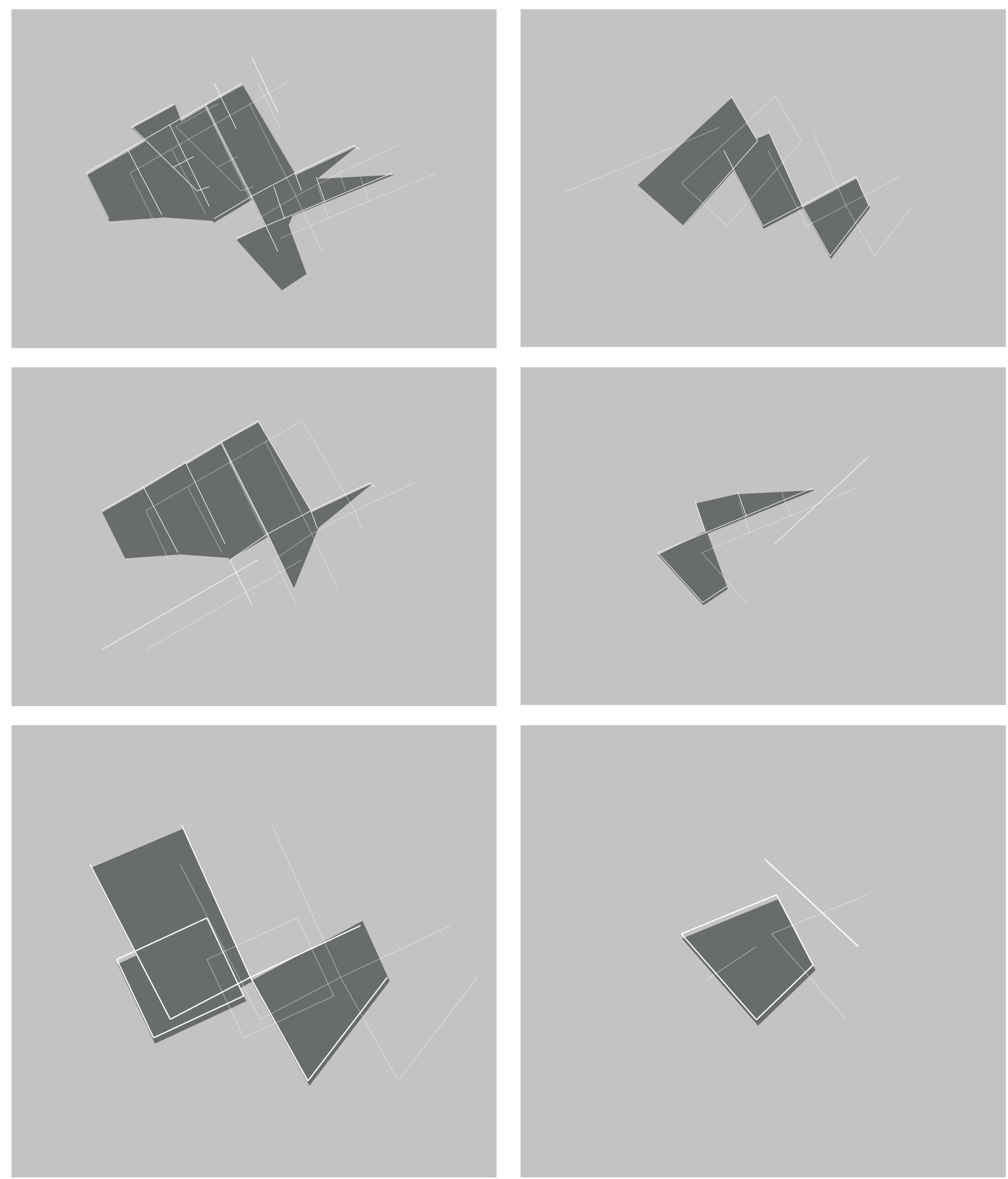

Fig.6.123. Pulling out key intersections exploring regulation and spontaneous ordering and patterning of lines and planes 

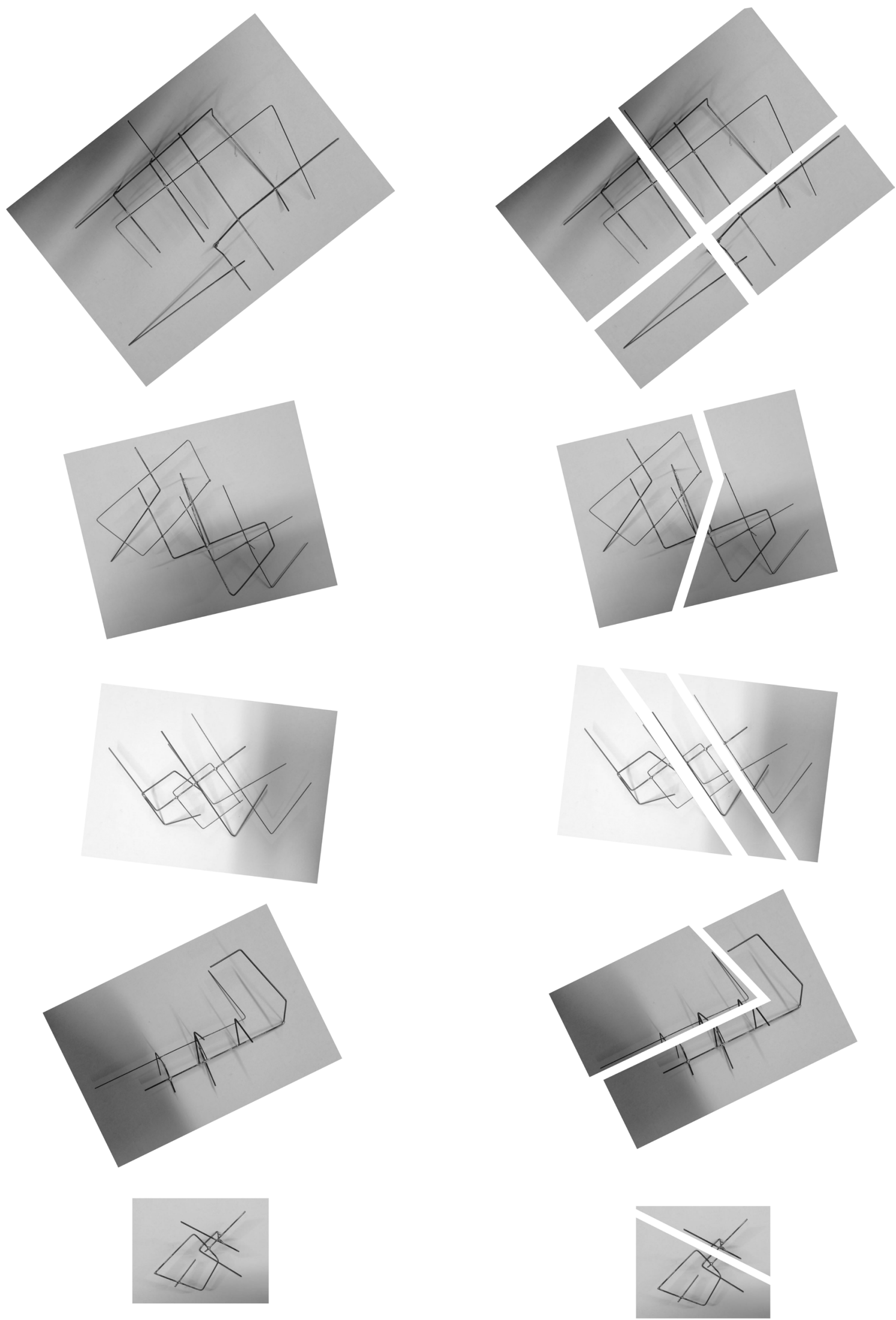

Fig.6.124. Series of wire frame models exploring intersection drawings in 3 dimensional form 

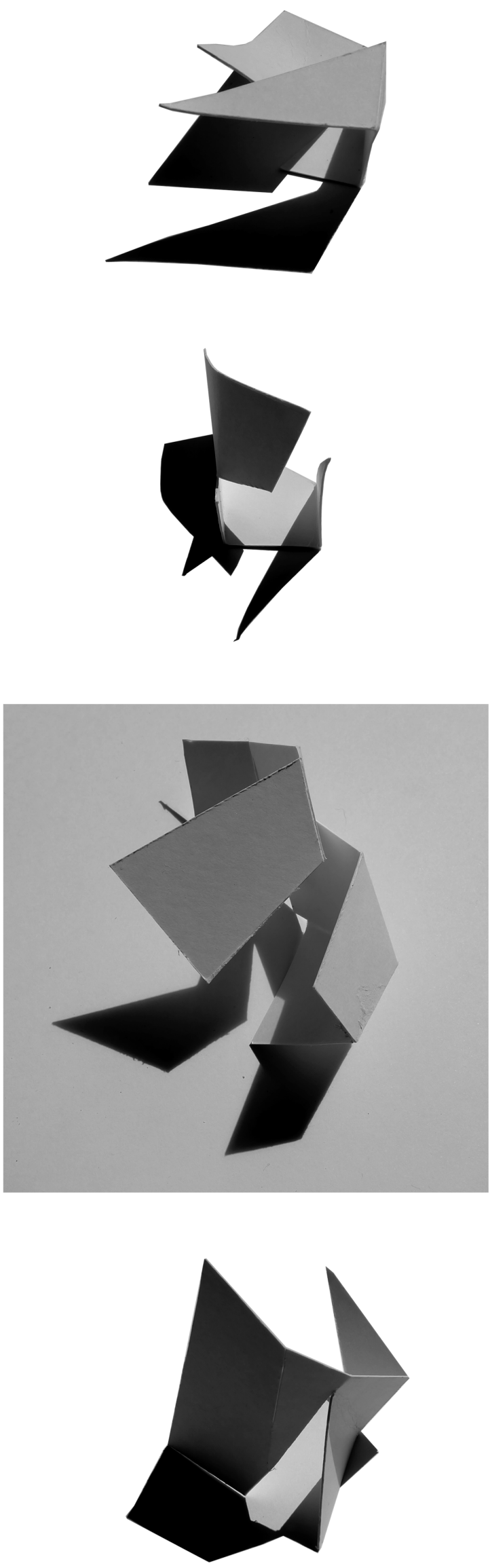

Fig.6.126. Form exploration, fold lines derived from intersection drawings and wire models

Fig.6.127. Site plan (opposite) 


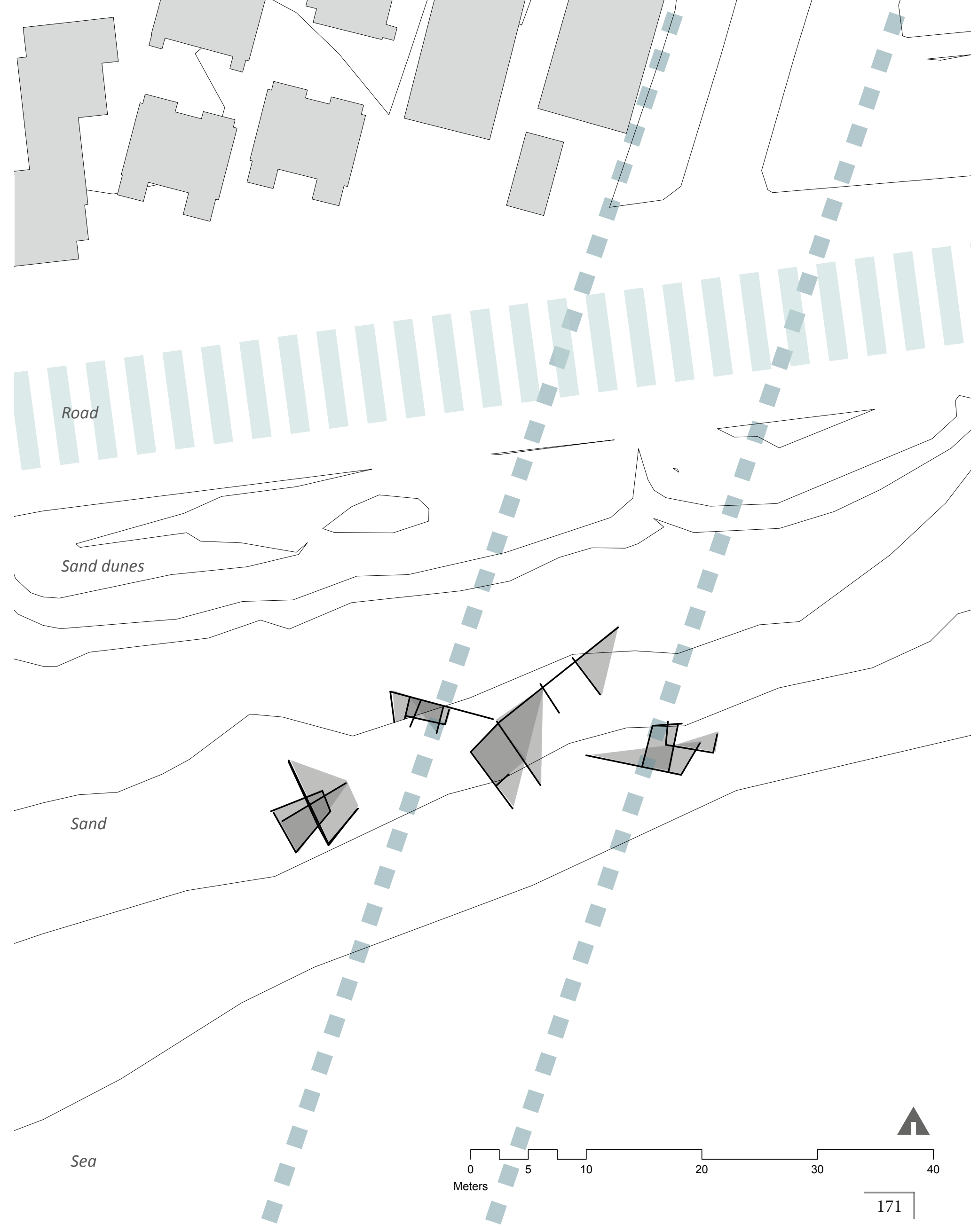




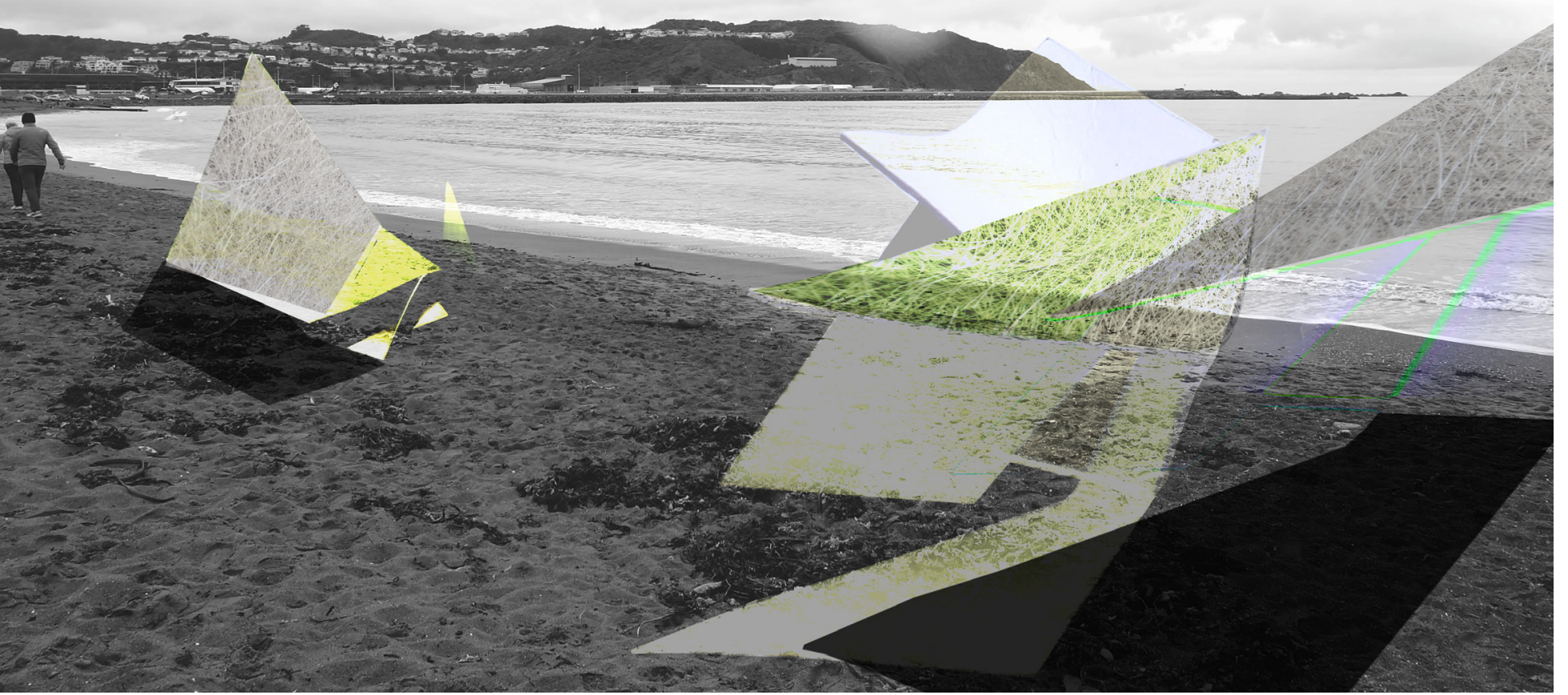

Fig.6.128. Perspective of interventions sites on the divide

Driven by the urbanised context surrounding the site, the architecture highlights the human impact and the divide that has been created between built and natural form. From the precedence that has been set further down the beach at the surf lifesaving buildings crossing the divide of the road the architectural intervention aims to highlight the notion of foreign objects invading the beach. Through its form and materials the architecture explores this tension between human occupation and nature and their interaction. Nature inevitably will leave its trace on the architecture, highlighting its overarching power, however on this site it is important, in contrast to other sites, to emphasize the level of control over the deterioration process. This is shown through the selection of man-made materials that resist/ deteriorate slowly. The foreign forms will obstruct the natural environmental process, the sand constantly moves and will build-up around the edges of the shelters. 

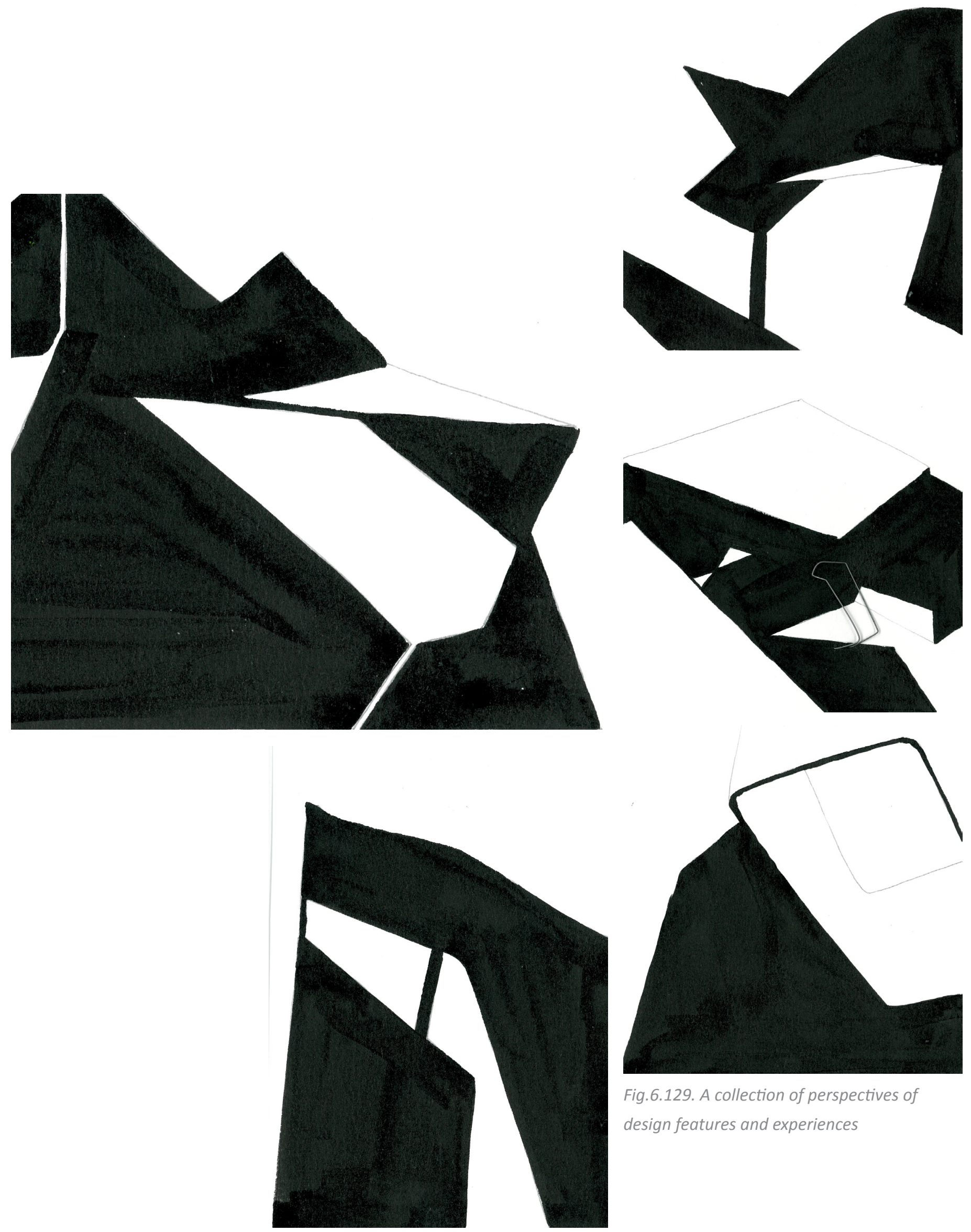

Fig.6.129. A collection of perspectives of design features and experiences 

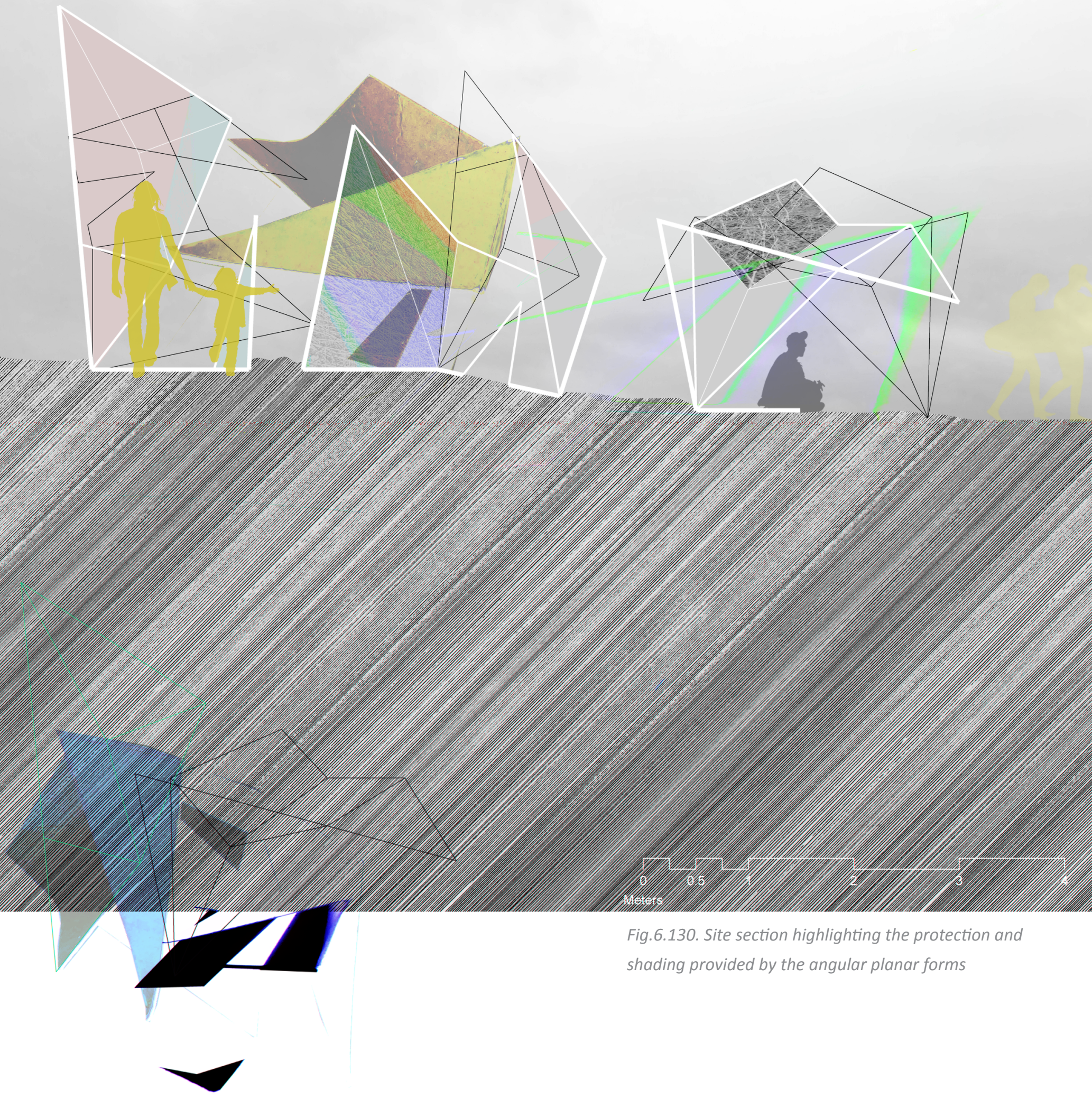


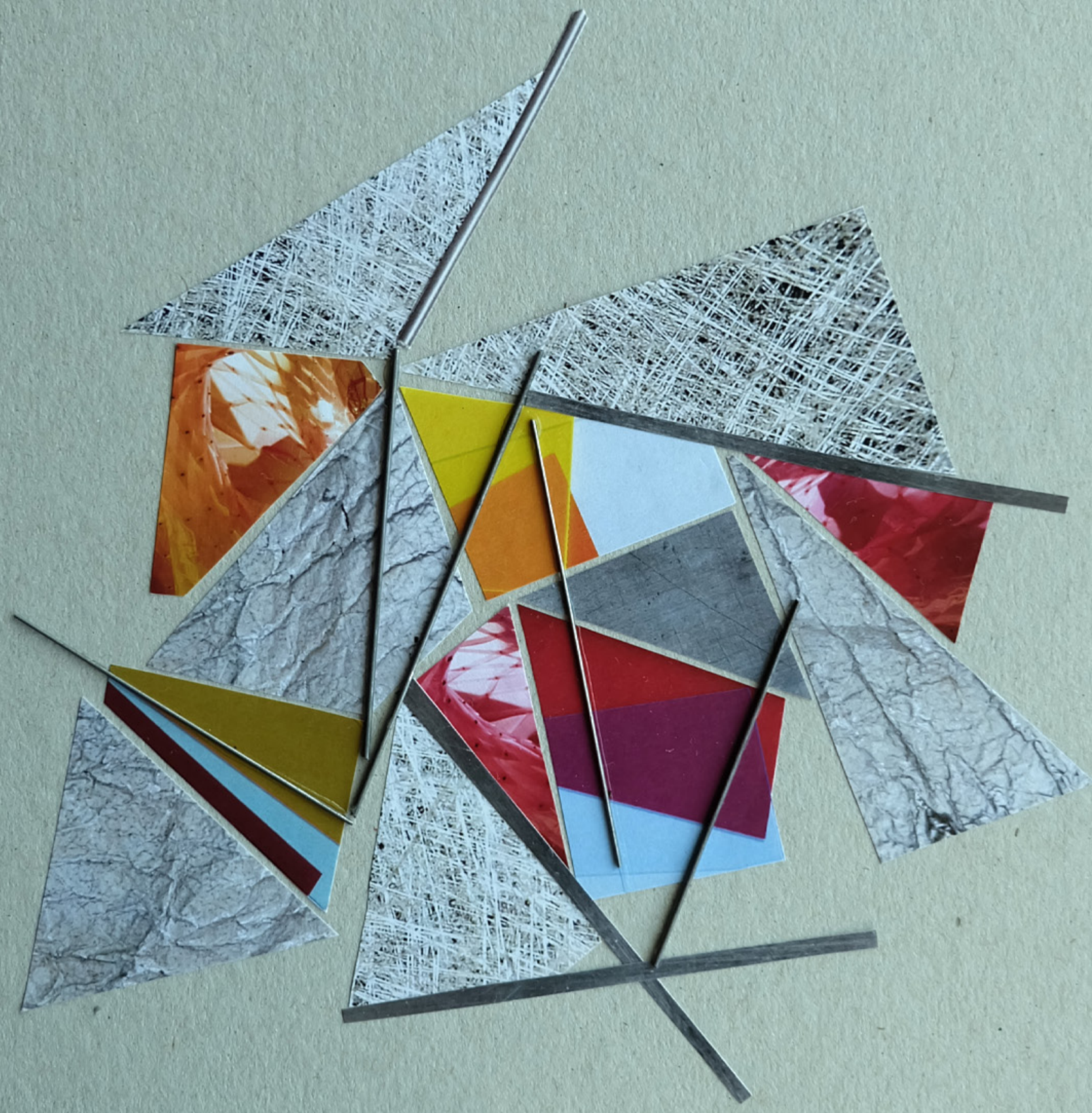


In evaluation, the design process has produced suggested design outcomes for each of the selected sites in response to the design filters and briefs. Throughout the process the aim was to develop a responsive architecture that engaged the users with both the landscape and architecture. An iterative methodology of experimentation has been used explored throughout the chapter leading to varying design responses. One site/design will be selected for the developed design phase. 


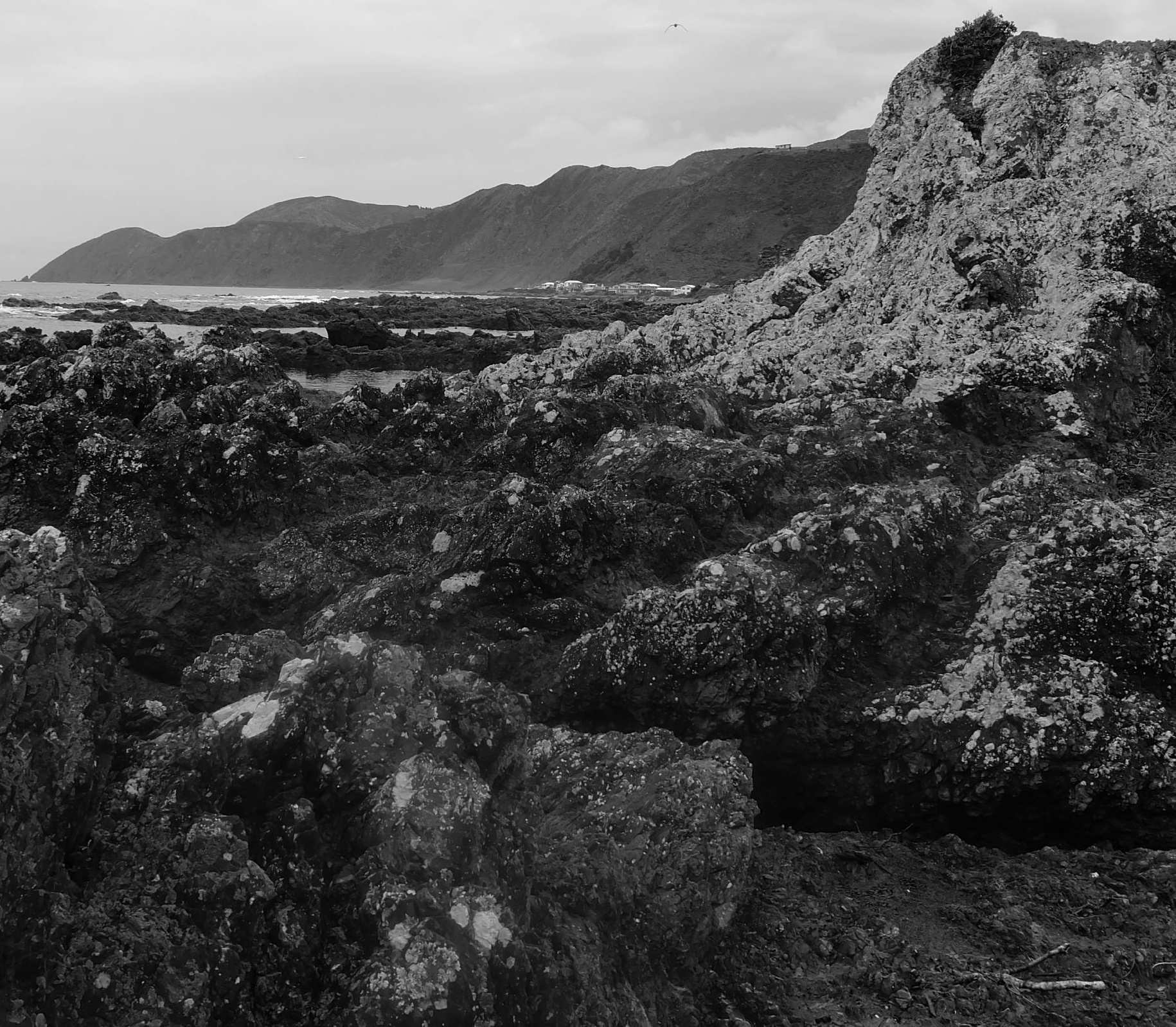




\section{Chapter 7}

\section{Developed Design}

The shelters at Sirens Rock site were selected for further design development. This site offered further opportunities for exploration and investigation regarding the brief and design filters. The design also featured a level of occupation in which the experiential and functional qualities of the shelter could intensely respond to the aims and research proposal of this thesis. In this chapter, the design is developed into a final outcome that intensifies the experience of the sea edge and celebrates the weathering life of the materials. 


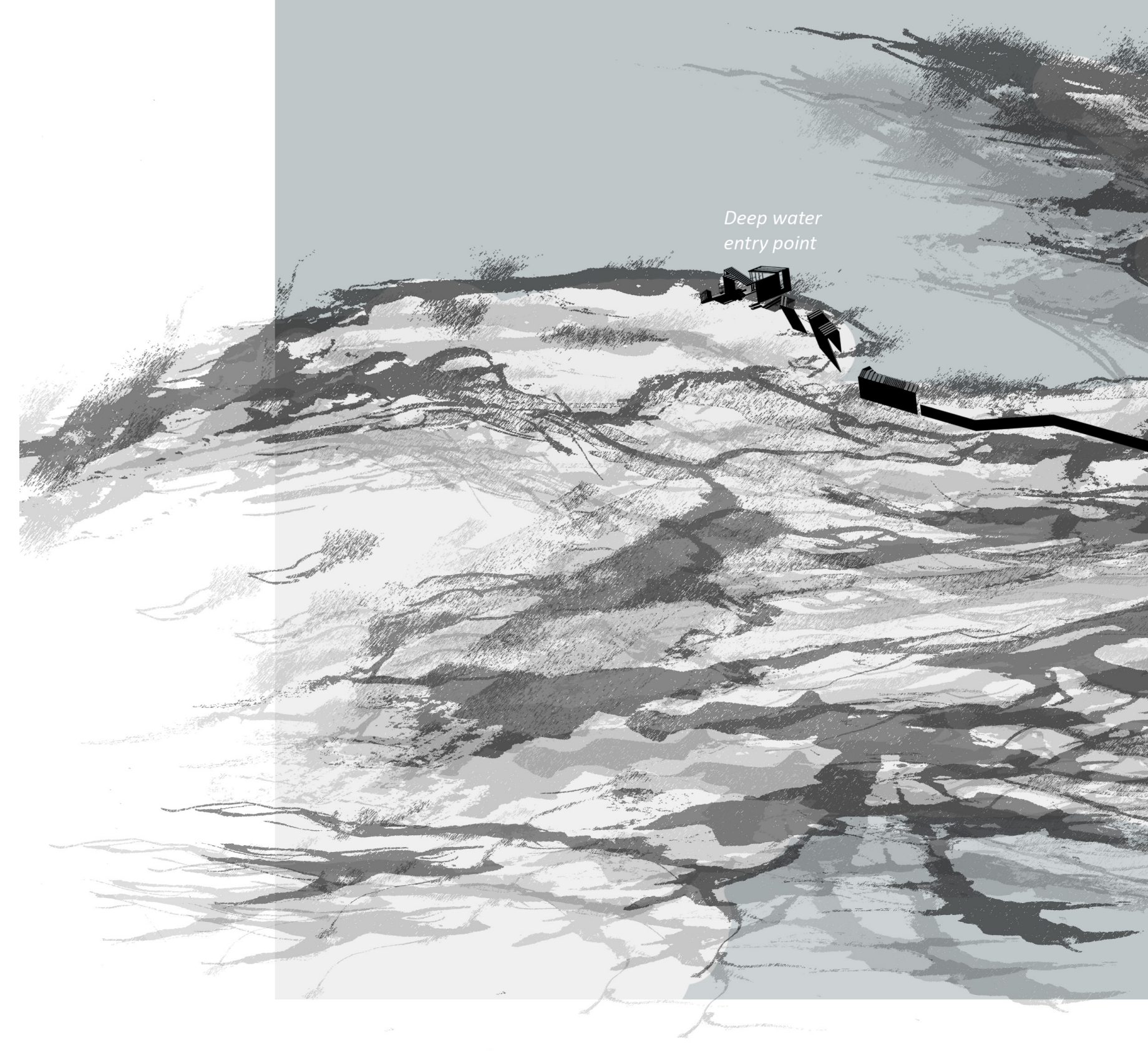


Fig 7.21. Overall perspective from the sea of the Sirens Rock shelter. It is an architectural expression of the sites narrative and experiential conditions 


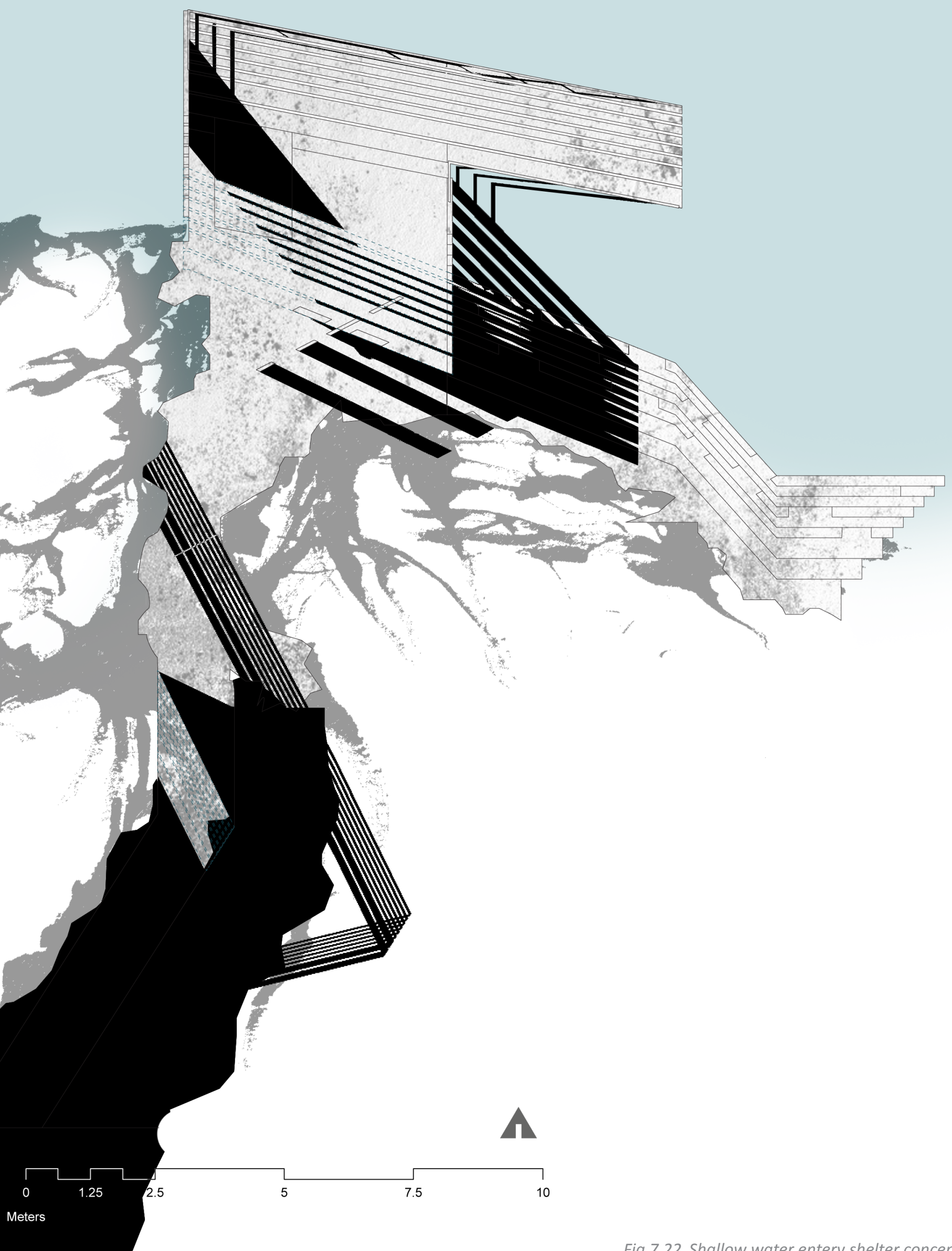



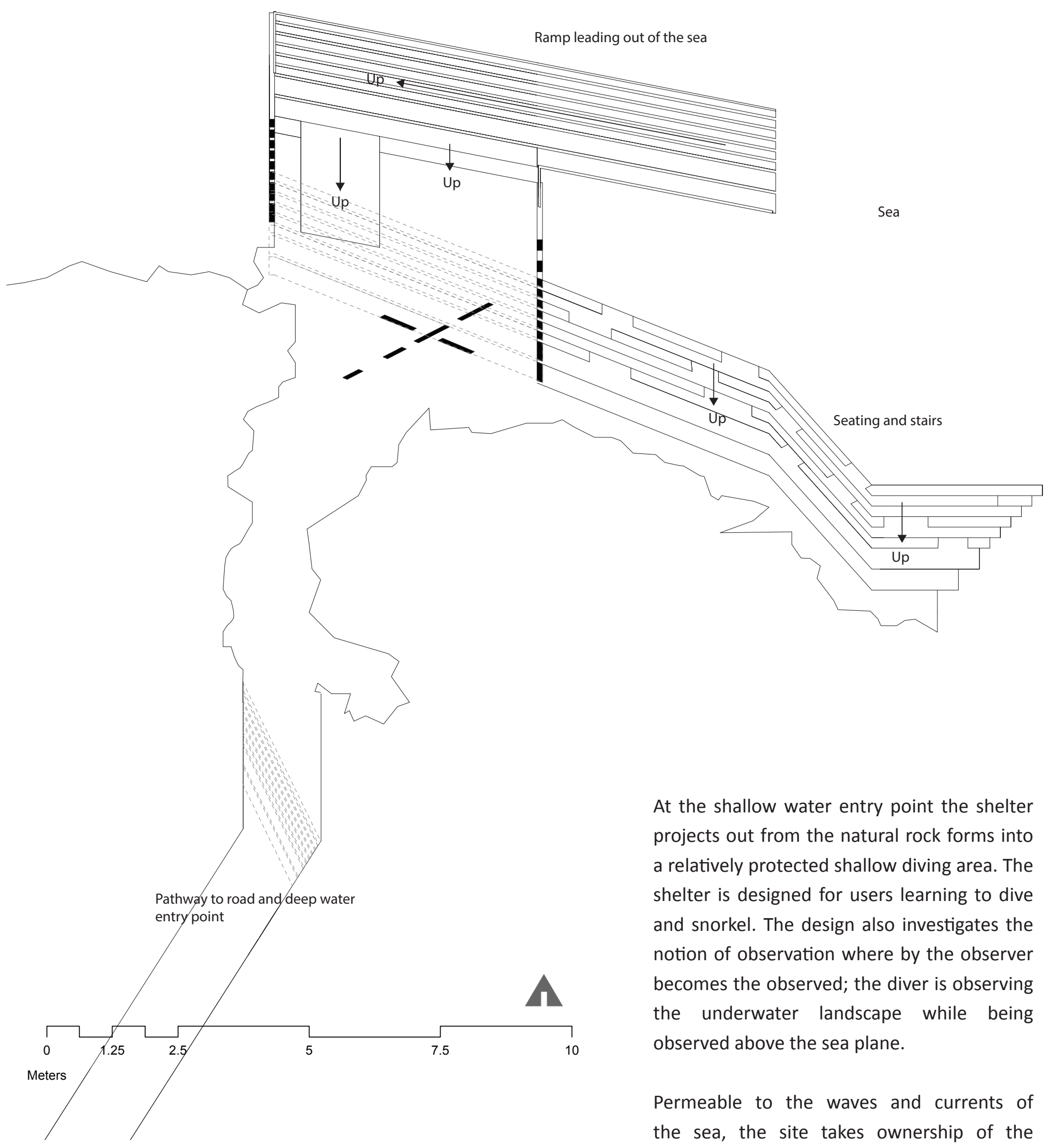

At the shallow water entry point the shelter projects out from the natural rock forms into a relatively protected shallow diving area. The shelter is designed for users learning to dive and snorkel. The design also investigates the notion of observation where by the observer becomes the observed; the diver is observing the underwater landscape while being observed above the sea plane.

Permeable to the waves and currents of the sea, the site takes ownership of the architecture allowing the users to intensely experience the expressions of the context. The water can move around and over the platforms depending on the tidal height. 


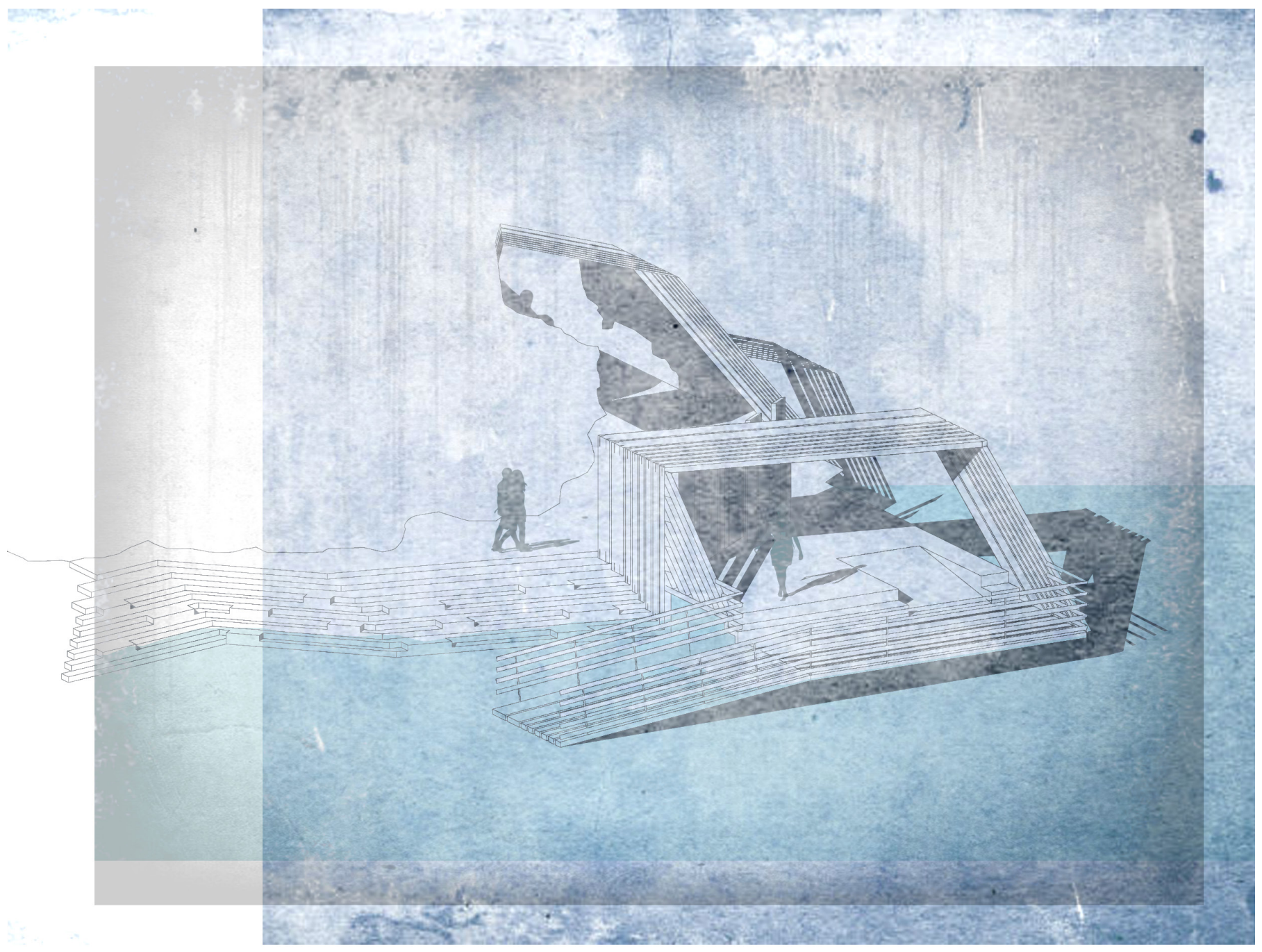

Fig 7.23. Seating area of shallow water entry shelter 


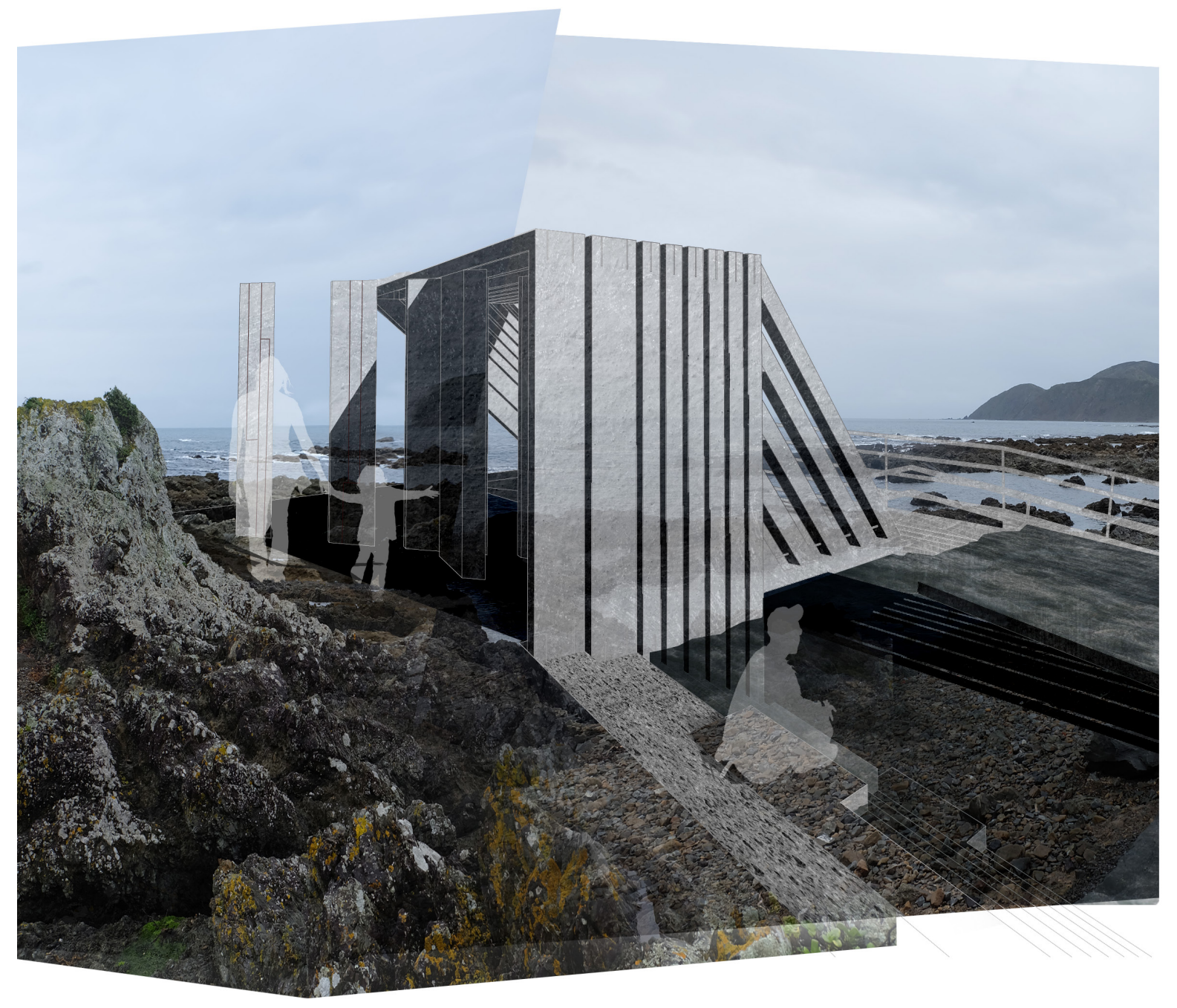

Fig 7.24. Perspective of shallow water entry platform looking out to sea 


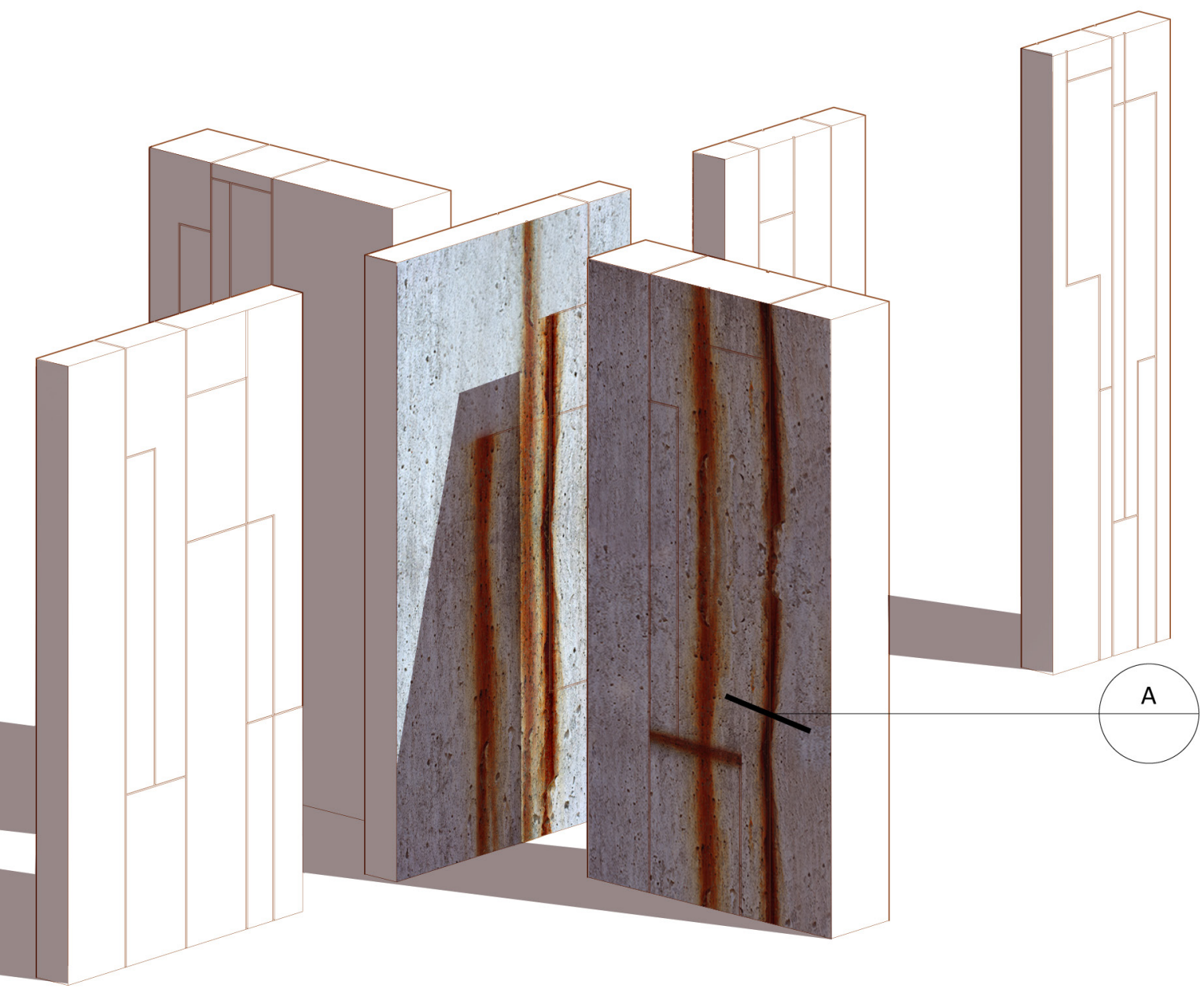

Fig 7.25. Diagram of intended staining of concrete from mild steel strips

A series of pre-cast concrete panels have been developed to highlight the progression of time and provide protection or intensify from the wind. Each panel has a series of pre-cast grooves in its surface that direct pathways of staining and weathering. Overtime, the pattern within the panels will become more pronounced highlighting the celebration of decay. Set within the grooves is a narrower strip of mild steel. Expansion gaps on either side of the strip will allow for the rusting milt steel to expand and prevent the concrete from cracking.

The angular orientation of the panels will create areas of protection and exposure from the wind creating an enhanced experience of the site conditions. 


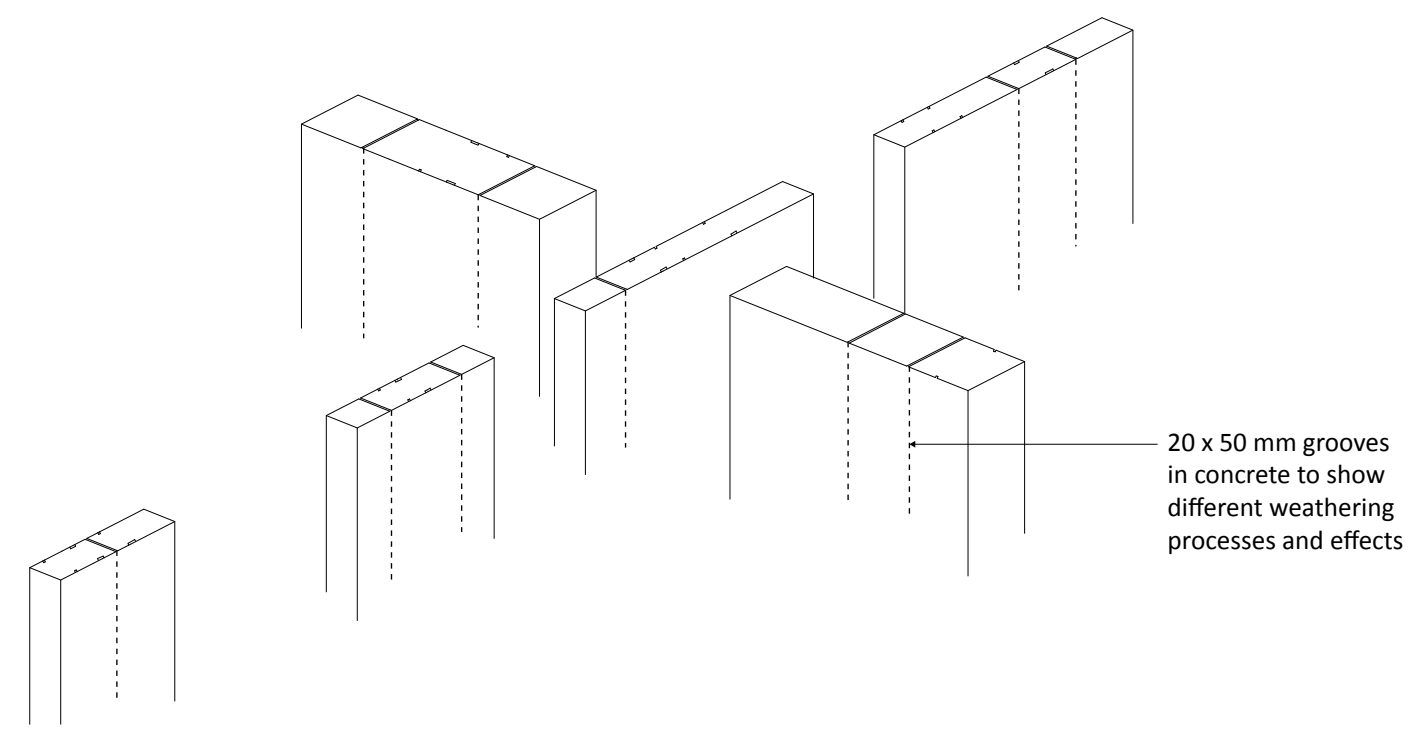

Fig 7.26. Plan 1:20 of panel's angled layout creating areas of protection and intensification from the wind

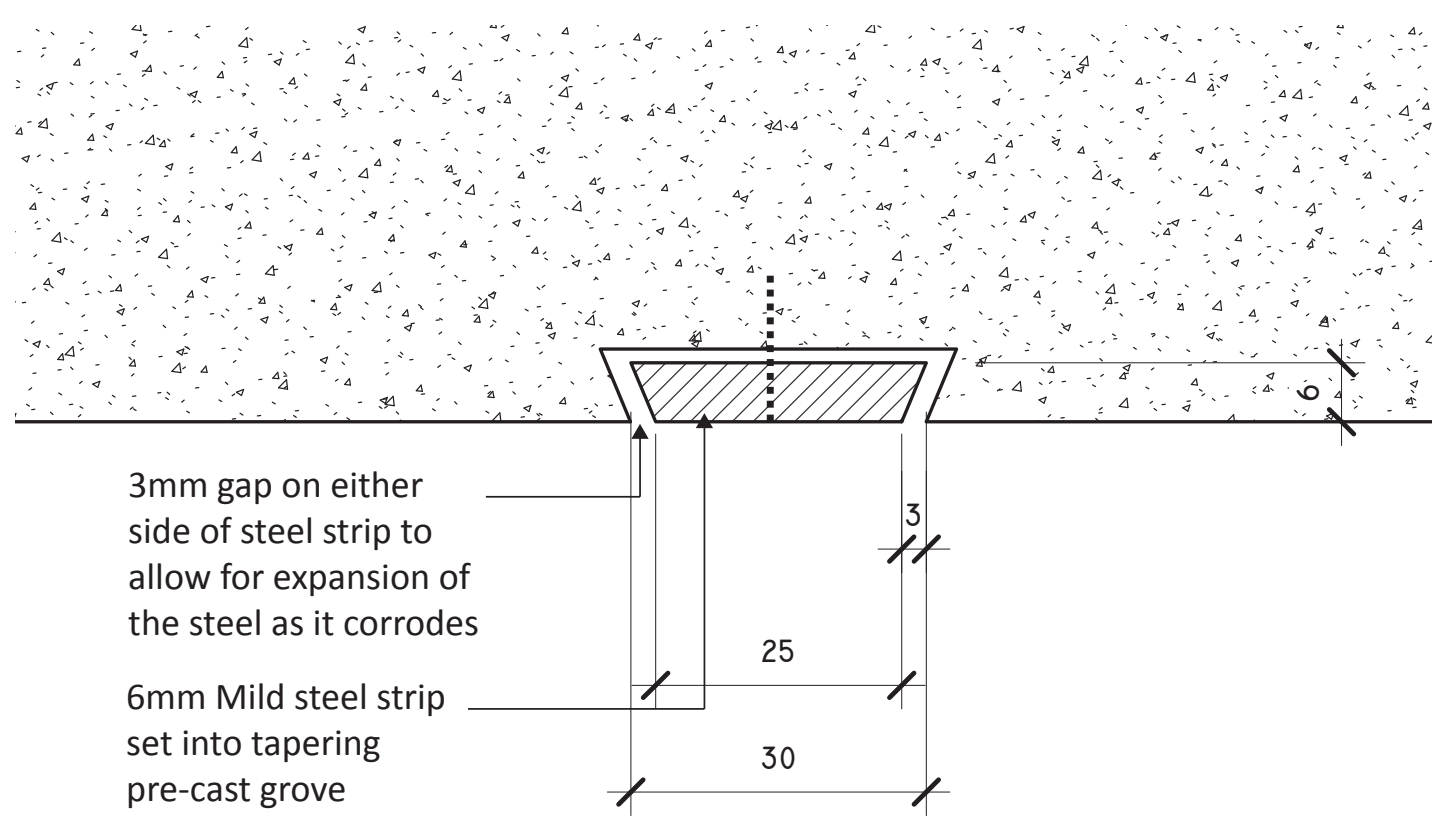

Fig 7.27. Detail A showing mild steel strip inserted into pre-cast groove in panel surface 


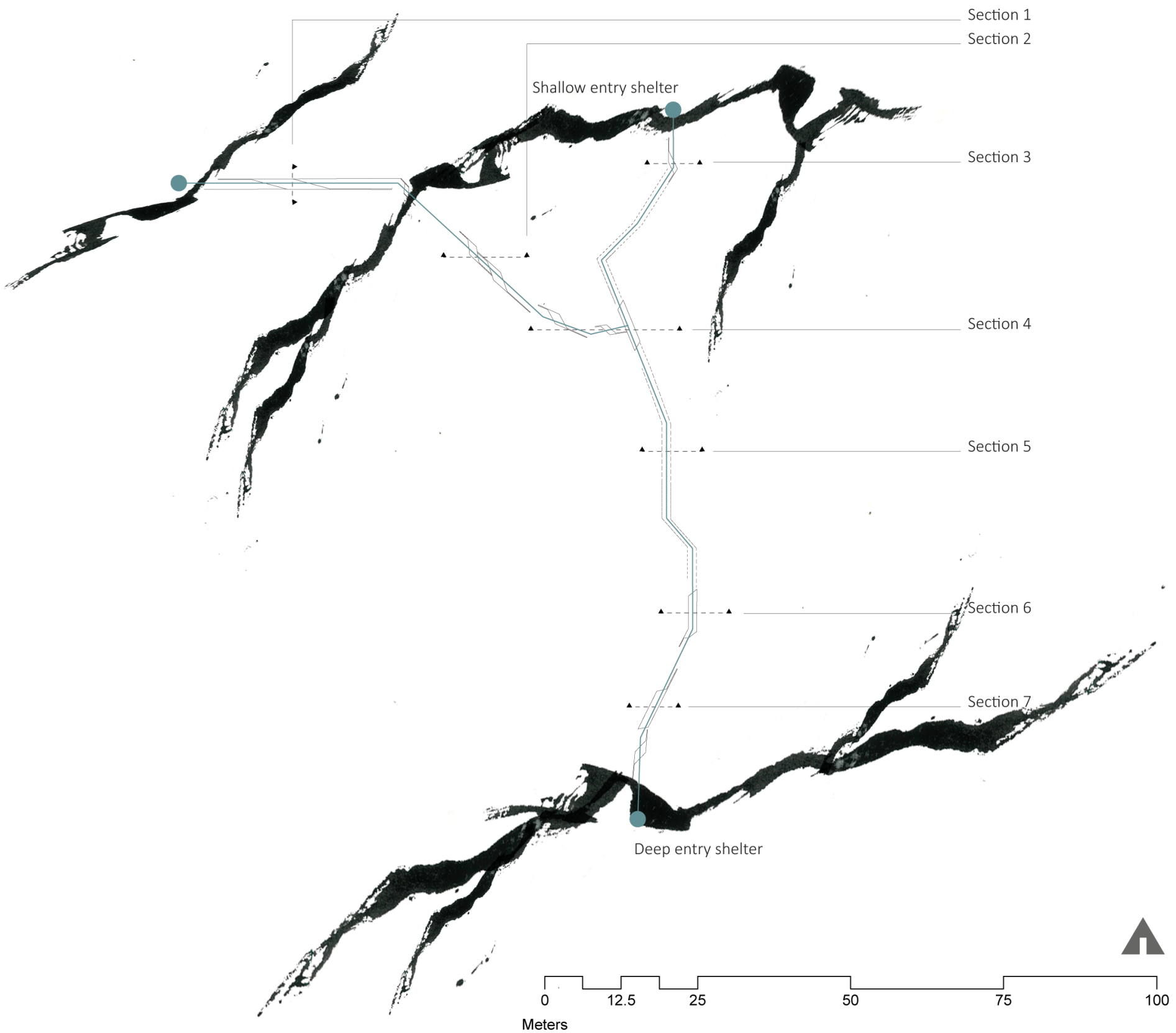

Fig 7.28. Site plan showing section cuts through connection pathway 


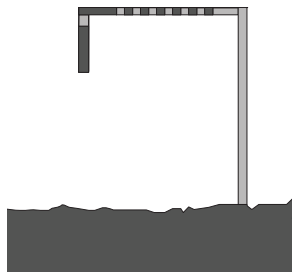

Section 1

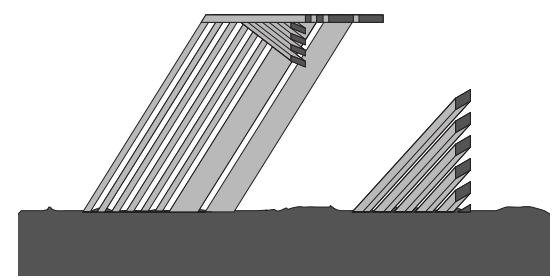

Section 2

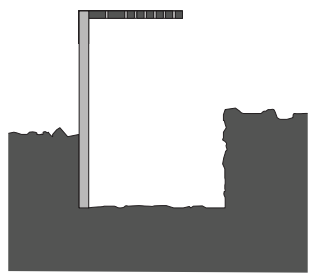

Section 3

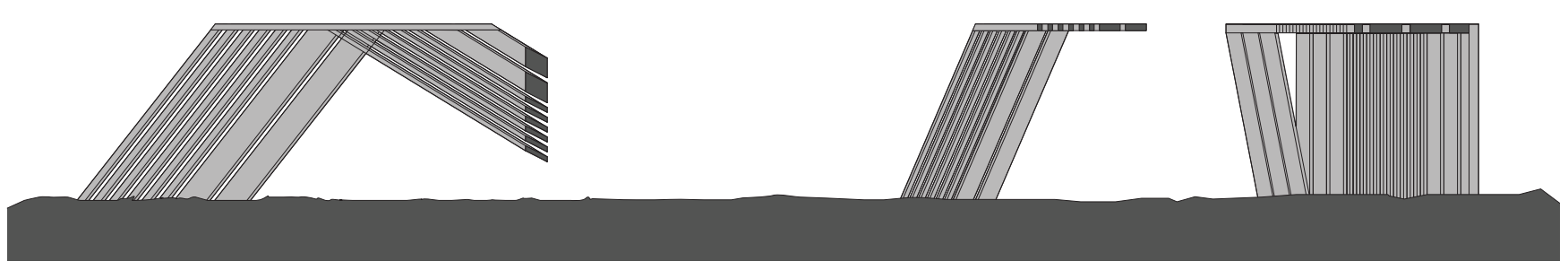

Section 4

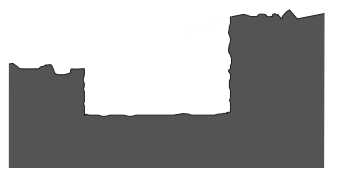

Section 5

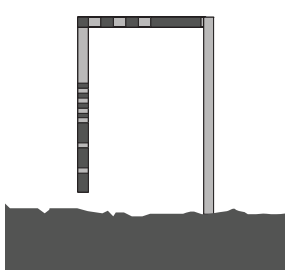

Section 6

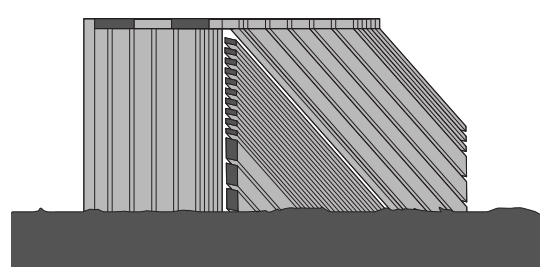

Section 7

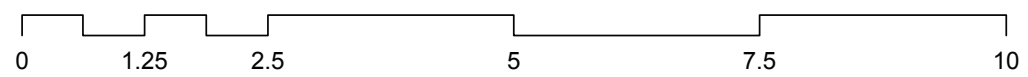

Meters

Fig 7.29. A series of sections throught the connection pathway 


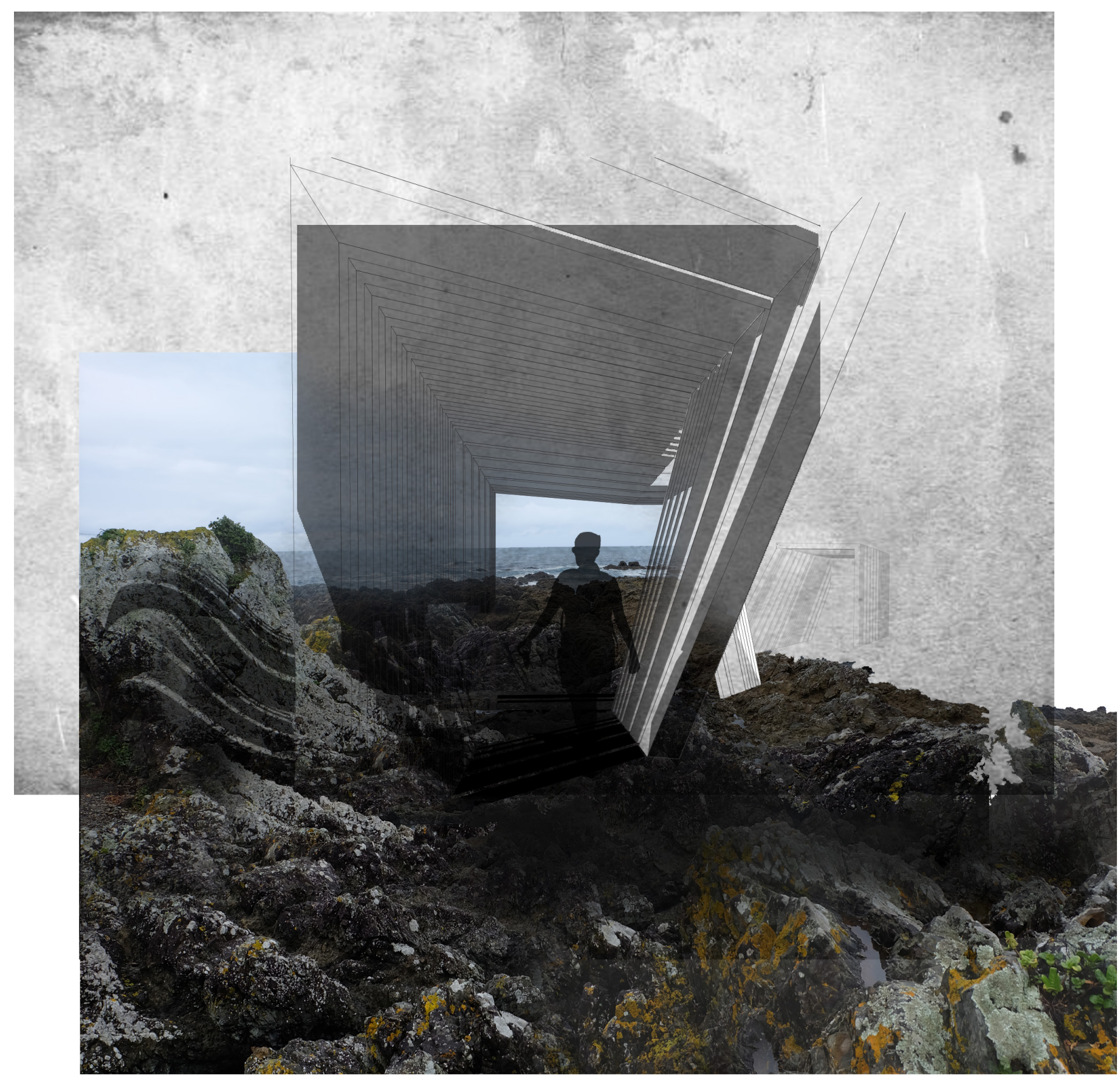

Fig 7.30. View through one of the connection structures highlighting the perspective focus and framing 


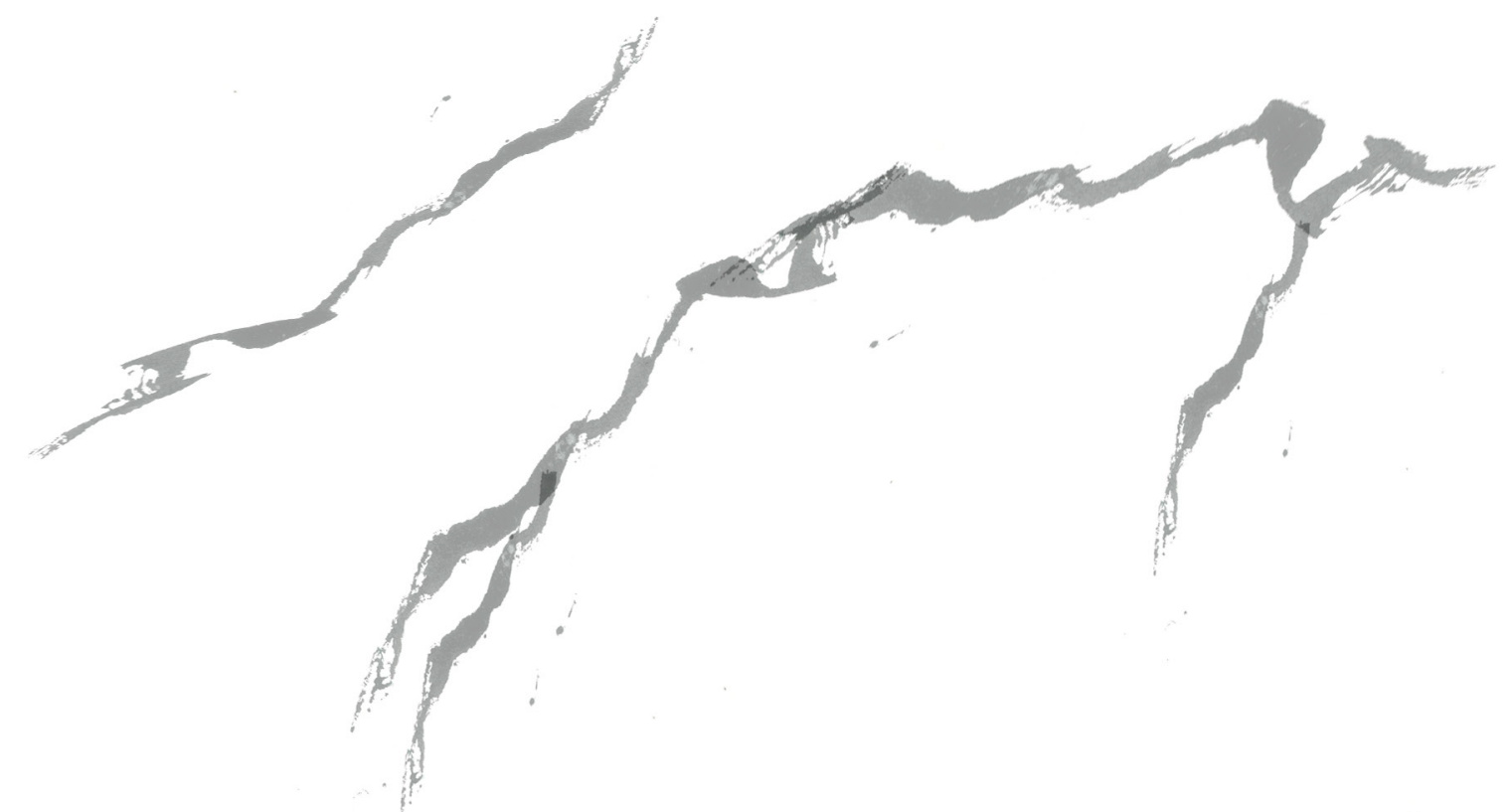

The pathways between the shelters are framed by a series of precast concrete planks of varying spacing's and widths; this creates a diversity of views. Each of the structures focuses on a different view shaft in both the vertical and horizontal direction. These enclosures, with varying views between planks and at the entry and exit, draw the eye down the perspective angle to the view beyond. This creates a contrast in views between the immediate tangible details to the landscape beyond. It is a parallel experience to that of a diver under the sea. 


\section{A}

Meters
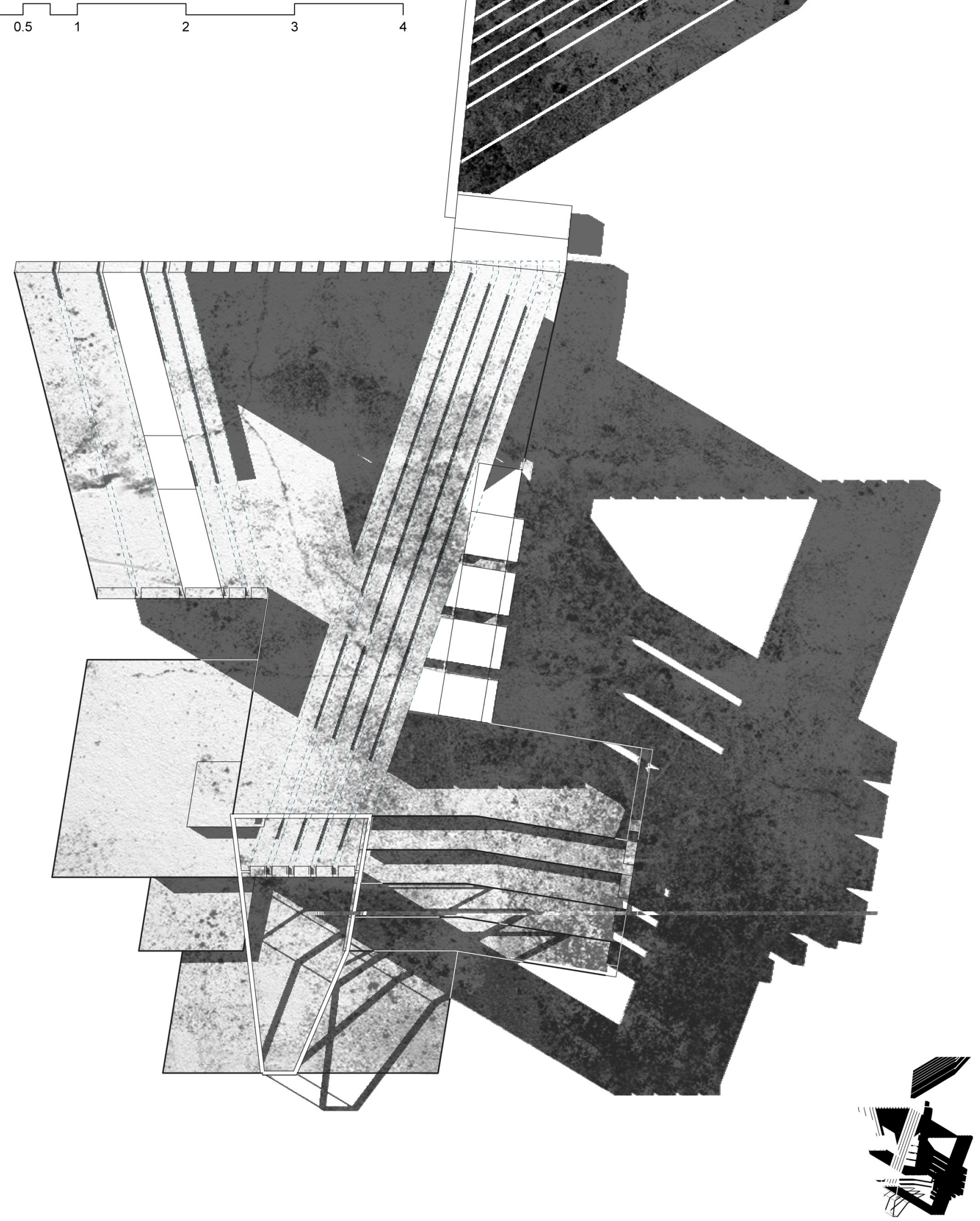

Fig 7.31. Deep water entery point shelter conceptual plan 
Pathway to road and shallow

water entry point

Timber seating

Staggered platforms

leading down to the sea

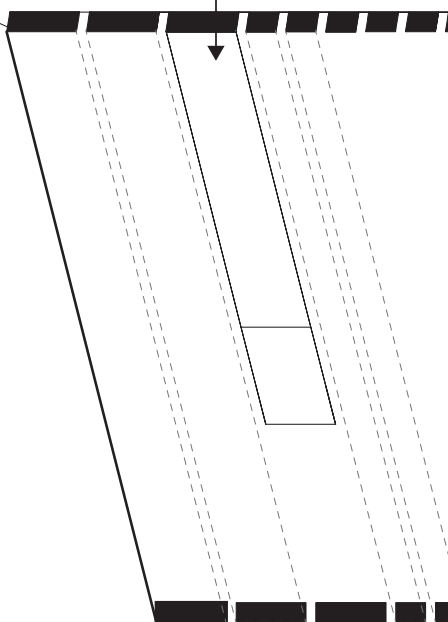

$\nabla$

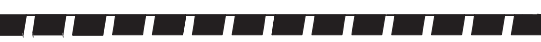




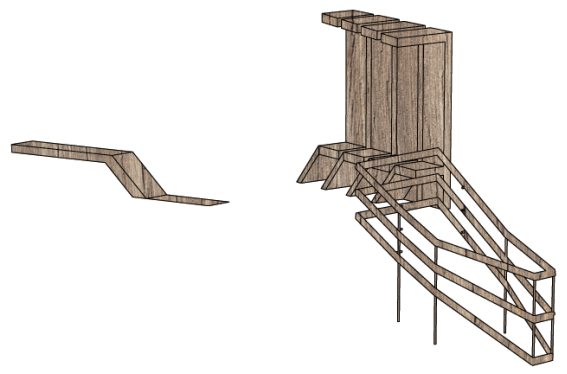

Recycled jarrah timber - is used for the handrails and seating, inviting interaction between architecture and people. In contrast to concrete, timber has a warmth and

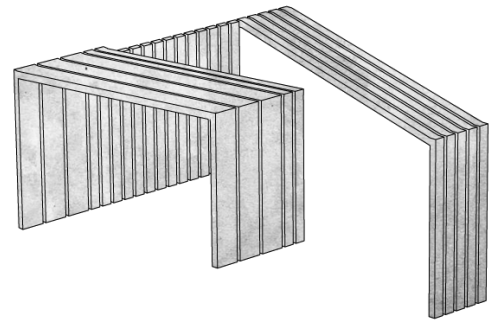
tactility that evokes an emotional response of comfort and familiarity. As the timber weathers the natural grain and texture will become deeper and richer, highlighting the truth and vulnerability of the material.

Pre-Cast concrete planks are used for the superstructure

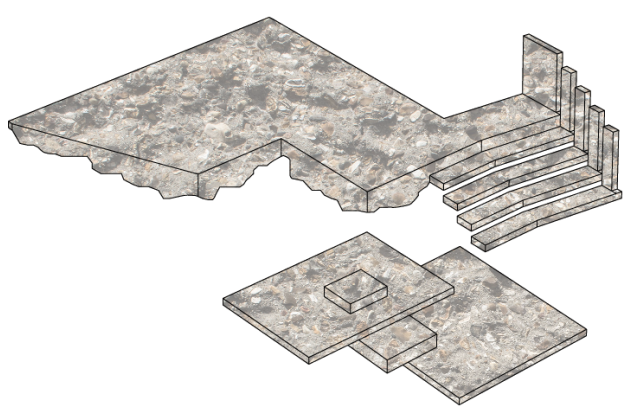

Cast-in-situ exposed aggregate concrete platforms

Platforms within the tidal zone are finished in exposed crushed aggregate - As these platforms will be submerged under the water for most of the time the concrete finish needs to rough to prevent slipping. All concrete uses crushed rock aggregate from the local Red Rocks quarry. 


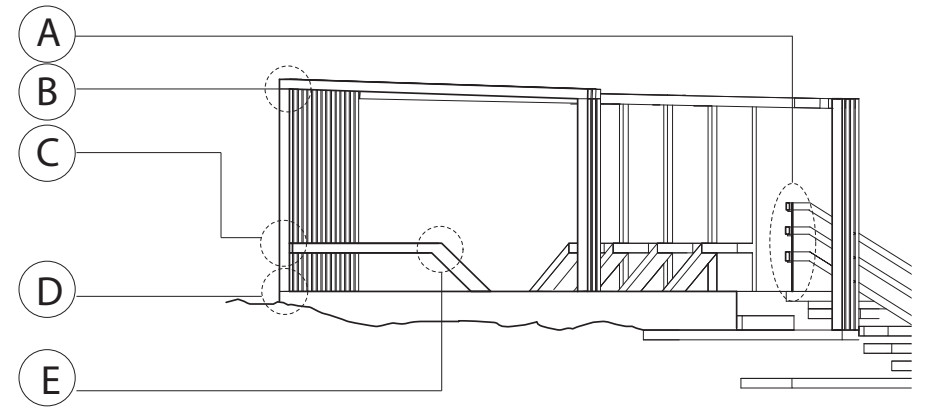

Fig 7.33. Section highlighting key connection points for details

Two $40 \times 150 \mathrm{~mm}$ Jarrah timbers encasing 40D $\times 4 \mathrm{~mm}$ marine grade stainless steel tube, as the timber weathers away the secondary stainless steel handrail will become exposed

40D $\times 4 \mathrm{~mm}$ Marine grade stainless steel tube

10D Marine grade stainless steel rod handrail bracket

$40 \mathrm{D} \times 4 \mathrm{~mm}$ Marine grade stainless set $400 \mathrm{~mm}$ deep into concrete

Cast-in-situ concrete floor slab, exposed crushed aggregate with fast setting agent for fast curing in marine conditions

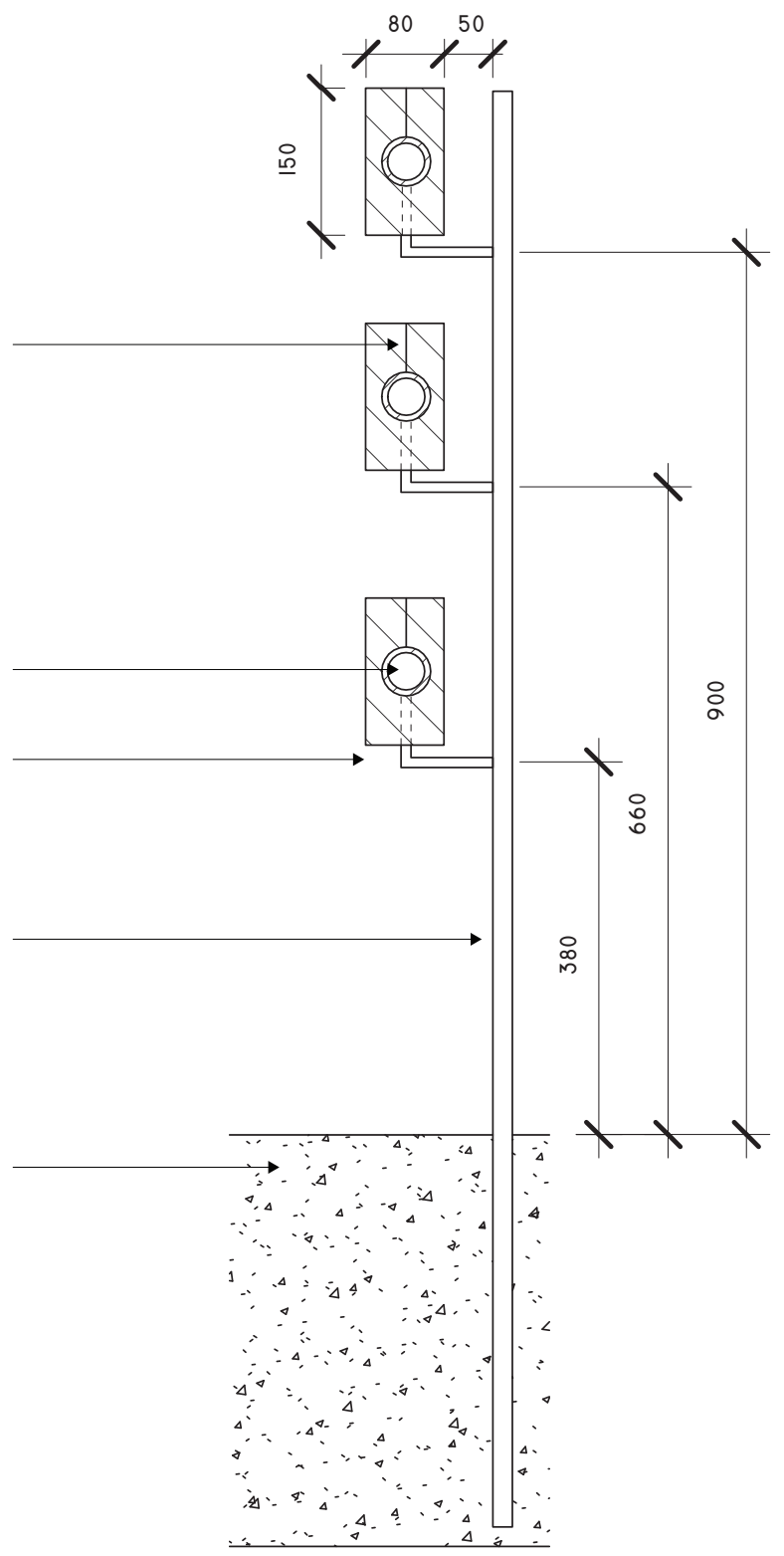




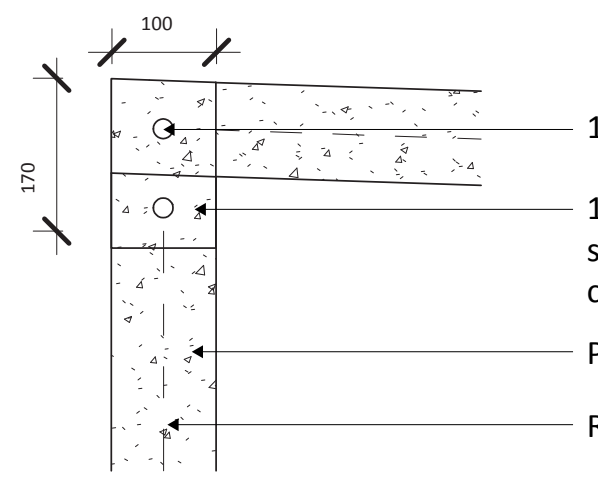

$10 \mathrm{~mm}$ marine grade threaded stainless steel rod

170x100x3mm Marine grade stainless steel flat plate embedded in vertical precast concrete panel, pre threaded fixing holes.

Pre-cast concrete panel $100 \times 400 \mathrm{~mm}$

Reinforcing to engineers specifications

$1: 10$

Fig 7.35. Detail B connection between pre-cast concrete vertical and horizontal planks

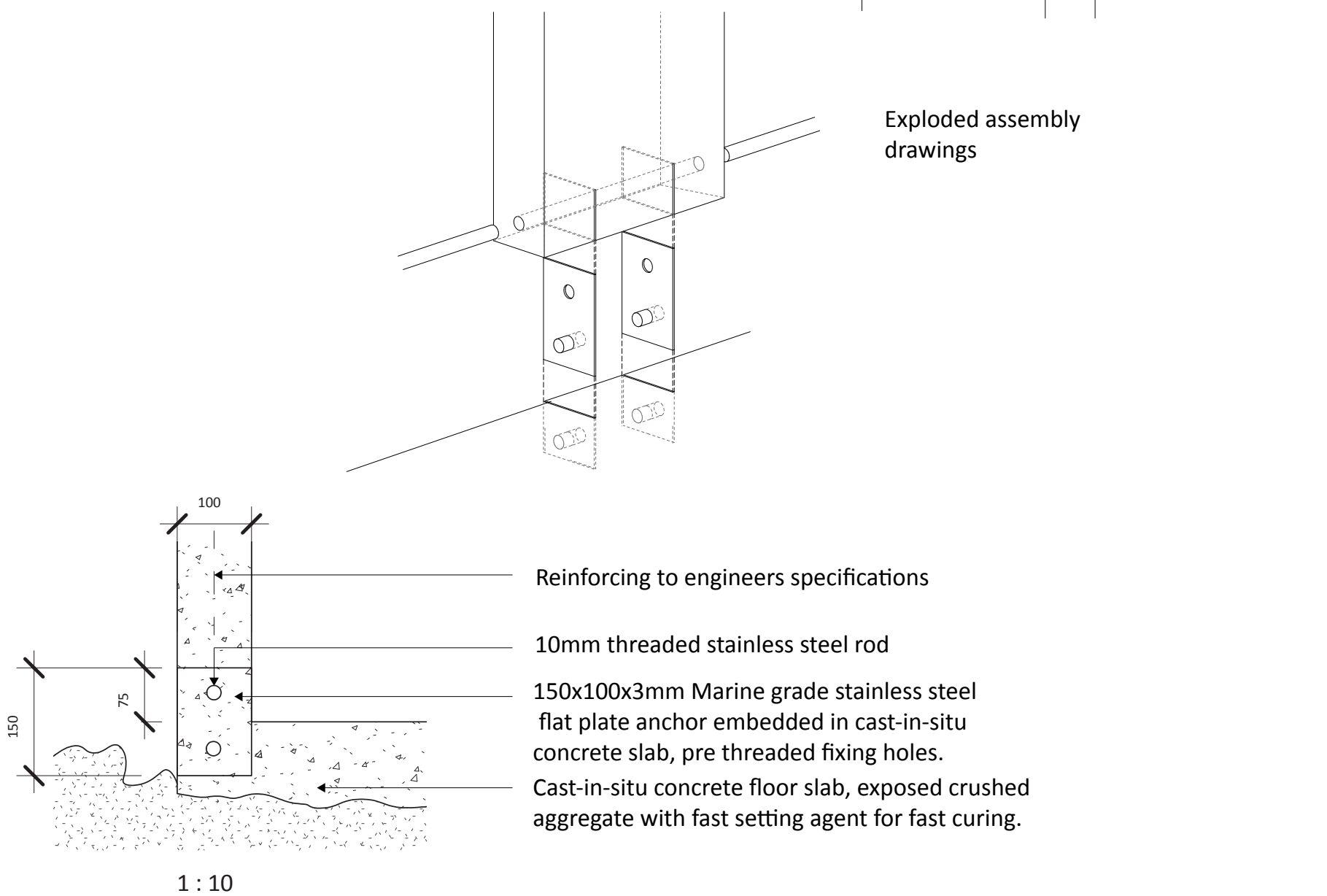




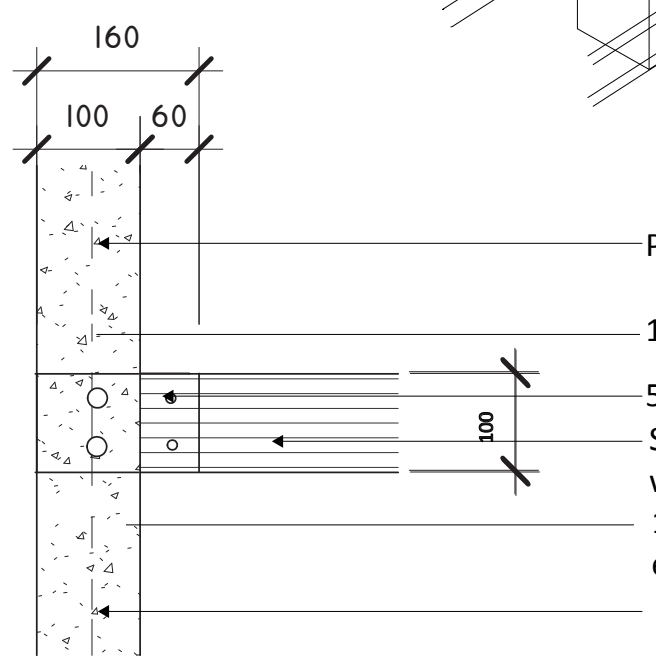

Pre-cast concrete panel 100x400mm

$10 \mathrm{~mm}$ threaded stainless steel rod

Exploded assembly drawing

$5 \mathrm{~mm}$ threaded stainless steel fixing rod Solid slab recycled Jarrah timber $100 \times 400 \mathrm{~mm}$ with $3 \mathrm{~mm}$ slots for stainless steel flat plates $125 \times 100 \times 3 \mathrm{~mm}$ Marine grade stainless steel flat plate embedded in precast concrete panel, pre threaded fixing holes. Reinforcing to engineers specifications

$1: 10$

Fig 7.37. Detail C connection between vertical pre-cast concrete plank and timber seat

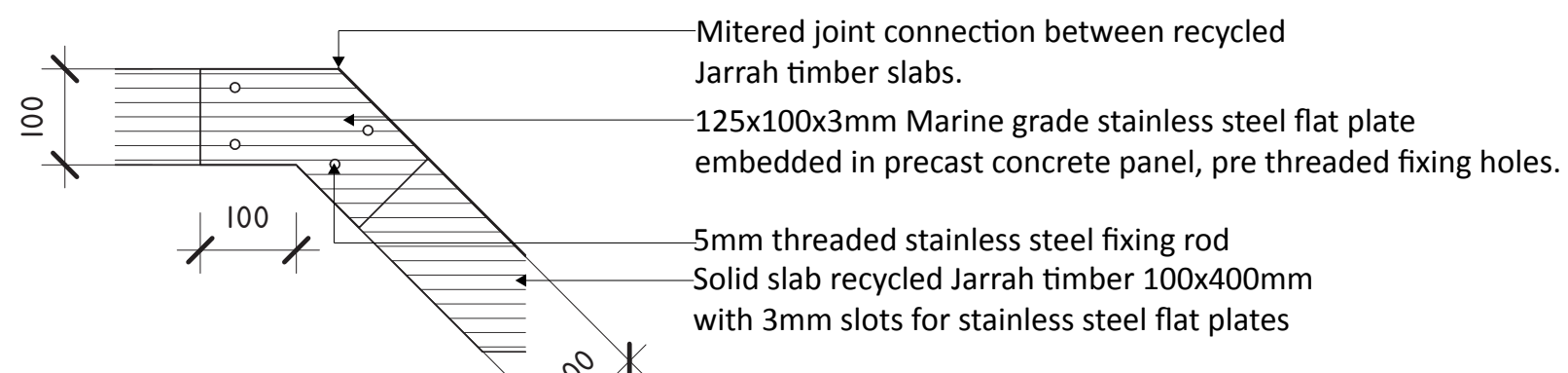

$1: 10$

$x$

Exploded assembly

Fig 7.38. Detail E of seat timber connection drawing 


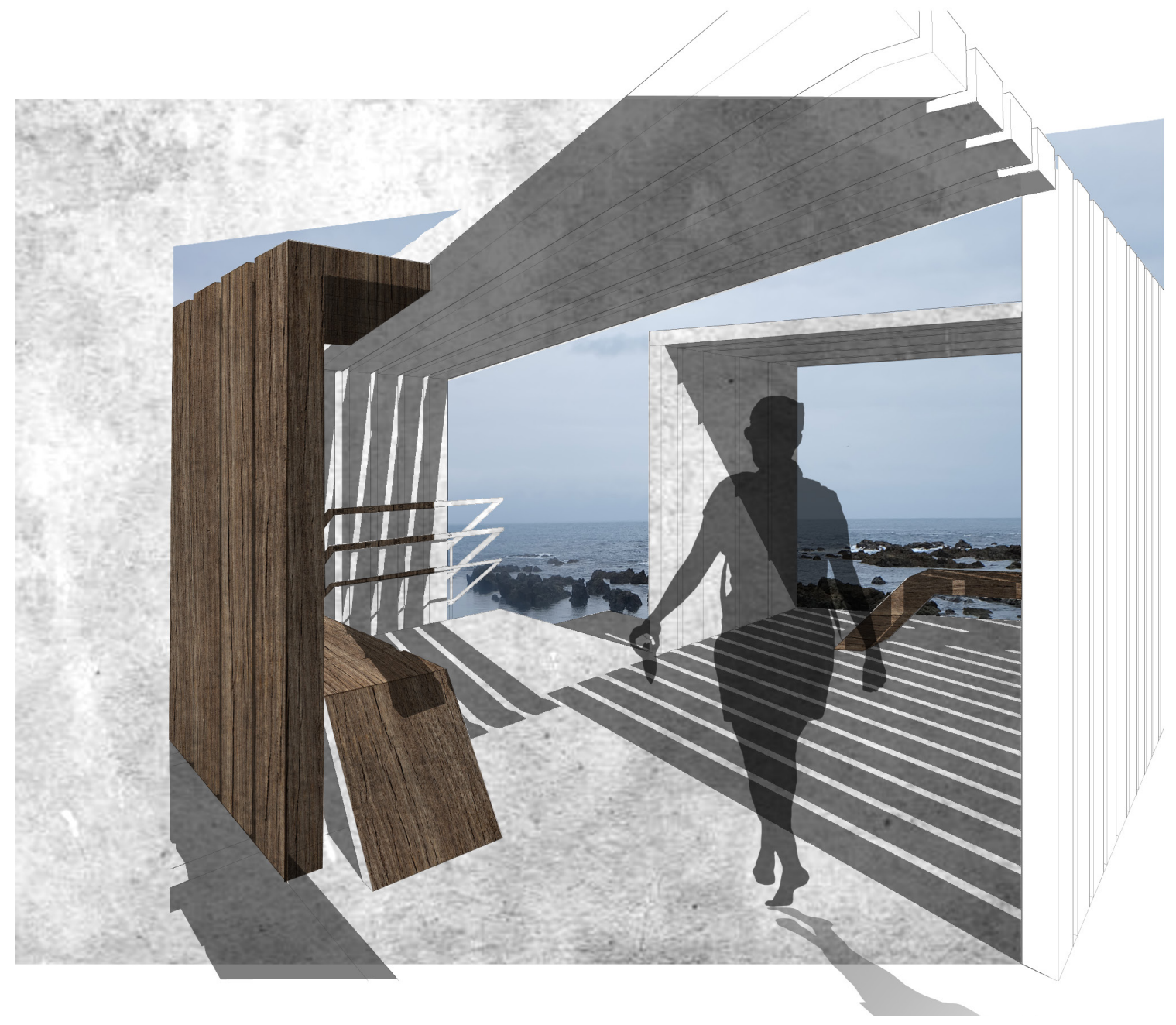

Fig 7.39. Perspective showing the view framing of the site beyond 


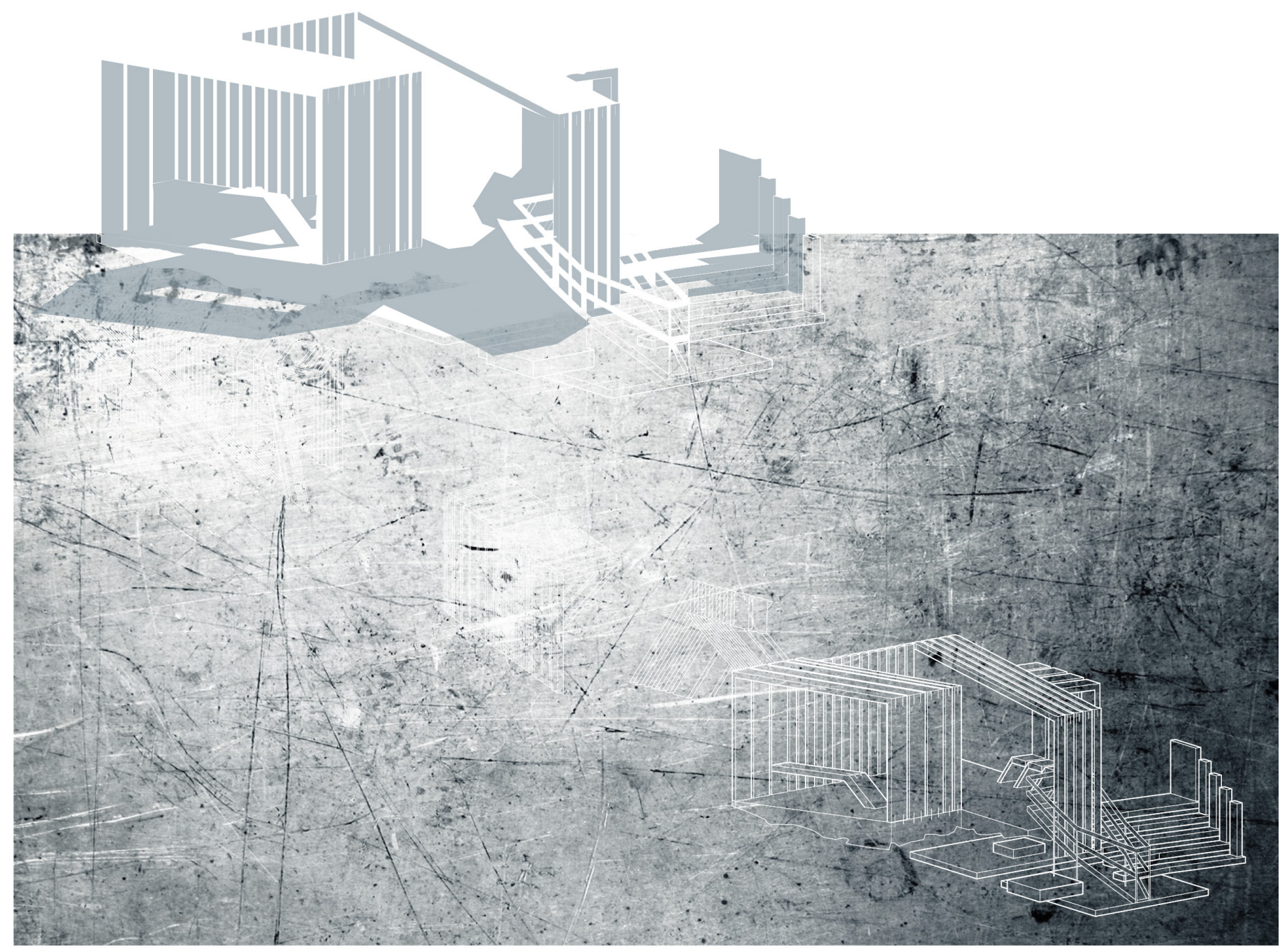

Fig 7.40. Exterior perspective 


\section{Design Conclusion}

The key focus of the further development of the Sirens Rocks shelter was on the weathering, experience and details of the architecture. Specific design features were developed to enhance and celebrate the traces of time. Concrete and mild steel strips were designed to highlight the passing of time through erosion and staining. Groves cast into the concrete panels create channels for water to flow. They will direct the trace of weathering, resulting in staining, further revealing their pattern.

Varying finishes of concrete used throughout the design highlight how different surface finishes respond to time. Rock from the Red Rocks quarry is specified for the concrete. This use of local materials intertwines both architecture and place reinforcing the notion of the architecture growing out from the rocks. The crushed, rust coloured rock of the exposed aggregate on the interior is likely to weather slowly in comparison to the exposed exterior. The weathered grey exterior finish reveals, through colour, the celebration of material vulnerabilities and complexities.

The process of decay is also designed for in the handrail. The outer layer of timber will weather away exposing a secondary stainless steel tube handrail. This reveals the truth and vulnerability of the material, nothing is permanent.

Each of these elements expresses the intensified experience of the contextual conditions revealing the sites ownership of the architecture. 


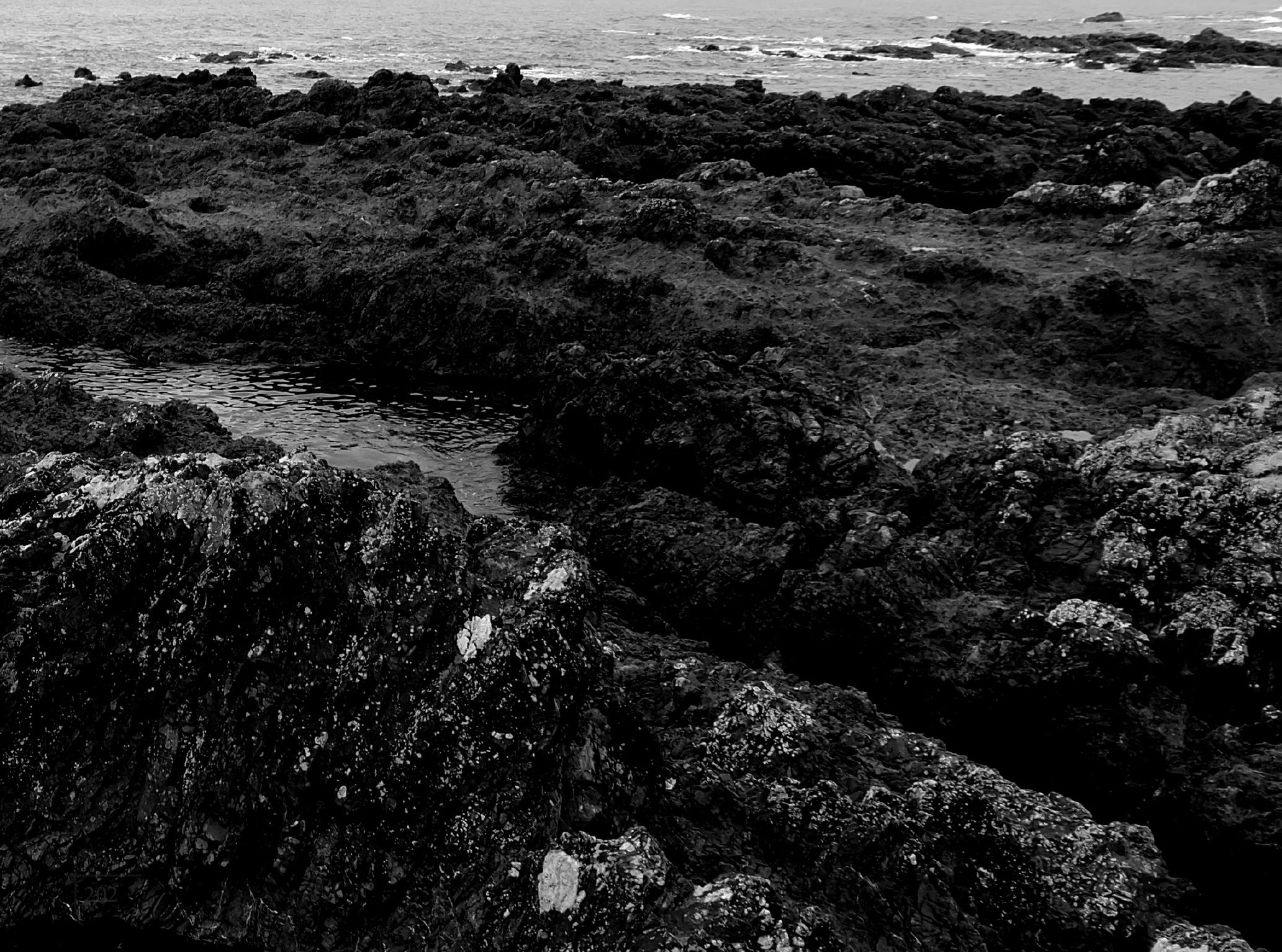


Chapter 8

Conclusion 
For New Zealanders, the coastline is a fundamental part of their identity. Within the selected site of Wellington's south coast, a wide variety of coastal landscapes can be experienced. It is a rugged and extreme landscape, which presently lacks any form of built shelter. Through a process of experiential analysis, a series of six sites were selected. Each site encapsulates differing coastal experiences that can be explored through design. The designs of the shelters provide a suggested solution to the research question: How can architecture intensify the experience of the sea edge and provide shelter for users?

This thesis confronts the commonly held view in New Zealand that architecture does not belong on the seashore. It presents an alternative vision for occupation on this edge. All six shelters work to successfully embody perceived site conditions and selected narratives. Through a personal exploration of the spatial and environmental conditions, architectural responses with varying qualities of 'shelter' from sun, wind, rain and sea have been designed. 'Shelter' has been used as a vehicle for investigation into a protective verses exposed form of spatial occupation. Both contrasting perceived experiences facilitate an intensified experience of place.

The methodology of the thesis has been successful in investigating the notions of shelter and intensity. Drawing, collage and photography have supported an intuitive design process that embodies a responsive exploration of place through art and architecture.

In answering the initial aims and objectives of this thesis, exploration of temporal conditions of the coastal edge through analysis of both the physical and experiential environments of the site took place. In detail, the developed design outcome at Sirens Rock exemplifies how architecture can successfully intensify our experience of coastal landscapes through form and materials. Through a series of design features, the correlating effects between architecture and -environment have been celebrated. This enriches and intensifies the experience of the site through activating a sensual response to place. 


\section{Limitations of the design}

Due to the unpredictability and extremes of weather conditions on the site it is difficult to predict the rates and patterns of weathering. Assumptions have to be made on how material will react within this environment. The collected fragments give an indication to weathering effects, however the time frame of the material weathering is unknown. The design has assumed ways in which materials and details will erode and weather.

Due to the broad scope of the six sites, only one design has been developed in further detail. Possible modes of construction are proposed, but would require further research and development.

Construction costs have also not been considered as this would have limited the creative design process.

\section{What has been learnt?}

This thesis experience confirmed that the relationship between architecture, time and experience must be considered as an integral aspect to the design process. The process of weathering and deterioration affects all scales of architecture, from the details to how the built form is read as a whole within its environment. Layers of time are inevitable, they shape experiential and physical understanding of a built form's life.

The experience and analysis of the site is not just through a visit or image at one point in time, but is an all-encompassing investigation into the narrative, history and processes that has shaped that site. Careful consideration needs to be given to the wider environment that will affect the experience of the architecture.

There are many forms of shelter. Most commonly thought of as a place of physical protection from the weather, shelter can also be a mode of visual, emotional or sensual protection. It can reveal experiential and sensual awakenings through the creation of contrasting spatial qualities that intensify the experience between one space and another.

\section{Further application}

This investigation has taken place through a series of diverse and contrasting sites. The key principles and ideas driving the architectural responses could be used as examples throughout New Zealand and in other parts of the world when designing built form on the sea edge.

Most significantly, this thesis provides a vision for architectural presence at the sea edge. 


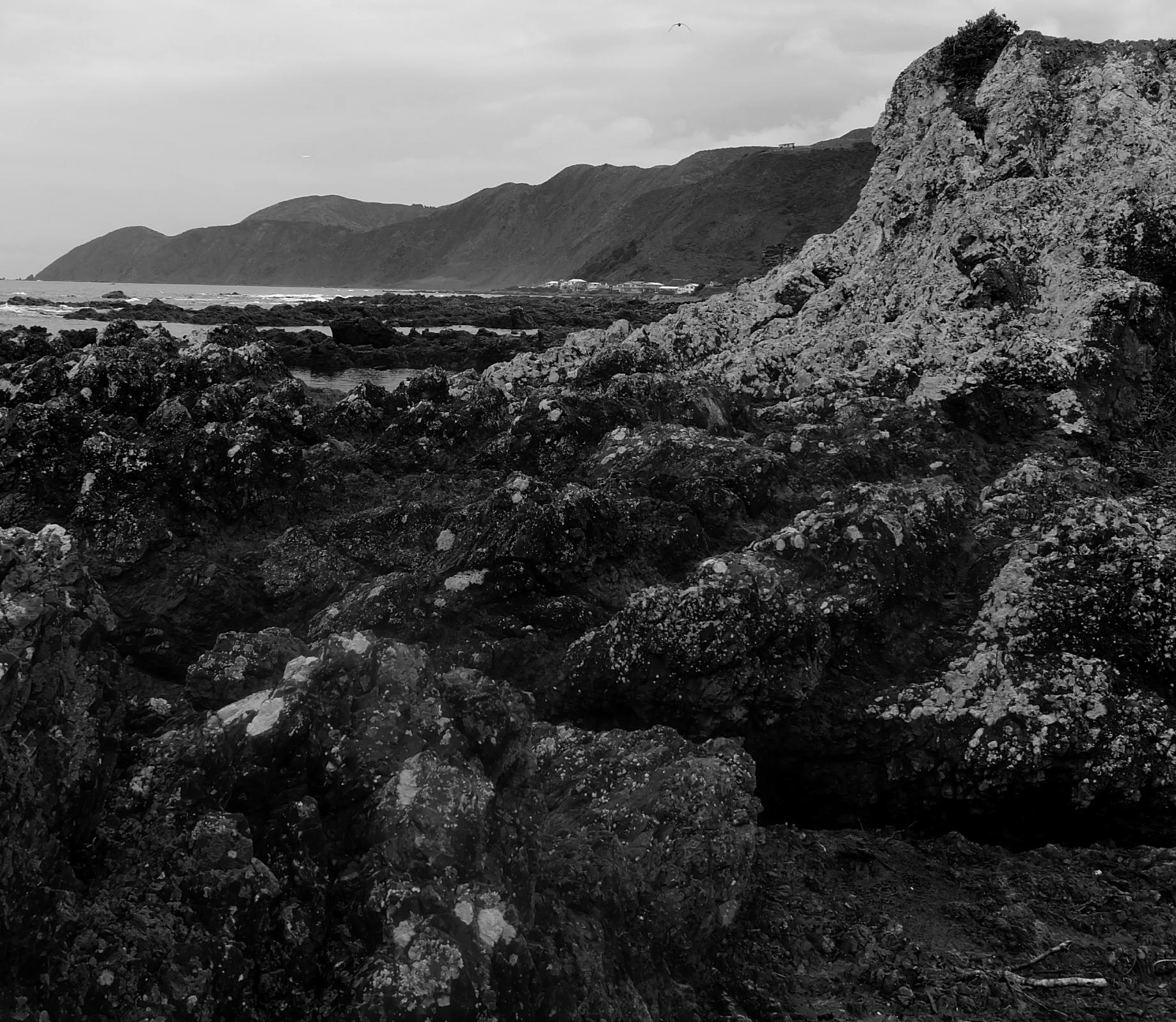


Chapter 9 


\section{Works Cited}

"Shore Geology and South Coast Habitats." Friends of Taputeranga Marine Reserve, Wellington community trust, 2015. Web. 26 May 2016. <http://taputeranga.org.nz/the-marine-life/the-geology.>

"South Coast." The Wellington dive guide, Web. 16 June 2016. <http://www.rexedra.gen.nz/wdg/sites/ southcst.htm.>

Balters, Sofia. "Ad Classics: Leça Swimming Pools / Alvaro Siza." ArchDaily, 06 Aug 2011, Web. 22 May 2016.<http://www.archdaily.com/150272/ad-classics-leca-swimming-pools-alvaro-siza.>

Berger, Tatiana. "Leca Swimming Pools, Leca Da Palmeira, Portugal." Galinsky, 2008, Web. 26 May 2016. <http://www.galinsky.com/buildings/leca/.>

Chappell, P.R. The Climate and Weather of Wellington Region: NIWA, 2014.Print.

“Tapu Te Ranga - Haewai Precinct”. Wellington City Council, Web. 21 May 2016. <http://www.wcl.govt.nz/ maori/wellington/ngawaahitapu.html>

Goldsworthy, Andy. Time. New York: Harry N. Abrams, Inc., 2000. Print.

“Wellington Weather and Climate." New Zealand Tourism Guide, 2016, Web. 13 Sep 2016, <http://www. tourism.net.nz/new-zealand/about-new-zealand/wellington-weather.html>

Koren, Leonard. Wabi-Sabi for Artists, Designers, Poets and Philosophers. California: Stone Bridge Press, 1994. Print. 
Mostafavi, Mohsen, and David Leatherbarrow. On Weathering: The Life of Buildings and Time. Cambridge, Massachusetts: MIT Press, 1993. Print.

NIWA. "Sunshine Hours." Statistics New Zealand, 21 October 2015, Web. 10 January 2017. <http://www. stats.govt.nz/browse_for_stats/environment/environmental-reporting-series/environmental-indicators/ Home/Atmosphere-and-climate/sunshine-hours.aspx>

Pallasmaa, Juhani. An Architecture of the Seven Senses. a+u Architecture and Urbanism: Question of Perception (1994): 40 - 49. Print.

---. The Eyes of the Skin. Great Britain: Wiley-Academy, 2005. Print.

---. The Space of Time. Oz Vol.20, 1998.Print.

"Shipwrecks in the Marine Reserve." Friends of Taputeranga Marine Reserve, 2015, Web. 21 Sep 2016, <http://taputeranga.org.nz/wp-content/uploads/Shipwrecks-in-the-Marine-Reserve.pdf>

Sharr, Adam, ed. Heidegger for Architects. Oxon, UK: Routledge, 2007. Print.

Sheperd, Joseph. "The Weathered Trace". Masters Thesis. Victoria University of Wellington, 2010, http:// hdl.handle.net/10063/1599.

Unwin, Simon. Analysing Architecture. Second ed. London: Routledge, 2003. Print.

Zumthor, Peter. Thinking Architecture. Germany: Birkhauser 2015. Print. 


\section{List of Figures}

All figures attributed to author, unless stated otherwise

Fig 1.02. Location of New Zealand marine reserves, Department of Conservation. 3 May 2016. Web. <http://www. doc.govt.nz/nature/habitats/marine/marine-reserves-a-z/marine-reserves-map/>

Fig 2.12.Image distortion from rain, 8 August 2016. Web. < http://typotic.com/i/raindrops/>

Fig 5.02. A collection of images from case studies. Refer to Fig. 5.03, 5.06, 5.10, 5.12, 5.17 for referenes.

Fig 5.03. Siza, Alcaro. Leca Swimming Pools , 1996. Leça de Palmeira, Portugal. 23 June 2016. Web. <http://spain. aricaustermann.com/08/leca-swimming-pools/>

Fig 5.04. Siza, Alcaro. Detail of intergration between natural rock formation and architecture, 1996. Leça de Palmeira, Portugal. 23 June 2016. Web. <http://www.archdaily.com/150272/ad-classics-leca-swimming-pools-alvaro-siza>

Fig 5.05. Siza, Alcaro. Leca Swimming Pool entrance, 1996. Leça de Palmeira, Portugal. 23 June 2016. Web. <http:// www.archdaily.com/150272/ad-classics-leca-swimming-pools-alvaro-siza>

Fig 5.06. Scarpa, Carlo. Weathering of Concrete, 1981. San Vito di Altivole, Italy. 27 June 2016. Web.<http:// openbuildings.com/buildings/brion-vega-cemetery-profile-2658>

Fig 5.07. Scarpa, Carlo. Brion Cemetery Meditation Pavilion, 1981. San Vito di Altivole, Italy. 27 June 2016. Web. <http://au.phaidon.com/agenda/architecture/articles/2013/december/23/carlo-scarpas-cemetery-for-brionvegaboss/>

Fig 5.08. Scarpa, Carlo. Brion-Vega Cemetery, 1981. San Vito di Altivole, Italy. 28 June 2016. Web. <http://www. urbanarchnow.com/2012/09/carlo-scarpas-brion-vega-cemetery.html>

Fig 5.09. Zumthor, Peter. The Therme Vals exterior and roof top, 1996. Graubunden, Switzerland. 16 July 2016. Web. <http://www.arcspace.com/features/atelier-peter-zumthor/vals-thermal-baths/>

Fig 5.10. Zumthor, Peter. The Therme Vals exterior, 1996. Graubunden, Switzerland. 16 July 2016. Web. <http://www. atzwanger.net/en/references/projekt/therme-vals-1-2/> 
Fig 5.11. Zumthor, Peter. Interior pool, 1996. Graubunden, Switzerland. 16 July 2016. Web. <http://homeli.co.uk/ therme-vals-spa-by-peter-zumthor/>

Fig 5.12. Gorden, Charles. Te Kopahou Reserve Gateway, 2008. Wellington, New Zealand. 29 June 2016. Web. <http:// trendsideas.com/article/gateway-to-the-coast>

Fig 5.13. Gorden, Charles. Te Kopahou Reserve Gateway in landscape, 2008. Wellington, New Zealand. 29 June 2016. Web <http://www.nzila.co.nz/projects/projects-list/2015-outstanding-design-between-\$500k-and-\$2m.aspx>

Fig 5.14. Gorden, Charles. Landscape materials, 2008. Wellington, New Zealand. 29 June 2016. Web <http://www. nzila.co.nz/projects/projects-list/2015-outstanding-design-between-\$500k-and-\$2m.aspx>

Fig 5.15. Gorden, Charles. Interior of information area, 2008. Wellington, New Zealand. 29 June 2016. Web http:// www.nzila.co.nz/projects/projects-list/2015-outstanding-design-between-\$500k-and-\$2m.aspx

Fig 5.16. Goldsworthy, Andy. Cairn, 1999. Canada. 13 July 2016. Web. <https://oaklandetsuko.wordpress. com/2010/11/13/andy-goldsworthy/>

Fig 5.17. Goldsworthy, Andy. Cairn - tide comming in, 1999. Canada. 13 July 2016. Web. <https://oaklandetsuko. wordpress.com/2010/11/13/andy-goldsworthy/>

Fig 5.18. Goldsworthy, Andy. Cairn - tide begining decay, 1999. Canada. 13 July 2016. Web. <https://oaklandetsuko. wordpress.com/2010/11/13/andy-goldsworthy/>

Fig 6.11. La Bella ashore on Owhiro Bay, Friends of Taputeranga Marine Reserve, 21 Sep 2016. Web. <http:// taputeranga.org.nz/wp-content/uploads/Shipwrecks-in-the-Marine-Reserve.pdf>

Fig 6.12. The Progress, Friends of Taputeranga Marine Reserve, 21 Sep 2016. Web. <http://taputeranga.org.nz/wpcontent/uploads/Shipwrecks-in-the-Marine-Reserve.pdf>

Fig 6.13. Yen Pen ship sinking, Friends of Taputeranga Marine Reserve, 21 Sep 2016. Web. <http://taputeranga.org. $\mathrm{nz} / \mathrm{wp}$-content/uploads/Shipwrecks-in-the-Marine-Reserve.pdf> 